Acessibilidade no desenvolvimento de sistemas web: um estudo sobre o cenário brasileiro

André Pimenta Freire 



\title{
Acessibilidade no desenvolvimento de sistemas web: um estudo sobre o cenário brasileiro
}

\author{
André Pimenta Freire
}

Orientadora: Profa. Dra. Renata Pontin de Mattos Fortes

Dissertação apresentada ao Instituto de Ciências Matemáticas e de Computação - ICMC-USP, como parte dos requisitos para obtenção do título de Mestre em Ciências - Ciências de Computação e Matemática Computacional.

\section{"VERSÃO REVISADA APÓS A DEFESA"}

Data da Defesa: $\quad$ 07/03/2008

Visto do Orientador:

USP - São Carlos

Abril/2008 

Que este trabalho possa ser oferta agradável ao coração de Deus, que por Sua misericórdia me permitiu realizá-lo sob os auspícios de Sua divina proteção e amparo. 



\section{Agradecimentos}

Primeiramente a Deus pelo dom da vida, e pela graça de todos os dias encontrar motivos para amá-Lo mais em todas as coisas e, a cada descoberta, poder amá-Lo mais que todas as coisas por meio das quais Ele se revela.

Aos meus pais, por terem me dado a riqueza de conhecimentos mais valiosos do que o melhor dos resultados que esta dissertação pudesse mostrar. Pelo carinho incondicional e pela perseverança em amar, sempre. Ao meu irmão, primos, familiares e entes queridos, por estarem sempre próximos de coração mesmo quando a distância torna raros os encontros e os abraços.

À minha namorada Evelise, pela vivência do amor verdadeiro em Deus que a cada dia descobrimos mais e mais profundo em nós. Que as linhas desta dissertação dêem testemunho de todo carinho e compreensão que tive de você neste tempo.

À professora Dra. Renata Pontin de Mattos Fortes, pela amizade e confiança adquiridas durante esses anos de convivência, e por todo apoio para a realização deste trabalho. Do que ficou do aprendizado da sua orientação científica esta dissertação até pode dizer um pouco. Contudo, o que ficou do aprendizado de coragem, honestidade, humildade e de vida não cabe aqui em palavras.

Aos amigos do Grupo de Oração Universitário, e a todo o Ministério Universidades Renovadas da Renovação Carismática Católica. Obrigado pela amizade e por serem minha família em São Carlos durante todo este tempo. Sejam canais de Deus para fazer a diferença na vida de muitos nas universidades mundo afora, como fizeram na minha!

Aos amigos Vagner, da Associação Mulheres da Unimed de apoio aos cegos, Ailton do Laboratório Prover da UFSCar, e todos amigos da Pastoral dos surdos. Obrigado por me fazerem acreditar que este trabalho vale a pena!

Ao professor Dr. Mário de Castro e à amiga Cibele Russo, por todo o apoio na realização das análises estatísticas deste trabalho.

A todos os amigos do Laboratório Intermídia e do grupo de pesquisa. Muito obrigado pela convivência e pelo crescimento que me proporcionaram. A todos os professores, funcionários e alunos do ICMC-USP, pela saudável convivência e por todo apoio dado durante a realização deste trabalho.

À amiga professora Dra. Débora Maria Barroso Paiva, pela amizade e pelas contribuições neste e nos trabalhos que vieram antes deste. Obrigado pelo incentivo e pela confiança neste trabalho, tomando a frente no prosseguimento dele!

A todos os participantes do levantamento pela disponibilidade em contribuir com a realização deste estudo.

Ao Conselho Nacional de Desenvolvimento Científico e Tecnológico (CNPq) pelo apoio financeiro. 


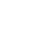




\begin{abstract}
$\mathrm{A}$ Universalização do acesso ao conteúdo disponibilizado em sistemas Web tem se tornado crucial para que todas as pessoas, independente de deficiências ou de outras restrições possam ter acesso a ele. Diversos estudos indicam que, apesar da instituição de leis federais sobre acessibilidade para conteúdo Web em diversos países, muitos sítios ainda apresentam problemas. A falta de conscientização das pessoas envolvidas em projetos de desenvolvimento Web sobre a acessibilidade e a não utilização de técnicas adequadas para desenvolvimento de aplicações têm um impacto considerável sobre a acessibilidade. Levantamentos foram realizados com o objetivo de identificar características dos desenvolvedores sobre o conhecimento e uso de técnicas para acessibilidade. Entretanto, os estudos realizados investigaram somente o uso de um conjunto restrito de técnicas e, além disso, também não investigaram a correlação entre as respostas obtidas pelos participantes e o nível de acessibilidade das páginas desenvolvidas por eles. Neste trabalho, propõe-se efetuar um levantamento sobre a percepção de acessibilidade e uso de técnicas para desenvolvimento de sistemas Web considerando acessibilidade com pessoas envolvidas em projetos de desenvolvimento Web no Brasil de diferentes áreas de atuação. Este levantamento foi acompanhado de avaliações de acessibilidade automatizadas com uso de métricas sobre sítios desenvolvidos pelos participantes, para verificar a influência dos fatores investigados na acessibilidade dos sítios e na percepção de acessibilidade dos participantes. O levantamento realizado contou com a participação de 613 participantes de todo o Brasil. Os resultados indicaram que no Brasil a percepção da acessibilidade por pessoas que participam de projetos de desenvolvimento Web ainda é bastante limitada. Mais do que promover o treinamento das pessoas envolvidas em projetos sobre questões técnicas, é necessário promover maior conscientização sobre a acessibilidade e sobre os problemas que pessoas com diferentes restrições e habilidades enfrentam ao utilizar a Web.
\end{abstract}



$\mathrm{U}^{\mathrm{N}}$ Niversal access to content in Web based systems is an essential aspect to enable everyone to have access to it, regardless of disabilities or any other restrictions. Several studies indicate that, although federal legislation regarding to Web accessibility have been promulgated in many countries, accessibility is still an issue for many Web sites. The limited awareness of accessibility by people involved in Web development and the lack of appropriate use of development techniques in the development of applications have a deep impact on accessibility. A few surveys have been carried out to identify the main characteristics of Web developers regarding accessibility concepts and techniques for accessibility. However, the studies reported up to this date have only investigated the use of a restricted set of techniques by developers. Besides, they have not addressed the analysis of the correlation between the answers provided by the subjects and the accessibility level of their Web pages. The proposal of the work presented in this master's thesis is the development of a survey on the accessibility awareness and on the use of techniques for accessibility by people involved in the development of Web based systems. Automatic metric based accessibility evaluations on the Web sites developed by the subjects were carried out to support the investigation of the impacts that the issues investigated have on the Web pages accessibility and on the accessibility awareness. The survey was answered by 613 subjects from all Brazilian states. The results show that in Brazil the accessibility awareness is still very limited. Training people involved in Web projects on technical issues alone is not enough. It is necessary to promote a wider awareness of accessibility and of the problems people with different restrictions and abilities deal with when using the Web. 

Resumo

$\begin{array}{lll}\text { Abstract } & \text { iii }\end{array}$

1 Introdução $\quad 1$

1.1 Contexto e motivação . . . . . . . . . . . . . . . . . . . . . . . . . . . . . . .

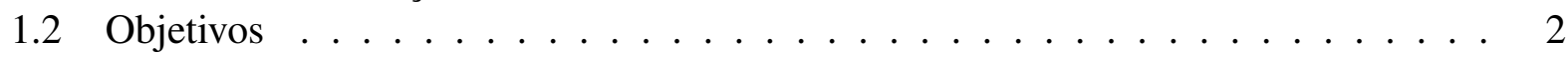

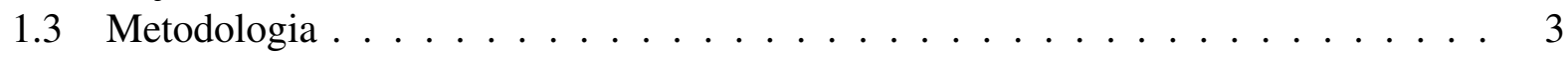

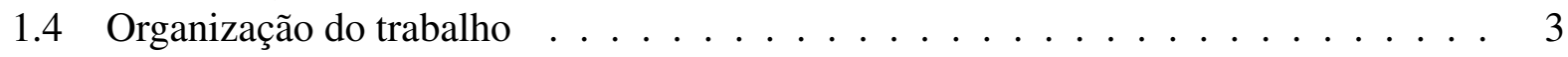

2 Acessibilidade na Web 5

2.1 Considerações iniciais . . . . . . . . . . . . . . . . . 5

2.2 Tecnologia assistiva e design universal . . . . . . . . . . . . . . . . . . . . . . . . . . . . . . .

2.3 Acessibilidade em sistemas Web . . . . . . . . . . . . . . . . . . 8

2.4 Legislação de acessibilidade . . . . . . . . . . . . . . . . . . . . . . . . . . . . . . 11

2.5 Diretrizes para acessibilidade na Web . . . . . . . . . . . . . . . . . 12

2.6 Avaliação de acessibilidade na Web . . . . . . . . . . . . . . . . 15

2.7 Considerações finais . . . . . . . . . . . . . . . . . . . 19

3 Técnicas para desenvolvimento de sistemas Web acessíveis 21

3.1 Considerações iniciais . . . . . . . . . . . . . . . . . 21

3.2 Engenharia Web . . . . . . . . . . . . . . . . . . . . 22

3.3 Revisão da literatura . . . . . . . . . . . . . . . . . . . . . . . 24

3.3 .1 Protocolo da revisão . . . . . . . . . . . . . . . . . . 27

3.3 .2 Condução da revisão . . . . . . . . . . . . . . . . . . . 28

3.4 Resultados da revisão da literatura . . . . . . . . . . . . . . . . . . . . . . . . . . . . . . . . . . . . . . . . . . . . . . . .

3.5 Considerações finais . . . . . . . . . . . . . . . 35

4 Métricas de acessibilidade $\quad 37$

4.1 Considerações iniciais . . . . . . . . . . . . . . . . . . . . 37

4.2 Métricas de acessibilidade . . . . . . . . . . . . . . . . 38

4.3 Métrica de problemas potenciais . . . . . . . . . . . . . . . . 39

4.4 Métrica de acessibilidade para usuários cegos . . . . . . . . . . . . . . . . . . . . . . . . . . . . . . . . .

4.5 Métrica WAB (Web Accessibility Barrier) . . . . . . . . . . . . . . . . . . . 41

4.6 Métrica UWEM - Modelo de agregação de resultados de testes . . . . . . . . . . . 41 
4.7 Métrica A3 - Modelo melhorado de agregação de resultados de testes . . . . . . . . 44

4.8 Métrica WAQM (Web Accessibility Quality Metric) . . . . . . . . . . . . . . . . 45

4.9 Considerações finais . . . . . . . . . . . . . . . . . . . 47

5 Hera metrics: módulo para cálculo de métricas 49

5.1 Considerações iniciais . . . . . . . . . . . . . . . . . . . . . 49

5.2 Estudo sobre a ferramenta Hera $2.0 \ldots \ldots \ldots$. . . . . . . . . . . . 51

5.3 Módulo para cálculo de métricas de acessibilidade . . . . . . . . . . . . . 53

5.4 Estudos de caso: análise da acessibilidade de sítios governamentais brasileiros . . . 56

5.4.1 Acessibilidade nos sítios dos governos estaduais brasileiros de 1996 a $2007 \quad 58$

5.4.2 Acessibilidade nos sítios das prefeituras municipais brasileiras . . . . . . . 60

5.5 Considerações finais . . . . . . . . . . . . . . . . . 62

6 Levantamento com pessoas envolvidas em projetos Web no Brasil 63

6.1 Considerações iniciais . . . . . . . . . . . . . . . . . 63

6.2 Pesquisas de levantamento . . . . . . . . . . . . . . . . . 64

6.3 Trabalhos relacionados ........................... 65

6.3 .1 Levantamento - Lazar et. al (2004) . . . . . . . . . . . . . . . . . . 66

6.3 .2 Levantamento - ENABLED (2005) . . . . . . . . . . . . . . . 67

6.3 .3 Levantamento - Ferreira et. al (2007) . . . . . . . . . . . . . . . . 69

6.3.4 Levantamento - Tangarife $(2007) \ldots \ldots$. . . . . . . . . . . 70

6.4 Planejamento e condução do levantamento . . . . . . . . . . . . . . . . 71

6.5 Resultados do levantamento . . . . . . . . . . . . . . . . 75

6.5.1 Análise descritiva . . . . . . . . . . . . . . . 75

6.5.2 Modelagem estatística . . . . . . . . . . . . . . . 85

6.5 .3 Análise da validade . . . . . . . . . . . . . . . . . . . 91

6.6 Considerações finais . . . . . . . . . . . . . . . . . . . . 92

7 Conclusões e trabalhos futuros $\quad 93$

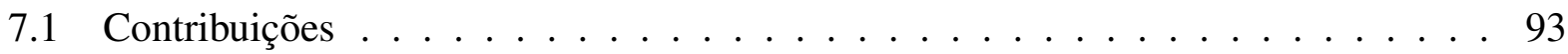

7.2 Limitações . . . . . . . . . . . . . . . . . . . . . . . . . . . . 94

7.3 Trabalhos futuros . . . . . . . . . . . . . . . . 95

7.4 Produção científica . . . . . . . . . . . . . . . . . . . . . 96

$\begin{array}{ll}\text { A Glossário } & 109\end{array}$

B Diretrizes e pontos de verificação do WCAG 1.0 111

C Levantamento sobre técnicas para desenvolvimento Web acessível 117

D Avaliação dos sítios dos governos estaduais brasileiros entre 1996 e 2007

$\begin{array}{lll}\text { E Avaliação dos sítios das prefeituras municipais brasileiras } & 127\end{array}$

F Instrumentos utilizados na pesquisa levantamento $\quad 131$

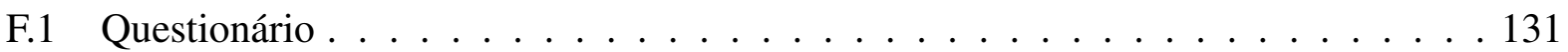

F.2 E-mail convite . . . . . . . . . . . . . . . . . 134

$\begin{array}{ll}\text { G Modelos estatísticos do levantamento } & 135\end{array}$ 


\section{Lista de Figuras}

2.1 Exemplo de problema de acessibilidade: página com exibição de elementos gráficos 10

2.2 Exemplo de problema de acessibilidade: página com problemas de acessibilidade em um navegador textual . . . . . . . . . . . . . . . . . . . . . . 10

2.3 Exemplo de página com recursos que favorecem a acessibilidade em um navegador gráfico . . . . . . . . . . . . . . . . . . . . 11

2.4 Exemplo de página com recursos que favorecem a acessibilidade em um navegador

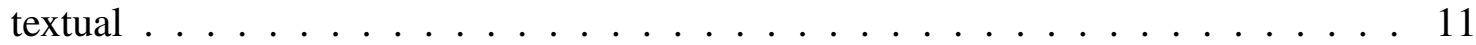

2.5 Exemplo de relatório de avaliação de uma página Web com a ferramenta Hera . . . 17

3.1 Processos da norma ISO/IEC $12207 \ldots \ldots \ldots \ldots \ldots$

3.2 Etapas para a revisão sistemática . . . . . . . . . . . . . . . . 26

3.3 Número de publicações de técnicas para acessibilidade para processos da ISO/IEC

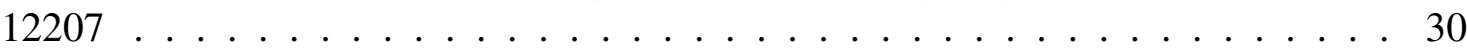

4.1 Primeiro e segundo estágios para o cálculo de métrica de acessibilidade do UWEM (Cluster, 2006b) . . . . . . . . . . . . . . . . . . . . 4 42

4.2 Aproximação do cálculo da métrica WAQM por uma hipérbole (Vigo et al., 2007) . 47

5.1 Estrutura básica da ferramenta Hera 2.0 (Benavídez et al., 2006) . . . . . . . . . . 52

5.2 Diagrama com as principais classes utilizadas para avaliação na ferramenta Hera 2.052

5.3 Diagrama com as principais classes utilizadas para avaliação na ferramenta Hera 2.0 com o módulo de cálculo de métricas . . . . . . . . . . . . . . . . 54

5.4 Gráfico de dispersão e coeficientes de correlação de Pearson para as diferentes métricas na análise dos sítios dos governos estaduais . . . . . . . . . . . . 59

5.5 Comparação entre os índices WAB dos sítios Web dos governos estaduais entre 2004 e $2006 \ldots \ldots$. . . . . . . . . . . . . . . . . . . . . . 60

6.1 Participantes do levantamento de acordo com as regiões do país . . . . . . . . . . 76

6.2 Participantes do levantamento de acordo com a faixa etária . . . . . . . . . . . 76

6.3 Participantes do levantamento de acordo com a área de atuação . . . . . . . . . . 76

6.4 Participantes do levantamento de acordo com a formação . . . . . . . . . . . . . 77

6.5 Distribuição dos participantes do levantamento de acordo com as funções exercidas em suas organizações . . . . . . . . . . . . . . . . . . . 77

6.6 Conhecimento dos participantes do levantamento sobre linguagem de marcação e de estilo . . . . . . . . . . . . . . . . . . . . 78

6.7 Conhecimento dos problemas enfrentados por cegos ao utilizar a Web . . . . . . 78 
6.8 Tecnologias assistivas conhecidas pelos participantes do levantamento . . . . . . . 79

6.9 Conhecimento sobre o Decreto Lei No. 5.296/2004 e suas implicações para Web pelos participantes do levantamento . . . . . . . . . . . . . . . . . 79

6.10 Conhecimento dos participantes do levantamento sobre as diretrizes do WCAG do

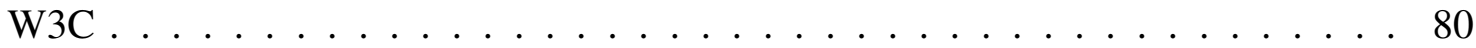

6.11 Treinamentos sobre acessibilidade recebidos pelos participantes . . . . . . . 80

6.12 Tipos de avaliação de acessibilidade realizados pelos participantes . . . . . . . . . 81

6.13 Opinião dos participantes sobre a consideração da acessibilidade nos projetos em que estão envolvidos . . . . . . . . . . . . . . . . . 81

6.14 Motivos porque acessibilidade é considerada nos projetos dos participantes . . . . 82

6.15 Motivos porque acessibilidade não é considerada ou é considerada parcialmente nos projetos dos participantes . . . . . . . . . . . . . . . . 83

6.16 Boxplots com o sumário dos resultados das avaliações das páginas dos participantes do levantamento com as métricas WAB, A3, UWEM e WAQM . . . . . . . . . 85

D.1 Número de estados com sítios web por ano entre 1996 e 2007 . . . . . . . . . . . . 121

D.2 Série histórica da análise das páginas com a métrica $\mathrm{A} 3$ dos sítios dos estados . . . 122

D.3 Série histórica da análise das páginas com a métrica UWEM dos sítios dos estados 123

D.4 Série histórica da análise das páginas com a métrica WAB dos sítios dos estados . . 124

D.5 Série histórica da análise das páginas com a métrica WAQM dos sítios dos estados 125 


\section{Lista de Tabelas}

2.1 Lista de ferramentas de apoio à avaliação de acessibilidade . . . . . . . . . . . . 18

4.1 Padronização de variáveis nas fórmulas das métricas de acessibilidade . . . . . . . 39

5.1 Sítios Web dos governos municipais por regiões . . . . . . . . . . . . . . 61

5.2 Resultados da avaliação dos sítios dos governos municipais com a métrica WAB . . 61

6.1 Sumário com as inferências obtidas por meio dos modelos estatísticos . . . . . . . 90

C.1 Lista de trabalhos incluídos na revisão da literatura . . . . . . . . . . . . . . . . 119

E.1 Resultados da avaliação dos sítios dos governos municipais com a métrica A3 . . . 127

E.2 Resultados da avaliação dos sítios dos governos municipais com a métrica UWEM 128

E.3 Resultados da avaliação dos sítios dos governos municipais com a métrica WAQM 128

E.4 Lista dos quinze municípios com menores índices WAB . . . . . . . . . . . . . 129

E.5 Lista dos quinze municípios com maiores índices WAB . . . . . . . . . . . . 129 


\subsection{Contexto e motivação}

O acesso à informação e à tecnologia por todas as pessoas tem se apresentado como um grande desafio para a indústria, academia e para toda a sociedade. Em particular, garantir a acessibilidade da informação e da comunicação é um importante aspecto para promover a inclusão na "Sociedade da Informação".

O crescimento do uso da Web como plataforma para aprendizado eletrônico, governo eletrônico, comércio eletrônico e muitos outros serviços online tornam a Web uma tecnologia essencial atualmente. Dessa forma, a promoção da inclusão na Sociedade da Informação passa inevitavelmente pela melhoria da acessibilidade das aplicações Web. No caso da Web, a acessibilidade é um objetivo que envolve a geração de documentos que possam ser "renderizados" por diferentes dispositivos. Isso inclui o acesso por cegos que utilizem leitores de tela com sintetizadores de voz, pessoas com baixa visão, surdos, pessoas com deficiência motora, idosos, entre outros grupos que possam ter algum tipo de dificuldade para ter acesso ao conteúdo disponibilizado. Para que esse objetivo seja alcançado, deve-se ter em mente princípios de design universal, evitando restringir o projeto a grupos restritos de usuários.

Apesar da existência de muitas diretrizes de acessibilidade, como o Web Content Accessibility Guidelines (WCAG 1.0) (W3C, 1999a) do W3C e leis federais em diversos países, relacionadas à acessibilidade na Web, ainda existem muitas páginas com problemas de acessibilidade.

No Brasil, o Decreto Lei No. 5.296/2004 de dezembro de 2004 havia estabelecido que todos os sítios governamentais deveriam se adequar para atender aos requisitos de acessibilidade no 
período de um ano. Em um levantamento preliminar realizado pela ONG Acessibilidade Brasil ${ }^{1}$ em dezembro de 2005, apenas 15 de 540 endereços avaliados foram considerados acessíveis. Nos Estados Unidos, apesar de a legislação de acessibilidade ser mais antiga, ainda existe uma grande quantidade de sítios inacessíveis, como apontado por Goette et al. (2006) e Hackett et al. (2004). A falta de acessibilidade em Taiwan também foi apontada por Chen et al. (2006).

A investigação sobre as causas desses problemas, bem como de propostas para melhorar a situação atual tem sido alvo de muitos trabalhos de pesquisa (Lazar et al., 2004; Brajnik, 2006; Parmanto e Zeng, 2005). Grande parte da responsabilidade pela acessibilidade de um sistema Web é dos desenvolvedores. Em levantamentos realizados por Lazar et al. (2004) e pela ENABLED (2005), verificou-se que muitos desenvolvedores não têm conhecimento aprofundado sobre acessibilidade, e mesmo alguns que têm conhecimento alegam não ter tempo ou interesse para tornar seus sistemas Web acessíveis.

Como os desenvolvedores possuem um papel fundamental para o desenvolvimento, a preparação adequada por meio de treinamentos e de uso de técnicas é de extrema importância para promover a melhoria da acessibilidade na Web.

A realização de levantamentos sobre a acessibilidade de sítios Web foi o alvo de diversos trabalhos (Snaprud et al., 2006; Chen et al., 2006; Sullivan e Matson, 2000; Hackett et al., 2004; Goette et al., 2006), e alguns esforços também foram realizados para identificar o perfil de desenvolvedores sobre conhecimento e uso de técnicas para acessibilidade.

Contudo, não existem relatos de estudos sobre o perfil das pessoas envolvidas com desenvolvimento Web no Brasil em relação à acessibilidade com mais ampla abrangência. Além disso, não foi encontrado na literatura nenhum estudo relacionando as características das pessoas envolvidas com o desenvolvimento e o nível de acessibilidade dos sistemas produzidos por elas.

Neste trabalho, foi efetuado um levantamento sobre a acessibilidade na Web sob o ponto de vista de pessoas envolvidas com projetos de sistemas Web no Brasil. Além disso, foi efetuado um estudo envolvendo a avaliação de aplicações desenvolvidas pelos participantes, por meio da extração de métricas com ferramentas de avaliação automática de acessibilidade.

\subsection{Objetivos}

O principal objetivo desta pesquisa foi de adquirir uma visão abrangente sobre a acessibilidade no desenvolvimento de sistemas Web no Brasil. Para tanto, um levantamento foi realizado, considerando os seguintes objetivos:

- Realização de um levantamento sobre o conhecimento de desenvolvedores a respeito de acessibilidade e sobre o uso de técnicas apropriadas voltadas para acessibilidade;

\footnotetext{
${ }^{1}$ http://www.acessobrasil.org.br
} 
- Realização de estudos bibliográficos para contextualização do estado da arte sobre as técnicas de Engenharia Web para desenvolvimento de sistemas Web acessíveis, auxiliando tanto o direcionamento sobre o uso de técnicas quanto na elaboração do levantamento sobre a percepção a respeito da acessibilidade;

- Desenvolvimento de um módulo de software para cálculo de métricas baseado em uma ferramenta de avaliação automática de acessibilidade, para apoiar a comparação da acessibilidade dos sistemas avaliados e do perfil das pessoas envolvidas em seu desenvolvimento;

- Análise estatística dos dados obtidos no levantamento, buscando verificar a influência das variáveis analisadas no perfil dos participantes.

\subsection{Metodologia}

Neste trabalho, o principal método de pesquisa utilizado foi o de pesquisa do tipo levantamento (survey), com a realização de uma pesquisa com pessoas envolvidas no desenvolvimento de sistemas Web, apoiada pelo cálculo de métricas sobre acessibilidade de páginas por meio de uma ferramenta de avaliação automática.

Para o desenvolvimento da ferramenta para cálculo de métricas, foram utilizados procedimentos para desenvolvimento de software baseados na engenharia reversa de uma ferramenta existente seguido do projeto e desenvolvimento das modificações necessárias. A validação da ferramenta foi feita por meio da realização de estudos de caso pontuais, contemplando casos em que foram realizadas avaliações em grandes quantidades de dados.

Também foi utilizado o método de pesquisa bibliográfica, por meio de uma revisão sistemática da literatura (Kitchenham, 2004), para identificar o estado da arte em técnicas para apoiar o desenvolvimento de sistemas Web acessíveis, para auxiliar na obtenção de uma visão mais ampla sobre o desenvolvimento de pesquisa sobre técnicas e sobre o seu uso na prática.

\subsection{Organização do trabalho}

O restante desta dissertação está organizado da seguinte forma: no Capítulo 2 são apresentados os conceitos elementares relacionados a acessibilidade em aplicações Web, incluindo conceitos sobre tecnologia assistiva, legislação e diretrizes para acessibilidade na Web; no Capítulo 3 são apresentados alguns dos principais elementares de Engenharia de Web e os resultados de um levantamento sobre técnicas para desenvolvimento de aplicações Web mais acessíveis. No Capítulo 4 são apresentados alguns dos principais conceitos sobre métricas de acessibilidade e o desenvolvimento de um módulo para cálculo de métricas no Capítulo 5. No Capítulo 6 é discutido o planejamento do levantamento com pessoas envolvidas em projetos de sistemas Web e os prin- 
cipais resultados obtidos com o levantamento e, finalmente, no Capítulo 7 são apresentadas as principais conclusões deste trabalho e apontamentos para trabalhos futuros. 


\section{Acessibilidade na Web}

\subsection{Considerações iniciais}

O crescimento do uso da Web a partir de dispositivos ubíquos, principalmente dispositivos móveis, e o uso de recursos da Web por pessoas com necessidades especiais tem motivado o desenvolvimento de técnicas para produzir páginas Web acessíveis (Thatcher et al., 2002). A globalização do acesso a informações requer uma atenção especial nos projetos de aplicações Web, que se depara com o desafio de atender a diferentes necessidades e restrições dos usuários. Acessibilidade é o conceito chave que permeia o conjunto de critérios que devem ser considerados para enfrentar esse desafio.

A instituição de leis que regulamentam a disponibilização de conteúdo acessível por parte de órgãos governamentais em diversos países, como Estados Unidos, Canadá, Portugal, Japão, e recentemente o Brasil, também tem alavancado iniciativas em prol do uso de técnicas para desenvolvimento de páginas Web acessíveis.

Contudo, nota-se que o grande entrave para a disseminação da cultura de acessibilidade na Web está na conscientização dos desenvolvedores sobre a importância do tema. Um outro entrave é relacionado às conseqüências trazidas pela utilização de tecnologias que se tornam barreiras para o acesso ao conteúdo disponibilizado na Web.

O objetivo deste capítulo é o de introduzir os principais conceitos relativos à acessibilidade na Web, e conceitos relacionados, como tecnologia assistiva, design universal, e também temas como legislação de acessibilidade, visando fornecer um contexto geral sobre o tema. As diretrizes de 
acessibilidade do $\mathrm{W}^{3} \mathrm{C}^{1}$ são apresentadas, e são discutidas técnicas para criar e avaliar conteúdo Web de acordo com as diretrizes.

Este capítulo está organizado da seguinte forma: na Seção 2.2 são apresentados os principais conceitos associados a tecnologia assistiva. Na Seção 2.3 são apresentados os principais conceitos relacionados a acessibilidade na Web. Na Seção 2.4 são apresentadas informações a respeito de legislação sobre acessibilidade na Web, e casos de países que já possuem tal legislação; é apresentado também um panorama sobre a legislação de acessibilidade brasileira. Na Seção 2.5 são apresentados conceitos sobre diretrizes de acessibilidade, e são discutidas as diretrizes de acessibilidade recomendadas pelo W3C. Na Seção 2.6 são apresentados conceitos e trabalhos relacionados que têm sido reportados sobre avaliação de acessibilidade.

\subsection{Tecnologia assistiva e design universal}

Tecnologia Assistiva é um termo utilizado para identificar todos os recursos e serviços que contribuem para proporcionar ou ampliar as habilidades funcionais das pessoas com necessidades especiais e, conseqüentemente, promover vida independente e inclusão social. O termo Tecnologia Assistiva é traduzido do inglês Assistive Technology, que é definido como o conjunto de equipamentos, serviços, estratégias e práticas concebidas e aplicadas para atenuar os problemas encontrados pelas pessoas com necessidades especiais (Cook e Hussey, 2001).

A aplicação de tecnologia assistiva abrange uma série de possibilidades, desde tarefas domésticas básicas até atividades de lazer e de trabalho. A obtenção da maior independência e autonomia possível é um dos caminhos para a completa integração social das pessoas com necessidades especiais ou mobilidade reduzida e deve, portanto, constituir-se no principal objetivo em matéria de inclusão social.

Apesar de o termo "tecnologia assistiva" ser amplamente utilizado na computação, deve-se ressaltar que recursos computacionais não são a única forma de tecnologia assistiva existente. Outros aparelhos como cadeiras de rodas, dispositivos de escrita em braille, e mesmo a bengala e os óculos são considerados como tecnologias assistivas.

Existem diversos tipos de tecnologias assistivas que dão apoio a usuários com deficiência para utilizar o computador. O objetivo destas tecnologias é permitir que esses usuários possam interagir com sistemas, independente de dificuldades motoras, de percepção, cognitivas ou de linguagem.

No Brasil, existe uma enorme quantidade de pessoas que podem e devem beneficiar-se da Tecnologia Assistiva. Segundo o documento Síntese de Indicadores Sociais do IBGE (IBGE, 2005), havia no país em 2003, 16,7 milhões de pessoas com 60 anos ou mais, representando 9,6\% do total de habitantes. Quanto às pessoas com necessidades especiais, esse grupo social representava 14,5\% da população brasileira em 2000, segundo o Censo Demográfico 2000, também elaborado pelo IBGE (IBGE, 2000).

\footnotetext{
${ }^{1}$ World Wide Web Consortium
} 
A Tecnologia Assistiva pode proporcionar assistência na comunicação, transporte, e outras atividades da vida diária. Entretanto, essa tecnologia também pode fornecer uma nova barreira se não for considerada a extensão da variabilidade humana, incluindo incapacidade (disability), idade, e tipo de corpo (Berliss-Vincent, 2000). Ao considerar opções para Tecnologia Assistiva é importante ressaltar que raramente existe a "melhor" tecnologia para uma determinada situação. Ao contrário, a conveniência tecnológica precisa ser julgada não somente sobre a funcionalidade mas também sobre a habilidade do usuário em adquirir, manter, e obter treinamento sobre o equipamento. Além disso, um equipamento geralmente é somente uma ferramenta entre muitas, e todas as opções devem ser consideradas antes de assumir que a tecnologia pode fornecer a solução ótima. Finalmente, ao mesmo tempo em que as pessoas devem ter tantas opções tecnológicas quanto possível, elas também precisam da opção de não utilizar tecnologia; por exemplo, uma pessoa com uma dificuldade na fala (speech disability) que prefere usar sua própria voz a usar um equipamento auxiliar de comunicação (communication aid) precisa ter a sua preferência respeitada.

Existem diversos tipos de software e dispostivos para auxiliar o uso do computador por pessoas com necessidades especiais. Para acessar a Web, muitas pessoas com deficiência visual utilizam o leitor de tela. Alguns usuários usam navegadores textuais como o Lynx ${ }^{2}$ ou navegadores com voz em vez de utilizar um navegador comum (navegador com interface gráfica). É muito comum as pessoas com deficiência visual se utilizarem da tecla "tab" para navegar somente em links ao invés de ler todas as palavras que estão na página. Deste modo, eles têm uma rápida noção do conteúdo da página ou podem acessar o link desejado mais rapidamente (Serpro, 2004). A seguir, são listados alguns exemplos de tecnologia assistiva para deficientes visuais:

- Leitor de Tela: é um software que lê o texto que está na tela do computador e a saída desta informação é fornecida através de um sintetizador de voz ou um display braille - o leitor de tela "fala" o texto para o usuário ou apresenta o texto em braille através de um dispositivo onde os pontos são salientados ou rebaixados para permitir a leitura. Exemplo de leitores de tela são o JAWS (Freedom Scientific, 2006) e o DOSVOX (NCE-UFRJ, 2007), que possui um sistema completo dotado de leitor de tela.

- Navegador Textual: é um navegador baseado em texto, diferente dos navegadores com interface gráfica onde as imagens são carregadas. O navegador textual pode ser usado com o leitor de tela por pessoas com deficiência visual e também por pessoas que acessam a internet com conexão lenta. Um dos principais navegadores textuais é o Lynx, utilizado em sistemas Linux.

- Navegador com voz: é um sistema que permite a navegação orientada pela voz. Alguns possibilitam o reconhecimento da voz e a apresentação do conteúdo com sons, outros permitem acesso baseado em telefone (através de comando de voz pelo telefone e/ou por teclas do telefone). O navegador Opera, por exemplo, fornece funções de reconhecimento de voz.

\footnotetext{
${ }^{2}$ Disponível em http://www.lynx.isc.org
} 
Além dos exemplos citados de tecnologia assistiva para deficientes visuais, existem diversos outros softwares e dispositivos, como aumentadores de tela para pessoas com pouca visão, teclados alternativos, mouses alternativos, entre outros.

Nesse sentido, o conceito de Design Universal (Universal Design), ou Design para Todos (Design for $A l l^{3}$ ), está ganhando popularidade (Melo e Baranauskas, 2006b). Design Universal referese à tecnologia desenvolvida de maneira que seja flexível o suficiente para acomodar as diversas habilidades humanas sem sacrificar a estética, a eficácia, ou o custo. Embora exista legislação específica sendo desenvolvida para garantir o Design Universal (nos Estados Unidos, por exemplo), o maior incentivo talvez seja a ampla recepção positiva das pessoas em relação aos benefícios do Design Universal. Por exemplo, quando uma inovação que pode ter sido inspirada inicialmente nas necessidades de pessoas com alguma incapacidade, também tem ampla aceitação por todas as pessoas por causa de diferenciais de conforto e segurança.

Na próxima seção são apresentados os principais conceitos relacionados a acessibilidade na Web.

\subsection{Acessibilidade em sistemas Web}

A World Wide Web (ou simplesmente Web) foi concebida com o principal intuito de oferecer uma tecnologia para disponibilização de conteúdo em um formato padrão simples e poderoso, por meio de informações disponibilizadas em hipertexto utilizando HTML (W3C, 1999). Desde a concepção da Web, Tim Berners Lee ${ }^{4}$ destacou que "o poder da Web está em sua universalidade. Ser acessada por todos, independente de deficiência, é um aspecto essencial”.

O avanço das novas tecnologias de computação móvel e ubíqua que utilizam a Web, assim como os avanços sociais para inclusão das pessoas com necessidades especiais têm colocado o tema de acessibilidade na Web em destaque nos ambientes acadêmicos, empresariais e governamentais.

Acessibilidade na Web corresponde a possibilitar que qualquer usuário, utilizando qualquer agente (software ou hardware que recupera e serializa conteúdo Web) possa entender e interagir com o conteúdo de um sítio (Thatcher et al., 2002). Acessibilidade incorpora ainda a idéia de que todas as pessoas têm o direito de serem incluídas na sociedade, independente de deficiências, localização geográfica, barreiras de linguagem, ou outro fator (Thatcher et al., 2002).

Durante o desenvolvimento de um sítio na Web é necessário que se leve em conta não só os usuários que utilizam tecnologias similares às utilizadas pelo desenvolvedor. Deve-se ter em mente que a Web pode ser usada em diferentes contextos por pessoas que, por exemplo (W3C, 1999a): sejam incapazes de ver, ouvir, se deslocar, ou interpretar determinados tipos de informações, tenham dificuldade em ler ou compreender textos, não tenham um teclado ou mouse, ou não sejam

\footnotetext{
${ }^{3} \mathrm{Na}$ Europa o termo "Design for All" tem o mesmo significado de "Universal Design"

${ }^{4}$ Inventor da Web e diretor do World Wide Web Consortium (W3C)
} 
capazes de utilizá-los, possuam tela que apresenta apenas texto, ou com dimensões reduzidas, ou ainda uma conexão lenta com a Internet, não falem ou compreendam fluentemente o idioma em que o documento foi escrito, estejam com seus olhos, mãos ou ouvidos ocupados (por exemplo, a caminho do trabalho, ou em um ambiente barulhento), possuam uma versão ultrapassada de navegador Web, diferente dos habituais, um navegador por voz, ou um sistema operacional pouco convencional.

A partir dos exemplos, pode-se verificar que o tema "Acessibilidade na Web" não diz respeito somente ao acesso à Web por usuários com deficiências. A utilização dos padrões e recomendações de acessibilidade traz benefícios para diversos grupos de usuários, e para a Web como um todo (Hull, 2004).

Como citado na Seção 2.2, em 2000, 14,5\% da população brasileira possuía algum tipo de necessidade especial e 9,6\% da população tinha mais de 60 anos de idade. Esta parcela da população é bastante significativa, e representa uma grande porção de potenciais clientes de sítios de comércio eletrônico, usuários de serviços do governo, visitantes de sítios de entretenimento entre outros.

A preocupação com acessibilidade na Web deve crescer ainda mais em um futuro próximo, pois a parcela da população idosa, por exemplo, está crescendo significativamente com o aumento da expectativa de vida. Segundo projeções do IBGE (2005), estima-se que em 2030 cerca de $20 \%$ da população mundial terá mais de 65 anos. Também deve-se considerar que existe uma estreita relação entre a faixa etária e o surgimento de deficiências. A proporção de pessoas portadoras de necessidades especiais com menos de 21 é de $10 \%$, enquanto que a proporção de pessoas com mais de 65 anos é de $47,3 \%$.

Existe uma grande quantidade de páginas Web que não seguem padrões de acessibilidade, e possuem diversas barreiras ao acesso por pessoas com necessidades especiais e usuários de dispositivos com capacidade reduzida de exibição. Para exemplificar um dos tipos de problemas de barreiras em páginas na Web, pode-se observar na Figura 2.1 a página do Speedy ${ }^{5}$ em um navegador gráfico. Na Figura 2.2 é ilustrada a mesma página acessada a partir de um navegador textual (Lynx). Pode-se notar que, como o conteúdo só é fornecido no formato Macromedia Flash, e não é fornecido nenhum conteúdo alternativo, não é exibida nenhuma informação no navegador textual. Um navegador com leitor de tela para um usuário cego apresentaria o mesmo resultado que o obtido a partir do navegador textual.

Desenvolver páginas acessíveis não significa que não se deve utilizar recursos gráficos e layouts avançados. Não há nada que impeça que um designer crie uma página rica em layout com o mínimo de barreiras de acessibilidade (Petrie et al., 2003) (Regan, 2004). Esta é uma das justificativas mais utilizadas por pessoas envolvidas com o projeto de sistemas Web para não desenvolver conteúdo acessível. Contudo, com o uso das técnicas adequadas, não é necessário de forma alguma "perder" em design em favor da acessibilidade.

\footnotetext{
${ }^{5}$ Disponível online em http://www.speedy.com.br, acessada em 19 de Janeiro de 2007
} 


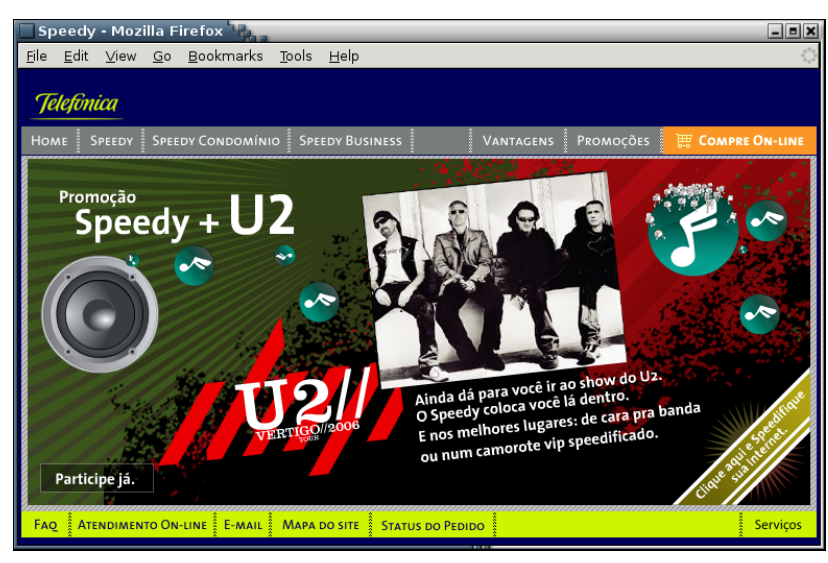

Figura 2.1: Exemplo de problema de acessibilidade: página com exibição de elementos gráficos

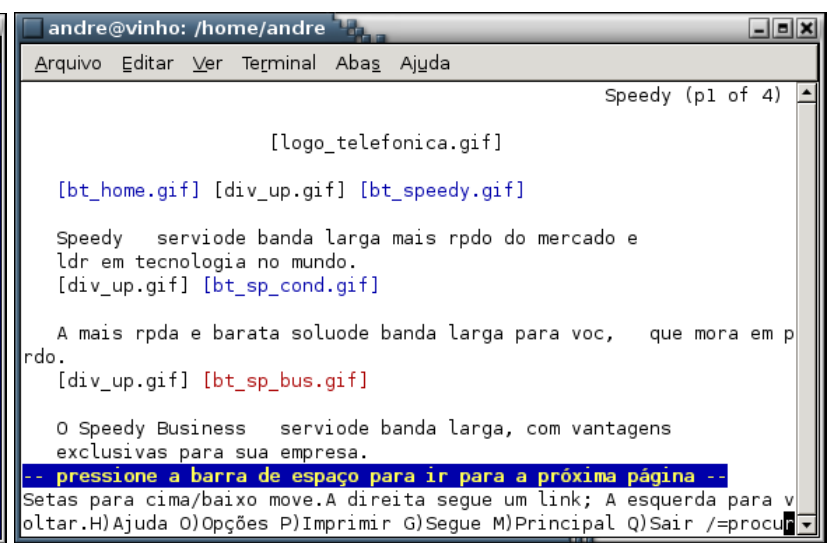

Figura 2.2: Exemplo de problema de acessibilidade: página com problemas de acessibilidade em um navegador textual

Um outro conceito mal interpretado em relação a acessibilidade é o de que o desenvolvimento visando acessibilidade implica em limitações na usabilidade. Muitos desenvolvedores argumentam que as recomendações de acessibilidade limitam o uso de tecnologias como Javascript, animações, applets e outras tecnologias que podem ser utilizadas para melhorar a usabilidade de um sítio. As recomendações não impedem o uso destas tecnologias a priori, só indicam que elas devem ser utilizadas com cuidado, e que não devem impedir o acesso por usuários que não disponham delas, para que não se tornem barreiras.

O desenvolvimento de páginas acessíveis consiste em confeccionar páginas levando em conta os princípios de acessibilidade e Design Universal. Há diversos exemplos de páginas que contêm auxílios para o uso por portadores de necessidades especiais e que se adaptam bem a diversos tipos de dispositivos. Para exemplificar, pode-se analisar uma página gerada pelo gerenciador de conteúdo Plone (Plone, 2007). Na página inicial do sítio do Plone, ilustrada na Figura 2.3, verifica-se que são disponibilizadas opções para utilização de diferentes tamanhos de fonte, além de utilizar padrões para codificação da página, que permitem o ajuste a diferentes resoluções de tela e diferentes dispositivos, sem prejudicar o layout. Na Figura 2.4 é ilustrada a exibição da página inicial do Plone em um navegador textual. Verifica-se que o conteúdo é disponibilizado mesmo sem a possibilidade de exibir imagens. As figuras possuem texto alternativo, e a página ainda disponibiliza outros apoios, como âncoras para saltar direto para o conteúdo, bastante útil para portadores de deficiências visuais que utilizam leitores de tela.

Na próxima seção é apresentado um panorama sobre legislações de acessibilidade da informação em alguns países, e sobre o estado atual da legislação brasileira de acessibilidade. 


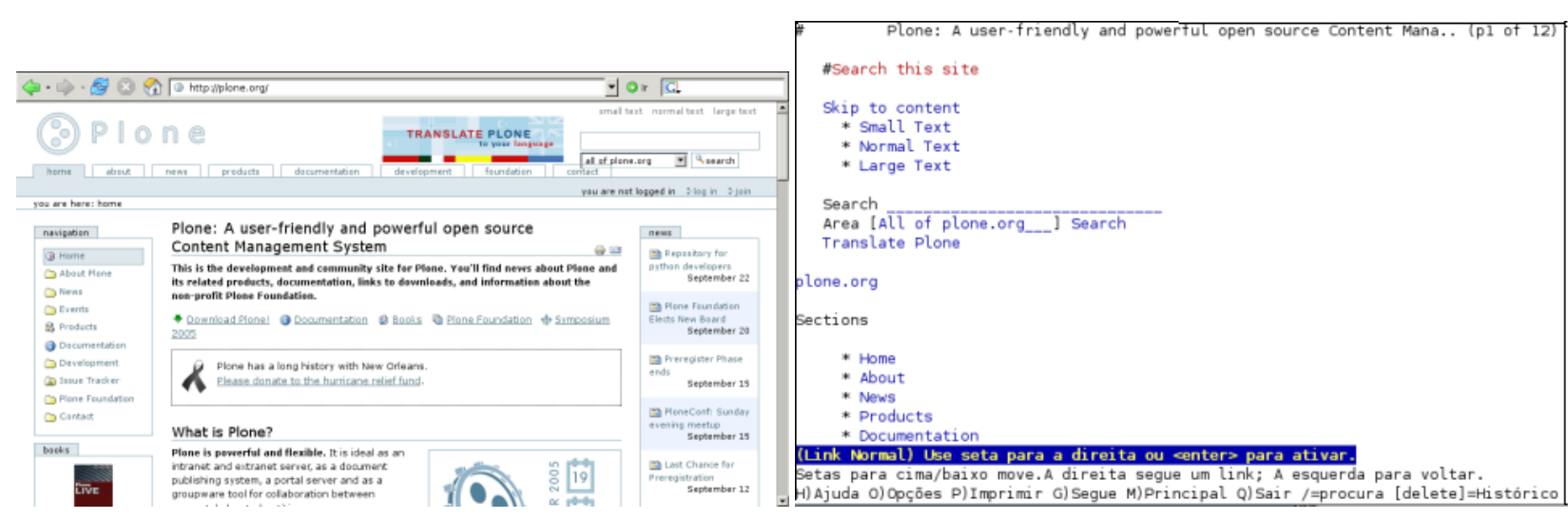

Figura 2.3: Exemplo de página com recursos que favorecem a acessibilidade em um navegador gráfico
Figura 2.4: Exemplo de página com recursos que favorecem a acessibilidade em um navegador textual

\subsection{Legislação de acessibilidade}

Os primeiros países que idealizaram parâmetros de acessibilidade na Internet foram Canadá, Estados Unidos e Austrália, em 1997. Nos Estados Unidos, em 1998, entrou em vigor a "Section 508", uma lei determinando que a tecnologia eletrônica e de informação dos órgãos federais fosse acessível às pessoas com necessidades especiais. Segundo essa lei, a tecnologia inacessível interfere na capacidade individual de adquirir e usar a informação de maneira rápida e fácil. A Section 508 foi decretada para eliminar barreiras na tecnologia da informação, disponibilizando novas oportunidades para as pessoas com necessidades especiais e incentivando o desenvolvimento de tecnologias que as auxiliem a atingir esses objetivos.

Com o objetivo de tornar a Web acessível a um número cada vez maior de pessoas e maximizar a interoperabilidade, o World Wide Web Consortium (W3C) criou a Iniciativa para a Acessibilidade na Web (Web Accessibility Initiative, WAI). Entre outras atribuições, a WAI mantém grupos de trabalho para elaborar conjuntos de recomendações para garantir a acessibilidade do conteúdo da Web às pessoas com necessidades especiais ou que acessam a Web em condições especiais de ambiente, equipamento, navegador e outras ferramentas Web. Como resultado desse trabalho, em 1999, foi publicada a primeira versão das Diretrizes para a Acessibilidade do Conteúdo da Web (Web Content Accessibility Guidelines, WCAG 1.0), principal referência mundial em termos de acessibilidade na Web e que se estabeleceu como uma recomendação.

No Brasil, a principal iniciativa para criação de diretrizes de acessibilidade foi o Modelo de Acessibilidade de Governo Eletrônico (e-MAG) (Governo Brasileiro, 2008).

O (e-MAG) foi elaborado pelo Ministério do Planejamento, Orçamento e Gestão para apoiar a construção e a adaptação dos conteúdos governamentais (informações, serviços, etc.) na Internet. Nesse modelo são fornecidas uma visão do cidadão (conceitual) e uma visão técnica (na forma de cartilha) com recomendações baseadas no conjunto de regras do W3C, mas com indicações simplificadas e priorizações adaptadas à realidade e necessidades brasileiras. Esse modelo é a 
referência de todas as instituições governamentais para a construção e adaptação das suas soluções de governo eletrônico com interface Web. O e-MAG foi criado especificamente para atender ao Decreto/lei 5.296/2004.

O Decreto 5.296/2004, que regulamenta as Leis 10.048/2000 e 10.098/2000, torna obrigatória a acessibilidade nos portais e sítios da administração pública para o uso das pessoas com necessidades especiais para garantir o pleno acesso às informações.

\subsection{Diretrizes para acessibilidade na Web}

A definição de diretrizes para a criação de interfaces é bastante utilizada no contexto de interação humano-computador. A utilização de diretrizes consiste em enumerar um conjunto de princípios e de orientações para a solução de problemas conhecidos, bem como soluções de reconhecida eficácia.

Existem diversos conjuntos de guidelines, ou diretrizes, para a confecção de sítios visando a acessibilidade. Os principais documentos que definem diretrizes de acessibilidade são o Section 508 (U.S. Government, 2007), do governo norte-americano, e o WCAG (W3C, 1999a), do W3C. Cada conjunto de diretrizes possui suas especificidades, mas os principais problemas de acessibilidade são tratados por ambos.

Nesta seção é abordada a primeira versão das Diretrizes para a Acessibilidade do Conteúdo da Web (Web Content Accessibility Guidelines, WCAG 1.0) [W3C, 1999]. No WCAG 1.0 é definido um conjunto de 14 diretrizes que tratam diversos problemas relacionados a acessibilidade de sítios. Basicamente, as diretrizes são relacionadas a dois temas principais:

- Garantir a transformação harmoniosa de páginas: páginas que garantem uma transformação harmoniosa permanecem acessíveis independente das restrições do usuário (por exemplo: restrições de percepção visual, auditiva ou motora) ou restrições tecnológicas (por exemplo: dispositivos com restrições de exibição ou restrição de velocidade de conexão).

- Facilitar a compreensão do conteúdo e a navegação através dele: o desenvolvedor deve utilizar uma linguagem simples e clara, e também disponibilizar mecanismos para facilitar a navegação dentro de uma página e a navegação entre as páginas que compõem o conteúdo.

No WCAG 2.0 (W3C, 2007b), as diretrizes são organizadas em torno de quatro princípios, de forma que as recomendações presentes no WCAG 1.0 são também atendidas, além de terem sido acrescentadas novas recomendações. Os quatro princípios de acessibilidade definidos nessa segunda versão são os seguintes:

1. O conteúdo deve ser perceptível (Perceivable);

2. Os componentes de interface com o usuário no conteúdo devem ser operáveis (Operable); 
3. O conteúdo e os controles do usuário devem ser fáceis de entender (Understandable);

4. O conteúdo deve ser suficientemente robusto (Robust) para funcionar com as tecnologias correntes e futuras.

Os quatro princípios de acessibilidade apontados pelo WCAG 2.0 já estavam de certa forma contidos nas recomendações do WCAG 1.0. Contudo, a classificação como um princípio reforça a sua importância, e redefine a forma da organização da nova versão da recomendação do W3C.

Embora a versão do WCAG 2.0 já esteja em estado avançado de desenvolvimento, diversos pontos ainda não foram concluídos pela equipe do W3C, de forma que a versão do WCAG 1.0 ainda é a versão considerada como recomendação. Dessa forma, neste material serão abordadas as recomendações de acessibilidade do WCAG 1.0. Os principais conceitos do WCAG 1.0 foram mantidos na nova versão, assim a nova versão não invalida a primeira.

\section{Diretrizes para acessibilidade do Web Content Accessibility Guideli- nes 1.0}

O WCAG 1.0 é composto por um conjunto de 14 diretrizes de acessibilidade, e cada diretriz possui pontos de verificação (checkpoints). Esses pontos de verificação são classificados por níveis de prioridade e cada ponto de verificação demanda uma técnica para implementá-lo. A lista completa com as diretrizes e pontos de verificação desta versão do WCAG está descrita no Apêndice B. A seguir são descritas em maiores detalhes as diretrizes do WCAG 1.0:

1. Fornecer alternativas para conteúdo sonoro e visual: esta diretriz indica a necessidade de disponibilizar conteúdo que ao ser apresentado ao usuário transmita, em essência, as mesmas funções e finalidade que o conteúdo sonoro ou visual. Assim, deve-se fornecer um equivalente textual a cada elemento não textual.

2. Não recorrer apenas a cor: deve-se garantir a percepção do texto e dos elementos gráficos do documento, mesmo quando são vistos sem cores. Assim, deve-se assegurar que todas as informações veiculadas por meio de cores estejam também disponíveis sem cor, por exemplo, a partir de informações do contexto ou de marcação apropriada.

3. Utilizar corretamente marcações e folhas de estilo: esta diretriz indica a necessidade de se utilizar marcação nos documentos com os elementos estruturais adequados e controlar a apresentação por meio de folhas de estilo, em vez de elementos de apresentação e atributos.

4. Indicar claramente qual o idioma utilizado: utilizar marcações que facilitem a pronúncia e a interpretação de abreviaturas ou de texto em língua estrangeira é imprescindível. Deve-se identificar claramente quaisquer mudanças de idioma no texto de um documento, bem como nos equivalentes textuais. 
5. Criar tabelas passíveis de transformação harmoniosa: deve-se assegurar que as tabelas tenham as marcações necessárias para poderem ser transformadas de forma harmoniosa por navegadores acessíveis e outros agentes do usuário. Em tabelas de dados, é preciso identificar os cabeçalhos de linha e de coluna.

6. Assegurar que as páginas dotadas de novas tecnologias sejam transformadas harmoniosamente: as páginas devem ser acessíveis mesmo quando as tecnologias mais recentes não forem suportadas ou tenham sido desativadas. Deve-se organizar os documentos de tal forma que possam ser lidos sem a necessidade de recorrer a folhas de estilo.

7. Assegurar o controle do usuário sobre as alterações temporais do conteúdo: deve-se possibilitar a interrupção momentânea ou definitiva do movimento, intermitência, transcurso ou atualização automática de objetos e páginas. Deve-se evitar páginas contendo movimento, até que os agentes utilizados pelos usuários (navegadores e similares) possibilitem a imobilização do conteúdo.

8. Assegurar a acessibilidade direta em interfaces integradas pelo usuário: a interface com o usuário deve obedecer a princípios de design para a acessibilidade: acesso independente de dispositivos, operacionalidade pelo teclado, possibilidade de emissão automática de voz (verbalização).

9. Projetar páginas considerando a independência de dispositivos: é imprescindível utilizar funções que permitam a ativação de elementos de página por meio de uma grande variedade de dispositivos de entrada.

10. Utilizar soluções provisórias ou de transição: deve-se utilizar soluções de acessibilidade transitórias, para que as tecnologias de apoio e os navegadores mais antigos funcionem corretamente.

11. Utilizar tecnologias e recomendações do W3C: deve-se utilizar tecnologias do W3C (de acordo com suas especificações) e seguir as recomendações de acessibilidade.

12. Fornecer informações de contexto e orientações: é fundamental fornecer contexto e orientações para ajudar os usuários a compreenderem páginas ou elementos complexos.

13. Fornecer mecanismos de navegação claros: deve-se fornecer mecanismos de navegação coerentes e sistematizados (informações de orientação, barras de navegação, mapa do sítio) de modo a aumentar a probabilidade de uma pessoa encontrar o que procura em um dado sítio.

14. Assegurar a clareza e a simplicidade dos documentos: deve-se assegurar a produção de documentos claros e simples, para que sejam mais fáceis de compreender. Deve-se também utilizar a linguagem mais clara e simples possível, adequada ao conteúdo do sítio. 
Conforme mencionado anteriormente, cada diretriz possui pontos de verificação. Cada ponto de verificação tem um nível de prioridade baseado no seu impacto na acessibilidade, que é associado pela equipe responsável pela definição das diretrizes.

De acordo com a classificação, existem três níveis de prioridade: a) Prioridade $\mathbf{1}$ - os pontos de verificação que possuem prioridade 1 são aqueles que "devem" ser atendidos; b) Prioridade 2 - pontos de verificação que "deveriam” ser atendidos e c) Prioridade 3: pontos de verificação que "podem" ser atendidos.

O conceito de nível de conformidade varia de acordo com a satisfação das diretrizes de acessibilidade. O WCAG 1.0 define três níveis de conformidade, nomeados: Nível "A" (atende a todas as recomendações de Prioridade 1), Nível "AA" (atende a todas as recomendações de Prioridades 1 e 2) e Nível "AAA"(atende a todas as recomendações de Prioridades 1, 2 e 3).

Na próxima seção são apresentados conceitos sobre avaliação de acessibilidade.

\subsection{Avaliação de acessibilidade na Web}

Durante o desenvolvimento de páginas Web, a atividade de avaliação é de grande importância para garantir a acessibilidade do conteúdo resultante. A avaliação é considerada uma das atividades mais importantes em projetos de interface (Rocha e Baranauskas, 2003) (Nielsen, 2000), porque por meio deste procedimento é possível validar a interface criada de acordo com os requisitos do usuário, e verificar se o usuário terá dificuldades em utilizá-la ou não. No contexto de avaliação de acessibilidade, o principal objetivo é identificar barreiras de acessibilidade em sítios e reportar estes problemas para correção (Fortes et al., 2005a) (Fortes et al., 2005b).

A avaliação de acessibilidade, assim como a avaliação de usabilidade, pode ser feita de diversas formas, por exemplo, envolvendo métodos de inspeção e métodos de testes com usuários. Deve-se observar que os métodos de inspeção (avaliação heurística, revisão de diretrizes, etc) são eficientes para encontrar diversos problemas, mas outros problemas ainda são encontrados somente quando são efetuados testes com usuários reais (Dix et al., 2003) (Rocha e Baranauskas, 2003). Da mesma forma, uma avaliação de acessibilidade deve contar também com a participação de usuários reais (Melo e Baranauskas, 2005).

A análise da acessibilidade de páginas Web por meio de guidelines, de maneira similar a outros métodos de inspeção de usabilidade, requer a observação, análise e interpretação das mesmas, visando identificar possíveis problemas de acessibilidade (Abascal et al., 2004).

A avaliação deve englobar procedimentos de teste com usuários e de inspeção de acessibilidade. A inspeção corresponde a avaliações efetuadas por especialistas em acessibilidade. $\mathrm{O}$ teste com usuários, por sua vez, deve ser realizado com usuários de diferentes perfis, que utilizam dispositivos diferentes para acesso e com diferentes habilidades e deficiências. 
No documento Evaluating Web Sites for Accessibility (W3C, 2003) são apresentados dois métodos principais para inspeção de acessibilidade de sítios: a "Avaliação Preliminar de Acessibilidade" e a "Avaliação de Conformidade".

O objetivo da avaliação preliminar é identificar de forma rápida problemas gerais de acessibilidade em um sítio. Neste tipo de avaliação, não são verificados todos os problemas de acessibilidade.

A avaliação preliminar combina a realização de testes manuais (efetuados de forma não tão detalhada como na Avaliação de Conformidade) de páginas representativas, e o uso de diversas ferramentas semi-automáticas de avaliação de acessibilidade.

A avaliação de conformidade é utilizada para verificar o grau de conformidade de um sítio com os padrões de acessibilidade, por exemplo, o WCAG. A forma de realizar uma avaliação de conformidade é similar a de uma avaliação usando o método de revisão de diretrizes (guidelines) de usabilidade. Ao contrário da avaliação preliminar, o objetivo deste método é encontrar problemas de acessibilidade mais específicos, envolvendo não só a avaliação utilizando ferramentas automáticas, mas também a avaliação manual de páginas representativas selecionadas de forma sistemática.

Além desses métodos, diversos outros estudos sobre métodos de avaliação de acessibilidade têm sido efetuados. Brajnik (2006) propôs um método denominado "Percurso baseado em barreiras", com uma abordagem similar ao método de percurso cognitivo para avaliação de interface. Neste método, o autor sugere que a avaliação seja feita por um especialista, e que a cada elemento da interface seja verificado se ele corresponde a uma barreira de acessibilidade.

Sloan et al. (2000) também propôs um método para avaliação de acessibilidade envolvendo procedimentos de inspeção de acessibilidade e de testes com usuário, na forma de um processo composto de várias atividades. Melo e Baranauskas (2006c,a) propuseram um método para a avaliação cooperativa de acessibilidade de interfaces, também definindo diversas etapas para o processo de avaliação.

Em um trabalho realizado pelo autor desta dissertação (Freire et al., 2007c), foi realizado um estudo com a utilização de tecnologias assistivas para o apoio à educação sobre acessibilidade para desenvolvedores iniciantes. Neste estudo, verificou-se que o uso das tecnologias assistivas pelos desenvolvedores se mostrou bastante eficaz para auxiliá-los a melhor identificar os problemas de acessibilidade nas avaliações.

Um outro trabalho importante relacionado a avaliação de acessibilidade é o "Unified Web Evaluation Methodology" (UWEM) (Cluster, 2006b), desenvolvido pelo WAB Cluster ${ }^{6}$. O UWEM é resultado de um trabalho conjunto de várias instituições européias, e tem como objetivo definir um método unificado para avaliação de acessibilidade, passando por procedimentos de inspeção, testes, e realização de benchmarks e extração de métricas.

\footnotetext{
${ }^{6}$ The EU Web Accessibility Benchmarking Cluster, Evaluation and benchmarking of Accessibility http://www.wabcluster.org/
} 
As ferramentas de apoio à avaliação também são instrumentos importantes para auxiliar os desenvolvedores a encontrar problemas de acessibilidade, principalmente os problemas relacionados à marcação. Essas ferramentas provêem diversas informações importantes para desenvolvedores e mantenedores de sítios Web para auxiliar na detecção de problemas e no processo de reparo. De acordo com Ivory et al. (2003), verifica-se que as ferramentas de apoio à avaliação têm obtido um bom nível de aceitação pelos desenvolvedores, e têm contribuído nas tarefas de melhorar a acessibilidade e usabilidade de sítios na Web. Além disso, nota-se que essas ferramentas colaboram no aprendizado sobre o uso de diretrizes para desenvolvedores iniciantes (Ivory, 2003).

De forma geral, as ferramentas possuem funcionalidades para auxiliar os desenvolvedores a identificar problemas relacionados a pontos de verificação de diretrizes de acessibilidade. As ferramentas indicam o ponto de verificação relacionado e a linha do código-fonte onde o problema foi encontrado. Algumas ferramentas também fornecem essas informações de maneira visual. Na Figura 2.5 é ilustrado um exemplo de um relatório gerado pela ferramenta Hera (Benavídez et al., 2006). Deve-se ressaltar que muitos problemas de acessibilidade não podem ser encontrados somente por meio de avaliação com ferramentas.

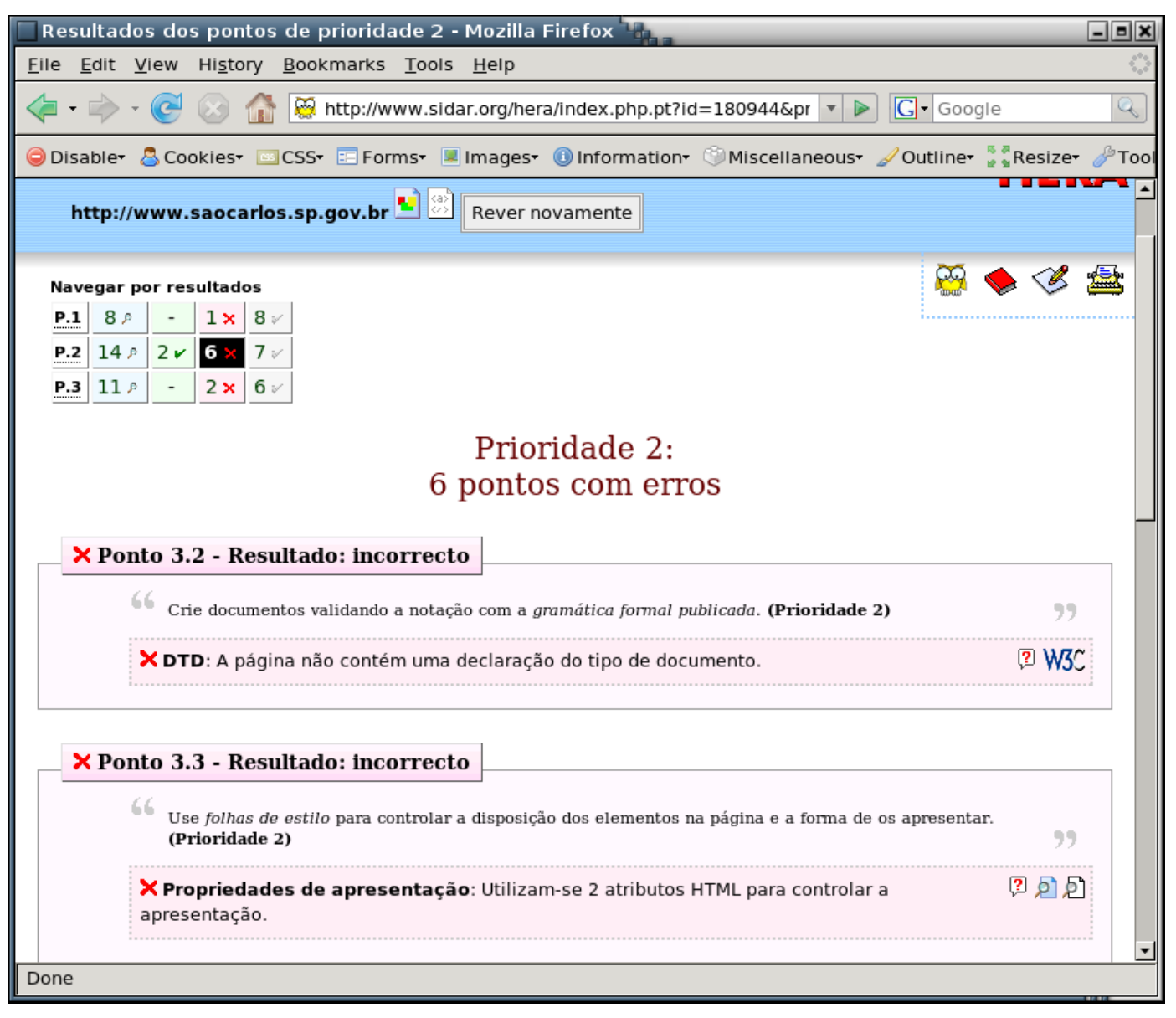

Figura 2.5: Exemplo de relatório de avaliação de uma página Web com a ferramenta Hera 
No contexto deste trabalho, as ferramentas de avaliação automática terão papel bastante importante para auxiliar no levantamento de dados sobre o nível de acessibilidade das páginas produzidas nos projetos dos participantes do levantamento.

Uma das tarefas compreendidas neste projeto de mestrado envolve a adaptação de uma dessas ferramentas para a coleta de dados sobre a acessibilidade. Na Tabela 2.1 são apresentadas ferramentas disponíveis que efetuam avaliação de acordo com as diretrizes do WCAG (W3C, 1999a), enumeradas a partir da listagem fornecida pelo WAI Evaluation (W3C, 2003). Também são apresentadas algumas das principais características que serão levadas em conta para a seleção da ferramenta para a realização do trabalho. Na coluna "plataforma", é identificado se a ferramenta é executada em um servidor (a maioria via interface $\mathrm{Web}$ ) ou em programa em plataforma Desktop. Quanto à licença, os softwares com livre acesso ao código fonte foram classificados como "Open source", softwares livremente distribuídos, mas sem acesso ao código fonte como "Freeware". Softwares pagos foram classificados como "Comercial". Algumas ferramentas que somente disponibilizam uma interface via Web para avaliação, mas não são distribuídas foram classificadas como "Não distribuída". Somente foram incluídas ferramentas com estágio de desenvolvimento considerado estável e ativo. Ferramentas descontinuadas não foram incluídas.

Tabela 2.1: Lista de ferramentas de apoio à avaliação de acessibilidade

\begin{tabular}{|c|c|c|c|c|}
\hline Ferramenta & Fornecedor & Plataforma & Linguagem & Licença \\
\hline $\begin{array}{l}\text { A-Checker } \\
\text { http://checker.atrc.utoronto.ca/ }\end{array}$ & ATRC U. Of Toronto & Servidor & Java & Open source \\
\hline $\begin{array}{l}\text { Accessibility Check } \\
\text { http://www.etre.com/tools/accessibilitycheck/ }\end{array}$ & Etre & Servidor & Não informado & Não distribuída \\
\hline $\begin{array}{l}\text { Access Valet } \\
\text { http://valet.webthing.com/access/ }\end{array}$ & WebThing Ltd & Servidor & $\mathrm{C} / \mathrm{C}++/ \mathrm{C} \#$ & Comercial \\
\hline $\begin{array}{l}\text { AccMonitor } \\
\text { http://www.hisoftware.com/access/monitor.html }\end{array}$ & HiSoftware & $\begin{array}{l}\text { Servidor / } \\
\text { Windows }\end{array}$ & .NET & Comercial \\
\hline $\begin{array}{l}\text { AccVerify } \\
\text { http://www.hisoftware.com/access/ }\end{array}$ & HiSoftware & $\begin{array}{l}\text { Desktop / } \\
\text { Windows }\end{array}$ & NET & Comercial \\
\hline $\begin{array}{l}\text { CommonLook Website Testing Tool } \\
\text { http://www.commonlook.com }\end{array}$ & $\begin{array}{l}\text { NetCentric Technolo- } \\
\text { gies Inc. }\end{array}$ & $\begin{array}{l}\text { Desktop / } \\
\text { Windows }\end{array}$ & Não informado & Comercial \\
\hline $\begin{array}{l}\text { Deque Ramp } \\
\text { http://www.deque.com/ }\end{array}$ & Deque Inc & Desktop & Não informado & Comercial \\
\hline $\begin{array}{l}\text { EvalAccess } \\
\text { http://sipt07.si.ehu.es/evalaccess2/index.html }\end{array}$ & $\begin{array}{l}\text { Lab. of HCI for Spe- } \\
\text { cial Needs - UPV/EHU }\end{array}$ & Servidor & Java & Não distribuída \\
\hline $\begin{array}{l}\text { Functional Accessibility Evaluator } \\
\text { http://fae.cita.uiuc.edu/ }\end{array}$ & $\begin{array}{l}\text { U. of Illinois at Urba- } \\
\text { na/Champaign }\end{array}$ & Servidor & PHP & Open Source \\
\hline $\begin{array}{l}\text { Hera } \\
\text { http://www.sidar.org/hera }\end{array}$ & Fundación Sidar & Servidor & PHP & Open Source \\
\hline $\begin{array}{l}\text { Hermish } \\
\text { http://www.hermish.com }\end{array}$ & Gareth Slinn & Servidor & Cold Fusion & Não distribuída \\
\hline $\begin{array}{l}\text { InFocus Evaluator } \\
\text { http://www.ssbtechnologies.com/ }\end{array}$ & SSB \& BART Group & $\begin{array}{l}\text { Servidor / } \\
\text { Desktop }\end{array}$ & Não informado & Comercial \\
\hline
\end{tabular}




\begin{tabular}{|c|c|c|c|c|}
\hline Ferramenta & Fornecedor & Plataforma & Linguagem & Licença \\
\hline $\begin{array}{l}\text { Lift Machine } \\
\text { http://www.usablenet.com/ }\end{array}$ & UsableNet & Servidor & Não informado & Comercial \\
\hline $\begin{array}{l}\text { Ocawa } \\
\text { http://www.ocawa.com }\end{array}$ & Urbilog & Servidor & Não informado & Comercial \\
\hline $\begin{array}{l}\text { Silvinha } \\
\text { http://www.dasilva.org.br/ }\end{array}$ & Acessibilidade Brasil & Servidor & Java & Comercial \\
\hline $\begin{array}{l}\text { SiteMorse } \\
\text { http://www.sitemorse.com/ }\end{array}$ & SiteMorse & Servidor & Não informado & Comercial \\
\hline $\begin{array}{l}\text { TAW Evaluator } \\
\text { http://www.tawdis.net/taw3 }\end{array}$ & Fundación CTIC & $\begin{array}{l}\text { Desktop / } \\
\text { Servidor }\end{array}$ & Java & Freeware \\
\hline $\begin{array}{l}\text { Truwex } \\
\text { http://checkwebsite.erigami.com/ }\end{array}$ & Erigami & Servidor & ASP & Não distribuída \\
\hline $\begin{array}{l}\text { WAEX Evaluator } \\
\text { http://www.it.uc3m.es/vlc/waex.html }\end{array}$ & $\begin{array}{l}\text { Vicente Luque- } \\
\text { Centeno }\end{array}$ & $\begin{array}{l}\text { Servidor / } \\
\text { Desktop }\end{array}$ & Java / XSLT & Open Source \\
\hline $\begin{array}{l}\text { WAhelper } \\
\text { http://wahelper.brailcom.org/ }\end{array}$ & Brailcom & Servidor & Python & Open Source \\
\hline $\begin{array}{l}\text { WAVE } \\
\text { http://wave.webaim.org/ }\end{array}$ & WebAIM & Servidor & Java & Open Source \\
\hline $\begin{array}{l}\text { Web Accessibility Inspector } \\
\text { http://www.fujitsu.com/global/accessibility/ }\end{array}$ & Fujitsu Limited & Desktop & Não informado & Freeware \\
\hline $\begin{array}{l}\text { WebXACT } \\
\text { http://webxact.watchfire.com/ }\end{array}$ & Watchfire & Servidor & Não informado & Não distribuída \\
\hline $\begin{array}{l}\text { WebXM } \\
\text { http://www.watchfire.com/products/webxm }\end{array}$ & Watchfire & Servidor & Não informado & Comercial \\
\hline
\end{tabular}

\subsection{Considerações finais}

Neste capítulo foram apresentados alguns dos principais conceitos relacionados a acessibilidade na Web. Esses conceitos foram fundamentais para o desenvolvimento do trabalho e para nortear toda a pesquisa.

O entendimento dos conceitos de tecnologia assistiva foi de grande importância para a compreensão mais aprofundada sobre os problemas enfrentados por pessoas com deficiência para o acesso à Web. O conhecimento sobre técnicas para avaliação também foi fundamental para ter bases para o desenvolvimento das atividades de levantamento sobre o status da acessibilidade de sistemas desenvolvidos pelos participantes da pesquisa realizada.

No próximo capítulo, é apresentada uma revisão com um levantamento sobre técnicas para o apoio ao desenvolvimento de sistemas acessíveis em diferentes processos do desenvolvimento de software. 



\section{Técnicas para desenvolvimento de sistemas Web acessíveis}

\subsection{Considerações iniciais}

A crescente necessidade da observação de critérios de acessibilidade no contexto de desenvolvimento de sistemas, em especial para Web, tem impulsionado a diversos esforços no sentido de definir métodos para suporte ao desenvolvimento de aplicações Web acessíveis. Além disso, diversas diretrizes têm sido definidas para facilitar o desenvolvimento de interfaces acessíveis. O principal documento referente a guidelines de acessibilidade é o WCAG (W3C, 1999a) (Web Content Accessibility Guidelines) do W3C, como descrito no capítulo anterior.

Além das guidelines, existem diversos métodos e ferramentas para apoio ao desenvolvimento de páginas acessíveis, desde a fase de implementação até a de avaliação (W3C, 2003) (Law et al., 2005) (Ivory et al., 2003). Assim como em processos consolidados de design de interfaces, no contexto de desenvolvimento visando a acessibilidade, a fase de avaliação é de extrema importância para garantir a qualidade e verificar a observância dos critérios estipulados na especificação do projeto.

Apesar do grande número de técnicas e métodos para apoiar o desenvolvimento de sistemas acessíveis, verifica-se que um dos grandes entraves para a disseminação da cultura de acessibilidade na Web está na conscientização dos desenvolvedores sobre a importância do tema, e sobre as consequiências trazidas pela utilização de tecnologias que se tornam barreiras para o acesso à Web.

A implantação de métodos e técnicas para o desenvolvimento de sistemas acessíveis demanda o conhecimento e a análise das vantagens e desvantagens de cada método. No contexto de pesquisa 
em acessibilidade, também verifica-se que diversos trabalhos sobre métodos e técnicas tem sido realizados. Entretanto, ainda não se tem um panorama claro sobre a distribuição das pesquisas nas diferentes etapas do processo de desenvolvimento de software Web.

O objetivo deste trabalho de mestrado se concentra sobre o estudo sobre a percepção da acessibilidade por desenvolvedores e pessoas envolvidas com o desenvolvimento de sistemas Web. Desta forma, o entendimento sobre as técnicas utilizadas no processo de desenvolvimento para apoiar acessibilidade é muito importante para apoiar o desenvolvimento do restante da pesquisa.

A Revisão Sistemática tem como objetivo produzir uma síntese mais completa de trabalhos da literatura relacionados a uma questão de pesquisa específica (Kitchenham, 2004) (Biolchini et al., 2005), utilizando um processo robusto e bem definido para guiar o procedimento de busca e análise de trabalhos.

Assim, o objetivo desta etapa do trabalho foi o de efetuar um levantamento e uma classificação das técnicas e métodos para Acessibilidade na Web com base no grupo de processos de Engenharia da norma ISO/IEC 12207, por meio do uso de procedimentos de Revisão Sistemática.

Ao contrário de revisões de literatura feitas de forma não sistemática, a revisão sistemática garante um valor científico ao trabalho. Neste trabalho, procedimentos de revisão sistemática foram utilizados para a condução do levantamento, e todos os passos envolvidos no seu desenvolvimento foram documentados, de forma a garantir a validade das conclusões tiradas a partir dos dados analisados.

Este capítulo está organizado na seguinte forma: na Seção 3.2 são descritos alguns dos principais conceitos relacionados a Engenharia Web utilizados para a classificação efetuada neste trabalho; na Seção 3.3 é descrita a metodologia de Revisão Sistemática, bem como as partes do método utilizadas para a revisão de métodos e técnicas para Acessibilidade na Web; na Seção 3.4 são apresentados os principais resultados obtidos com o levantamento realizado; finalmente, na Seção 3.5 são discutidas as principais conclusões a partir da realização deste levantamento.

\subsection{Engenharia Web}

O uso de sistemas Web tem sido cada vez mais comum nos mais diversos contextos. Esses sistemas servem de apoio para o desenvolvimento de diversas atividades relacionadas a negócios, governo, educação, e outros domínios.

O dinamismo e a criticidade de muitos sistemas Web torna a qualidade no desenvolvimento desses sistemas um aspecto crucial. Para entender, controlar e melhorar a qualidade de sistemas Web é necessário utilizar métodos modelos e técnicas de engenharia adequadas (Olsina et al., 2001).

Acessibilidade também é um importante requisito de qualidade para sistemas Web. O desenvolvimento de aplicações acessíveis envolve o uso de técnicas apropriadas para fornecer suporte para as atividades inerentes ao design e à implementação. 
A Engenharia Web surgiu como uma iniciativa disciplinada que visa apoiar e otimizar os esforços freqüentemente exigidos nos processos de criação, gerenciamento, manutenção e controle de qualidade de sistemas Web. Ela se refere ao estabelecimento e uso de sólidos conceitos científicos e de engenharia, de princípios de gerenciamento, e de forma disciplinada e sistemática para desenvolver, tornar disponível e efetuar manutenção de sistemas Web de alta qualidade (Pressman, 2006).

Engenharia de Web se refere à aplicação de uma abordagem sistemática, disciplinada e passível de quantificação para o desenvolvimento, operação e manutenção de aplicações Web (Deshpande et al., 2002).

O Modelo Espiral é o modelo de processo de software que melhor representa as atividades realizadas na Engenharia Web, uma vez que é utilizado em projetos com um nível alto de incerteza dos requisitos e nos quais a natureza das tecnologias utilizadas mudam constantemente. Os sistemas Web possuem essas características. Usualmente, a cada ciclo de realização das atividades de Engenharia Web, o sistema "cresce", no sentido de que sua construção incorpora mais componentes, suas funcionalidades aumentam, e os seus requisitos são melhor identificados progressivamente, de forma que os riscos tendem a ser reduzidos (Costagliota et al., 2002).

Diversos métodos de Engenharia de Web foram desenvolvidos. Esses métodos levam em conta as principais características de sistemas Web (navegabilidade, uso de tecnologias hipermídia, estética e evolução contínua), o que faz com que esses métodos tenham características diferentes dos métodos para desenvolvimento de aplicações convencionais.

Fraternali \& Paolini (Fraternali e Paolini, 1998) definem que o desenvolvimento de aplicações Web devem considerar três aspectos essenciais: estrutura, navegação e semântica de apresentação.

Para os fins deste trabalho, foram analisados diversos métodos de Engenharia de Web, com o objetivo de identificar as principais atividades, para a classificação das técnicas de acessibilidade encontradas.

Foram analisados os métodos: OOHDM (Object Oriented Hypermedia Design Model) (Schwabe et al., 1996), UWE (UML-Based Software Engineering) (Koch e Kraus, 2002), WebML (Web Modeling Language) (Ceri et al., 2000), WAE (Web Application Extension for UML) (Conallen, 2002) e OOWS (Object Oriented Web Solutions) (Fons et al., 2003).

O método OOHDM (Schwabe et al., 1996) envolve as atividades de Projeto conceitual, Projeto navegacional, Projeto da interface abstrata e Implementação. O método UWE (Koch e Kraus, 2002) utiliza uma abordagem com a adoção de UML para as atividades de Engenharia de Requisitos, Modelagem conceitual, Projeto navegacional e Projeto de interface. O método WebML (Ceri et al., 2000) propõe o uso de Modelos estruturais, Modelo de Hipertexto, englobando o Modelo de composição (para conteúdo) e Modelo navegacional, além do Modelo de apresentação (para interface) e Modelo para personalização. O modelo WAE (Conallen, 2002) apresenta extensões da UML para projeto arquitetural de aplicações Web. Por fim, o modelo OOWS (Fons et al., 2003) apresenta uma abordagem com o uso de Elicitação de requisitos e Modelagem conceitual para a 
especificação de sistemas. A Modelagem conceitual neste método envolve o uso de um Modelo estrutural, um Modelo dinâmico e um Modelo funcional, e também o uso de Modelos navegacionais e Modelo de apresentação (interface).

A maioria dos métodos de Engenharia de Web analisados tem como foco principal o design de conteúdo. Grande parte deles sugere atividades para a definição da estrutura, navegação, interface e arquitetura de sistemas.

Após analisar os métodos para identificar as principais características de métodos de Engenharia Web, o modelo adotado para efetuar a classificação de técnicas para acessibilidade foi a norma ISO/IEC 12207 (ISO - International Standard Organization, 1998).

A norma ISO/IEC 12207 (ISO - International Standard Organization, 1998) esbelece uma arquitetura em alto nível para processos de ciclo de vida de software. A arquitetura consiste em um conjunto de processos e nos relacionamentos entre processos. Cada processo corresponde a um conjunto de atividades relacionadas.

Na Figura 3.1 são ilustrados os grupos de processo da norma ISO/IEC 12207.

Como a norma é definida como um framework para processos (ou um meta-processo), ela incorpora recursos para a representação de diferentes processos de Engenharia de Software, incluindo métodos de Engenharia de Web.

Por meio da observação das principais características dos métodos de Engenharia de Web citados anteriormente, foram observadas algumas características particulares dos processs de desenvolvimento Web para o processo de Projeto de Software.

Foram analisados os métodos: OOHDM (Object Oriented Hypermedia Design Model) (Schwabe et al., 1996), UWE (UML-Based Software Engineering) (Koch e Kraus, 2002), WebML (Web Modeling Language) (Ceri et al., 2000), WAE (Web Application Extension for UML) (Conallen, 2002) e OOWS (Object Oriented Web Solutions) (Fons et al., 2003).

Assim, definiu-se neste trabalho que seria utilizada uma classificação das técnicas para o processo de Projeto de Software com a separação em quatro subcategorias: projeto arquitetural, projeto navegacional, projeto de interface e projeto de conteúdo.

Na próxima seção, são descritos os principais conceitos relacionados à revisão da literatura realizada.

\subsection{Revisão da literatura}

O principal objetivo de uma Revisão sistemática é produzir uma síntese completa de trabalhos publicados sobre uma questão de pesquisa específica (Kitchenham, 2004), (Biolchini et al., 2005), utilizando um processo robusto e bem definido para guiar o procedimento de busca e análise de trabalhos.

Em revisões não sistemáticas, mesmo quando são conduzidas de acordo com regras de boas práticas, a revisão não é dotada de rigor científico. O desenvolvimento de uma revisão sistemática 


\begin{tabular}{|c|c|}
\hline Processos Fundamentais & Processos organizacionais \\
\hline $\begin{array}{l}\text { Grupo de Processos de Aquisiçāo (ACQ) } \\
\text { ACQ.1 Preparação da Aquisição } \\
\text { ACQ.2 Seleção de Fornecedor } \\
\text { ACQ.3 Acordo Contratual } \\
\text { ACQ.4 Monitoramento do Forneced or } \\
\text { ACQ.5 Aceitação pelo Cliente } \\
\end{array}$ & \multirow[t]{2}{*}{$\begin{array}{l}\text { Grupo de Processos de Gerência (MAN) } \\
\text { MAN.1 Alinhamento Organizacional } \\
\text { MAN.2 Gerência Organizacional } \\
\text { MAN.3 Gerência de Projeto } \\
\text { MAN.4 Gerência de Qualidade } \\
\text { MAN.5 Gerência de Riscos } \\
\text { MAN.6 Medição }\end{array}$} \\
\hline Grupo de Processos de Fornecimento (SPL) & \\
\hline $\begin{array}{l}\text { SPL.2 Liberação de Produto } \\
\text { SPL.3 Apoio para Aceitação do Produto }\end{array}$ & \multirow{2}{*}{$\begin{array}{l}\text { Grupo de Processos de Melhoria de } \\
\text { Processo (PIM) } \\
\text { PIM.1 Estabelecimento de Processo } \\
\text { PIM.2 Avaliação de Processo } \\
\text { PIM.3 Melhoria de Processo }\end{array}$} \\
\hline Grupo de Processos de Engenharia (ENG) & \\
\hline $\begin{array}{l}\text { ENG.1 Elicitação de Requisitos } \\
\text { ENG.2 Análise de Requisitos de Sistema }\end{array}$ & \\
\hline $\begin{array}{l}\text { ENG.3 Projeto de Arquitetura de Sistema } \\
\text { ENG.4 Análise de Requisitos de Software } \\
\text { ENG.5 Projeto de Software }\end{array}$ & \multirow{4}{*}{$\begin{array}{l}\text { Grupo de Processos de Recursos e } \\
\text { Infra-estrutura (RIN) } \\
\text { RIN.1 Gerência de Recursos Humanos } \\
\text { RIN.2 Treinamento } \\
\text { RIN.3 Gerência de Conhecimento } \\
\text { RIN.4 Infra-estrutura }\end{array}$} \\
\hline ENG.6 Construção de Software & \\
\hline ENG.7 Integração de Software & \\
\hline ENG.10 Teste de Sistema & \\
\hline $\begin{array}{l}\text { ENG.11 Instalação de Software } \\
\text { ENG.12 Manutenção de Software e Sistema }\end{array}$ & \\
\hline Grupo de Processos de Operaçāo (OPE) & \multirow{2}{*}{$\begin{array}{l}\text { Grupo de Processos de Reúso (REU) } \\
\text { REU.1 Gerência de Ativos } \\
\text { REU.2 Gerência de Programa de Reúso } \\
\text { REU.3 Engenharia de Domínio }\end{array}$} \\
\hline $\begin{array}{l}\text { OPE. } 1 \text { Operação } \\
\text { OPE. } 2 \text { Suporte ao Cliente }\end{array}$ & \\
\hline \multicolumn{2}{|c|}{ Processos de Apoio } \\
\hline $\begin{array}{l}\text { Grupo de Processos de Gerência de } \\
\text { Configuraçāo (CFG) } \\
\text { CFG.1 Documentação } \\
\text { CFG.2 Gerência de Configuração } \\
\text { CFG.3 Gerência de Resolução de Problemas } \\
\text { CFG.4 Gerência de Solicitações de Mudança }\end{array}$ & $\begin{array}{ll}\text { Grupo de Processos de Garantia de } \\
\text { Qualidade (QUA) } \\
\text { QUA.1 Garantia de } & \text { QUA.4 Revisão Conjunta } \\
\text { Qualidade } & \text { QUA.5 Auditoria } \\
\text { QUA.2 Verificação } & \text { QUA.6 Avaliação de } \\
\text { QUA.3 Validação } & \text { Produto } \\
\end{array}$ \\
\hline
\end{tabular}

Figura 3.1: Processos da norma ISO/IEC 12207

para a pesquisa bibliográfica tem como objetivo estabelecer um processo mais formal e controlado para condução desse tipo de investigação (Biolchini et al., 2005).

De acordo com Kitchenham (Kitchenham, 2004), os principais motivos que podem levar um pesquisador a optar por conduzir uma revisão sistemática são:

- Sumarizar a existência de evidências referentes a um tratamento ou tecnologia;

- Identificar gaps no estado da arte em uma área de pesquisa para sugerir novas áreas de investigação

- Prover background para posicionar novas áreas atividades de pesquisa apropriadamente no contexto de pesquisa 
Dentre as principais vantagens de se utilizar uma revisão sistemática ao invés de uma revisão informal, pode-se citar:

- Busca abrangente e exaustiva;

- Critérios de qualificação claros e passíveis de reprodução;

- Avaliação crítica de acordo com método explícito e prédeterminado.

A metodologia de revisão sistemática tem sido amplamente utilizada em pesquisas de medicina há bastante tempo, desde o início do século XX. A introdução do uso de revisão sistemática no contexto de pesquisa em Engenharia de Software foi efetuada por Kitchenham (Kitchenham, 2004), por meio da adaptação dos métodos de pesquisa em medicina.

Diversos trabalhos de revisão sistemática no contexto de Engenharia de Software tem sido realizados. Esses trabalhos têm focado a revisão de características de diferentes áreas, como métodos de inspeção de software (Mafra e Travassos, 2005), melhoria de processo (Niazi e Staples, 2006), estimativa de custo (Kitchenham et al., 2006) e processos de Engenharia de Web (Conte et al., 2005). A alta qualidade dos resultados obtidos nesses trabalhos demonstra que a utilização de revisão sistemática é adequada para pesquisa em engenharia de software baseada na análise de evidências científicas.

De uma forma geral, o processo de revisão sistemática pode ser analisado como um processo de três etapas, que envolvem os processos que passam da análise de conceitos para a obtenção de estudos encontrados na literatura, pela análise dos resultados dos estudos e, finalmente, pela obtenção das conclusões a partir desses estudos, como ilustrado na Figura 3.2.

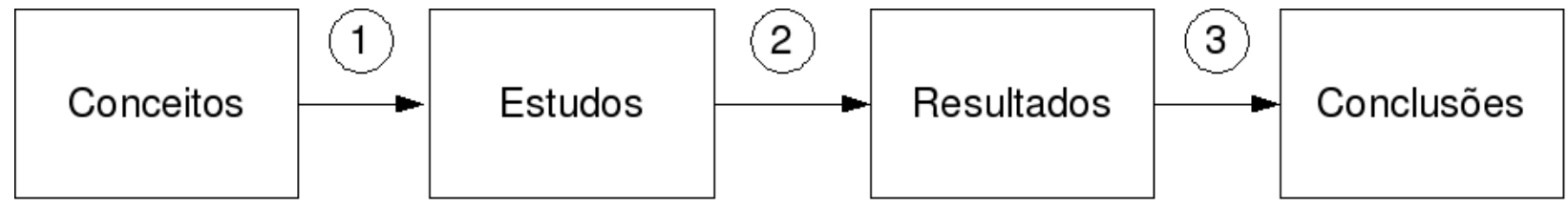

Figura 3.2: Etapas para a revisão sistemática

A revisão sistemática geralmente envolve as seguintes atividades:

1. Planejamento da revisão

- Identificação da necessidade de uma revisão

- Desenvolvimento de um protocolo de revisão

2. Condução da Revisão

- Identificação das fontes de busca relevantes

- Seleção de estudos primários 
- Avaliação da qualidade dos estudos

- Extração dos dados

- Síntese dos dados

\section{Documentação da revisão}

De fato, o estudo realizado durante este mestrado, sobre técnicas para desenvolvimento de sistemas Web acessíveis, não se configurou como uma revisão sistemática completa. De forma geral, revisões sistemáticas são fortemente relacionadas ao levantamento de trabalhos experimentais. Como muitos trabalhos de pesquisa em técnicas para acessibilidade na Web são recentes, foram encontrados poucos trabalhos com validação experimental de suas propostas. Além disso, o grande número de trabalhos de pesquisa que deveriam ser encontrados não poderiam ser incluídos de maneira trivial em uma definição de questão de pesquisa muito específica, como é necessário para uma revisão sistemática.

Nas subseções seguintes, são apresentados alguns detalhes da condução do levantamento sobre os estudos e sobre a metodologia utilizada. Os detalhes sobre a metodologia utilizada para a realização deste estudo foram reportados em relatório técnico (Freire et al., 2007a) e em um artigo científico (Freire et al., 2007b).

\subsubsection{Protocolo da revisão}

Um protocolo de revisão define o método que deve ser utilizado para realizar uma revisão sistemática. Um protocolo pré-definido é necessário para reduzir possíveis vieses de pesquisa (Kitchenham, 2004).

O protocolo de revisão descrito a seguir foi baseado nas diretrizes indicadas por Kitchenham (Kitchenham, 2004) e foi utilizado para guiar todo o processo de levantamento. Informações mais detalhadas sobre o protocolo e materiais utilizados estão documentadas em relatório técnico (Freire et al., 2007a).

- Objetivo: o principal objetivo desta revisão foi o de identificar trabalhos de pesquisa relacionados a técnicas de desenvolvimento Web para apoio a acessibilidade. A motivação para esta pesquisa é indicar um panorama do estado da arte em técnicas de desenvolvimento Web para acessibilidade. Além de identificar pesquisas existentes, este estudo também envolveu a classificação das técnicas identificadas de acordo com as atividades dos processos de software que eles apóiam.

- Questão de pesquisa: “Quais técnicas estão disponíveis para oferecer suporte às atividades de desenvolvimento para construir sistemas Web mais acessíveis?"

- Método para busca de fontes: as fontes de pesquisa devem ser recuperadas por Web. A busca manual não foi considerada nesta pesquisa.

- Palavras-chave: Web accessibility, Web universal usability, universal Web design 
- Lista de fontes: artigos e anais de eventos disponíveis em bibliotecas digitais e indexados pela IEEE Xplore ${ }^{1}$, ACM Digital Library ${ }^{2}$, Springerlink ${ }^{3}$, Science Direct ${ }^{4}$, IBM Journals ${ }^{5}$ and Wiley Interscience ${ }^{6}$.

- Critérios de inclusão e exclusão: os artigos a ser considerados no processo de revisão devem estar disponíveis na Web em formato eletrônico, ser escritos em inglês e descrever técnicas para apoio à acessibilidade em qualquer fase do desenvolvimento de sistemas Web. Artigos descrevendo estudos exploratórios, desenvolvimento de tecnologias assistivas ou de transformação automática de páginas não devem ser incluídos, pois não são relacionados diretamente a técnicas a serem aplicadas por desenvolvedores no processo de construção de software.

- Critérios de avaliação de qualidade: os critérios de avaliação de qualidade devem considerar a implementabilidade em ambientes reais de cada técnica. Propostas em estágio inicial de desenvolvimento sem nenhuma indicação de implementação devem ser excluídas.

O protocolo da revisão foi desenvolvido por um pesquisador e revisado por outros dois participantes da pesquisa, durante a realização da disciplina de Tópicos em Hipermídia em 2006.

\subsubsection{Condução da revisão}

Após o desenvolvimento do protocolo de revisão descrito na Seção 3.3.1, a condução da revisão foi realizada. A condução da revisão foi feita pelo autor deste trabalho e todas as atividades foram supervisionadas por outros dois pesquisadores. O processo de condução da revisão detalhado também está descrito no relatório técnico produzido com os resultados do trabalho de revisão (Freire et al., 2007a).

Durante a atividade de identificação da pesquisa, foram efetuadas buscas nas fontes identificadas no Procotolo de Revisão.

A execução da busca utilizando as palavras-chave apresentadas na Seção 3.3.1, realizadas no dia 13 de setembro de 2006, retornaram 844 artigos: 275 da IEEE Xplore, 360 da ACM Digital Library, 146 da SpringerLink, 43 da ScienceDirect, 10 da Wiley Interscience e 10 da IBM journals.

Em seguida, foi feita a seleção dos estudos primários ${ }^{7}$. Devido à definição de uma string de busca muito ampla, a busca retornou um número muito grande de arquivos, o que resultou em um trabalho extenso para seleção manual dos artigos. A seleção foi feita com base na observação dos critérios de inclusão e exclusão após a leitura do título e do resumo de cada artigo. Dos 844 artigos encontrados, 149 foram selecionados na análise inicial.

A seleção dos estudos primários foi seguida da avaliação de qualidade dos estudos. Depois de ler o título e os resumos de todos os artigos, foi efetuada a leitura do texto completo. Durante a

\footnotetext{
${ }^{1}$ http://ieeexplore.ieee.org

${ }^{2} \mathrm{http}: / /$ portal.acm.org

${ }^{3} \mathrm{http}: / /$ www.springerlink.com

${ }^{4} \mathrm{http} / / / \mathrm{www}$.sciencedirect.com

${ }^{5}$ http://www.research.ibm.com/journal

${ }^{6} \mathrm{http}: / /$ interscience.wiley.com

${ }^{7}$ estudos a serem analisados com mais cuidado
} 
avaliação por meio da leitura do texto completo, foi verificado se cada artigo descrevia apropriadamente uma técnica para desenvolvimento, e se a técnica era implementável ou não. Artigos resumidos, trabalhos em andamento e outros estudos que não estavam suficientemente de acordo com os critérios de inclusão foram eliminados da revisão. Após a avaliação de 149 artigos da seleção inicial, 53 artigos foram selecionados para o levantamento.

Em seguida, foi executado o trabalho de extração dos dados. Nesta fase, todos os dados referentes a cada técnica e à sua forma de implementação foram armazenados em um banco de dados. para os estudos que reportavam algum tipo de validação experimental, também foi armazenada uma descrição resumida do experimento realizado. Durante a extração, cada técnica foi classificada de acordo com os processos do padrão ISO/IEC 12207 que eram apoiados por ela.

Finalmente, os dados extraídos foram analisados e sintetizados em tabelas e gráficos. No Apêndice $\mathrm{C}$ está contida a lista dos trabalhos encontrados. As análises completas sobre os trabalhos estão reportadas em relatório técnico (Freire et al., 2007a).

Na próxima seção, é apresentado um sumário sobre os resultados encontrados no levantamento, agrupados de acordo com os processos da norma ISO/IEC 12207.

\subsection{Resultados da revisão da literatura}

A questão primária deste levantamento teve como objetivo identificar quais estudos sobre técnicas de Engenharia Web para acessibilidade estão disponíveis na literatura. Além da identificação dos estudos existentes, a revisão também tem como objetivo efetuar a classificação desses estudos de acordo com os processos da norma ISO/IEC 12207 (ISO - International Standard Organization, 1998) que são apoiados pelas técnicas.

Durante a extração de dados, cada estudo foi classificado como técnica de apoio a um ou mais processo da norma ISO/IEC 12207. Como apontado na Seção 3.2, as técnicas classificadas no processo de Projeto de Software foram divididas em: projeto arquitetural, projeto navegacional, projeto de interface e projeto de conteúdo.

Também foi registrado se cada técnica possuía uma ferramenta associada ou não. Cerca de 55\% dos estudos (19 de 53) apresentou uma ferramenta associada.

Para cada estudo, também foi registrado se havia algum tipo de validação experimental reportada. Cerca de $42 \%$ dos estudos ( 22 de 53 ) possuiam algum tipo de validação experimental reportada. A maioria dos estudos utilizavam estudos de caso para validar as técnicas, envolvendo poucos desenvolvedores. Poucos estudos reportaram experimentos formais e rigorosos.

Shull (Shull et al., 2004) indica que o uso de procedimentos experimentais é bastante importante para garantir a confiabilidade de métodos e técnicas de Engenharia de Software. O número pequeno de estudos que reportaram o uso de procedimentos experimentais indica a necessidade da adoção de métodos mais disciplinados para pesquisa de técnicas para acessibilidade na Web. 
A seguir, são descritas as principais conclusões obtidas por meio da classificação dos estudos obtidos no levantamento. A análise contém uma descrição geral das características dos estudos observadas, de acordo com cada processo da norma ISO/IEC 12207. Cada estudo foi classificado como técnica de apoio para um ou mais processos. Na Figura 3.3 é mostrado o número de estudos que contemplam técnicas para cada processo.

\section{Técnicas para os processos da ISO/IEC 12207}

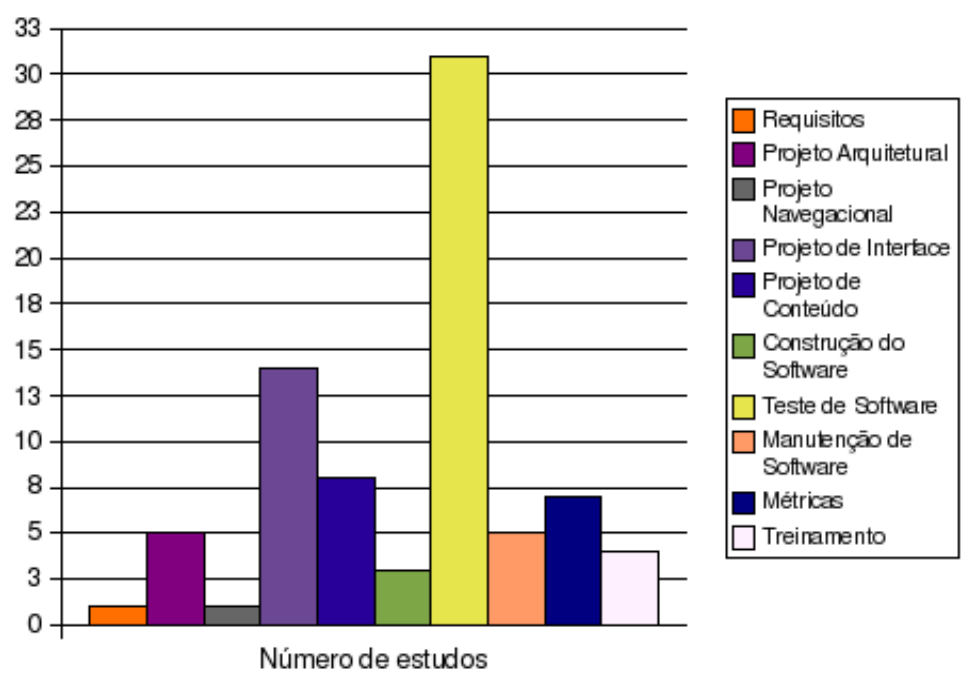

Figura 3.3: Número de publicações de técnicas para acessibilidade para processos da ISO/IEC 12207

- Engenharia de Requisitos: neste estudo, decidiu-se que as atividades relacionadas à manipulação de requisitos seriam classificadas em um conjunto único. As atividades envolvidas nos processos de Elicitação de Requisitos, Análise de Requisitos de Sistema e Análise de Requisitos de Software foram agrupadas como atividades de Engenharia de Requisitos.

O principal propósito das atividades de Engenharia de Requisitos é de coletar as necessidades dos usuários e documentá-las de maneira adequada.

Apenas um estudo foi classificado como uma técnica para Engenharia de Requisitos. Neste estudo, desenvolvido por Sloan et. al (Sloan et al., 2006), propõe-se que a elicitação de requisitos de acessibilidade deve envolver a identificação das características dos usuários, a documentação dos requisitos de domínio, os requisitos tecnológicos e os requisitos de desempenho. Esse estudo também apresenta técnicas para Projeto de Interface e Projeto de Conteúdo.

A elicitação de requisitos e a documentação dos requisitos de um sistema é uma tarefa muito importante durante o desenvolvimento de um software. O desenvolvimento de novas técnicas para apoiar a Engenharia de Requisitos poderia prover métodos mais disciplinados para garantir a acessibilidade de sistemas Web. Masuwa-Morgan (Masuwa-Morgan e Burrell, 2004) apontam para a necessidade de utilizar técnicas baseadas em ontologias para prover 
suporte para a documentação de requisitos. Este estudo não foi incluído na revisão, porque se tratava de uma proposta teórica ainda não implementável.

Além dessa proposta, ainda existe espaço para muitos trabalhos de pesquisa relacionados a técnicas para apoiar a garantia da acessibilidade na Engenharia de Requisitos, como o desenvolvimento de templates e de novas técnicas para elicitação de requisitos com diferentes tipos de usuário.

- Projeto Arquitetural: o propósito do projeto arquitetural é o de dividir o software em partes menores (como módulos, componentes, classes, por exemplo). O Projeto Arquitetural de sistemas Web é muito importante para garantir a sua qualidade e a manutenibilidade.

As técnicas propostas nos cinco estudos encontrados para este processo apresentavam abordagens como a utilização de separação entre lógica e interface, o uso de composição de componentes de interface, e o uso de modelos para guiar o Projeto Arquitetural. Um dos estudos também apresentava a proposta do uso de um framework baseado em princípios de Web semântica para prover suporte para o desenvolvimento de sistemas acessíveis.

O uso de arquiteturas de sistemas Web que levem em consideração a acessibilidade tem um grande impacto no aumento das possibilidades de uso de soluções para melhorar a acessibilidade. Apesar de muitas técnicas como o uso de templates e de Web semântica serem bastante exploradas em trabalhos de pesquisa, elas são pouco aplicadas na prática.

O desenvolvimento de pesquisas sobre propostas para projeto arquitetural de sistemas Web levando em conta a acessibilidade apresenta desafios de pesquisa bastante interessantes. Existem muitas abordagens de arquitetura de software que poderiam ser exploradas para prover acessibilidade para sistemas Web.

- Projeto Navegacional: é a atividade que tem como objetivo definir a estrutura navegacional de um sistema Web. A maioria dos métodos de Engenharia Web, discutidos na Seção 3.2 tratam de questões relacionadas a navegação.

Nos dois estudos encontrados, foram abordadas soluções para auxiliar o projeto de navegação de sistemas Web considerando diferentes abordagens. Ahmad (Ahmad et al., 2006) apresenta uma proposta de um método para medir a sobrecarga de navegação em aplicações. Essa técnica apresenta uma métrica para auxiliar na verificação da quão eficaz é a navegação, e se ela consiste em uma barreira para o usuário. Kouroupetroglou et. al (Kouroupetroglou et al., 2006) apresenta uma proposta para utilização de dados semânticos para melhorar a navegação por meio de anotações.

Muitos problemas de acessibilidade em sistemas Web são relacionados a um projeto navegacional ruim. O desenvolvimento de técnicas para auxiliar os desenvolvedores a identificar problemas na navegação nas fases iniciais de design poderia previnir a implementação de interfaces de navegação com problemas. O custo na fase de projeto para alterações des- 
ses problemas antecipadamente também poderia ser reduzido, uma vez que as alterações na estrutura navegacional geralmente têm um custo alto de manutenção.

- Projeto de Interface: o propósito do Projeto de Interface é desenvolver atividades com o objetivo de projetar os componentes de interface. Ela é uma das atividades do processo de Engenharia de Web que tem maior impacto sobre a acessibilidade, uma vez que uma parcela considerável dos problemas de acessibilidade estão relacionados à interface.

Os catorze estudos encontrados apresentaram uma grande variedade de técnicas, incluindo diretrizes para interfaces para usuários cegos, com baixa visão e idosos, bem como sistemas para suporte a gerenciamento de diretrizes. Além disso, outros estudos descrevem o uso de ferramentas para simular a visualização de interfaces para usuários cegos e outros ainda, o uso de representação abstrata de interfaces. Em um dos estudos, Zajicek (Zajicek, 2004) propõe alguns design patterns para interfaces para usuários idosos.

Diversas pesquisas em Interfaces Humano-Computador têm sido realizadas com o objetivo de desenvolver interfaces acessíveis. Contudo, o uso de novos paradigmas de interface como interfaces ubíqüas e dispositivos não convencionais ainda podem ser a motivação para o desenvolvimento de novas técnicas para projeto de interfaces acessíveis. O desenvolvimento de design patterns para o desenvolvimento de interfaces acessíveis também se apresenta como uma técnica promissora para futuros projetos de pesquisa.

- Projeto de conteúdo: a maioria dos métodos de Engenharia Web apontam que os sistemas Web são essencialmente direcionados a conteúdo. Desta forma, o projeto de conteúdo acessível é uma questão crucial. Os oito estudos classificados como técnicas para Projeto de Conteúdo cobriam desde questões gerais relacionadas a design de conteúdo acessível, como a simplificação do uso de linguagem natural, até o uso de anotações semânticas para enriquecer o significado das informações (Plessers et al., 2005).

Algumas técnicas interessantes incluem, por exemplo, o tratamento da acessibilidade de imagens e tabelas. Ault (Ault et al., 2002) propõe um conjunto de diretrizes para descrever gráficos para usuários cegos e com baixa visão. Filepp (Filepp et al., 2002) sugere uma linguagem de marcação para auxiliar a descrição de tabelas.

O desenvolvimento de técnicas para o desenvolvimento de conteúdo específico é essencial para a obtenção de sistemas realmente acessíveis. A definição de técnicas para auxiliar a garantia de acessibilidade em conteúdo armazenado em sistemas CMS (Content Management Systems), por exemplo, é uma questão de pesquisa bastante interessante.

- Construção de Software: após efetuar o projeto de um software, segue a implementação em si do software, por meio da codificação de seus componentes. A construção de um sistema Web envolve a implementação da lógica, interface e de sua estrutura navegacional hipermídia. 
Dentre os três estudos classificados como técnicas para apoio a acessibilidade no processo de Construção de Sotware, um deles propõe algumas técnicas específicas para a implementação. Os outros dois estudos propõem linguagens de marcação diferenciadas.

As diretrizes de acessibilidade existentes mostram diversas formas de apoiar o desenvolvimento de sistemas acessíveis. Contudo, ainda se verifica que os desenvolvedores, principalmente aqueles mais ligados a tarefas de codificação, ainda tem muitas resistências para aplicar essas guidelines. Dessa forma, se faz necessário um aprofundamento no desenvolvimento de técnicas para apoiar a implementação de sistemas Web acessíveis, que sejam facilmente entendidos pelos desenvolvedores.

- Teste de software: o propósito do teste de software é identificar defeitos. No contexto de acessibilidade, o teste corresponde a atividades de inspeção e teste relacionadas à avaliação de acessibilidade.

No total, foram encontrados 31 estudos classificados como técnicas para avaliação de acessibilidade. A maioria das técnicas são relacionadas a avaliação manual ou automática direcionada por diretrizes. Técnicas para escolha e comparação de ferramentas de avaliação de acessibilidade também foram reportadas.

É importante ressaltar que foram encontrados trabalhos com formas diferentes de avaliação de acessibilidade que não haviam sido exploradas por outros trabalhos, como percurso baseado em barreiras (análogo a métodos de avaliação como o percurso cognitivo), avaliação baseada em casos de teste e diversas técnicas para avaliação com usuário final.

Apesar de o processo de Teste ser um dos processos que possui mais técnicas reportadas, ainda existem diversas questões de pesquisa relacionadas à avaliação de acessibilidade. Problemas como a avaliação automatizada de aplicações com conteúdo dinâmico ainda tem recebido pouca atenção (Freire e Fortes, 2005).

- Manutenção de Software e de sistema: a Manutenção de Software é o processo de efetuar alterações no software. Ela pode ser feita para corrigir problemas, ou para efetuar modificações perfectivas, adaptativas ou preventivas.

Cinco estudos foram classificados como técnicas para manutenção. A maioria dos estudos são focados em auxiliar os desenvolvedores a identificar e reparar páginas com problemas de acessibilidade. Os estudos apontaram diversas soluções, como a visualização de páginas em mapas baseados em árvore, e abordagens utilizando abordagem de engenharia reversa, para melhor entendimento do código. Também são reportados estudos com ferramentas automáticas de reparo.

Muitos métodos para reparo têm sido desenvolvidos no contexto de pesquisa em acessibilidade na Web. Contudo, ainda existe um número enorme de páginas não acessíveis. O desenvolvimento de métodos efetivos para reparo de páginas é um auxílio muito importante para auxiliar os desenvolvedores a tornar páginas existentes mais acessíveis. 
- Medidas (métricas): o propósito do processo de Medidas é coletar e analisar dados referentes a produtos desenvolvidos e a processos implementados em uma organização e em seus projetos (ISO - International Standard Organization, 1998).

Sete estudos foram classificados como técnicas para medidas. Todos os estudos são relacionados a métricas para avaliação de acessibilidade de sistemas Web ou técnicas para interpretação de dados resultantes de avaliação.

O processo de Medidas definido pela norma ISO/IEC 12207 envolve o uso de outras métricas relacionadas a questões organizacionais e de processo, não só relacionadas a produtos. Dentre os possíveis trabalhos futuros relacionados a medidas para acessibilidade, seria interessante investigar o uso de métricas para produtividade e custos envolvidos com acessibilidade.

- Treinamento: o processo de Treinamento envolve atividades que têm como objetivo desenvolver novas habilidades para os recursos humanos de uma organização. O treinamento de desenvolvedores e outras pessoas envolvidas com o desenvolvimento para entender melhor os conceitos de acessibilidade é essencial para o sucesso da implementação de políticas visando acessibilidade em organizações.

Três estudos foram classificados como técnicas para treinamento em acessibilidade na Web. Um dos estudos descreve a utilização de uma ferramenta de avaliação automática e de uma página que contém um conjunto bem definido de erros de acessibilidade como apoios para o ensino de acessibilidade. Os demais estudos relatam a implementação de cursos de graduação e de pós-graduação contendo conteúdo sobre acessibilidade na Web.

A implementação de treinamentos na indústria e na academia é muito importante para a disseminação dos conceitos de acessibilidade na Web. O desenvolvimento de novas técnicas para a educação em acessibilidade é um campo de pesquisa bastante promissor e que pode trazer contribuições efetivas para a melhoria da acessibilidade.

Muitos processos da norma ISO/IEC 12207 não tiveram nenhum estudo com técnica relacionada na revisão sistemática. $\mathrm{O}$ desenvolvimento de técnicas para apoiar esses processos consistem em potenciais temas de pesquisa em acessibilidade na Web.

Mesmo no grupo de processos de Engenharia, não foram encontradas técnicas para os processos de Integração de Software e Instalação de Software.

Seria interessante investigar quais são os impactos da utilização de software ou de partes de software de outras organizações na acessibilidade. Para tanto, novas técnicas para os grupos de processos de Aquisição e de Fornecimento poderiam ser consideradas.

No tocante aos processos de Operação, novas técnicas podem ser desenvolvidas para propor formas de fornecer suporte à utilização de páginas por usuários com diferentes tipos de habilidade. Para tanto, é necessário fornecer subsídios adequados para as equipes de suporte. 
No grupo de processos de Gerência de Configuração, existem diversas questões relacionadas à documentação de acessibilidade no processo de Engenharia de Web. Além disso, os processos de Gerência de Configuração, resolução de problemas e solicitação de mudanças também possuem diversas atividades que podem ter impactos sobre a acessibilidade.

Quanto aos processos de Garantia de Qualidade, existem diversas técnicas para avaliação de acessibilidade, contudo, ainda existe a possibilidade de efetuar pesquisas sobre métodos mais abrangentes envolvendo a verificação, validação, e avaliação do produto de forma mais efetiva. Também é possível utilizar técnicas de revisão conjunta, e agregar de forma efetiva a acessibilidade aos procedimentos de garantia de qualidade.

Finalmente, também nota-se uma falta de técnicas para implementação dos conceitos de acessibilidade em nível organizacional. A acessibilidade deve ser levada em conta também nos níveis de gerência. Os processos de Melhoria de Processo devem levar em conta a adoção de técnicas para acessibilidade durante o desenvolvimento. A implementação de técnicas para o reúso efetivo considerando acessibilidade também é um amplo campo de pesquisa.

A partir da análise dos gaps identificados, é possível observar que a pesquisa sobre técnicas para acessibilidade ainda é uma área de pesquisa ampla, com diversas questões em aberto. $\mathrm{O}$ conjunto de questões comentadas neste trabalho ainda é bastante restrito, e muitos trabalhos inovadores têm sido realizados, com o envolvimento de pesquisadores das mais diversas áreas.

\subsection{Considerações finais}

Neste capítulo, foi apresentado um estudo sobre o estado da arte em técnicas de Engenharia de Web para acessibilidade. O panorama obtido a partir deste estudo se apresenta como uma importante contribuição para guiar a implementação de novas técnicas em organizações.

Apesar de não ter sido possível utilizar os critérios de revisão sistemática para definição da string de busca, a utilização dos procedimentos de revisão sistemática para seleção e avaliação dos trabalhos encontrados foi muito importante para garantir a qualidade do levantamento e a validade do estudo.

Além do panorama do estado da arte obtido, também é possível identificar diversos gaps de pesquisa. O desenvolvimento de trabalhos relacionados a áreas onde não foram identificados trabalhos também consistem em áreas de pesquisas promissoras.

O desenvolvimento de novas técnicas para acessibilidade na Web não auxilia somente desenvolvedores e organizações a desenvolver sistemas de software de qualidade, mas também auxilia na promoção do desenvolvimento de uma Web mais inclusiva, de forma a construir uma sociedade da informação mais acessível.

Como trabalhos futuros, pretende-se desenvolver trabalhos de revisão sistemática para identificar o estado da arte em pesquisas sobre interfaces para pessoas com deficiência e pessoas idosas, e também identificar o estado da arte em técnicas para transformação de interfaces. 
A investigação de soluções para a avaliação de acessibilidade para contextos ainda não explorados também será alvo de pesquisas a serem realizadas.

Finalmente, diante das constatações obtidas da revisão realizada, foi possível contextualizar os processos, atividades e técnicas usualmente mencionadas nas pesquisas que envolvem Engenharia Web.

A partir desse contexto, tivemos bases para auxiliar na formulação do questionário que foi veiculado para pessoas envolvidas com projetos de sistemas Web no Brasil, visando obter informações relativas à consideração da acessibilidade nesses projetos.

Por outro lado, para obter dados objetivos dos produtos Web desenvolvidos por essas pessoas, foram realizadas medições de acessibilidade. No próximo capítulo, são introduzidas as principais métricas de acessibilidade adotadas neste trabalho. 


\subsection{Considerações iniciais}

A avaliação dos sistemas de software produzidos é de grande importância. Contudo, também é importante que sejam avaliados os processos de desenvolvimento, para verificar se os objetivos de qualidade definidos pela organização são atingidos. Da avaliação dos produtos e dos processos em uma organização, surgem indicadores importantíssimos para auxiliar na melhoria da qualidade (Fenton e Pfleeger, 1998).

Neste contexto, a atividade de extração e registro de métricas é de grande importância. O processo de medição corresponde à atribuição de números ou símbolos a atributos ou entidades do mundo real, de forma a descrevê-los de acordo com regras bem definidas (Fenton e Pfleeger, 1998).

Métricas são importantes para auxiliar a entender, controlar e melhorar elementos de produtos e processos em organizações (Fenton e Pfleeger, 1998). No contexto de acessibilidade, métricas podem ser muito importantes para auxiliar tanto organizações que já desenvolvem seus sistemas considerando acessibilidade a melhorar a qualidade desses, quanto para auxiliar organizações que estão iniciando a introdução de questões de acessibilidade em seu processo de desenvolvimento.

Neste trabalho, em particular, o uso de métricas foi muito importante para possibilitar a realização de uma análise quantitativa sobre a acessibilidade de páginas Web para apoiar o levantamento com desenvolvedores.

Desta forma, durante a realização deste trabalho de mestrado, foram realizados estudos sobre métricas de acessibilidade e sobre como seria possível implementar um ferramental computacional 
para auxiliar na medição de acessibilidade de grandes quantidades de páginas. Assim, a partir de estudos da literatura realizados sobre métricas de acessibilidade, foi efetuada a implementação de um módulo para medição de acessibilidade baseado em uma ferramenta de avaliação automática. Para efetuar a validação e analisar a adequação do módulo, foram realizados estudos de caso com a avaliação de sítios governamentais.

Este capítulo está organizado da seguinte forma: na Seção 4.2 são descritos alguns dos principais conceitos sobre métricas de acessibilidade. Na Seção 4.3 é apresentada a primeira métrica de acessibilidade encontrada na literatura. Na Seção 4.4 são apresentados os conceitos de outra métrica que trouxe importantes contribuições conceituais. Na Seção 4.5 são apresentados os conceitos da métrica WAB (Web Accessibility Barrier). Na Seção 4.6 é discutida a proposta da métrica do modelo UWEM (Unified Web Evaluation Method). Na Seção 4.7 é apresentada a métrica A3. Na Seção 4.8 é apresentada a proposta da métrica WAQM (Web Accessibility Quality Metric) e, finalmente, na Seção 4.9 são discutidas as condierações finais deste capítulo.

\subsection{Métricas de acessibilidade}

O uso de métricas para acessibilidade em sistemas Web apresenta inúmeras possibilidades de investigação e desafios a serem enfrentados. Do ponto de vista do processo de desenvolvimento, diversas métricas podem indicar como a melhorar questões técnicas e gerenciais enfrentadas pelas organizações. Do ponto de vista das sistemas Web como produtos, o uso de medidas possibilita que o estado atual da acessibilidade de um sistema Web seja medido, e também possibilita a comparação do nível de acessibilidade de sistemas diferentes, ou mesmo sobre a evolução da acessibilidade de um sítio no decorrer do tempo (Parmanto e Zeng, 2005). Entretanto, o estabelecimento de métricas que considerem os fatores humanos envolvidos se apresenta como um grande desafio de pesquisa.

Recentemente, alguns trabalhos têm sido dedicados para o estabelecimento de métricas de acessibilidade para sistemas e sítios Web. O objetivo dessas métricas é o de estabelecer um valor que possa sumarizar o resultado de avaliações de acessibilidade baseadas em diretrizes (guidelines).

Nas subseções a seguir, são apresentadas as principais métricas de acessibilidade propostas na literatura, encontradas a partir da revisão da literatura reportada no Capítulo 3 e de outras pesquisas por trabalhos mais recentes publicados posteriormente. Para facilitar a compreensão, foi estabelecida um padrão para normatização das fórmulas das métricas.

Assim, cada conceito utilizado no cálculo das métricas foi representado de acordo com as variáveis apresentadas na Tabela 4.1. 
Tabela 4.1: Padronização de variáveis nas fórmulas das métricas de acessibilidade

\begin{tabular}{|l|l|}
\hline Variável & Significado \\
\hline B & Número de barreiras ou problemas encontrados \\
\hline $\mathbf{P}$ & Número de problemas em potencial \\
\hline $\mathbf{W}$ & $\begin{array}{l}\text { Peso da barreira no cálculo geral da métrica (relacionada ao } \\
\text { impacto sobre o usuário) }\end{array}$ \\
\hline $\mathbf{W C}$ & Peso relacionado à confiança do teste realizado \\
\hline $\mathbf{R}$ & Resultado de um teste de acessibilidade \\
\hline $\mathbf{N P}$ & Número de páginas avaliadas \\
\hline NT & Número de testes considerados \\
\hline
\end{tabular}

\subsection{Métrica de problemas potenciais}

O primeiro trabalho publicado sobre uma medida de acessibilidade foi proposto por Sullivan \& Matson (Sullivan e Matson, 2000). Nesta métrica, foi considerado o conceito de problemas potenciais, de forma a estabelecer um valor referente ao número de barreiras encontradas em relação ao número de barreiras potenciais.

No estudo realizado, os autores apontaram o problema de se utilizar números absolutos para efetuar a comparação. Por exemplo, a avaliação de duas páginas pode fornecer como resultado um número de 10 ocorrências de problemas relacionados à falta de textos alternativos para imagens. A comparação direta entre as duas páginas fica comprometida se, por exemplo, uma das páginas tem um total de 10 imagens e a outra um total de 100 imagens. Considerando que a existência de uma imagem é um problema potencial, a primeira página teria um índice de $100 \%$ de imagens inacessíveis, enquanto a segunda teria um índice de $10 \%$.

A fórmula considera o número total de problemas encontrados em uma página $\left(B_{p}\right)$ em relação ao número de problemas potenciais $\left(P_{p}\right)$, de acordo com a fórmula a seguir:

$$
I_{p}=\frac{B_{p}}{P_{p}}
$$

\subsection{Métrica de acessibilidade para usuários cegos}

González et al. (2003) propuseram uma métrica para obter um índice de acessibilidade. O objetivo do desenvolvimento desta métrica foi o de apoiar a navegação no sistema KAI (Kit for the Accessibility to the Internet). No sistema KAI, as páginas são convertidas para uma linguagem intermediária, denominada BML (Blind Markup Language), de forma a melhorar a navegação por 
usuários cegos com o sintetizador de voz baseado em BML presente no sistema. Durante o processo de conversão da página, são extraídas informações referentes à acessibilidade de elementos como imagens, textos, formulários e outros, que são utilizados posteriormente para a determinação do índice de acessibilidade da página. O objetivo do sistema é que, de posse desse índice, o usuário possa optar por navegar ou não pela página.

O índice de acessibilidade proposto por González et al. (2003) é calculado considerando que uma página é acessível se todos os seus elementos são acessíveis. Dado o endereço de uma página, é estabelecido o índice de acessibilidade de cada elemento. Para o cálculo do índice de cada elemento, são consideradas diretrizes de acessibilidade do WCAG (W3C, 1999a) e outras diretrizes estipuladas pelos autores. Para cada ponto de verificação, é atribuído um índice percentual de importância.

Na definição do percentual de importância, verifica-se qual é o impacto de um problema de acessibilidade para aquele ponto de verificação. Por exemplo, para o ponto de verificação 1.1 (Prover um equivalente em texto para todo elemento não visual), atribui-se $100 \%$ de importância, pois tem um impacto grande para todo usuário cego. Para o ponto de verificação 2.2 (Contraste entre cor de fundo e cor do texto), atribui-se o índice relativo ao percentual de cegueira do usuário (1/\%cegueira), pois para usuários cegos ele não terá impacto algum.

Após calcular o índice de acessibilidade para cada elemento da página, o método proposto define o cálculo de um índice global de acessibilidade para a página. A definição do índice de acessibilidade é efetuada de acordo com o modelo "WebQEM" (Web Quality Evaluation Method) (Olsina e Rossi, 2002), passando pela definição dos atributos de qualidade avaliados, avaliação de cada elemento, avaliação global e conclusão da avaliação.

Para efetuar a avaliação global, toma-se o índice percentual (EP) de cada elemento da página avaliada, definido como a fração das barreiras em relação aos problemas potenciais, e atribui-se um peso a ele $\left(W_{b}\right)$, e calcula-se o índice global (GP) como:

$$
G P_{p}=\sum_{\text {possivel barreira } b \in \text { pagina } p} \frac{B_{b p}}{P_{b p}} W_{b}
$$

a soma dos pesos deve ser definida de forma que:

$$
\left(W_{1}+W_{2}+\ldots+W_{m}\right)=1, W_{i}>0, i=1 . . m
$$

Os autores afirmam que os resultados obtidos por meio de uma validação informal foram bons, contudo, não é apresentada nenhuma validação experimental formal da métrica proposta. Além disso, verifica-se que os autores se concentraram em efetuar uma avaliação voltada somente para a comunidade de usuários cegos, o que dificulta a utilização direta da métrica proposta para outros contextos. 


\subsection{Métrica WAB (Web Accessibility Barrier)}

A definição de uma métrica para acessibilidade também foi alvo de um trabalho realizado por Parmanto e Zeng (2005). A métrica definida pelos autores, denominada WAB (Web Accessibility Barrier) tem como objetivo auxiliar a determinação de um índice de acessibilidade para a avaliação automática de acessibilidade de sítios e sistemas Web.

Dentre as motivações apontadas pelos autores, pode-se apontar a necessidade de proporcionar uma automatização da avaliação de grandes quantidades de páginas Web, e de estabelecer índices para comparar e acompanhar a evolução da acessibilidade.

$\mathrm{Na}$ métrica desenvolvida, também são considerados os conceitos de problemas potenciais e de peso como em outras métricas existentes na literatura. Além disso, também leva em conta o número de páginas em um sítio $(N P)$, e estipula uma atribuição de pesos, correspondente ao inverso da prioridade definida pelo WCAG (W3C, 1999a) ${ }^{1}$. A fórmula para cálculo da métrica WAB é conforme a seguir:

$$
W A B_{\text {stio }}=\frac{\sum_{p=1}^{N P} \sum_{\text {possivel barreira } b \in W C A G 1.0}\left(\frac{B_{b p}}{P_{b p}}\right)\left(W_{b}\right)}{N P}
$$

Os autores apresentam uma validação experimental do método. A validação foi efetuada por meio da comparação do resultado da avaliação com uma avaliação de referência. Os autores compararam a avaliação efetuada utilizando o WAB de sítios classificados como "A", "AA" e "AAA". Com os resultados, verificou-se que, em média, sítios com melhor classificação nos níveis estabelecidos pelo WCAG tinham um índice WAB menor (com menos barreiras).

\subsection{Métrica UWEM - Modelo de agregação de resultados de testes}

No contexto da metodologia para avaliação UWEM (Cluster, 2006b), citada na Seção 2.6, um dos objetivos definidos era o de definir uma forma de agregar o resultado de testes de acessibilidade.

No UWEM é descrito um método para obtenção de medidas obtidas a partir de testes de acessibilidade em três estágios. A métrica proposta se baseia no cálculo da probabilidade de que o usuário encontre uma barreira em um sítio Web, calculada a partir da probabilidade de encontrar barreiras pontuais em cada uma de suas páginas.

A partir da realização do primeiro e do segundo estágios, descritos na Figura 4.1, é obtida a probabilidade de encontrar uma barreira de acessibilidade em uma única página.

\footnotetext{
${ }^{1}$ Os níveis de prioridade de cada ponto de verificação são definidos como 1, 2 ou 3
} 
O primeiro estágio corresponde à avaliação de acessibilidade, na forma de inspeção, efetuada ou por um especialista ou por meio de uma ferramenta de avaliação automática. A partir dos resultados dos testes, calcula-se o índice de barreiras de cada página por tipo de barreira. Em seguida, aplica-se um peso ao valor baseado no nível de confiança do procedimento de teste.

Os resultados de cada teste no estágio 1 é dado por um relatório $R_{p b} \in[0,1]$, onde $p$ designa a página em questão, e $b$ um dado tipo de barreira. $R_{p b}=1$ significa que o teste para uma barreira do tipo $b$ falhou, enquanto $R_{p b}=0$ indica que o teste para a barreira do tipo $b$ foi aprovado. Em avaliações automáticas, é possível efetuar a avaliação de todos os elementos da página de maneira mais rápida. Assim, os resultados podem ser dados em função do número de testes que resultaram em falhas, denotado por $B_{p b}$, em relação ao número de elementos relevantes para a barreira $b$, designado por $P_{p b}$, de acordo com a fórmula $R_{p b}^{\text {automatic }}$, descrita na Figura 4.1.

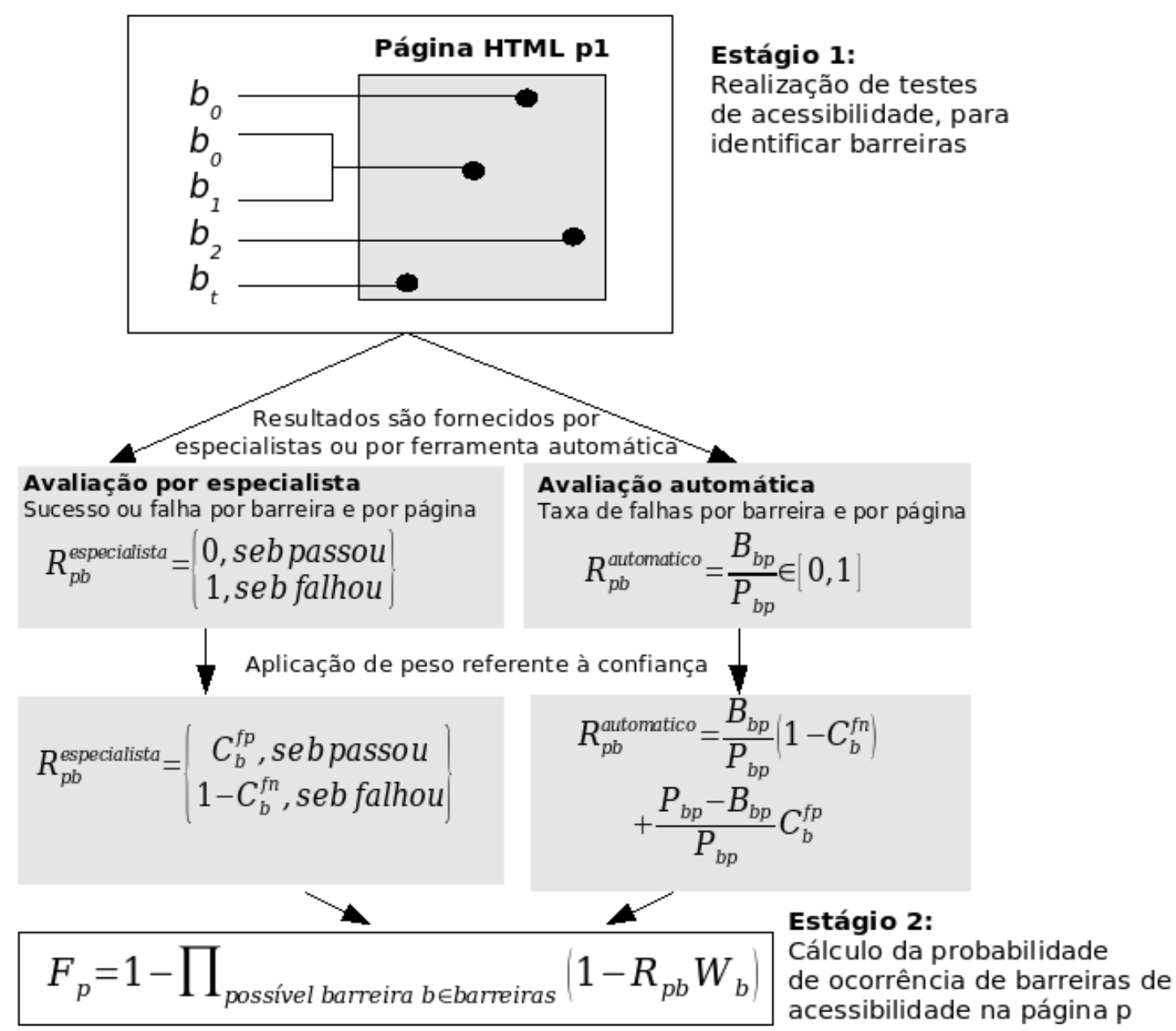

Figura 4.1: Primeiro e segundo estágios para o cálculo de métrica de acessibilidade do UWEM (Cluster, 2006b)

Em seguida, pode-se aplicar o peso referente ao peso da confiança do teste realizado na avaliação, caso ele seja conhecido. Os pesos da confiança se referem à probabilidade de acusar um "falso positivo" $\left(C_{b}^{f p}\right)$, ou seja, de apontar a existência de uma barreira que na realidade não existe, e à probabilidade de não acusar uma barreira que existe, que correspondende a um "falso nega- 
tivo" $\left(C_{b}^{f n}\right)$. Na versão atual do UWEM, não existe nenhuma indicação sobre como especificar essas probabilidades. Caso não seja possível utilizar esses pesos, o documento recomenda que eles sejam definidos como $C_{b}^{f p}=C_{b}^{f n}=0$, que corresponde ao mesmo que não aplicá-los. Caso seja possível determinar essas probabilidades, utiliza-se as fórmulas descritas descritas na Figura 4.1, para a etapa após a aplicação dos pesos de confiança.

No segundo estágio, também representado na Figura 4.1, é efetuado o cálculo da probabilidade de encontrar barreiras de acessibilidade para cada página avaliada, designado pela variável $F_{p}$.

Para o cálculo da probabilidade de encontrar barreiras em uma página, é utilizado o fator $\left(W_{b}\right)$, definido no intervalo $W_{b} \in[0,1]$. Um valor pequeno de $W_{b}$ indica que a probabilidade de que é baixa a probabilidade de uma barreira $b$ signifique um real problema de acessibilidade pelos usuários. Ou seja, refere-se ao índice de impacto da barreira sobre a acessibilidade. Na versão atual do método, ainda não existem dados experimentais suficientes para a determinação do valor de $W_{b}$ para cada barreira de acessibilidade. No documento, determina-se que seja utilizado o valor $W_{b}=0.05 \forall b$. Espera-se que com o avanço do projeto EIAO (European Internet Accessibility Observatory) (Snaprud et al., 2006) seja possível determinar valores mais exatos para esses índices.

O cálculo é efetuado com base nos príncipios do modelo UCAB (User Centric Accessibility Barrier Model), considerando que 1) a ocorrência de barreiras é independente e 2) a ocorrência de barreiras em uma página tem efeito cumulativo, ou seja, cada barreira encontrada tem um efeito sobre a diminuição da acessibilidade global da página.

Após efetuar o cálculo de $F_{p}$ para cada página, é efetuado o cálculo da probabilidade de encontrar barreiras no sítio como um todo, como na fórmula seguinte.

$$
F_{s}=\frac{1}{N P} \sum_{j=1}^{N P} F_{p j}
$$

O desvio padrão é dado pela fórmula a seguir:

$$
S_{s}=\sqrt{\frac{1}{N P} \sum_{p=1}^{N P}\left(F_{p}-F_{s}\right)^{2}}
$$

O valor final encontrado pela métrica para a acessibilidade do sítio corresponde à probabilidade de que um usuário com um determinado tipo de deficiência encontre, ao utilizar o sítio, barreiras que o impeçam de completar uma tarefa.

Nos estudos realizados no contexto deste trabalho de mestrado, não foram considerados os conceitos de confiança de teste para esta métrica. A seguir, é ilustrada a fórmula simplificada para o cálculo de $F_{s}:$ :

$$
F_{s}=\frac{1}{N P} \sum_{p=1}^{N P} 1-\prod_{\text {possivel barreira } b \in \text { barreiras }}\left(1-\frac{B_{b p}}{P_{b p}} W_{b}\right)
$$


Até o momento da redação desta dissertação, não existia nenhum documento publicado com resultados finalizados de validação experimental da métrica.

\subsection{Métrica A3 - Modelo melhorado de agregação de re- sultados de testes}

Em um outro trabalho referente a métricas de acessibilidade, Bühler et al. (2006) propuseram algumas melhorias para a métrica para agregação de resultados de testes do UWEM 0.5 (Cluster, 2006a). No momento da escrita do artigo, ainda não havia sido publicada a nova versão do UWEM 1.0 (Cluster, 2006b). Contudo, houve poucas alterações no método, com exceção de algumas questões de notação.

No trabalho de Bühler et al. (2006), considerou-se a notação utilizada na versão UWEM 0.5 (Cluster, 2006a), para indicar que o índice utilizado para denotar o nível de barreiras de uma página era específico para um grupo de usuários $u$. Dessa forma, denota-se o impacto de uma barreira sobre um usuário $u$ por $W_{u b}$. Assim, a fórmula original, denotada por $A_{1}$, seria redefinida como:

$$
A_{1}(p, u)=1-\prod_{\text {possivel barreira } b \in \text { barreiras }}\left(1-W_{u b}\right)
$$

Os autores propõem uma primeira modificação na fórmula, de modo a contemplar a representação da ocorrência de mais de uma falha relacionada a uma mesma barreira. Assim, obtem-se uma fórmula $A_{2}$, levando em consideração que o número de ocorrências de uma barreira é $B_{p b}$ :

$$
A_{2}(p, u)=1-\prod_{\text {possivel barreira } b \in \text { barreiras }}\left(1-W_{u b}\right)^{B_{p b}}
$$

Nota-se que esta fórmula modela barreiras absolutas. Uma barreira é absoluta se ela impossibilita que o usuário complete uma tarefa. A severidade de tal barreira é $W_{u b}=1$. Essa condição resulta em $A_{2}(p, u)=1$ porque o produto resulta em zero (um dos fatores é $\left(1-W_{u b}\right)^{B_{p b}}=$ $\left.(1-1)^{B_{p b}}=0\right)$. O modelo proposto por Bühler et al. (2006) é baseado em uma mudança no expoente desta fórmula, conforme a seguir:

$$
A_{3}(p, u)=1-\prod_{b}\left(1-W_{u b}\right)^{\left(\frac{B_{b} p}{P_{b p}}+\frac{B_{p b}}{B_{p}}\right)}
$$

O fator $C_{p b}$, utilizado no expoente do fator multiplicativo é o valor que descreve a complexidade da página $p$ em relação à barreira $b$, que é definido da seguinte forma:

$$
C_{p b}=\frac{B_{p b}}{P_{p b}}+\frac{B_{p b}}{B_{p}}
$$


Os dados relevantes para o cálculo de $C_{p b}$ são $B_{b p}$ (número de barreiras tipo $b$ na página), $P_{p b}$ (número de barreiras potenciais do tipo $b$ na página), e $B_{p}$ (número total de barreiras na página). $C_{p b}$ deve satisfazer as seguintes condições:

- Se nenhuma barreira do tipo $b$ é encontrada, não há nenhuma contribuição para a função de agregação. ( $\left.B_{p b}=0 \Rightarrow C_{p b}=0\right)$

- Se uma barreira do tipo $b$ é encontrada, isso irá diminuir o resultado da função de agregação. $\left(B_{p b}>0 \Rightarrow C_{p b}>0\right)$

Essa função leva em conta a relação das barreiras reais e barreiras em potencial. Além da relação de todas as falhas com o número de falhas para um tipo de barreira. Essa contribuição adicional garante que essas barreiras sejam consideradas de acordo com a sua proporção global de ocorrência dentro de uma página Web.

Bühler et al. (2006) também reportam a realização de um experimento inicial para efetuar a validação do método. O experimento foi realizado durante um teste com usuários. Participaram do teste quinze usuários com deficiência, dentre os quais havia um grupo de usuários cegos. Os autores não informam o percentual de usuários cegos e nem quais eram os outros tipos de deficiência que os demais participantes possuíam.

Para efetuar a comparação, foram computadas métricas com índices de barreiras de acessibilidade diferentes, e também foi computado um índice avaliado pelos usuários. O objetivo da avaliação foi de verificar qual das métricas fornecia uma melhor aproximação para a avaliação dos usuários. Na comparação, foram computadas as métricas do modelo de agregação do UWEM 0.5 (Cluster, 2006a), o modelo melhorado A3 e o modelo proposto por Sullivan e Matson (2000).

De forma geral, o método $A_{3}$ foi o que se aproximou mais dos índices dos usuários. O método de Sullivan e Matson (2000), apesar de simples, também obteve resultados satisfatórios.

Embora a validação tenha sido feita com um grupo pequeno de usuários, e com poucas páginas, os resultados preliminares indicam que o método $A_{3}$ apresenta vantagens em relação aos demais métodos.

\subsection{Métrica WAQM (Web Accessibility Quality Metric)}

A métrica WAQM (Web Accessibility Quality Metric) (Vigo et al., 2007) considera as diretrizes do WCAG 1.0 classificadas de acordo com os princípios do WCAG 2.0, de que o conteúdo deve ser: perceptível, operável, inteligível (understandable) e robusto. Ao contrário das outras métricas apresentadas, esta métrica também considera problemas identificados como warnings na contagem.

No algoritmo para cálculo da métrica, basicamente os pontos de verificação são divididos em doze grupos, derivados da combinação das seguintes possíveis variações: 
- Princípio: pontos de verificação contidos no conjunto $\{P, O, U, R\}$, referentes aos quatro princípios do WCAG 2.0.

- Tipo de assertiva: pontos de verificação dados como erros (errors) ou avisos (warnings), no conjunto $\{\mathrm{e}, \mathrm{w}\}$;

- Prioridade: pontos de verificação de prioridades definidas no conjunto $\{1,2,3\}$ do WCAG 1.0 .

São utilizadas duas abordagens diferentes para o cálculo do WAQM, utilizando a aproximação de uma hipérbole. Uma decisão é tomada, com base em valores obtidos experimentalmente, para escolher qual das duas fórmulas deve ser utilizada. A fórmula resumida é ilustrada a seguir. A variável $N_{x}$ denota o número de pontos de verificação feridos para um dado princípio. Por exemplo, quando $x=p, N_{p}$ é o número de pontos de verificação violados para o princípio "perceptível". A variável $\mathrm{N}$ corresponde ao número total de pontos de verificação observados. A variável $N_{x y}$ denota o número de pontos de verificação para um dado princípio e tipo de assertiva. Por exemplo, $N_{p, e}$ denota o número de pontos de verificação para o princípio “perceptível” que podem ser definidos como erros.

Os pesos $W_{z}$ foram definidos pelos autores do trabalho experimentalmente como $W_{1}=0.80$, $W_{2}=0.16$ and $W_{3}=0.04$. Os valores da métrica variam entre 0 e 100 , onde 100 corresponde a sítios com boa acessibilidade, ao contrário de outras métricas, em que valores altos se referem a páginas com mais barreiras de acessibilidade. Com os pesos definidos desta forma, o total dos pontos de verificação de prioridade 1 somam um total de 80 pontos, os de prioridade 2 somam 16 pontos e de prioridade 3,4 pontos, totalizando a nota máxima de 100 pontos.

$$
W A Q M=\frac{1}{T} \sum_{j=1}^{T} \sum_{x \in\{p, o, u, r\}} \frac{N T_{x}}{N T} \sum_{y \in\{e, w\}} \frac{N T_{x y}}{N T_{x}} \sum_{z \in\{1,2,3\}} W_{z} A_{x y z}
$$

Para efetuar o cálculo do peso de cada ponto de verificação, é adotada uma abordagem baseada em uma aproximação por meio de uma hipérbole. Na Figura 4.2, traduzida e adaptada de Vigo et al. (2007) é apresentada uma representação gráfica dessa aproximação. Com essa aproximação, na região onde estão concentrados a maioria dos resultados da avaliação, o gráfico apresenta uma distribuição mais discriminativa, "espalhando" melhor os valores, segundo os autores.

Desta forma, a definição do fator $A_{x y z}$ é feita de acordo com a fórmula descrita a seguir. As constantes $a$ e $b$ foram definidos por Vigo et al. (2007) empiricamente como $a=20$ e $b=0.3$.

$$
A_{x y z}=\left\{\begin{array}{l}
\left(\frac{b_{x y z}}{B_{x y z}}\right)\left(\frac{-100}{b}\right)+100, \frac{b_{x y z}}{B_{x y z}}<\frac{a-100}{a-100 / b} \\
-a\left(\frac{b_{x y z}}{B_{x y z}}\right)+a, \text { caso contrario }
\end{array}\right.
$$

Os autores apresentam testes efetuados com duas ferramentas automáticas diferentes para 15 sítios Web e é feita uma comparação com algumas pré-condições definidas pelos próprios autores. 


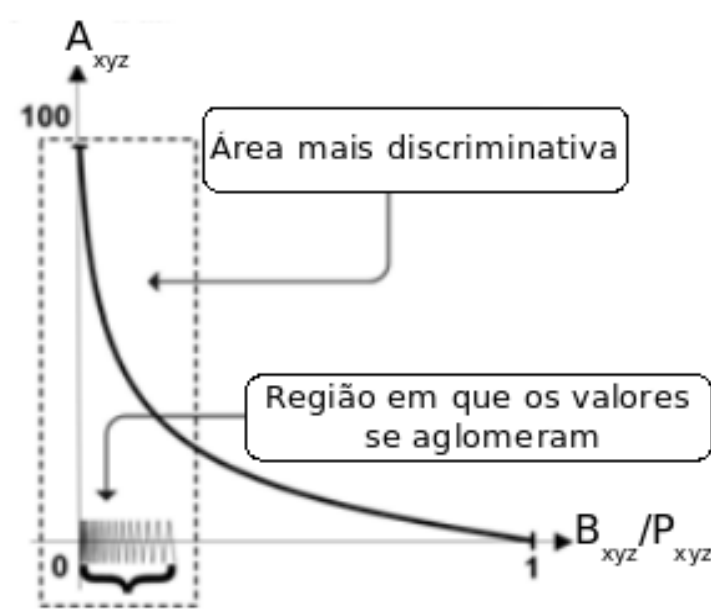

Hipérbole ideal

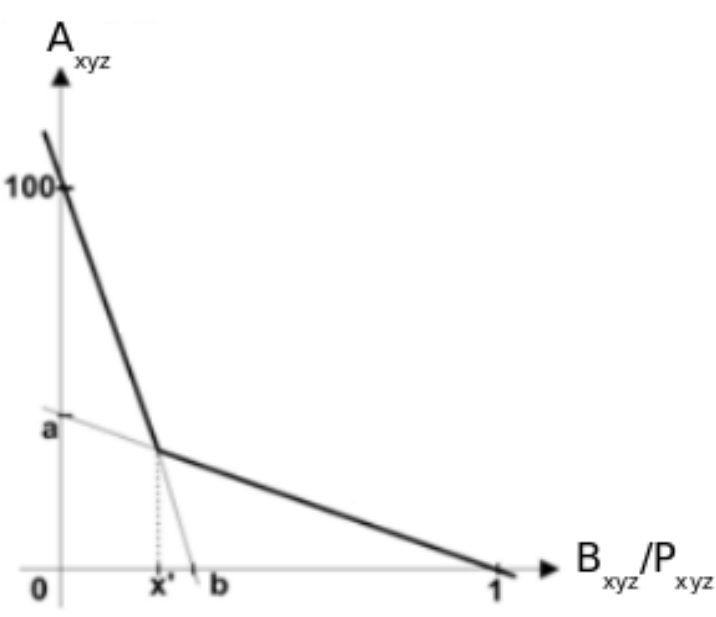

Aproximação por duas retas

Figura 4.2: Aproximação do cálculo da métrica WAQM por uma hipérbole (Vigo et al., 2007)

Contudo, nenhuma comparação da métrica em relação a outras, nem comparação das métricas obtidas em relação a resultados de testes com usuários são apresentados.

\subsection{Considerações finais}

Neste capítulo foram apresentados alguns conceitos e trabalhos relacionados a métricas de acessibilidade.

Foram apresentadas algumas das principais métricas de acessibilidade reportadas na literatura, com especial destaque para as métricas WAB, UWEM, A3 e WAQM, utilizadas nos estudos de caso e, posteriormente, no levantamento com pessoas envolvidas em projetos Web.

A necessidade de estabelecer métodos para realização de análises quantitativas se mostra como um aspecto muito importante. Pode-se observar que a partir da primeira proposta de utilização de uma abordagem quantativa para análise da acessibilidade no ano de 2000 (Sullivan e Matson, 2000), passando pelos estudos de González et al. (2003), o interesse pela investigação deste tema tem sido crescente nos últimos anos (Parmanto e Zeng, 2005; Cluster, 2006b; Bühler et al., 2006; Vigo et al., 2007).

Contudo, também verifica-se que exite uma grande necessidade de estabelecer mecanismos para que a utilização dessas métricas leve em consideração os impactos dos problemas de acessibilidade enfrentados por cada tipo de usuário. Em particular, o estabelecimento de coeficientes a partir das experiências de usuários com diferentes tipos de deficiências tem sido apontado como um dos grandes desafios a serem alcançados no projeto UWEM (Cluster, 2006b; Bühler et al., 2006). 
No próximo capítulo, são apresentadas as atividades relacionadas com a implementação de um módulo para apoiar o cálculo das métricas apresentadas a partir de avaliações com ferramentas automáticas baseadas em diretrizes. 


\section{Hera metrics: módulo para cálculo de métricas}

\subsection{Considerações iniciais}

A utilização de métricas quantitativas para análise de atributos de qualidade de software é muito importante para apoiar as atividades de garantia de qualidade. Entretanto, muitas vezes o cálculo dessas métricas pode ser muito dispendioso. A utilização de ferramentas adequadas para apoiar as atividades para coleta de dados e cálculo de métricas é muito importante para viabilizar a utilização de processos de medição de maneira eficiente.

Desta forma, no contexto deste projeto, após efetuar o estudo sobre as métricas de acessibilidade existentes na literatura, foi desenvolvido um módulo para cálculo dessas métricas por meio de uma ferramenta de avaliação de acessibilidade baseada nas diretrizes do WCAG 1.0 (W3C, 1999a).

Para efetuar a implementação deste módulo, foram analisadas diferentes ferramentas de avaliação disponíveis, enumeradas na Tabela 2.1. Foram consideradas as ferramentas de avaliação disponíveis como sofware de código aberto com licença livre. 
As ferramentas consideradas para a análise foram a Hera ${ }^{1}$, A-Checker ${ }^{2}$, a Functional Accessibility Evaluator ${ }^{3}$, a WAEX ${ }^{4}$ a WAHelper ${ }^{5}$ e a WAVE ${ }^{6}$.

Como primeiro passo, foi feita a instalação de cada uma das ferramentas a serem analisadas. Apesar de terem sido declaradas como ferramentas de código aberto, as ferramentas WAHelper e Functional Accessibility Evaluator não disponibilizavam o código para acesso em nenhum local, impossibilitando sua instalação.

A ferramenta WAEX se apresentou a princípio como uma alternativa bastante interessante, pelo fato de utilizar transformações XSLT (W3C, 1999b) para efetuar a avaliação das páginas, o que destaca a preocupação com o uso de padrões Web. Contudo, a utilização desta tecnologia limitava a utilização da ferramenta para a avaliação de páginas que necessariamente estivessem em formato XHTML (W3C, 2002b), excluindo páginas em HTML 4.0 (W3C, 1999) ou anterior que não estivessem em conformidade com o padrão XHTML.

As ferramentas WAVE e A-Checker também foram instaladas e examinadas. As duas ferramentas foram implementadas em linguagem Java. A ferramenta WAVE se mostrou bastante eficaz para a avaliação. Contudo, na análise do código verificou-se que a sua API não fornecia uma interface adequada para obter os problemas de acessibilidade para cálculo das métricas de forma objetiva. A ferramenta A-Checker se mostrou bastante interessante para uso, pois possui uma implementação bastante modular e oferece recursos para adaptar facilmente o conjunto de diretrizes utilizado para avaliação. Entretanto, verificou-se que esta ferramenta ainda possui muitos problemas de desempenho, pois exigia muitos recursos de processamento e memória, além de que constantemente estava indisponível.

Finalmente, a ferramenta Hera mostrou-se a ferramenta mais adequada para efetuar as modificações necessárias para efetuar cálculos de métricas de acessibilidade. A ferramenta é implementada em PHP e também tem o seu código modular, facilitando o entendimento e a realização de trabalhos de manutenção. Apesar de também apresentar problemas de desempenho, verificou-se que normalmente a ferramenta não tinha problemas sérios de disponibilidade.

Este capítulo está organizado da seguinte forma: na Seção 5.2 são apresentados os estudos realizados sobre a ferramenta Hera 2.0, na Seção 5.3 é apresentada a implementação do módulo para cálculo de métricas, na Seção 5.4 são apresentados os estudos de caso realizados com avaliação de acessibilidade baseada em métricas de sítios governamentais brasileiros e, finalmente, na Seção 5.5 são discutidas as considerações finais deste capítulo.

\footnotetext{
${ }^{1}$ Disponível em http://www.sidar.org/hera

${ }^{2}$ Disponível em http://checker.atrc.utoronto.ca/

${ }^{3}$ Disponível em http://fae.cita.uiuc.edu/

${ }^{4}$ Disponível em http://www.it.uc3m.es/vlc/waex.html

${ }^{5}$ Disponível em http://wahelper.brailcom.org/

${ }^{6}$ Disponível em http://wave.webaim.org/
} 


\subsection{Estudo sobre a ferramenta Hera 2.0}

A partir da escolha da ferramenta Hera para efetuar a implementação do módulo para cálculo de métricas, foi feito um estudo sobre o funcionamento da ferramenta. Na página da ferramenta havia pouca documentação disponível. Somente algumas descrições básicas sobre cada módulo eram disponibilizadas.

Desta forma, a maior parte do estudo teve que ser feita a partir do código-fonte, utilizando o procedimento de engenharia reversa para gerar as devidas descrições e modelos da ferramenta.

Parte da ferramenta foi implementada utilizando o paradigma de orientação a objetos, mas algumas partes foram implementadas utilizando programação estruturada. Assim, parte da descrição da ferramenta aqui reportada será feita por meio de diagramas de classes e parte com descrição sobre as funcionalidades e funções disponíveis nas bibliotecas.

A ferramenta Hera 2.0 é considerada uma ferramenta de avaliação de acessibilidade semiautomática. Ela apresenta funcionalidades para a realização de avaliações preliminares de forma automática para um subconjunto de diretrizes e fornece suporte para a realização de avaliação manual por especialistas. A ferramenta também provê funcionalidades para geração de relatórios.

Na Figura 5.1, adaptada e traduzida de Benavídez et al. (2006) é apresentada a estrutura básica da ferramenta. Verifica-se que o fluxo convencional para utilização em avaliações consiste em efetuar uma avaliação preliminar automaticamente e, em seguida, efetuar uma inspeção manual. Para a inspeção manual, a ferramenta disponibiliza diversos auxílios, como ajuda com as diretrizes, visualização de sumário dos resultados até o momento, instruções gerais para avaliação, visualização gráfica da página com indicação dos lugares onde ocorreu cada erro, visualização do código fonte e inserção dos resultados de avaliação. Após efetuar a avaliação, a ferramenta também oferece suporte para geração de relatórios em formato HTML, PDF ou EARL (W3C, 2007a).

Na organização de sua estrutura de arquivos, a ferramenta possui três grandes grupos: a) arquivos para processamento de interface com o usuário, b) bibliotecas e classes para implementação das funcionalidades e c) arquivos para tratamentos de localização para diferentes línguas.

Nas funcionalidades para tratamento da interface, existem arquivos com a página inicial da busca, avaliação de contraste de cores, visualização dos resultados, geração de relatórios e as folhas de estilo.

Para efetuar a localização, foram utilizados arquivos com as definições dos termos na interface, separados em grupos: nomes dos elementos revistos, textos de ajuda, textos da interface em geral, textos dos manuais para os pontos de verificação, textos para visualização da página com erros, textos das diretrizes, informações sobre pontos de verificação, e outros tipos de mensagens.

A ferramenta também possui outros módulos para manipulação das funcionalidades e para apoio à geração de interface. Contudo, o principal interesse no contexto deste projeto era referente às funcionalides de parsing e de avaliação de acessibilidade. Desta maneira, nesta dissertação é apresentado somente um modelo das classes que são referentes a essas funcionalidades. 


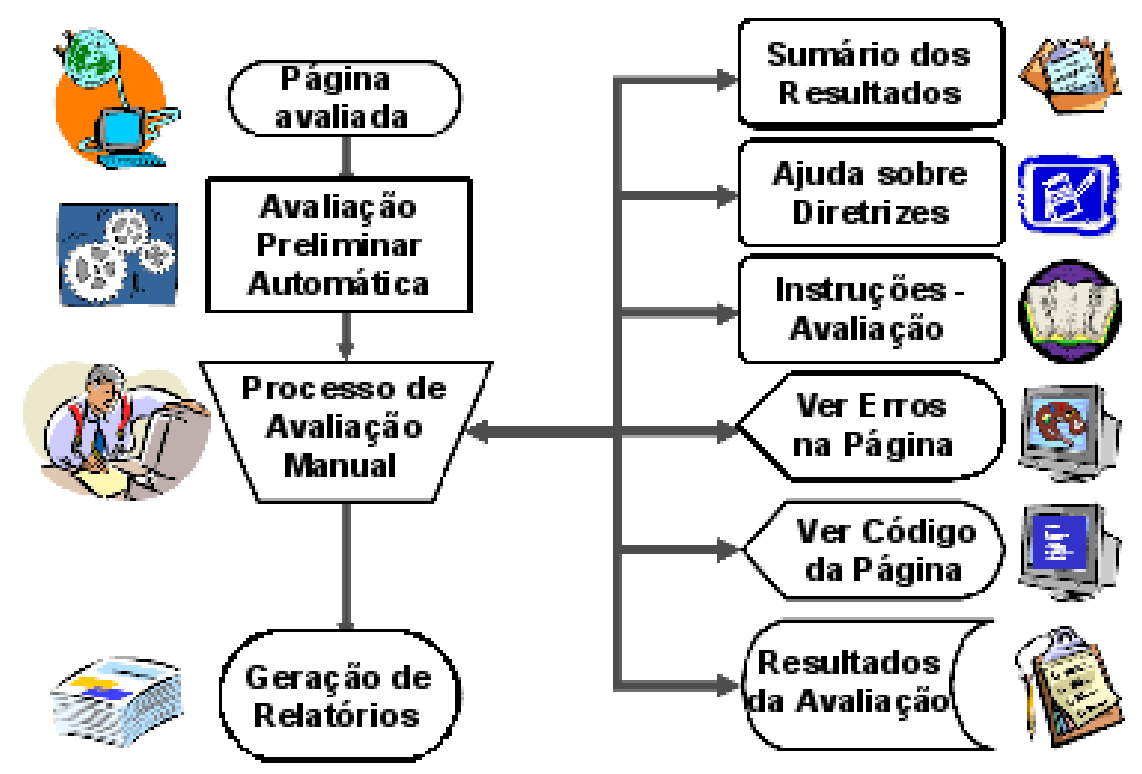

Figura 5.1: Estrutura básica da ferramenta Hera 2.0 (Benavídez et al., 2006)

Na Figura 5.2 são apresentadas as principais características das classes File, Parse e Resumen. A classe File contém funções para manipulação dos arquivos avaliados e para o tratamento inicial do texto, realizando as primeiras etapas do parsing. No classe Parse são feitas as análises dos problemas de acessibilidade para cada elemento HTML. A classe Resumen é responsável pelo tratamento dos dados para a exibição dos relatórios-resumo.

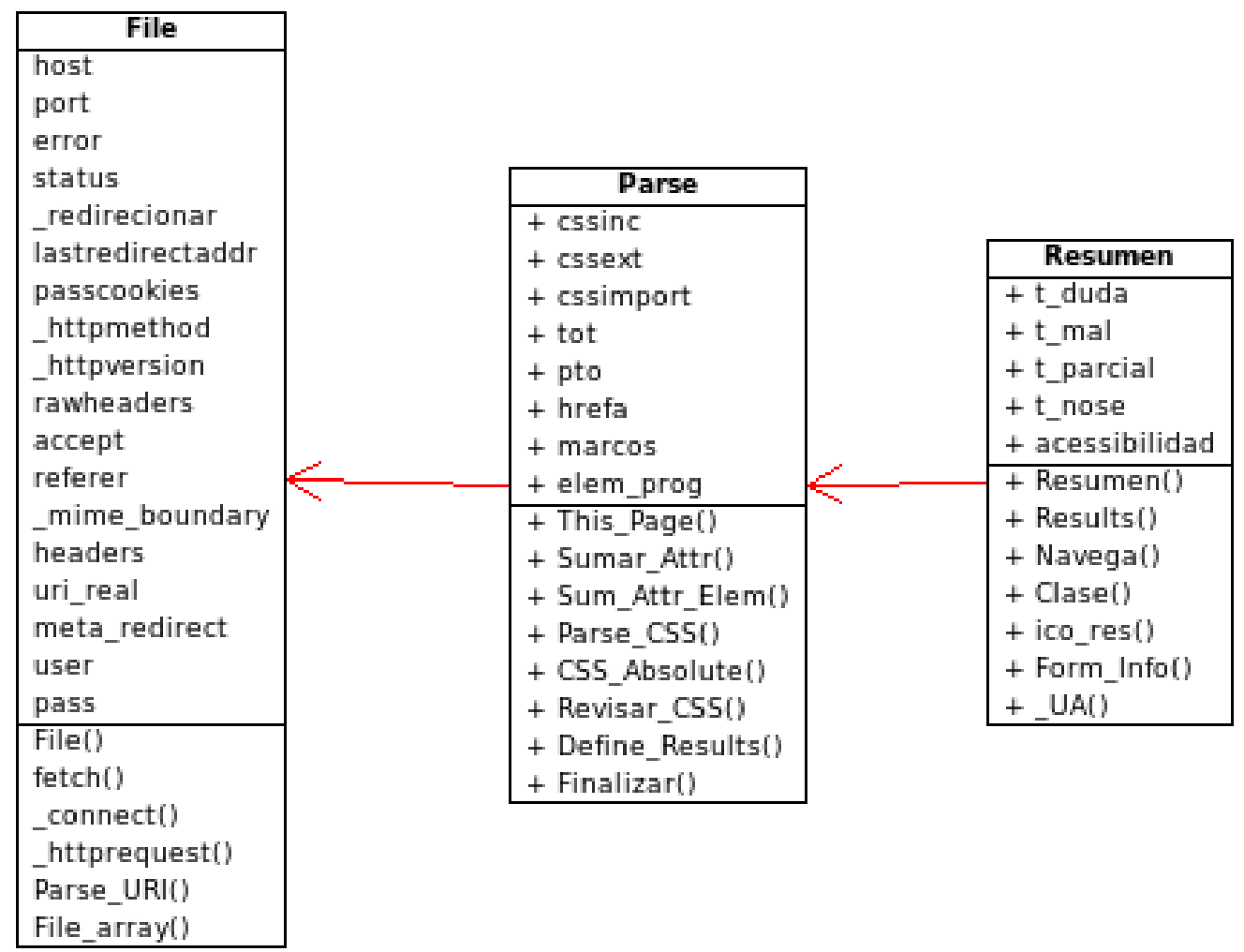

Figura 5.2: Diagrama com as principais classes utilizadas para avaliação na ferramenta Hera 2.0 
A principal classe utilizada para o cálculo das métricas é a classe parse, que contém informações sobre o número de problemas encontrados para cada ponto de verificação. $\mathrm{O}$ atributo tot corresponde a um array indexado pelo número de cada ponto de verificação ou pelo nome do elemento HTML. Por exemplo, tot[102] corresponde ao número de falhas do ponto de verificação 10.2. O atributo pto também é um array, e cada elemento indica o resultado do teste de cada elemento, que pode ser mal (teste automático falhou), bien (teste automático passou), duda (não pode ser testado automaticamente) e $N A$ (não aplicável).

\subsection{Módulo para cálculo de métricas de acessibilidade}

Após a realização dos estudos sobre a ferramenta, foi feito o projeto para a implementação do módulo para cálculo de acessibilidade a partir da ferramenta Hera 2.0.

Como se tratava de um desenvolvimento bastante pontual, foi feito um projeto simples por meio de um processo de software do tipo cascata, com uma interação. Foram levantados os principais requisitos para o módulo (que não eram atendidos pela versão atual da ferramenta), seguido da adaptação do diagrama de classes, implementação e teste.

\section{- Requisitos}

De forma geral, os principais requisitos do módulo implementado foram: de fornecer auxílio para o cálculo de métricas de acessibilidade a partir de uma ferramenta de avaliação automática; e e de prover funcionalidades para a automatização da avaliação de grandes quantidades de páginas.

\section{Requisitos Funcionais}

RF1. O módulo deve automatizar o cálculo de métricas de acessibilidade a partir de avaliações por revisão de diretrizes do WCAG 1.0 feitas por ferramenta automática.

RF2. O módulo deve automatizar o cálculo de problemas em potencial para cada ponto de verificação das diretrizes do WCAG 1.0, para auxiliar o cálculo de métricas por avaliações manuais.

RF3. O módulo deve fornecer meios para obter diferentes métricas de acessibilidade a partir da mesma avaliação, e em princípio deve implementar as métricas: problemas potenciais, WAB, UWEM, A3 e WAQM.

RF4. O módulo deve fornecer uma interface para ser utilizada por outros programas para a automatização de cálculos de métricas.

RF5. O módulo deve permitir a alteração dos pesos aplicados a cada barreira de acessibilidade.

RF6. O módulo deve permitir a totalização de barreiras por ponto de verificação e totais por diretrizes. 
RF7. O módulo deve permitir a relação entre as diretrizes e os princípios de acessibilidade do WCAG 2.0.

\section{Requisitos Não-Funcionais}

RNF1. O módulo deve ser facilmente extensível para acomodar o cálculo de outras métricas que venham a ser definidas.

RNF2. O módulo deve ter uma baixa complexidade para cálculo das métricas, de modo a não aumentar o tempo necessário para efetuar avaliações inerente à ferramenta.

\section{- Projeto}

A partir dos requisitos elaborados, foi feito o projeto do módulo para cálculo de métricas de acessibilidade por meio da adaptação do projeto da ferramenta Hera 2.0 apresentado na Subseção 5.2. Na Figura 5.3 é apresentado o novo diagrama de classes com a classe Metric, que faz uso das classes Parse e File.

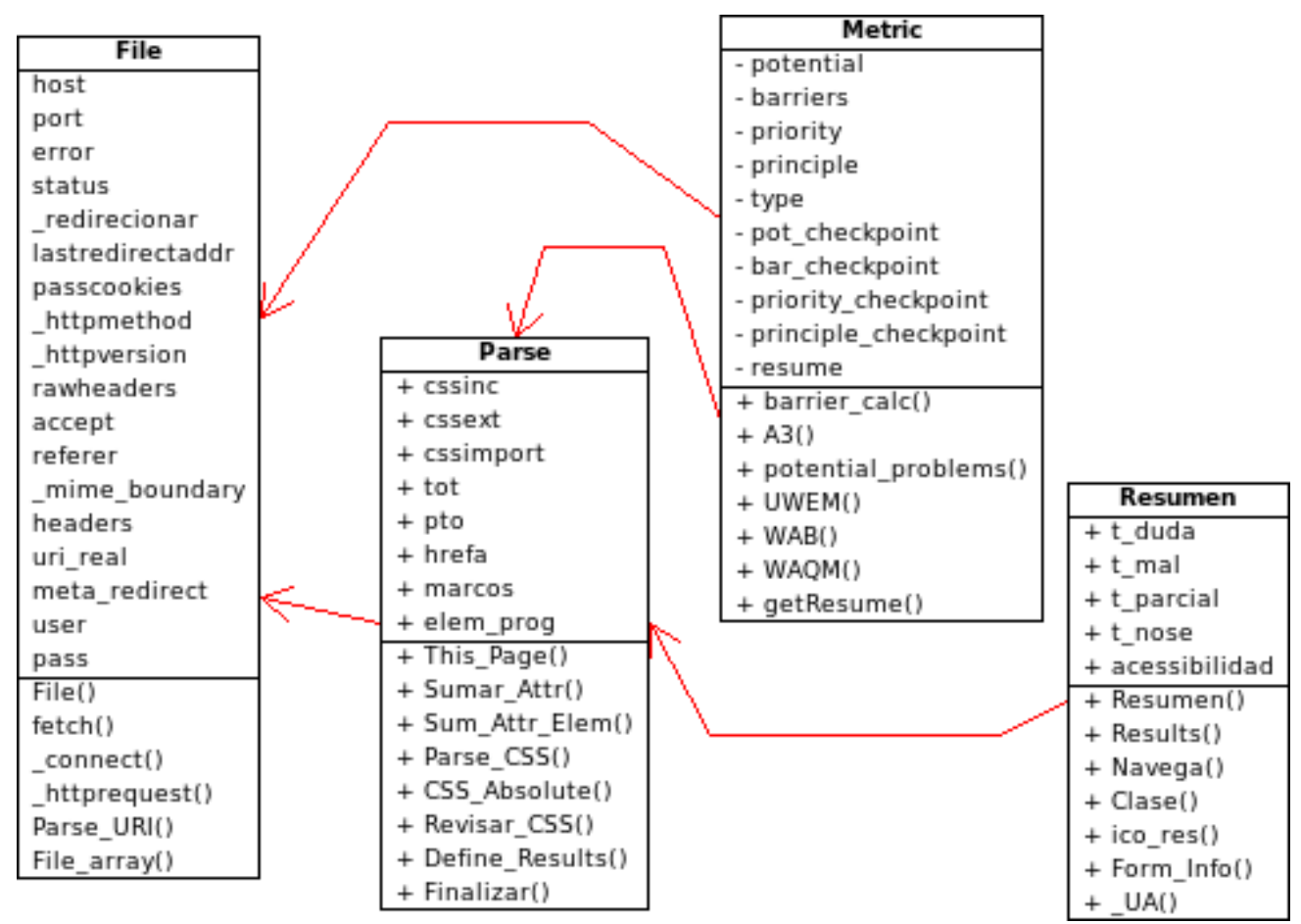

Figura 5.3: Diagrama com as principais classes utilizadas para avaliação na ferramenta Hera 2.0 com o módulo de cálculo de métricas

Os objetos da classe Metric possuem informações referentes aos números relevantes para o cálculo de barreiras em uma dada página. Levou-se em consideração que cada ponto de verificação pode ter mais de um caso de teste relacionado. Assim, foram definidos atributos para armazenar os números para cada caso de teste e os totais para cada ponto de verificação. A seguir, é apresentada uma breve descrição de cada um dos atributos:

url: URL da página avaliada; 
potential: número de problemas em potencial de cada teste;

barriers: número de barreiras de cada teste;

priority: prioridade de cada teste, variando entre 1, 2 ou 3;

principle: princípio de acessibilidade do WCAG 2.0 correspondente (perceivable, operable, understandable, robust);

type: indicação se o teste é avaliado automaticamente ou manualmente;

pot_checkpoint: número de total de problemas em potencial para um ponto de verificação;

bar_checkpoint: número total de barreiras encontradas para um ponto de verificação;

priority_checkpoint: prioridade de um ponto de verificação, variando entre 1, 2 e 3;

principle_checkpoint: princípio de acessibilidade do WCAG 2.0 do ponto de verificação; resume: objeto serializado com o resultado da avaliação obtido por meio da ferramenta Hera.

\section{- Implementação}

A partir do projeto realizado, foi feita a implementação do módulo para cálculo de métricas utilizando a ferramenta Hera 2.0.

A principal tarefa realizada durante a implementação dos métodos identificados foi a de identificar na ferramenta Hera onde eram armazenados os totais de problemas e de elementos encontrados para cada teste.

Para cada teste, deveriam ser totalizados: a) o número de barreiras relevante para ele (obtida por meio do atributo tot da classe parse, indexado pelo número do teste), b) o número de barreiras potenciais (obtida por meio dos elementos relevantes para o teste em tot, indexado pelo nome do elemento), c) a prioridade do teste, d) o princípio do WCAG 2.0 referente ao teste.

A atribuição da prioridade do teste e do princípio do WCAG 2.0 equivalente foi efetuada por meio de uma verificação manual de cada teste e da equivalência entre as diferentes versões do WCAG.

Após a implementação da função para contagem das barreiras e problemas potenciais para cada teste, foram implementados os métodos com os diferentes algoritmos de cálculos das métricas de problemas potenciais, UWEM, A3 e WAQM.

Em cada método, é possível especificar se devem ser considerados somente os testes realizados automaticamente ou se os testes manuais também devem ser considerados, com vistas a auxiliar na geração de relatórios para métricas calculadas manualmente.

\section{- Testes}


Em seguida à implementação, foram realizados testes visando verificar se o módulo funcionava corretamente para casos de avaliações efetuadas automaticamente. Foi implementado um programa que utilizava o módulo e que retornava todas as métricas implementadas.

Foram realizados testes com páginas com problemas de acessibilidade conhecidos, e verificouse se os números gerados para cada caso de teste eram coerentes com os problemas conhecidos. Nesses testes, foram identificados problemas com a identificação do número de problemas em potencial, resultantes da identificação incorreta dos elementos relevantes para cada verificação pela ferramenta. Também foram identificados alguns problemas pontuais em alguns dos algoritmos para cálculo das métricas.

Após a identificação dos problemas, foram realizadas as devidas modificações para correção destes.

Além dos testes funcionais realizados, foram realizados estudos de caso mais elaborados para validação do módulo. Na próxima seção, são apresentados detalhes sobre a realização dos estudos de caso.

\subsection{Estudos de caso: análise da acessibilidade de sítios governamentais brasileiros}

Antes de realizar a avaliação dos sítios informados pelos participantes do levantamento com pessoas envolvidas em projetos de desenvolvimento de sistemas Web, foram realizados estudos de caso visando validar o módulo para cálculo de métricas de acessibilidade desenvolvido.

Foram realizados dois estudos de caso com avaliações automáticas e um terceiro estudo de caso com uma avaliação manual feita por especialistas. Neste terceiro estudo de caso, o módulo foi utilizado para auxiliar na geração dos relatórios para calcular as métricas e identificar os números de problemas em potencial para cada ponto de verificação.

Neste terceiro estudo (Freire et al., 2007d), foram feitas avaliações de páginas de três ferramentas de aprendizado eletrônico: o TIDIA-Ae (Fapesp, 2008), o SAKAI (Fundação Sakai, 2008) e o Moodle (Moodle, 2008). Esta avaliação foi importante para observar como o uso das métricas pode auxiliar na comparação da acessibilidade de diferentes sistemas. O ambiente Moodle foi o que apresentou os menores índices de barreiras. Também foi interessante observar que as métricas A3, UWEM e WAB apresentavam dados bastante concordantes com os resultados obtidos a partir das avaliações realizadas utilizando leitores de tela para cegos. A métrica WAQM, entretanto, apresentou alguns resultados que distoavam dos resultados obtidos pelas outras métricas.

Os outros dois estudos de caso foram realizados com portais governamentais brasileiros utilizando somente avaliação automática com a ferramenta Hera 2.0 por meio da revisão de diretrizes. Esses estudos de caso se aproximam mais do cenário de utilização com grandes volumes de dados, para o qual o módulo foi projetado. 
O primeiro estudo de caso, relatado na Subseção 5.4.1 se refere à avaliação dos sítios dos governos estaduais brasileiros entre 1996 e 2007. O segundo estudo de caso, relatado na Subseção 5.4.2 se refere à avaliação dos sítios dos governos municipais no ano de 2007.

Nesses estudos de caso, somente considerados na avaliação somente os pontos de verificação do WCAG 1.0 que podiam ser avaliados automaticamente. A seguir são enumerados os pontos de verificação considerados. A lista completa com a descrição das diretrizes e pontos de verificação está disponível no Apêndice B.

- Diretriz 1: pontos de verificação 1.1 e 1.5;

- Diretriz 3: pontos de verificação 3.2, 3.3, 3.4 e 3.5;

- Diretriz 4: ponto de verificação 4.3;

- Diretriz 5: ponto de verificação 5.5;

- Diretriz 6: pontos de verificação 6.2, 6.3 e 6.5;

- Diretriz 7: pontos de verificação 7.4 e 7.5;

- Diretriz 9: pontos de verificação 9.5;

- Diretriz 10: pontos de verificação 10.2, 10.4 e 10.5;

- Diretriz 11: pontos de verificação 11.1 e 11.2;

- Diretriz 12: pontos de verificação 12.1, 12.2, 12.3 e 12.4 .

Em todas as avaliações, também foram utilizados os mesmos valores para as constantes utilizadas nas métricas. Para as métricas A3 e UWEM, como ainda não estão definidos valores para os pesos obtidos experimentalmente, foram utilizados valores fixos para os pontos de verificação, de forma que a soma dos pesos atribuídos para todos os pontos de verificação resultassem em um, considerando os diferentes níveis de prioridade. Para pontos de verificação de prioridade 1 , o valor $W_{b}$ foi definido como 0,0236 , para prioridade 2, como 0,0157 e para prioridade 3 , como 0,0079, de forma que a soma de todos os pesos resultasse em 1.

Na métrica WAQM, foram utilizados os mesmos valores definidos por Vigo et al. (2007). O peso $W_{z}=0,80$ foi definido para pontos de verificação de prioridade $1, W_{z}=0,16$ para prioridade 2 e $W_{z}=0,04$ para prioridade 3 .

As métricas de problemas potenciais (Sullivan e Matson, 2000) e métrica para usuários cegos (González et al., 2003) não foram consideradas para as avaliações. Neste trabalho, considerou-se que essas métricas foram muito importantes para a definição de conceitos utilizados em métricas, mas que não apresentavam diretrizes claras para a definição de pesos mais acurados. 


\subsubsection{Acessibilidade nos sítios dos governos estaduais brasileiros de 1996 a 2007}

O primeiro estudo de caso realizado, referente à avaliação dos sítios Web dos governos estaduais brasileiros, teve como principal objetivo verificar a adequação do módulo para cálculo de métricas para avaliações em larga escala e para verificar a adequação das métricas para este tipo de análise.

Além desses objetivos, também foi objetivo a verificação da evolução da acessibilidade desses sítios no período entre 1996 e 2007. Em dezembro de 2004, com a promulgação do Decreto/Lei No. 5.296, estabeleceu-se um prazo de 12 meses para que todos os portais governamentais fossem adequados para acomodar requisitos de acessibilidade. Assim, também foi proposta a verificação da hipótese de que essa determinação tenha sido realmente cumprida ou não no prazo estipulado.

Para recuperar as versões antigas das páginas, foi utilizada a ferramenta Way Back Machine (Internet Arquive, 2008) do Projeto Internet Archive. Neste projeto, foram feitas amostragens de páginas de toda a internet em diferentes dias, desde 1996. Essas páginas foram armazenadas em um servidor para posterior recuperação.

$\mathrm{Na}$ análise, utilizou-se a primeira ocorrência válida do sítio de cada governo estadual de cada ano. Para o ano de 2007, utilizou-se a versão do dia 1 de setembro de 2007, pois até a data da realização, as amostras do ano de 2007 não estavam disponíveis por meio do Way Back Machine.

Para obter métricas de acessibilidade mais precisas, além da avaliação da página principal de cada sítio, também foi feita a avaliação de todas as páginas que se encontravam no nível de hierarquia imediatamente abaixo da página principal. Desta forma, foi feita a avaliação de um total de 1.232 páginas, correspondendo a uma média de 45,63 páginas por sítio. A ferramenta HTTrack (Httrack, 2008) foi utilizada para efetuar a varredura dos links nas páginas e para fazer cópia de todos os arquivos das páginas a serem avaliadas. Esta etapa levou em torno de 10 horas para completar o processamento.

Após efetuar a coleta das páginas por meio do crawler, foi efetuada a avaliação com cálculo de métricas para todas as páginas coletadas a partir das URLs armazenadas em banco de dados MySQL. O tempo total de processamento em torno de 8 horas. A avaliação de cada página levou em torno de 23 segundos.

Nesta seção é apresentado um sumário com os principais dados obtidos apenas com a métrica WAB. Os resultados completos com todas as análises históricas de todas as métricas estão disponíveis no Apêndice D.

A primeira análise efetuada teve o objetivo de verificar o grau de correlação entre as métricas, para analisar a adequação de cada uma delas para as análises. Na Figura 5.4 é apresentado o gráfico de dispersão com os coeficientes de correlação de Pearson para as métricas A3, UWEM, WAB e WAQM gerado por meio do ambiente estatístico R (R Development Core Team, 2007). No quadrante da direita, é apresentado o gráfico de dispersão relacionando as análises dos dados 
referentes às métricas duas a duas, e no quadrante da esquerda é apresentado o coeficiente de correlação correspondente. Por exemplo, o gráfico da primeira linha na terceira coluna é referente ao gráfico de dispersão das métricas A3 e WAB, e o valor na terceira linha na primeira coluna é o coeficiente de correlação correspondente a este gráfico para as duas métricas. Pode-se observar que, de forma geral, as métricas A3, UWEM e WAB têm um índice de correlação alto, o que indica que elas apresentam resultados que estão em concordância. A métrica WAQM, entretanto, apresenta resultados com um índice de correlação baixo, o que indica que ela está em discordância com as demais métricas.

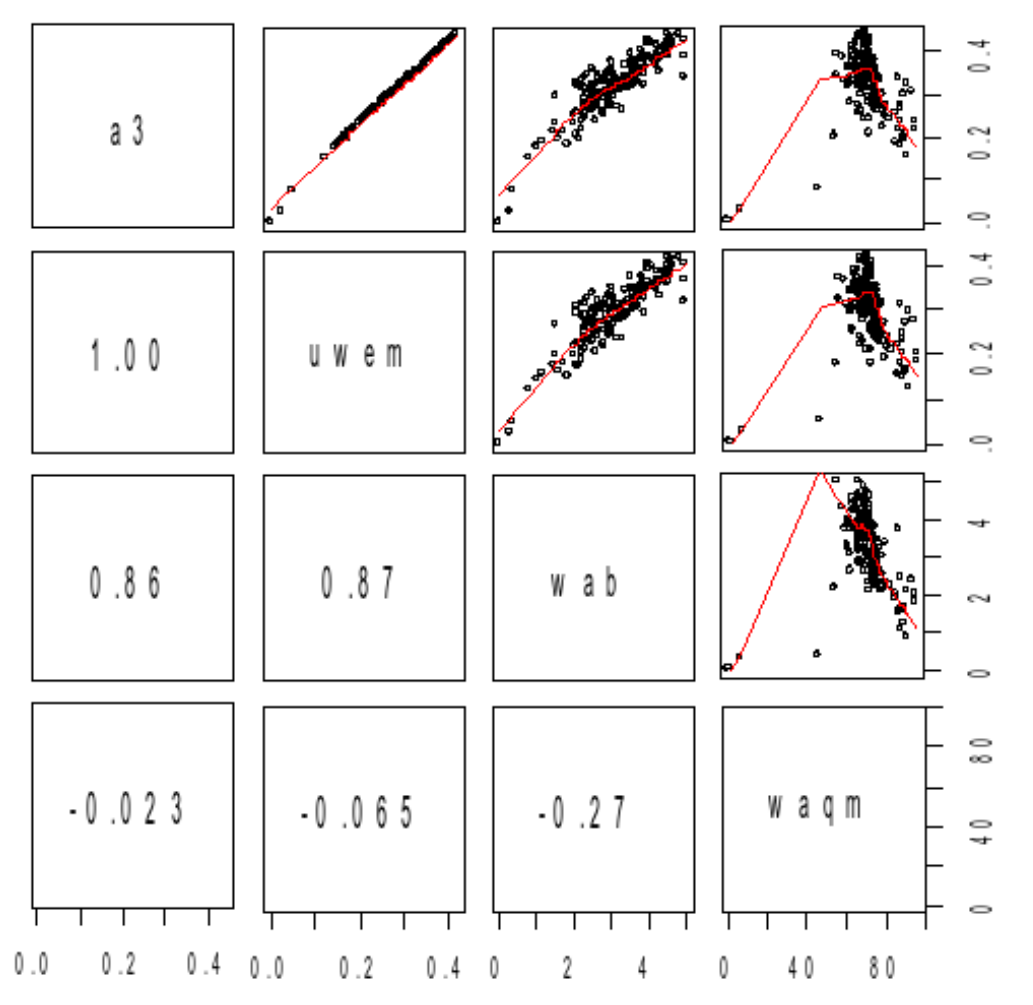

Figura 5.4: Gráfico de dispersão e coeficientes de correlação de Pearson para as diferentes métricas na análise dos sítios dos governos estaduais

Desta forma, optou-se por utilizar a métrica WAB para as análises e comparações, por utilizar pesos baseados nas prioridades dos pontos de verificação e por ser de mais fácil entendimento. As métricas UWEM e A3 são bastante promissoras por permitir o uso de pesos obtidos por meio de experimentos com usuários. Contudo, como esses pesos ainda não estão disponíveis, as métricas não foram escolhidas. Além disso, o modelo matemático utilizado nessas métricas é mais complexo, o que dificulta o entendimento dos resultados.

Na Figura 5.5 é apresentado um gráfico mostrando a relação entre os índices WAB dos sítios Web dos governos estaduais em 2004 (eixo das abcissas) e em 2006 (eixo das ordenadas). Neste gráfico, os estados na parte superior da linha que divide o quadrante correspondem aos estados que tiveram um aumento no índice WAB, e os estados que estão abaixo correspondem a estados que 
tiveram uma diminuição no índice. Assim, verifica-se que, apesar da determinação do Decreto Lei No. 5.296 de 2004, muitos sítios (37\%) pioraram o índice de acessibilidade ao invés de diminuí-lo.

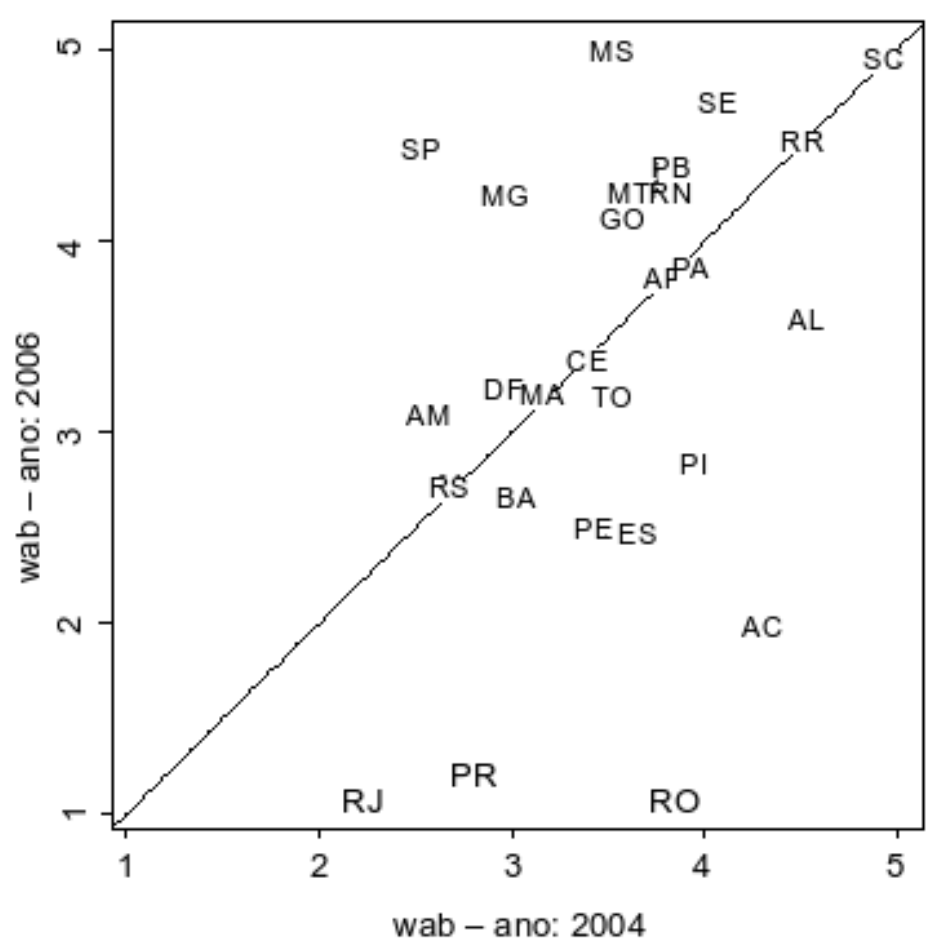

Figura 5.5: Comparação entre os índices WAB dos sítios Web dos governos estaduais entre 2004 e 2006

Com a realização de um teste $t$, verificou-se que também não é possível afirmar, com nível de significância de 5\%, que tenha havido diferenças significativas entre as médias dos índices WAB entre 2004 e 2006 (p-valor $=0,3842$ ).

\subsubsection{Acessibilidade nos sítios das prefeituras municipais brasilei- ras}

A realização dos estudos de caso com os sítios das prefeituras municipais do Brasil (Freire et al., 2008) contou com a utilização de uma outra ferramenta, denominada EGOVMeter (Bittar et al., 2005).

A ferramenta EGOVMeter, desenvolvida em um projeto de mestrado no Departamento de Computação da UFSCar (Bittar, 2006) é um crawler que faz estatísticas periódicas sobre os sítios Web das prefeituras municipais do Brasil.

O procedimento utilizado para a realização desse estudo de caso iniciou com a obtenção da lista de todos os sítios Web das prefeituras encontrados pela ferramenta EGOVMeter. Em seguida, essas URLs seriam foram avaliadas utilizando o módulo Hera metrics, descrito na Subseção 5.3. 
A execução da EGOVMeter em setembro de 2007 foi efetuada a partir de uma lista com 5.551 municípios cadastrados a partir de dados obtidos do IBGE. Desses municípios, 1.980 deles $(37,67 \%)$ tinham um sítio na Web.

Tabela 5.1: Sítios Web dos governos municipais por regiões

\begin{tabular}{|l|l|l|l|}
\hline Região & Mun. & $\begin{array}{l}\text { Mun. } \\
\text { com sítios } \\
\text { Web }\end{array}$ & Percentual \\
\hline Sul & 1188 & 466 & $39.23 \%$ \\
\hline Sudeste & 1668 & 771 & $46.22 \%$ \\
\hline Centro-oeste & 458 & 148 & $32.31 \%$ \\
\hline Nordeste & 1790 & 516 & $28.82 \%$ \\
\hline Norte & 447 & 79 & $17.67 \%$ \\
\hline
\end{tabular}

Os resultados da Tabela 5.1 mostram que as regiões mais desenvolvidas do país (sul e sudeste) têm o maior percentual de municípios com sítios Web.

Da mesma forma que na avaliação dos sítios dos governos estaduais, também foi feita a avaliação das páginas em dois níveis da hierarquia da navegação. Desta forma, foi feita a avaliação de um total de 26.250 páginas, correspondendo a uma média de 13,25 páginas por sítio. A ferramenta HTTrack (Httrack, 2008) foi utilizada para efetuar a varredura dos links nas páginas e para fazer cópia de todos os arquivos das páginas a serem avaliadas. Esta etapa levou em torno de dois dias para completar o processamento.

Em seguida, foram realizadas as avaliações por meio do módulo Hera metrics. Foi feito um programa para efetuar o cálculo das métricas a partir de cada URL armazenada em um banco de dados MySQL. A execução da avaliação sobre as páginas levou em torno de 134 horas (aproximadamente 6 dias). Com esses dados, verifica-se que a execução da avaliação e do cálculo das métricas levou em média 18 segundos por página.

A seguir, são sumarizados os resultados das médias obtidas para cada uma das cinco regiões geográficas do Brasil. Na Tabela 5.2 são apresentados os resultados para a métrica WAB, que não possui limitante superior. Porém, com os pontos de verificação adotados neste trabalho, o valor máximo que poderia ser alcançado é o de 12,5.

Tabela 5.2: Resultados da avaliação dos sítios dos governos municipais com a métrica WAB

\begin{tabular}{|l|c|c|}
\hline Região & Média & Desvio padrão \\
\hline Sul & 2.67 & 1.1 \\
\hline Sudeste & 2.78 & 0.97 \\
\hline Centro-oeste & 3.07 & 0.95 \\
\hline Nordeste & 2.83 & 1.12 \\
\hline Norte & 2.71 & 0.86 \\
\hline
\end{tabular}

Pode-se observar que, na média, os sítios Web dos municípios brasileiros têm um nível alto de barreiras de acessibilidade. 
Os resultados também mostram que não há uma diferença significativa entre as médias dos índices de barreiras das diferentes regiões.

\subsection{Considerações finais}

Neste capítulo, foram apresentadas as principais atividades desenvolvidas e as discussões envolvidas com a construção de um módulo para apoiar o cálculo de métricas de acessibilidade a partir de avaliações automáticas baseadas em diretrizes de acessibilidade.

O desenvolvimento do módulo Hera Metrics foi descrito, desde o trabalho de engenharia reversa da ferramenta Hera 2.0 até os testes realizados com o módulo.

Esse módulo de métricas foi desenvolvido com o intuito de apoiar a realização do levantamento sobre a percepção da acessibilidade por pessoas envolvidas em projeto Web. Entretanto, antes de efetuar o uso do módulo para o seu fim maior, foram realizados dois estudos de caso com a avaliação por meio de métricas de sítios Web de governos estaduais e municipais.

A partir da realização desses estudos de caso, foi possível obter dados interessantes sobre a acessibilidade nos sítios governamentais brasileiros, bem como apontar a falta do cumprimento das determinações da nossa legislação para acessibilidade. Além disso, esses estudos de caso também foram muito importantes para verificar a eficácia do uso de métricas para avaliação de grandes quantidades de dados.

Pelas análises de correlação dos resultados, verificou-se que as métricas A3, UWEM e WAB de forma geral têm comportamentos concordantes, enquanto que a métrica WAQM apresenta alguns resultados que discordam das demais. Por meio dessa análise, optou-se por utilizar a métrica WAB para as análises, pelo fato de ela também ser mais simples de entender e por ela utilizar de maneira mais direta os dados obtidos por meio de avaliações por diretrizes.

No próximo capítulo, são apresentados o procedimento para realização do levantamento com pessoas envolvidas em projeto Web e os resultados deste levantamento. 


\section{Levantamento com pessoas envolvidas em projetos Web no Brasil}

\subsection{Considerações iniciais}

Apesar do reconhecimento da importância da acessibilidade na Web pelos governos de diversos países, por muitas indústrias e instituições de pesquisa, diversos levantamentos recentes mostram que existe um grande número de sítios que apresentam problemas de acessibilidade (Chen et al., 2006) (Hackett et al., 2004) (Goette et al., 2006).

Um dos motivos que tem grande impacto sobre a acessibilidade dos sítios desenvolvidos é a falta de conhecimento sobre acessibilidade pelas pessoas envolvidas em projetos Web. Verifica-se que a maior parte dessas pessoas tem pouco ou nenhum treinamento sobre conceitos e técnicas de acessibilidade.

Neste capítulo, são discutidos os resultados do levantamento efetuado com pessoas envolvidas em projetos Web. Na Seção 6.2 são apresentados os principais conceitos relacionados a pesquisas de levantamento utilizados neste trabalho. Na Seção 6.3 são apresentados trabalhos relacionados. Na Seção 6.4 são apresentados o planejamento do levantamento e a condução do levantamento. Na Seção 6.5 são discutidos os resultados e a análise estatística e, finalmente, na Seção 6.6 são apresentadas as considerações finais deste capítulo. 


\subsection{Pesquisas de levantamento}

O conhecimento sobre detalhes importantes das pesquisas do tipo levantamento foi importante para nortear a metodologia utilizada nesta parte do trabalho.

Segundo Freitas et al. (2000), uma pesquisa tipo levantamento (survey) pode ser descrita como um método para a obtenção de dados ou informações sobre características, ações ou opiniões de determinado grupo de pessoas, indicado como representante de uma população- alvo, por meio de um instrumento de pesquisa, normalmente por meio de um questionário.

As pesquisas do tipo levantamento, segundo Pinsonneault e Kraemer (1993) podem ser explanatórias, quando têm o objetivo de testar uma suposição e as relações causais, exploratórias, quando têm o objetivo de ter um conhecimento inicial sobre um tópico ou descritivas, quando buscam identificar características de uma população sem uma relação de causa.

Em uma pesquisa do tipo de levantamento, o processo de amostragem possui grande influência sobre seus resultados. Esse processo é composto pela definição da população-alvo, pelo contexto de amostragem, pela unidade de amostragem, pelo método de amostragem, pelo tamanho da amostra e pela seleção da amostra ou pela execução do processo de amostragem. Esta amostragem pode ser probabilística ou não probabilística (Freitas et al., 2000).

A amostragem probabilística consiste em garantir que todos os elementos da população tenham a mesma chance de serem escolhidos, o que faz com que essa amostra seja representativa. Já na amostragem não probabilística, é estabelecido algum critério, o que faz com que os resultados não sejam tão generalizáveis quanto em uma amostragem probabilística. Algumas formas de se fazer amostragem não probabilística são: amostragem por conveniência, seleção dos mais similares ou dos mais diferentes, por quotas, bola de neve (os participantes podem indicar novos participantes), casos críticos ou casos típicos (Freitas et al., 2000).

Um outro ponto importante durante a condução de uma pesquisa de levantamento é o instrumento de pesquisa utilizado. O questionário é um dos instrumentos mais utilizados para este tipo de pesquisa. Gil (1991) aponta alguns cuidados a serem tomados durante a elaboração de um questionário:

- Manter o número de perguntas limitado;

- Garantir que questões fechadas cubram todas as possibilidades;

- Considerar as implicações do formato das perguntas na tabulação e análise;

- Não provocar constrangimento nos respondentes;

- As questões devem ter uma única interpretação;

- Considerar a ordem das perguntas, iniciando pelas mais simples até as mais complexas; 
- Observar a apresentação gráfica do questionário;

- Fornecer instruções sobre o correto preenchimento do questionário;

- Descrever objetivamente o objetivo da pesquisa;

- Redigir as questões de forma simples e coesa.

Antes da realização da pesquisa em larga escala, deve-se realizar uma pesquisa piloto, com um conjunto representativo e reduzido de pessoas, para verificar possíveis problemas com o questionário antes que ele seja aplicado.

Um outro aspecto importante a ser considerado em uma pesquisa de levantamento são a confiabilidade e a validade (Mattar, 1996). Segundo Mattar (1996), a confiabilidade se refere a quanto o processo está isento de erros amostrais, e a validade é referente a quanto o processo está isento, simultaneamente, de erros amostrais e não amostrais.

Em relação à validade, deve-se analisar a validade interna e externa. A validade interna se refere às condições de aplicação do instrumento de medição, e a validade externa se refere às condições para generalização (Mattar, 1996).

Finalmente, na etapa de análise dos resultados de uma pesquisa de levantamento, deve-se verificar os tipos de variáveis analisadas e que tipos de estatísticas podem ser aplicadas sobre elas. A análise corresponde a uma etapa de obtenção de estatísticas descritivas sobre os dados (médias, medianas, moda, por exemplo) e uma outra etapa em que se realiza inferências sobre os dados. Para a realização de inferências, podem ser utilizados modelos estatísticos baseados em regressão linear, por exemplo, ou podem ser realizados testes sobre as hipóteses propostas.

\subsection{Trabalhos relacionados}

Alguns estudos têm se dedicado a investigar o conhecimento de pessoas envolvidas com projetos Web sobre acessibilidade e outras questões envolvidas.

Nesta seção, são apresentados alguns dos principais resultados de quatro levantamentos deste tipo encontrados na literatura. Dois estudos foram conduzidos por instituições estrangeiras, uma americana e outra européia. Os outros dois estudos foram realizados por instituições brasileiras, com principal foco no desenvolvimento de sistemas acessíveis por entidades governamentais. Um dos estudos também contou com a realização de páginas desenvolvidas. Contudo, nenhuma avaliação quantitativa com métricas foi apresentada.

Também verificou-se que os estudos também não apresentavam amostragens significativas, dada a natureza específica das análise que se propunham a fazer. Também não foram encontradas nesses estudos análises estatísticas mais refinadas. A maioria deles se restringia a fazer análises descritivas, sem nenhuma inferência.

Nas subseções seguintes, são descritos os principais detalhes e resultados obtidos nos estudos. 


\subsubsection{Levantamento - Lazar et. al (2004)}

O primeiro levantamento reportado foi realizado por Lazar et al. (2004) na Towson University nos Estados Unidos. O trabalho faz parte de uma série de estudos realizados sobre acessibilidade e pesquisas envolvendo usuários com deficiência.

O levantamento foi desenvolvido com questões direcionadas a desenvolvedores e mantenedores de sítios Web sobre seu conhecimento de acessibilidade e sobre sua percepção de quando e porque os sítios devem ou não ser acessíveis. Os participantes foram convidados por meio de listas de e-mails. Não foi utilizada amostragem probabilística.

O questionário continha 15 perguntas, além de outras questões para caracterização da amostra, referentes ao gênero, localização, faixa etária, experiência em computação e área de atuação.

No total, 175 desenvolvedores e webmasters responderam o questionário, dos quais 58,86\% eram homens e $41,14 \%$ eram mulheres. A maioria dos participantes afirmou ser dos Estados Unidos (45\%). Cerca de 49\% dos participantes tinha entre 25-35 anos. Quanto à experiência em computação, $68 \%$ dos participantes afirmaram ser especialistas. Para a questão sobre a área de atuação, 38\% dos participantes responderam que atuam na área de educação, $23 \%$ no setor governamental, $11 \%$ no setor corporativo, $6 \%$ na área da saúde e $22 \%$ em outras áreas.

No tocante ao conhecimento dos participantes sobre acessibilidade e conceitos relacionados, verificou-se que $65,7 \%$ dos participantes afirmaram já ter criado um sítio Web acessível alguma vez; 73,7\% indicaram que são familiares a legislação de acessibilidade como o Section 508; 57,7\% afirmaram que seus sítios Web não estão sujeitos à Section 508; 56\% afirmaram que seus sítios Web eram acessíveis; 78,9\% afirmaram saber da existência de ferramentas para auxiliar a verificação da acessibilidade de sítios, e 69,1\% responderam que já utilizaram uma ferramenta de avaliação via Web; contudo, somente $21,7 \%$ responderam que já haviam utilizado alguma ferramenta de avaliação que não era baseada na Web; somente 38,9\% responderam que já utilizaram a Web com um leitor de tela; $58,8 \%$ responderam que suas organizações têm planos para melhorar a acessibilidade de seus sítios Web.

Sobre a familiaridade com as recomendações do W3C para acessibilidade, 64\% afirmaram serem familiares ao WCAG (W3C, 1999a), menos de 1\% afirmaram ser familiares ao ATAG (W3C, 2000), cerca de $1 \%$ afirmaram ser familiares ao UAAG (W3C, 2002a), e 23\% não eram familiares a nenhum deles.

Quando questionados sobre os principais desafios para tornar sítios Web acessíveis para usuários cegos, os participantes apontaram como principais a conscientização dos clientes, o balanceamento entre acessibilidade e design gráfico, a falta de tempo, a necessidade de treinamento e a necessidade de melhores ferramentas para auxiliar o desenvolvimento.

Nas respostas sobre quem é o responsável por manter um sítio Web acessível, 52\% dos participantes apontaram o Webmaster (mantenedor da página) como responsável pela acessibilidade; o analista de sistemas foi apontado por $30,18 \%$ dos participantes, o programador por $34,9 \%$, o 
gerente de suporte por $10,18 \%$, e o responsável pela gerência de assuntos relacionados a pessoas com deficiência foi apontado por 31,63\% dos participantes.

Os participantes indicaram que os fatores que mais os influcienciariam a tornar o seu sítio Web acessível eram exigências governamentais, a existência de usuários cegos que utilizam o sítio, financiamento externo, direcionamentos de gerência ou de clientes, treinamento sobre acessibilidade, e melhores ferramentas de apoio.

Os participantes foram questionados sobre sua preocupação sobre a acessibilidade no momento de atualizar os seus sítios Web. Das respostas, verificou-se que 37,81\% dos participantes indicaram que consideram acessibilidade quando atualizam seus sítios, 10,18\% dos participantes indicaram que não consideram, e 5,82\% indicaram que tentam considerar, de acordo com limitações como tempo e custo.

O estudo realizado por Lazar et al. (2004) foi bastante interessante e revelou diversas informações importantes sobre o ponto de vista de Webmasters e desenvolvedores de sítios Web. Contudo, verifica-se que o público alvo não foi devidamente direcionado. Um possível viés do estudo é o fato de que a maioria dos participantes que responderam pode ser pessoas interessadas em acessibilidade.

Além disso, a maioria das questões objetivas permitia respostas do tipo "Sim/Não/Não tenho certeza”. O uso de respostas com variáveis aleatórias em escala ordinal poderia proporcionar a realização de análises mais detalhadas sobre o nível de conhecimento dos desenvolvedores sobre questões específicas.

\subsubsection{Levantamento - ENABLED (2005)}

Um outro estudo (ENABLED, 2005) realizado com desenvolvedores de sistemas Web foi realizado pelo grupo ENABLED ${ }^{1}$, formado por universidades, centros de pesquisa e empresas européias.

O questionário foi disponibilizado por meio de um formulário disponibilizado via Web e foi divulgado para participantes do projeto, e pelo boletim da Fundação Health on the Net ${ }^{2}$. O questionário ficou disponível no período de 20 de janeiro a 2 de fevereiro de 2005 . No total, 269 pessoas participaram da pesquisa.

O questionário consistia de 11 perguntas, que envolviam questões sobre o conhecimento dos participantes sobre acessibilidade, ferramentas utilizadas e sobre necessidade de treinamento.

Cerca de $87 \%$ dos participantes eram oriundos de países europeus ou da América do Norte. Quanto à area de atuação, as respostas com maior número de indicações foram a) desenvolvedor Web/ webmaster (29\%), b) área não especificada (29\%), c) gerência $(21,9 \%)$ e d) edição de conteúdo $(7,8 \%)$. O valor alto de pessoas que indicaram ser de "área não especificada" também é um indício de falhas no planejamento do questionário.

\footnotetext{
${ }^{1}$ Enhanced Network Accessibility for the Blind and Visually Impaired - http://www.enabledweb.org

${ }^{2}$ http://www.hon.ch/
} 
Aproximadamente 36\% dos participantes afirmam tentar tornar seus sítios Web acessíveis. Os principais motivos apontados pelos participantes que responderam de forma negativa à pergunta foram a falta de conhecimento sobre diretrizes de acessibilidade, falta de conhecimento técnico e falta de tempo.

Também verificou-se que 51\% dos participantes tentam se preocupar com a usabilidade dos seus sítios Web. Os participantes que responderam negativamente apontam como principais motivos para não se atender aos princípios de usabilidade a falta de conhecimento técnico, a falta de tempo e a falta de conhecimento sobre usabilidade.

Cerca de $63 \%$ dos participantes utilizam ferramentas para apoiar o desenvolvimento. Dentre as ferramentas indicadas, as ferramentas mais mencionadas foram DreamWeaver e FrontPage. As linguagens mais utilizadas são HTML/CSS, PHP e ASP. Verificou-se que $41 \%$ dos participantes afirmam ter um nível médio de habilidade de programação, e 37\% declararam ter um nível alto.

Quanto à qualificação, verificou-se que apenas $13 \%$ dos participantes receberam algum treinamento. As principais fontes de treinamento apontadas foram a própria Internet, escola ou universidade e amigos com conhecimento sobre o assunto. Verificou-se também que $74 \%$ dos participantes gostariam de receber treinamento.

Os principais tópicos que os participantes gostariam que fossem cobertos em cursos ministrados foram sobre o Web Accessibility Initiative (WAI), do W3C, diretrizes para construir sítios acessíveis, usabilidade, e teste de acessibilidade. Verificou-se que os participantes têm grande interesse em todos os tópicos listados no questionário (diretrizes de acessibilidade, usabilidade, apresentação do WAI, relação entre usabilidade e acessibilidade, teste de acessibilidade, e aspectos legais).

Os resultados obtidos na análise efetuada pelo grupo ENABLED (ENABLED, 2005) mostram um grupo de desenvolvedores com um perfil diferente daquele mostrado por Lazar et al. (2004). A porcentagem de desenvolvedores que conhecem acessibilidade é menor do que no outro estudo. Verifica-se que há indícios de que existam diferenças entre os tipos de participantes nos dois estudos.

Sob o ponto de vista metodológico, também verifica-se que o estudo não abordou as questões de acessibilidade de maneira exaustiva. Não foram abordadas questões sobre o conhecimento de legislação de acessibilidade, e em outras técnicas de avaliação e projeto de sítios Web acessíveis. Da mesma forma como no estudo de Lazar et al. (2004), não foram usadas escalas ordinais para classificar o nível de conhecimento dos desenvolvedores sobre os tópicos listados no questionário.

Também observa-se que foram abordadas muitas questões sobre treinamento e necessidades de treinamento. Isso se deve ao fato de que o objetivo principal do grupo não era de traçar um perfil dos desenvolvedores, mas de obter informações específicas relevantes para as atividades do projeto. Dentre as atividades, o grupo ENABLED fornece treinamentos via Web sobre acessibilidade e outros temas abordados pelo grupo. 


\subsubsection{Levantamento - Ferreira et. al (2007)}

Ferreira et al. (2007), em um estudo realizado pela Unirio, conduziram um levantamento com instituições governamentais brasileiras visando verificar se elas conduzem algum projeto para adequação de seus sítios Web a requisitos de acessibilidade. O principal objetivo do levantamento foi de verificar a adequação dos órgãos públicos às recomendações do Decreto Lei No. 5.296/2004 e outras questões sobre a acessibilidade. Este estudo também contou com a avaliação por estudos de caso com usuários com deficiência visual e avaliação automática de sítios governamentais (federais, estaduais e municipais) com a ferramenta daSilva (Acessibilidade Brasil, 2007).

$\mathrm{Na}$ avaliação automática foram verificados 351 sítios Web da administração pública em três momentos: novembro de 2005 (um mês antes de encerrar o prazo para adaptação), em março de 2006 e março de 2007. No primeiro teste, somente cinco sítios estavam totalmente em conformidade com o WCAG e quatro com o e-MAG. No teste realizado em março de 2006, apenas um sítio estava totalmente em conformidade. No terceiro teste, em março de 2007, verificou-se que 22 sítios estavam em conformidade com o WCAG e 23 com o e-MAG.

$\mathrm{Na}$ etapa de levantamento com os responsáveis pelos sítios, foi enviado um questionário para cada uma das organizações públicas selecionadas, e 87 delas responderam à pesquisa. O questionário foi dividido em duas partes: uma primeira parte geral, e uma segunda parte que variava de acordo com a resposta dada pelo participante sobre o estágio de adequação da acessibilidade de seu sítio.

Da primeira parte, verificou-se que 69\% dos participantes afirmaram conhecer o Decreto Lei No. 5.296/2004, 53\% afirmaram conhecer sobre o prazo para adaptação dos sítios e $42 \%$ afirmaram conhecer o e-MAG.

Da análise das organizações que afirmaram já ter adaptado seus sítios de acordo com as diretrizes de acessibilidade ( $22 \%$ do total), verificou-se que $47 \%$ delas não exibem o selo da acessibilidade Brasil. Quanto à forma de condução do processo de adaptação, $42 \%$ responderam que foi uma equipe da própria organização, $37 \%$ por uma equipe terceirizada e $21 \%$ afirmaram ter feito de outras formas. As maiores dificuldades que essas organizações afirmaram ter encontrado durante esse processo foram: conteúdo do sítio muito grande (47\%) e falta de pessoal da organização especializado (32\%). Cerca de $47 \%$ das organizações afirmou ter realizado avaliações com usuário com necessidades especiais. Um total de $21 \%$ dos respondentes afirmou ter tido dificuldades para manter a acessibilidade nas atualizações, enquanto $21 \%$ afirmou não ter tido dificuldades e $58 \%$ não souberam responder.

Das organizações que afirmaram estar com o processo de adaptação em andamento (31\% dos participantes), observou-se que $64 \%$ afirmaram ter uma equipe da organização nomeada para realizar as adaptações, enquanto $18 \%$ afirmaram ter uma equipe terceirizada e $18 \%$ afirmaram usar de outros meios. As maiores dificuldades para efetuar as adaptações de acessibilidade apontadas pelas organizações foram: a baixa prioridade da acessibilidade nos projetos (30\%), conteúdo do 
sítio muito grande (30\%), falta de pessoal especializado (11\%) e a grande quantidade de padrões a ser alterados $(11 \%)$.

Quanto às organizações que afirmaram não ter seus sítios acessíveis (47\%), verificou-se que $68 \%$ delas não têm previsão para iniciar as adaptações para acessibilidade. Quando perguntadas sobre o conhecimento sobre o avaliador daSilva, 83\% dos respondentes afirmaram não conhecêlo. As maiores barreiras apontadas para iniciar a adaptação dos sítios foram: a baixa prioridade da acessibilidade nos projetos (24\%), falta de pessoal especializado na organização (22\%), conteúdo do sítio muito grande (10\%), e outros motivos, como o desconhecimento do decreto, falta de conscientização da gerência, entre outros.

O levantamento realizado por Ferreira et al. (2007) apresenta resultados bastante interessantes sobre o panorama da acessibilidade no Brasil. Contudo, o público-alvo do estudo se restringiu a organizações governamentais. Além disso, apesar de os autores terem realizado avaliações dos sítios, não foi feita nenhuma associação entre os resultados do questionário e das avaliações.

\subsubsection{Levantamento - Tangarife (2007)}

Em outro trabalho, realizado no mestrado de Tangarife (2007) na PUC-Rio, foi realizado um estudo com a participação de 68 profissionais envolvidos com desenvolvimento de sítios Web, no período entre 20 e 30 de maio de 2005, por meio de um questionário disponibilizado via Web. Também não foi feita amostragem probabilística. O convite foi enviado a 70 participantes selecionados pelo autor.

O questionário com 30 questões foi dividido em oito partes (Tangarife e Mont'alvão, 2006): 1) questões sobre o perfil do usuário, 2) experiência com desenvolvimento de sítios Web e opinião sobre a necessidade de garantir acessibilidade, 3) conceitos sobre acessibilidade e usabilidade, 4) desenvolvimento considerando legislação de acessibilidade, 5) consideração da acessibilidade nos projetos de que participa, 6) postura em relação à posição da empresa sobre acessibilidade e em relação à cartilha técnica do e-MAG, 7) responsabilidade sobre a acessibilidade no desenvolvimento de sítios e 8) questão aberta sobre os motivos que levam a tornar um sítio acessível.

Os resultados aqui reportados consistem em um resumo dos dados disponíveis em Tangarife e Mont'alvão (2006) e Tangarife (2007). Os participantes eram na maioria homens (75\%), cerca de $61,7 \%$ tinham entre 25 e 35 anos. A maioria era da área governamental (57,35\%). Os participantes ocupavam cargos de: analista de sistemas (41,18\%), programador $(25,00 \%)$ e Web designer $(20,59 \%)$. Verificou-se que $75 \%$ dos participantes trabalham há mais de 5 anos com desenvolvimento de sítios Web. Quanto à experiência, 44,11\% consideram-se especialistas, 47,1\% de nível intermediário $8,9 \%$ iniciantes. A grande maioria $(83,82 \%)$ também afirma que considera muito importante que um sítio possa ser acessado por qualquer pessoa.

$\mathrm{Na}$ terceira parte, de forma geral, boa parte dos participantes tinham uma compreensão correta sobre usabilidade e acessibilidade. Contudo, $94,11 \%$ dos participantes afirmaram nunca ter 
participado de um projeto que envolvia acessibilidade. O conhecimento sobre legislação de acessibilidade também foi identificado como bastante baixo, cerca de 82,35\% não conhecem a Section 508 e $81 \%$ não conhecem o Decreto Lei No. 5.296/2004. Cerca de $80 \%$ também não têm certeza se o sítio que desenvolvem é acessível. Aproximadamente $49 \%$ conhecem ferramentas de avaliação de acessibilidade, mas somente cerca de $18 \%$ afirmam utilizá-las. Somente 8,9\% afirmaram já ter avaliado um sítio com um leitor de tela.

Quanto à consideração da acessibilidade nas empresas, cerca de 3\% afirmaram que a organização sempre levou em conta, $31 \%$ que atualmente leva em consideração e $66 \%$ que nunca levou em consideração. Os principais motivos apontados para não levar em conta foram: orçamento $(32,35 \%)$, falta de especialistas no assunto $(32,35 \%)$, tempo $(27,94 \%)$ e desconhecimento do assunto pela gerência $(26,47 \%)$.

Do conhecimento de diretrizes, somente $16,17 \%$ afirmaram ter familiaridade com o WCAG (W3C, 1999a), 13,23\% com o ATAG (W3C, 2000) e 7,35\% com o UUAG. Uma porcentagem de $86,76 \%$ afirmou nunca ter lido a cartilha técnica do e-MAG (Governo Brasileiro, 2008).

Nesse estudo, não foi feita nenhuma análise comparando a acessibilidade das páginas desenvolvidas com as respostas atribuídas. Também só foi feita uma análise descritiva dos resultados.

\subsection{Planejamento e condução do levantamento}

Antes de iniciar a condução do levantamento sobre acessibilidade, foi efetuado um planejamento para a realização da pesquisa. O principal objetivo do levantamento foi o de verificar o perfil de pessoas envolvidas em projetos de sistemas Web no Brasil sobre questões de acessibilidade.

De acordo com a classificação discutida na Seção 6.2, esta pesquisa pode se configurar como uma pesquisa com características de explanatória e de descritiva. O objetivo da pesquisa é de coletar informações sobre como as pessoas envolvidas em projetos Web compreendem certos conceitos de acessibilidade, e de fazer inferências sobre a influência dos fatores analisados, a consideração efetiva da acessibilidade em seus projetos e sobre índice de barreiras de sítios Web produzidos nos projetos dos participantes.

\section{Instrumento de pesquisa: questionário}

Na elaboração do questionário, buscou-se incluir questões que englobassem diferentes aspectos da acessibilidade, envolvendo tanto aspectos técnicos quanto aspectos organizacionais.

No início do projeto, tinha-se a intenção de investigar sobre o uso de novas técnicas encontradas na literatura na prática por meio deste questionário. Entretanto, como pôde-se verificar no levantamento de técnicas para acessibilidade encontradas na literatura, reportado no Capítulo 3, um grande número de técnicas foram propostas muito recentemente, e poucas delas têm relatos de 
aplicação na prática. Além disso, a partir da análise de outros trabalhos relacionados, verifica-se que muitas das técnicas mais simples ainda não são utilizadas na prática. Desta forma, optou-se por investigar somente sobre o uso de diretrizes e técnicas de avaliação mais consolidadas, ao invés de investigar sobre o uso de técnicas do estado da arte.

O desenvolvimento do questionário foi feito em duas etapas. Primeiramente foi desenvolvido um questionário preliminar para ser utilizado no estudo piloto, e em seguida foram corrigidos os problemas apontados pelos participantes do estudo piloto.

A versão final do questionário está disponível na íntegra no Apêndice F.

O questionário possuia 17 questões: 6 questões sobre dados demográficos, 9 questões fechadas e 2 questões abertas. O conjunto de questões fechadas foi dividido em duas partes: uma parte com questões gerais sobre acessibilidade e uma outra com questões sobre os motivos porque a acessibilidade é considerada ou não nos projetos em que participam.

Nas questões demográficas, foram incluídas questões sobre o estado de residência, gênero, faixa etária, área de atuação, formação acadêmica e função na organização em que atua.

Nas questões fechadas, foram incluídas questões sobre o conhecimento das linguagens HTML e CSS, conhecimento sobre a forma como pessoas com deficiência visual utilizam a Web, conhecimento sobre tecnologias assistivas, conhecimento sobre a legislação brasileira de acessibilidade, uso de técnicas para avaliação de acessibilidade, consideração da acessibilidade nos projetos em que participa, e os motivos para considerar ou não a acessibilidade.

Nas questões abertas, pediu-se que os participantes descrevessem qual a importância da acessibilidade nos projetos Web de sua organização e para que dessem sugestões sobre como melhorar a acessibilidade na Web no contexto brasileiro. Também foi pedido que os participantes indicassem, opcionalmente, algumas URLs de sítios Web que tivessem participado de alguma etapa do desenvolvimento.

No final do questionário, havia uma opção para que os usuários marcassem atestando que os dados podem ser utilizados para a pesquisa, e também informando sobre a confidencialidade dos mesmos.

Houve uma grande preocupação com o tamanho do questionário, para que fossem incluídas somente questões realmente relevantes.

Após a conclusão da primeira versão do questionário, foi feito um estudo piloto com dez participantes, sendo cinco do meio acadêmico, três profissionais da indústria de software e dois analistas que atuam em órgãos públicos. Das observações dos respondentes do estudo piloto que o fizeram na presença do pesquisador, verificou-se que o preenchimento do questionário levava em torno de 10 minutos.

Este questionário foi enviado por e-mail e as respostas não foram consideradas nas análises posteriormente. Os participantes do estudo piloto apontaram importantes contribuições para melhorar o entendimento de algumas questões que estavam dúbias e apontaram alguns problemas com 
a completude de algumas respostas das questões fechadas. Também foram apontados problemas com questões que poderiam gerar constrangimento para os participantes.

Após a modificação do questionário a partir das sugestões obtidas com o estudo piloto, foi desenvolvida uma versão do questionário que foi disponibilizada via Web. Tomou-se o devido cuidado para que este questionário tivesse boa usabilidade e fosse acessível para pessoas com diferentes habilidades.

\section{Amostragem}

Na pesquisa realizada, não foi utilizada a amostragem probabilística. Para aumentar a representatividade do estudo, teve-se como objetivo selecionar participantes de forma a ter representação de todos os estados do país. Também foi objetivo diversificar as áreas de atuação dos participantes, com participantes da academia, da indústria e de órgãos governamentais.

A seleção dos participantes foi feita de forma que houvesse um número aproximado de participantes das três áreas de atuação. Também foi tomado o devido cuidado para que houvessem representantes de todos os estados de cada uma das áreas.

Para a seleção de participantes da indústria, foi utilizado o catálogo de empresas da Softex ${ }^{3}$, buscando por empresas que atuassem na área de desenvolvimento Web e outros tipos de sistemas comumente disponibilizadas via Web, como comércio eletrônico e aprendizado eletrônico. Também foram utilizados outros catálogos locais para aumentar a representação de outros estados. No total, foram cadastrados 1.041 participantes de empresas de software ou de design.

Na seleção de participantes do governo, foi armazenado o endereço de contato de mantenedores de sítios governamentais. O processo de seleção foi bastante demorado, pois foi necessário visitar diversos sítios e buscar pelo endereço de contato do mantenedor. Foram visitados sítios ligados ao governo federal, como ministérios, agências, e órgãos ligados a governos estaduais e municipais das prefeituras das capitais. Um total de 514 endereços foram cadastrados por este método.

Além do cadastro de e-mails consultados manualmente, também foram enviados e-mails para o endereço webmaster dos domínios das prefeituras cujos sítios foram avaliados no estudo de caso reportado na Seção 5.4. Foram cadastrados 1.980 endereços por este método.

Para a seleção de participantes da academia, foi utilizado o Portal Inovação ${ }^{4}$. Este portal fornece uma interface para fazer buscas mais detalhadas sobre a base de dados da plataforma Lattes $^{5}$. Foi efetuada uma busca por pesquisadores com as palavras chave "desenvolvimento Web". Com esta palavra chave mais ampla, esperava-se incluir pesquisadores que trabalhassem com Web, mas que não necessariamente fossem pesquisadores sobre acessibilidade e áreas afins, para não criar viés nos resultados. Foi feito um filtro por estado, de forma a selecionar os 200, 150, 100 ou 50 primeiros resultados de cada estado, de acordo com a proporção populacional de cada um deles. Foram selecionados 1.349 pesquisadores para a pesquisa.

\footnotetext{
${ }^{3}$ Softex - Programa de Exportação de Software Brasileiro, disponível em http://www.softex.br

${ }^{4}$ Disponível em http://portalinovacao.mct.gov.br

${ }^{5}$ Cadastro nacional de pesquisadores brasileiros, mantido pelo CNPq e disponível em http://lattes.cnpq.br
} 
Os convites para os participantes foram enviados por e-mail, a partir dos dados cadastrados na base de dados. Contudo, os participantes também poderiam enviar o convite para outras pessoas mais indicadas ou interessadas na pesquisa (amostragem bola de neve).

\section{Condução do levantamento}

Após efetuar a seleção dos participantes e implementar o sistema para suporte ao preenchimento do questionário via Web, foram enviados e-mails com o convite para participação para todos os endereços cadastrados.

O e-mail foi elaborado de forma a explicar do que se tratava a pesquisa e dava instruções sobre como participar. Os e-mails foram enviados por meio de um sistema utilizando o servidor de email do ICMC/USP e a conta de e-mail do próprio aluno. Os e-mails eram enviados com espaços de tempo suficientemente grandes para que não fossem considerados spam (e-mails enviados em massa).

Do total de 4.804 e-mails enviados, estima-se que não foram entregues com sucesso os e-mails enviados para cerca de $20 \%$ dos participantes de empresas, cerca de $65 \%$ dos e-mails enviados para órgãos governamentais e 15\% dos e-mails enviados para pesquisadores. O grande número de e-mails com problemas para os órgãos governamentais se deve à utilização da base de domínios de prefeituras combinado com o usuáriowebmaster@. Desta forma, estima-se que em torno de 2.800 e-mails tenham sido enviados com sucesso.

O questionário ficou disponível para preenchimento entre 25 de junho de 2007 e 25 de Agosto de 2007. Tendo em vista que foram obtidas 613 respostas válidas, verifica-se que a taxa de retorno foi de aproximadamente $22 \%$, que é próxima da taxa de $25 \%$, apontada como usual em pesquisas deste tipo (Mattar, 1996).

Quando se encerrou o período para resposta ao questionário, foram efetuadas as avaliações automáticas dos sítios indicados pelos participantes com o apoio de métricas.

Foi utilizado o módulo Hera metrics para auxiliar no processo de avaliação. Da mesma forma como nos estudos de caso reportados na Seção 5.4, para cada sítio foi avaliada sua página inicial mais as páginas no nível imediatamente inferior da estrutura navegacional. No total foram avaliados 382 URLs, de um total de 181 participantes que indicaram pelo menos uma URL. O número total de páginas avaliadas foi de 8.059 .

Como muitos participantes indicaram mais de uma URL, para efeitos estatísticos era considerada a URL cuja avaliação tivesse resultado o menor índice de barreiras de acordo com a métrica WAB.

Os resultados da avaliação automática foram enviados para os participantes por e-mail, juntamente com os resultados das análises descritivas do resultado da pesquisa. 


\subsection{Resultados do levantamento}

Após a conclusão da etapa de coleta de dados, foi obtido um total de 630 questionários respondidos, dos quais 613 foram considerados válidos. Apesar de terem sido enviados convites para os participantes, o questionário era de acesso irrestrito, para permitir que esses participantes pudessem convidar outras pessoas. Pelo fato de o questionário ser de acesso irrestrito, muitas respostas inválidas foram recebidas. Essas respostas se referiam tanto a preenchimento incorreto, quanto à participação de pessoas que não se enquadravam no perfil esperado de participantes.

O número de questionários válidos é considerado bastante representativo, e posiciona esta pesquisa como a mais abrangente em número de participantes em comparação com outros trabalhos semelhantes encontrados na literatura até o momento, reportados na Seção 6.3.

A análise dos resultados do questionário foi feita em duas etapas. Primeiramente foi realizada uma análise descritiva dos dados, com uma visão individual sobre cada questão do questionário. Os resultados desta etapa são descritos na Subseção 6.5.1. Na segunda etapa, foi realizada uma modelagem estatística dos dados, com o objetivo de fazer inferências sobre os dados. Os resultados das inferências estão descritos na Subseção 6.5.2. A descrição detalhada dos modelos estatísticos está apresentada no Apêndice G. Na Subseção 6.5.3 são apresentadas as discussões referentes à validade do estudo.

\subsubsection{Análise descritiva}

Nesta seção, é apresentado um sumário com as principais observações a partir da análise dos dados obtidos por meio dos questionários. Os resultados da análise descritiva foram enviados para todos os participantes do levantamento, e também foram disponibilizados via Web no endereço http://safe.icmc.usp.br/pesquisaacessibilidade.

\section{Dados demográficos}

No levantamento realizado houve representação de todos os estados do Brasil. De forma geral, apesar da tentativa de distribuir os participantes entre as regiões, o maior número de participantes era advindo da região sudeste. Cerca de $41,8 \%$ dos participantes eram desta região, enquanto $21,7 \%$ eram do sul, $17,8 \%$ do nordeste, $10,3 \%$ do centro-oeste e $8,5 \%$ do norte, como pode ser observado no gráfico da Figura 6.1. De certa forma, a distribuição está em acordo com a distribuição de especialistas na área pelo país.

Referente ao perfil pessoal, verificou-se que a maioria dos participantes eram do gênero masculino $(70,15 \%)$, com $28,55 \%$ de mulheres e $1,31 \%$ sem reposta. A faixa etária com o maior número de participantes foi a de 25 a 35 anos, com $41,76 \%$ dos participantes, seguida da faixa de 36 a 45 anos, com 26,26\%, como pode ser observado no gráfico da Figura 6.2. 


\section{Distribuição geográfica dos participantes}

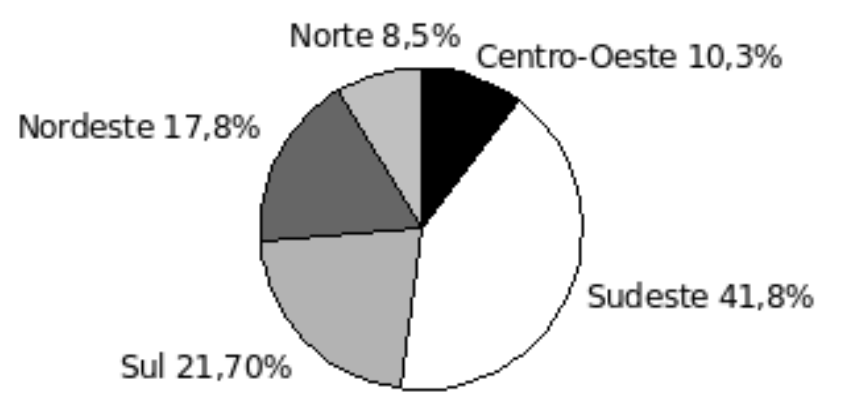

Figura 6.1: Participantes do levantamento de acordo com as regiões do país

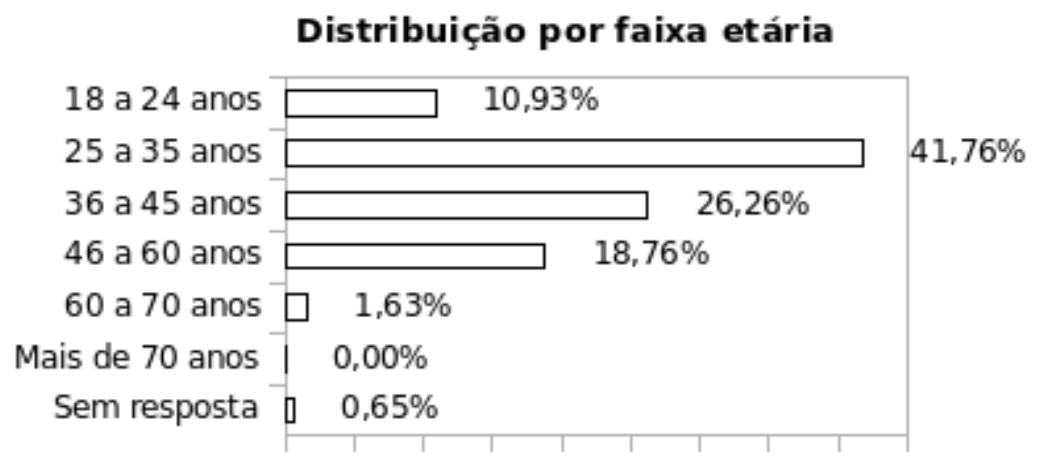

Figura 6.2: Participantes do levantamento de acordo com a faixa etária

Da mesma forma que na distribuição geográfica, apesar da tentativa de se distribuir os participantes entre as diferentes áreas: - indústria, academia e governo - a maioria dos participantes eram oriundos das áreas de ensino e pesquisa $(56,12 \%)$, como pode ser verificado no gráfico na Figura 6.3. Uma das possíveis explicações para este fato é que normalmente pesquisadores e docentes têm maior receptividade para participar em trabalhos de pesquisa.

\section{Distribuição por área de atuação}

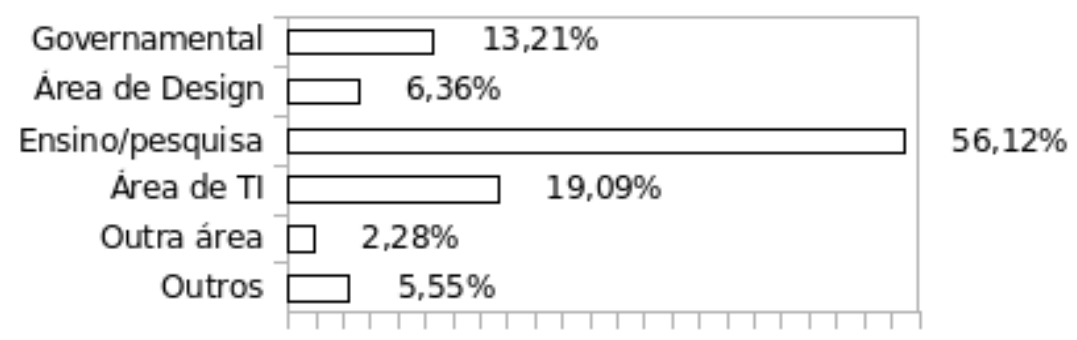

Figura 6.3: Participantes do levantamento de acordo com a área de atuação

A grande representatividade de pessoas do meio acadêmico também pôde ser verificada pela formação dos participantes, com 30,67\% deles com formação em nível de doutorado, 23,49\% com mestrado, e 16,15\% com especialização, como pode ser verificado na Figura 6.4. O mesmo vale para a função exercida, em que se verificou que $43,07 \%$ dos participantes afirmaram ser pes- 
quisadores ou docentes. As demais funções com maior representatividade foram as de analista $(12,40 \%)$, gerente $(10,28 \%)$ e coordenador $(8,65 \%)$, como pode ser verificado na Figura 6.5 .

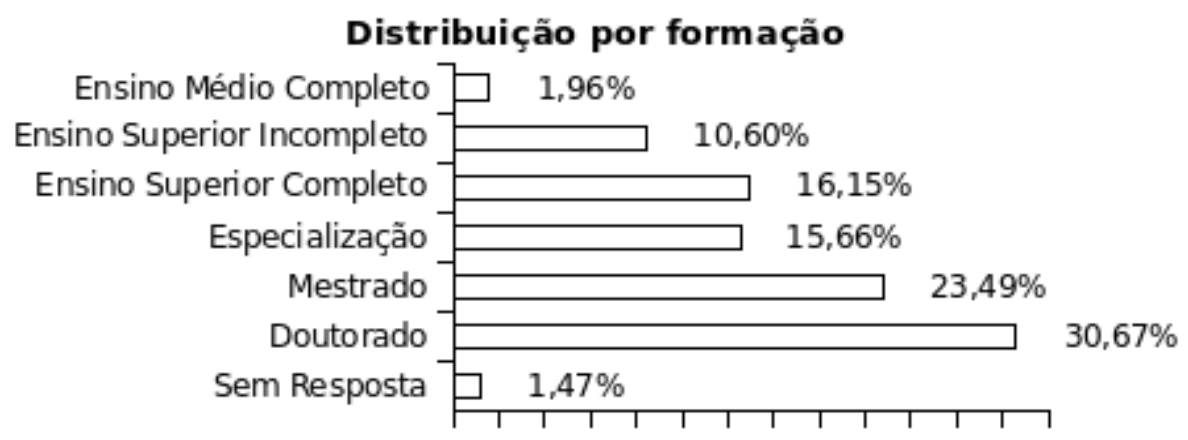

Figura 6.4: Participantes do levantamento de acordo com a formação

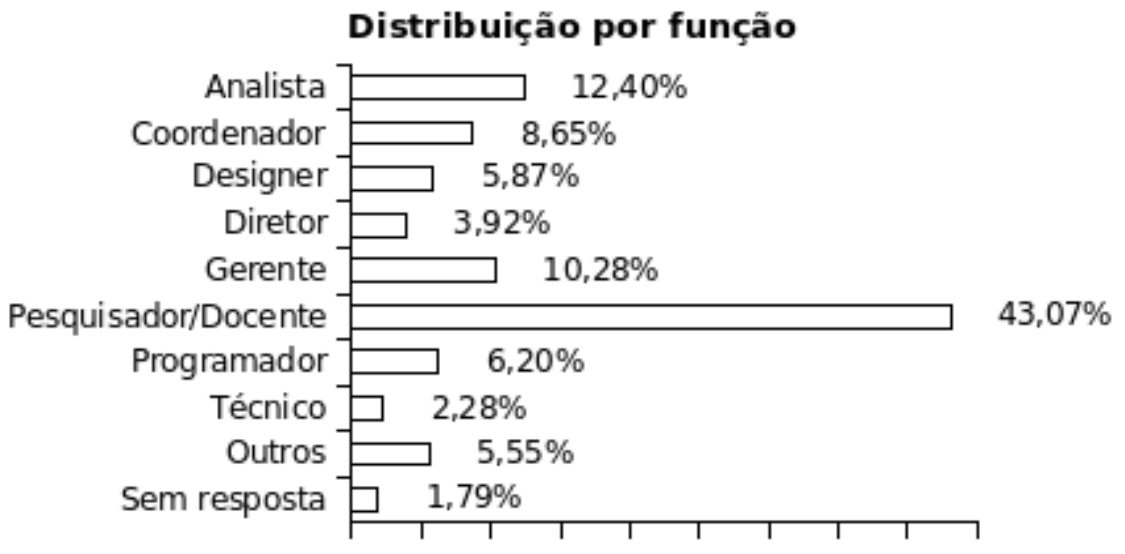

Figura 6.5: Distribuição dos participantes do levantamento de acordo com as funções exercidas em suas organizações

O grande número de participantes da indústria com cargos de gerência ou coordenação pode ser atribuído ao fato de que os e-mails de contato fornecidos nos catálogos geralmente eram de gerentes.

\section{Análise das questões}

\section{Conhecimento sobre as linguagens HTML e folhas de estilo CSS}

Foi observado que a maioria dos participantes afirmou possuir conhecimento básico $(23,33 \%)$, intermediário $(30,02 \%)$ ou avançado $(30,83 \%)$ sobre as linguagens de marcação e de estilo mais populares utilizadas na Web, como pode ser verificado no gráfico da Figura 6.6.

\section{Consciência sobre os problemas enfrentados por usuários cegos ao utilizar a internet}

$\mathrm{Na}$ análise da questão 2, verificou-se que poucos participantes afirmaram já terem feito alguma página acessível para usuários cegos alguma vez. Como pode ser observado no gráfico da Figura 


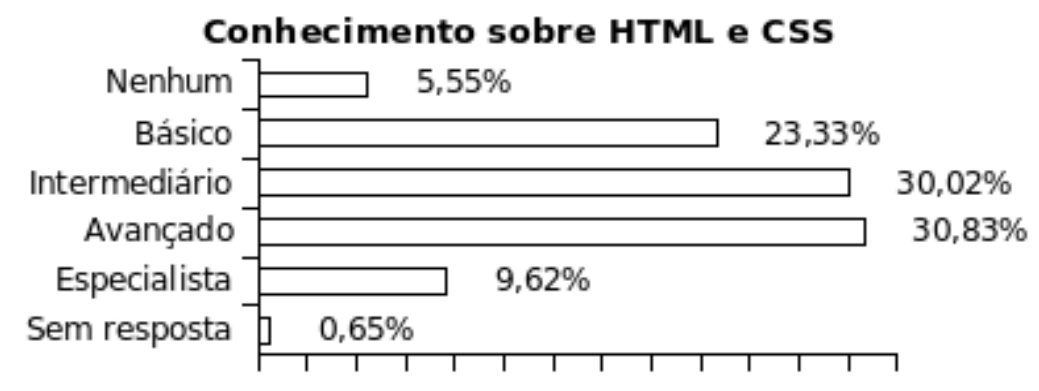

Figura 6.6: Conhecimento dos participantes do levantamento sobre linguagem de marcação e de estilo

6.7, um grande número de participantes $(45,19 \%)$ afirmou que conhece tecnologias para permitir o uso da Web por cegos, mas que não sabe como criar páginas acessíveis para eles. Um número bastante expressivo $(27,57 \%)$ afirmou que já ouviu falar sobre o uso da Web por cegos, mas não sabe por que meios isso é possível.

\section{Conhecimento sobre como cegos usam a Web}

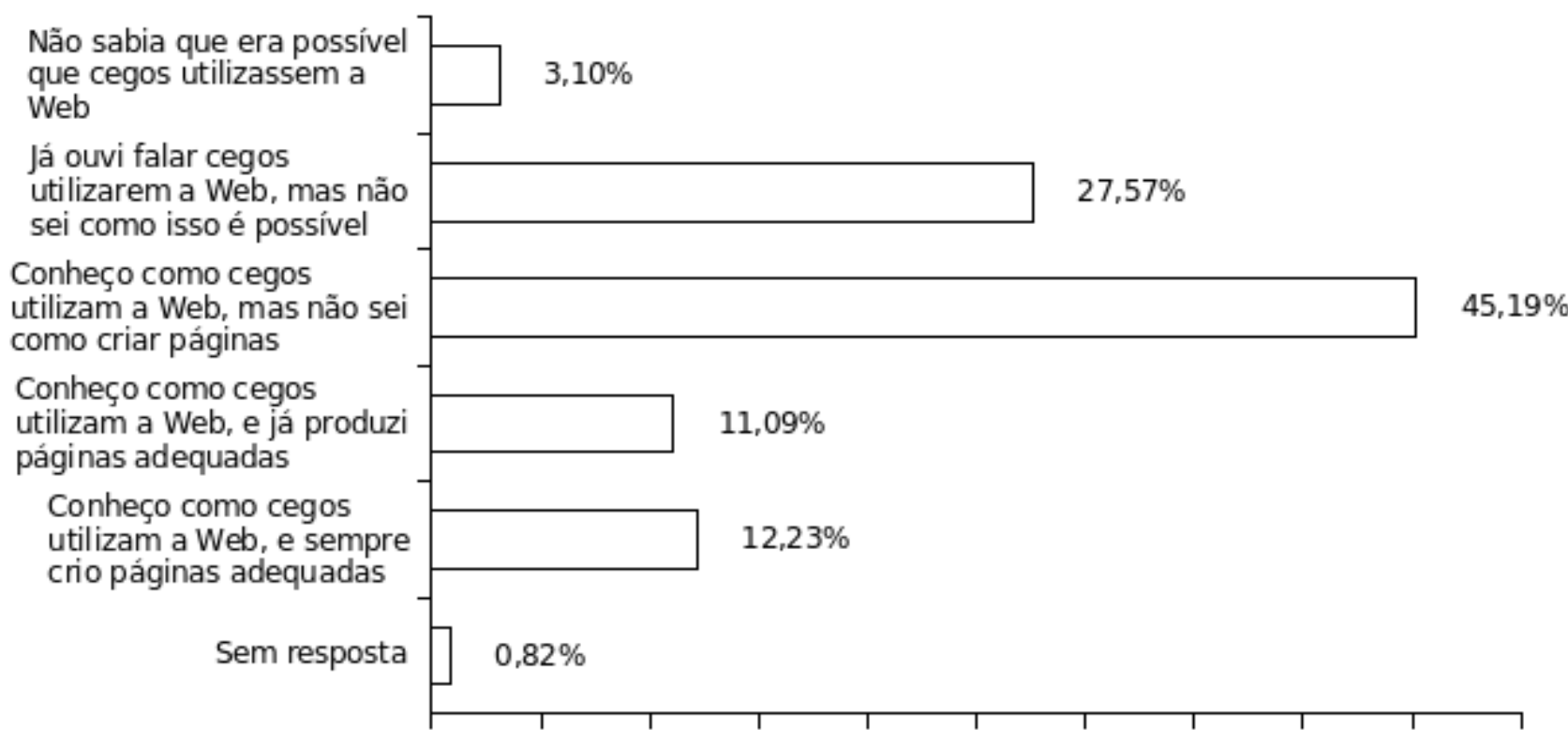

Figura 6.7: Conhecimento dos problemas enfrentados por cegos ao utilizar a Web

\section{Tecnologias assistivas conhecidas ou já utilizadas}

Com os dados obtidos a partir da questão 3, observou-se com quais tecnologias assistivas os participantes tinham algum tipo de familiaridade, admitindo-se mais de uma resposta. Na Figura 6.8 pode-se observar que as tecnologias assistivas que tiveram o maior número de indicações entre os participantes foram o navegador com voz $(55,46 \%)$, o leitor de tela $(48,12 \%)$ e o ampliador de tela $(43,56 \%)$. 


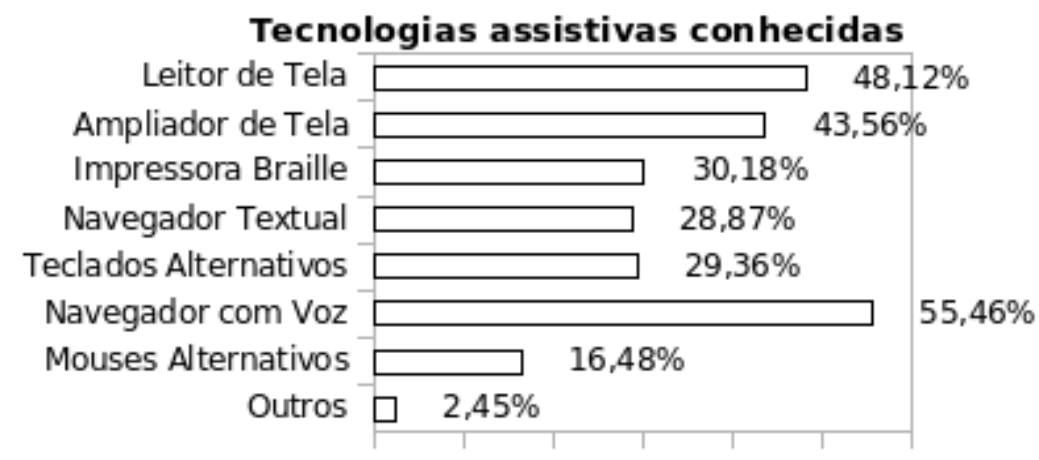

Figura 6.8: Tecnologias assistivas conhecidas pelos participantes do levantamento

\section{Conhecimento do Decreto Lei No. 5.296/2004 e suas implicações para a Web}

A partir da análise da questão 4, observou-se que uma pequena parcela dos participantes tinha conhecimento sobre o decreto. Na Figura 6.9 pode-se observar que 40,29\% afirmaram nunca ter ouvido falar do decreto e que $32,95 \%$ deles já ouviram falar, mas não conhecem ou conhecem vagamente.

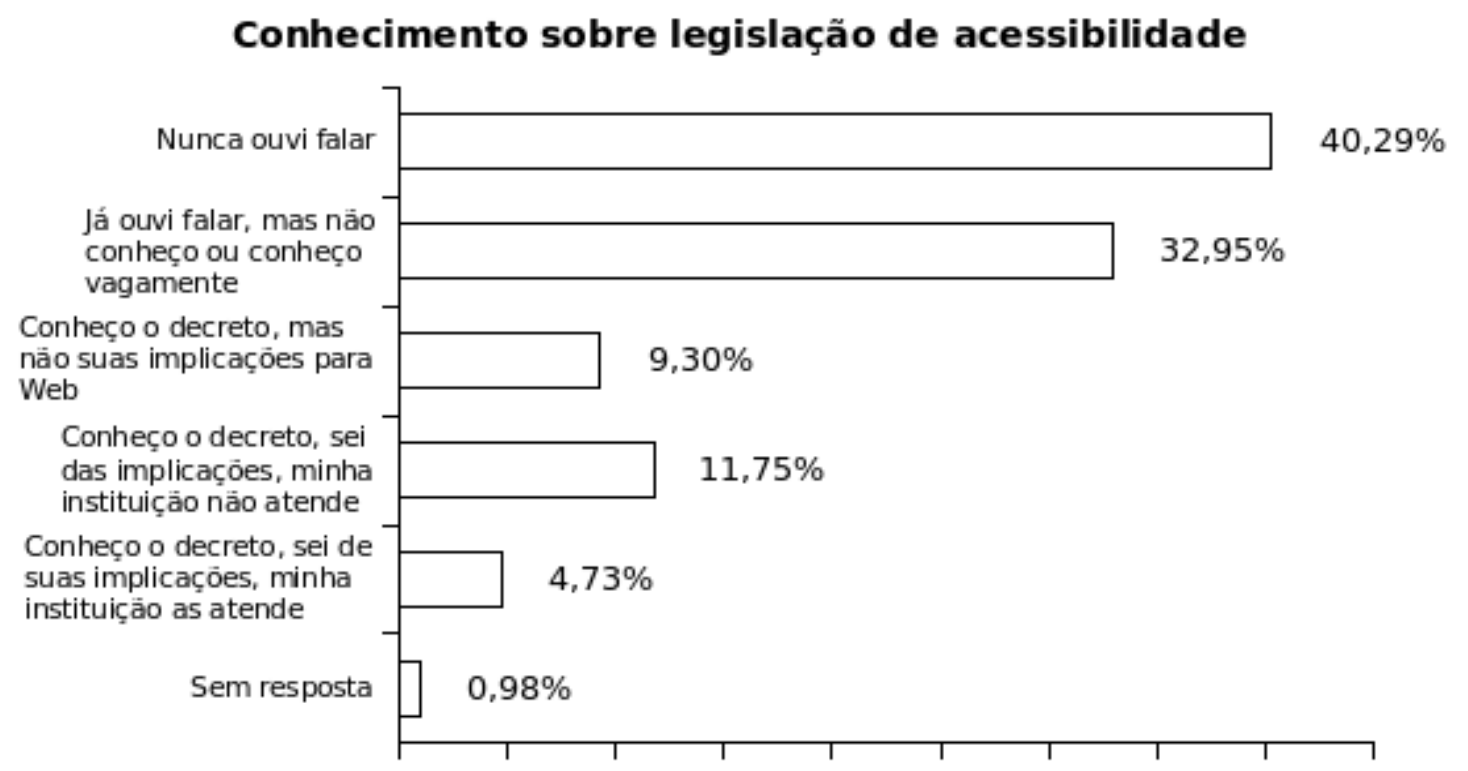

Figura 6.9: Conhecimento sobre o Decreto Lei No. 5.296/2004 e suas implicações para Web pelos participantes do levantamento

\section{Conhecimento sobre as diretrizes de acessibilidade do W3C}

$\mathrm{Na}$ análise da questão 5, observou-se que a maioria dos participantes tinham nenhum conhecimento $(39,15 \%)$ ou somente conhecimento básico $(30,18 \%)$, como pode ser verificado na Figura 6.10 . 


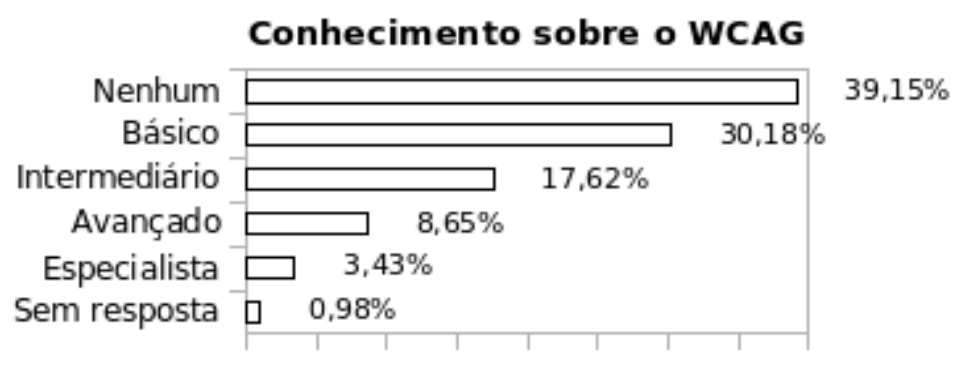

Figura 6.10: Conhecimento dos participantes do levantamento sobre as diretrizes do WCAG do W3C

\section{Treinamentos sobre acessibilidade recebidos pelos participantes}

Na questão 6, verificou-se que tipos de treinamento os participantes afirmaram ter tido sobre acessibilidade. Na Figura 6.11 pode-se observar que a maioria dos respondentes $(56,38 \%)$ afirmou nunca ter tido nenhum tipo de treinamento. Os tipos de treinamento mais apontados foram palestras $(22,02 \%)$ e outros tipos não citados $(11,26 \%)$. Dentre os tipos de treinamento apontados em "outros", os mais ocorrentes foram afirmações de que o conhecimento sobre acessibilidade foi adquirido durante a realização de trabalhos de pesquisa, de trabalhos voluntários, oficinas ou de estudos auto-didatas.

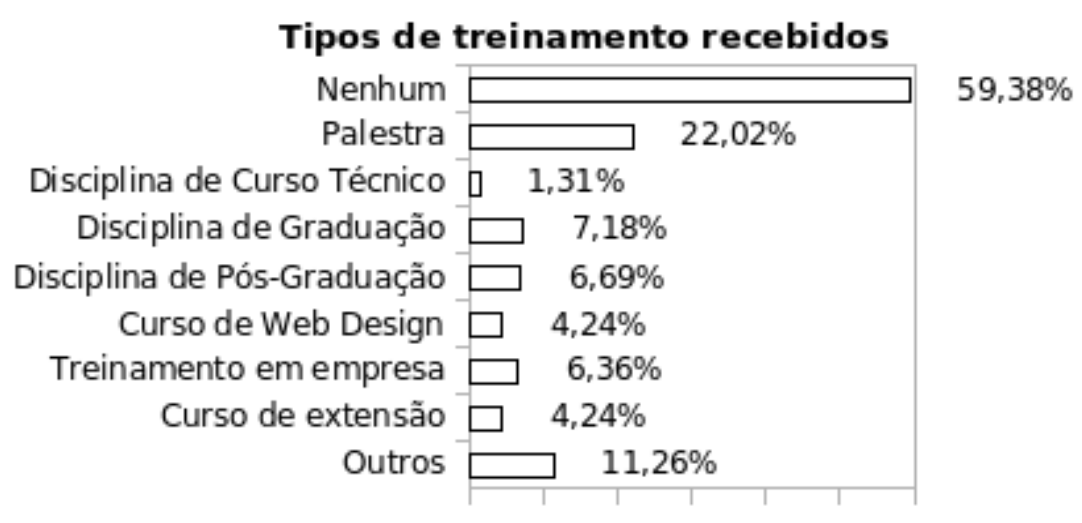

Figura 6.11: Treinamentos sobre acessibilidade recebidos pelos participantes

\section{Formas de avaliação de acessibilidade realizadas pelos participantes}

Da análise da questão 7, verificou-se que um grande número de respondentes (47,80\%) afirmou não utilizar nenhuma forma de avaliação de acessibilidade. Como pode ser observado na Figura 6.12, os tipos de teste com maior número de indicações foram a validação de HTML $(34,42 \%)$ e validação de CSS (30,18\%), seguida da realização de testes com ferramentas automáticas $(18,11 \%)$.

A observação desses dados é um índicio de que a avaliação de acessibilidade ainda é pouco utilizada. Os tipos de avaliação com mais indicações não necessariamente são utilizados com o fim de verificar acessibilidade. Observa-se também que a realização de inspeções manuais e testes com usuários também ainda é bastante restrita em projetos Web. 


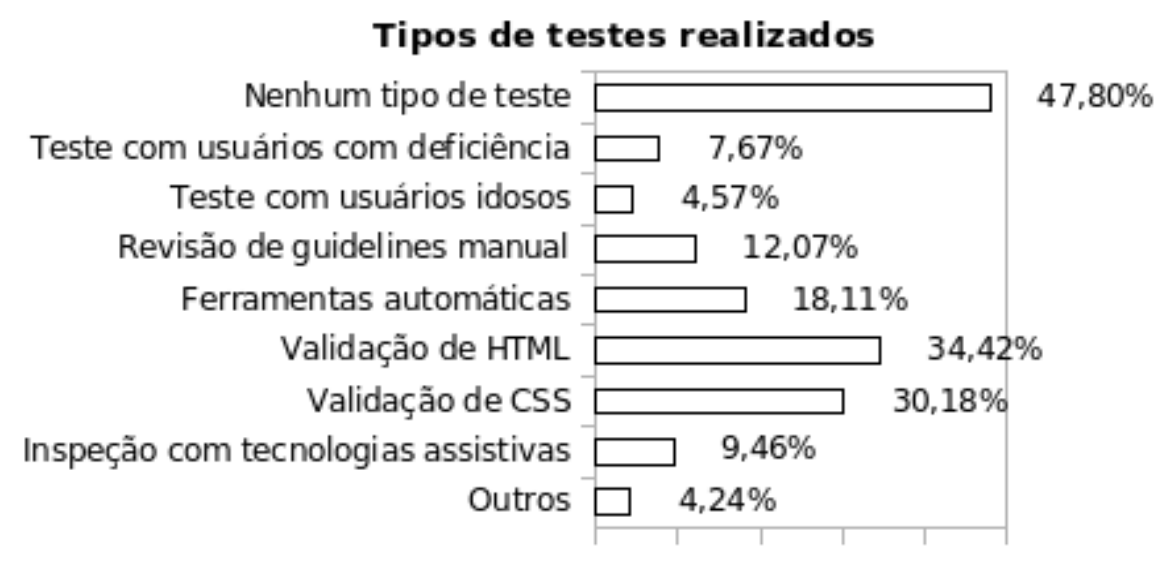

Figura 6.12: Tipos de avaliação de acessibilidade realizados pelos participantes

Dentre os tipos de avaliação apontados na opção "outros", destaca-se a realização de testes com diferentes dispositivos e realização de testes de usabilidade.

\section{Consideração da acessibilidade nos projetos em que os participantes estão envolvidos}

Na questão 8, verificou-se a opinião dos participantes em relação à consideração ou não da acessibilidade nos projetos em que eles estão envolvidos. Como pode ser observado no gráfico da Figura 6.13, somente 19,90\% dos participantes afirmaram que a acessibilidade é considerada nos projetos em que estão envolvidos, enquanto $35,40 \%$ deles afirmaram que acessibilidade não é considerada e $44,37 \%$ afirmam que é considerada parcialmente.

\section{Consideraçāo da acessibilidade em projetos}

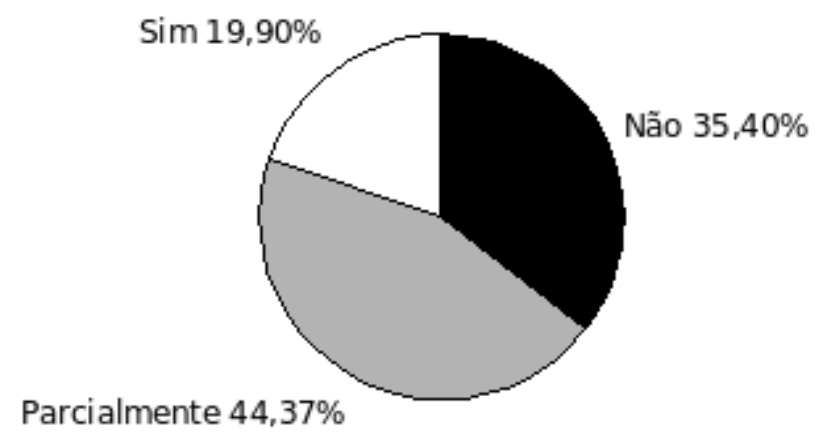

Figura 6.13: Opinião dos participantes sobre a consideração da acessibilidade nos projetos em que estão envolvidos

\section{Motivos apontados pelos participantes para considerar acessibilidade nos pro- jetos}

Para os participantes que responderam "sim" na questão 8 , foi pedido para que apontassem os principais motivos porque a acessibilidade é considerada nos projetos em que participam. Como 
pode ser verificado no gráfico da Figura 6.14, a motivação pessoal foi o motivo com maior número de indicações. Curiosamente, a exigência da empresa e exigência dos clientes tiveram os menores números de indicações, com respectivamente $17,21 \%$ e $24,59 \%$.

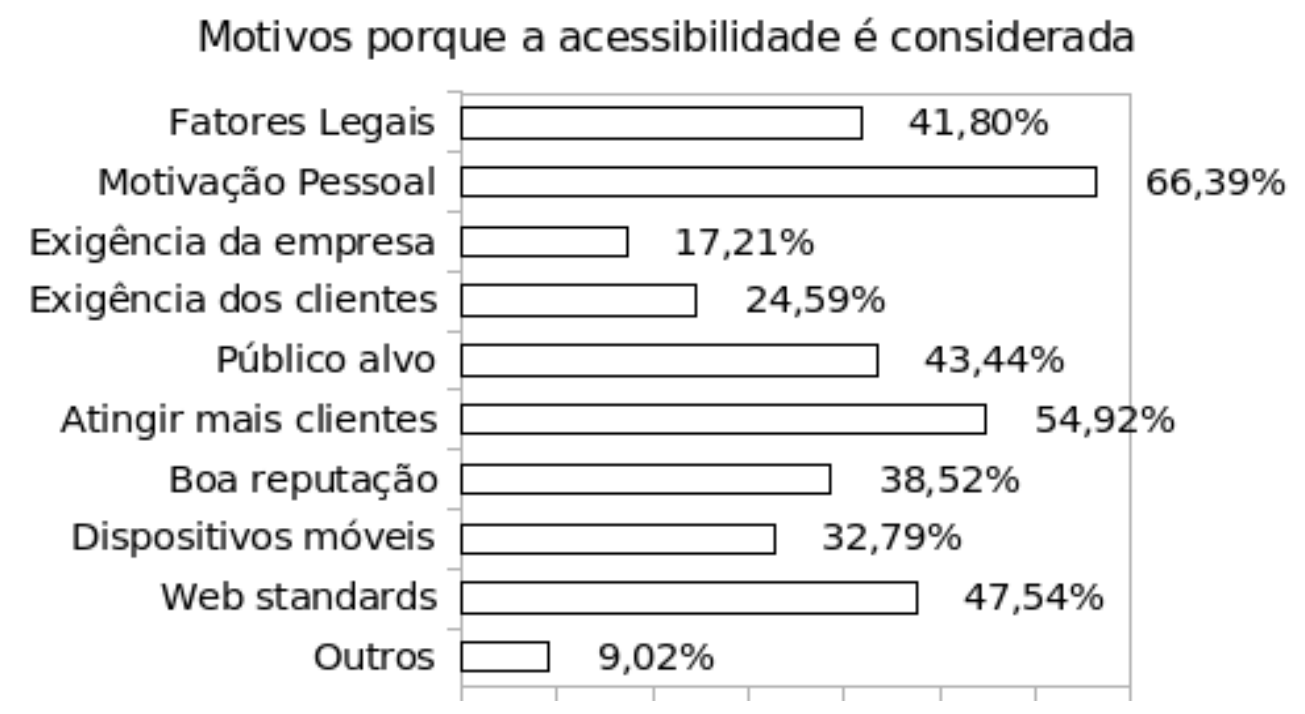

Figura 6.14: Motivos porque acessibilidade é considerada nos projetos dos participantes

Dos usuários que apontaram a opção "outros", os principais motivos apontados foram a responsabilidade social e a inclusão digital e social.

\section{Motivos apontados pelos participantes para não considerar acessibilidade nos projetos}

Para os participantes que responderam "não" na questão 8, foi pedido para que apontassem os principais motivos porque a acessibilidade não considerada ou é considerada somente parcialmente nos projetos em que participam. Como pode ser verificado no gráfico da Figura 6.15, os maiores motivos apontados pelos participantes foram a falta de exigência pela empresa ou organização $(51,33 \%)$, a falta de exigência pelos clientes $(49,08 \%)$ e falta de treinamento adequado $(53,17 \%)$.

Dos usuários que apontaram outros motivos, as principais razões enumeradas foram a necessidade de utilizar tecnologias que ainda não fornecem recursos para acessibilidade, número reduzido de pessoal no desenvolvimento, e falta de conscientização dos níveis de direção e gerência.

\section{Comentários sobre a importância da acessibilidade nas organizações dos par- ticipantes}

Na questão 11, pediu-se que os participantes apontassem considerações sobre como a acessibilidade é vista em suas organizações. De forma geral, muitos participantes comentaram que em suas organizações a inclusão é considerado um aspecto muito importante. Outros comentários afirmaram que a acessibilidade é considerada em algumas esferas, mas que nos níveis de direção e gerência ainda é um tema com pouca importância. 
Motivos porque acessibilidade nāo é considerada

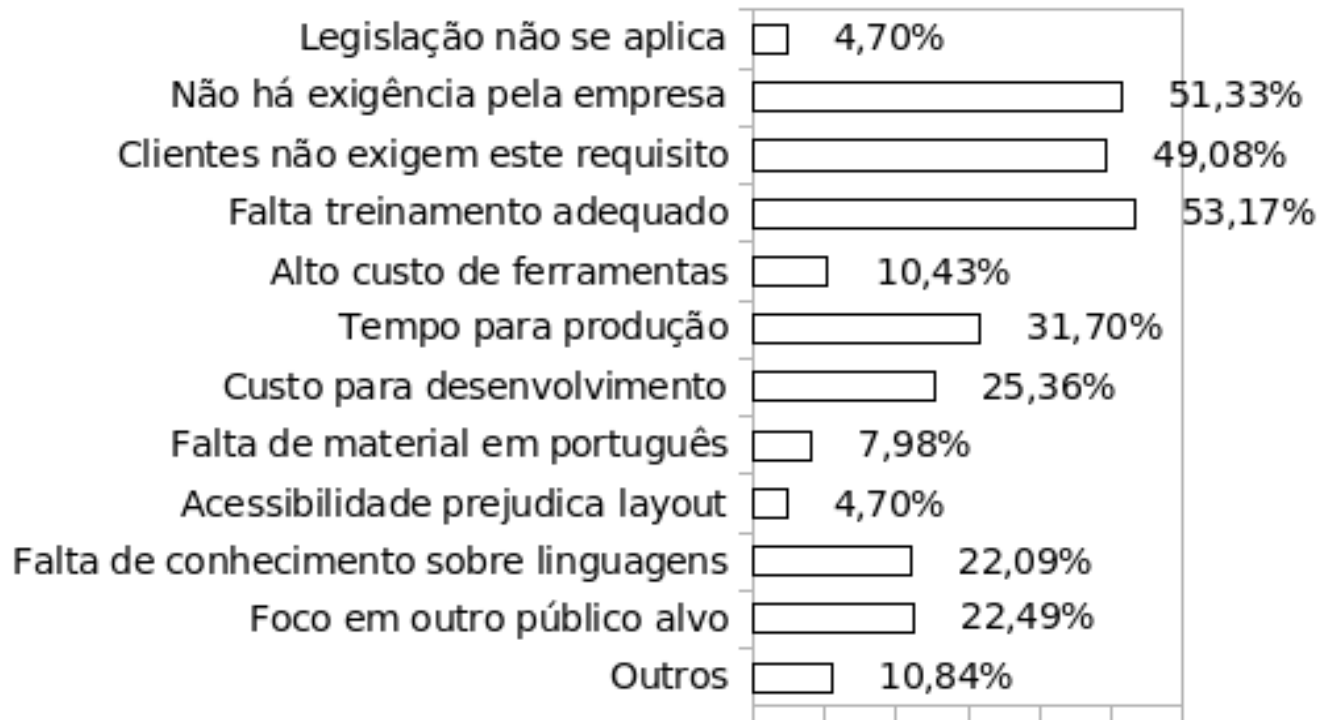

Figura 6.15: Motivos porque acessibilidade não é considerada ou é considerada parcialmente nos projetos dos participantes

A seguir, são transcritos alguns comentários interessantes fornecidos por alguns dos participantes:

"Uma instituição de ensino deve prover acesso a todos os alunos seja lá qual for a sua deficiência”.

"Acho muito importante a inclusão digital de pessoas com algum tipo de deficiência ou pessoas idosas mesmo. Com certeza isso pode abrir novas portas para novos usuários até agora excluídos".

“Todos os recursos deverão ser utilizados para maximizar a acessibilidade. Infelizmente a sociedade ainda não se tocou (sic) para o problema. Somente agora, com a divulgação maior da legislação é que as pessoas começam a ter consciência sobre o problema. É uma questão de tempo”.

“Atualmente essa preocupação não está inserida em meus projetos. O questionário chamou-me a atenção para o problema. Acredito que passarei a considerar esse viés nos próximos projetos”.

“Atualmente a acessibilidade ainda não é levada por completo, mas será necessário fazer uma reformulação dos projetos desenvolvidos para abraçar cada vez mais este tema, pois é importante expandir e desenvolver sistemas com acesso universal".

\section{Sugestões para melhorar a acessibilidade na Web}

Na questão 12, pediu-se que os participantes apontassem sugestões para melhorar a acessibilidade na Web. De forma geral, muitos participantes sobre a necessidade de se divulgar mais a 
legislação existente e de promover maior conscientização, por meio do fornecimento de treinamentos nas empresas e da inclusão do tema nos currículos de cursos relacionados.

A seguir, são transcritos alguns dos comentários fornecidos pelos participantes:

"Divulgação, inclusão desse tópico em todos os processos de desenvolvimento de software”.

"Maior divulgação dos padrões e da legislação, incentivando assim as empresas a adoção”.

"Primeiramente, maior conscientização da sociedade sobre a importância do acesso à informação e ao conhecimento. Depois, desenvolver ferramentas ou objetos que facilitem a sua implementação ficando à disposição dos profissionais”.

"Não creio que existam ações para obrigar. Mas a conscientização e o treinamento dos desenvolvedores levará a médio prazo para a consideração da usabilidade”.

"Ampla divulgação do número de consumidores em potencial que deixam de consumir produtos e ou serviços por não terem acesso a páginas mal construidas. Ampla divulgação de que o tempo e dinheiro gasto a mais em um projeto acessível, testado e validado na prática(com usuários reais e não somente concordância com as especificações de acessibilidade) é muito pequeno se comparado com o retorno que o investimento pode dar”.

"Acredito que toda instituição que desenvolve sítios deveria fazer testes com os diferentes perfis de usuários que pretendem atingir durante o desenvolvimento de cada projeto".

\section{Métricas de acessibilidade das páginas indicadas pelos participantes}

$\mathrm{Na}$ análise das URLs indicadas pelos participantes, foi feita a análise dos sítios indicados, utilizando a média das métricas da avaliação das páginas iniciais e das páginas no nível imediatamente abaixo na navegação. No total, 181 participantes indicaram pelo menos uma URL. Para os participantes que indicaram mais de uma URL, foi utilizada a métrica com o menor índice de barreiras.

Na Figura 6.16, pode-se observar um gráfico do tipo boxplot com os resultados das análises com as métricas WAB, A3, UWEM e WAQM. Verifica-se que as métricas A3 e UWEM apresentaram comportamentos bastante semelhantes. Da mesma forma que na análise efetuada nos estudos de caso reportados na Seção 5.4, nota-se uma discordância entre a métrica WAQM e as demais. A métrica WAQM apresenta um número maior de páginas com resultados mais favoráveis do que as demais.

De acordo com a métrica WAB, utilizada na maior parte das análises, verifica-se que $50 \%$ dos sítios tiveram média de índice de barreiras até 2,4. Com as diretrizes consideradas na avaliação, que podem ser 


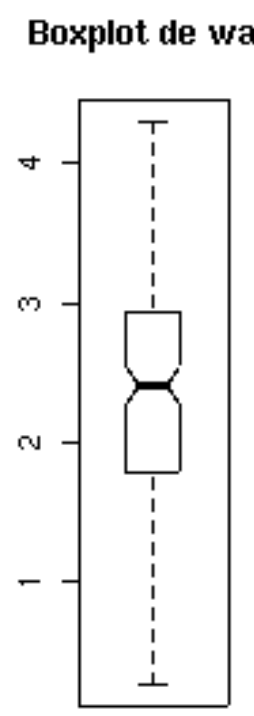

\section{Boxplot de a3}

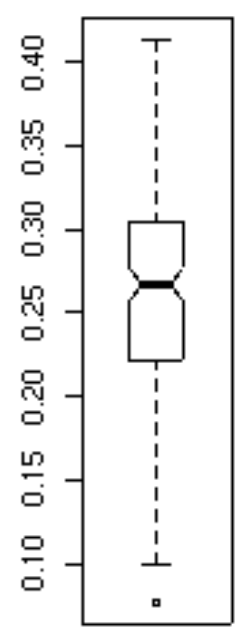

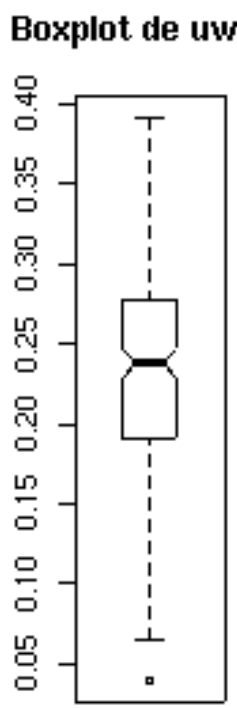

Boxplot de waqm

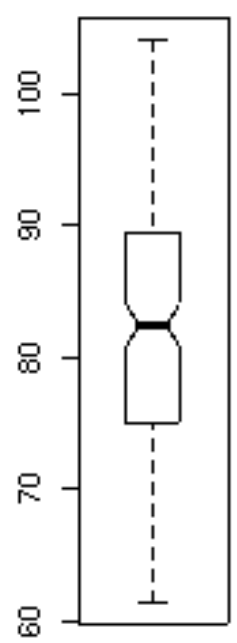

Figura 6.16: Boxplots com o sumário dos resultados das avaliações das páginas dos participantes do levantamento com as métricas WAB, A3, UWEM e WAQM

\subsubsection{Modelagem estatística}

Na estrutura do questionário, dois aspectos tinham particular importância como resultados objetivos em relação à acessibilidade: a) a opinião dos participantes sobre a consideração da acessibilidade nos projetos em que participa e b) o resultado das métricas das avaliações das URLs dos sítios indicados pelos participantes.

Desta forma, foram elaborados dois modelos estatísticos para realização de inferências utilizando técnicas de regressão linear. No primeiro modelo, analisou-se o conjunto de questões de 1 a 8 mais as questões pessoais e demográficas e, no segundo, analisou-se todo o conjunto de questões somado à análise da avaliação dos sítios com a métrica WAB. As inferências estatísticas foram efetuadas com o apoio do ambiente estatístico R (R Development Core Team, 2007).

\section{Modelo Logístico - Análise em relação à opinião quanto a consideração da acessibilidade nos projetos}

No primeiro modelo, utilizou-se a variável da questão 8 (se a acessibilidade é considerada nos projetos em que participa) como variável resposta. Esta questão admitia respostas "Sim", "Não" ou "Parcialmente". As respostas "Não" e "Parcialmente" foram agrupadas em um mesmo grupo. O objetivo desta etapa foi de verificar a influência das variáveis estudadas para que a acessibilidade fosse considerada ou não em projetos de sistemas Web.

Em um modelo logístico, é feita uma aproximação de uma função que modela a probabilidade de que a variável resposta resulte em "sucesso" em função das demais variáveis (Paula, 2004, 2008). Neste tipo de modelo a variável resposta é do tipo binária (“0 ou 1"). O modelo de regressão logística busca obter uma função linear que modele a probabilidade de que a variável resposta seja 1, ajustando os coeficientes de cada variável de acordo com sua influência sobre a probabilidade modelada. 
Desta forma, contexto desta análise, se uma variável resulta tem um coeficiente positivo, quer dizer que de acordo com a amostra existem indícios de que ela contribui com o aumento da probabilidade de "sucesso". Ou seja, um valor positivo contribui para que um dado participante que tenha dado uma resposta considerada favorável a essa questão tenha maior tendência a responder "Sim" sobre a percepção sobre acessibilidade ser considerada ou não.

No modelo proposto neste trabalho, a variável da questão 8 foi ajustada de forma que as respostas "Sim" foram consideradas como "sucesso', e atribuídas com o valor 1. As respostas "Não" ou "Parcialmente" foram definidas como "fracasso" e atribuídas com o valor 0. Neste modelo, também foram excluídas algumas observações que continham valores nulos nas respostas que poderiam prejudicar a análise no modelo. Assim, o modelo foi ajustado para 581 participantes.

Para otimizar o modelo ajustado, foi realizada a seleção de variáveis pelo Método AIC (Akaike Information Criterion) (Neter et al., 1996). O método de Akaike consiste na otimização de um modelo, selecionando as variáveis mais significativas. Neste caso, utilizou-se o Método AIC com processo backward, ou seja, inicia-se o ajuste com todas as covariáveis e retira-se as não-significativas em cada passo. O resultado final é o melhor modelo possível com o menor número de variáveis necessárias.

A partir da execução do método AIC, as variáveis consideradas mais relevantes para o modelo foram as respostas às questões $1,2,3,5,6$ e 7 . Para verificar que variáveis foram consideradas relevantes, foi considerado o nível de significância de $10 \%$ para os testes estatísticos. A partir das análises das variáveis incluídas e de seus coeficientes, surgem diversas discussões sobre a análise desses dados, as quais são descritas a seguir:

\section{- Perfil: Influência não significativa de características geográficas, pessoais, de formação} e profissionais: as variáveis de idade, gênero, localização geográfica, formação, área de atuação e função tiveram pouca influência para o modelo. Isso significa que essas variáveis podem ter pouca influência sobre a probabilidade de que a acessibilidade seja considerada em projetos de sistemas Web. Este resultado contraria a hipótese de que, por exemplo, a área de atuação poderia ter influência sobre este fator, devido ao fato de os participantes da área governamental serem afetados por leis de acessibilidade.

- Pequena influência do conhecimento sobre linguagens (Questão 1): o conhecimento sobre as linguagens HTML e CSS apresentou um coeficiente relativamente baixo no modelo $(-0,2513)$, mas foi considerado relevante de acordo com os testes estatísticos (p-valor = 0,00167). Contudo, o fato de este coeficiente ter sido negativo foi um resultado surpreendente. Isso indica que, de acordo com este modelo, o aumento de conhecimento sobre linguagens tende a contribuir negativamente com a probabilidade de que a acessibilidade seja considerada nos projetos.

Esta inferência ressalta validade da impressão que se tem de que o conhecimento técnico não é suficiente para que as pessoas tenham consciência sobre a consideração da acessibilidade e outros fatores humanos no projeto de sistemas computacionais. 
- Importância da consciência sobre a forma como as pessoas com necessidades especiais utilizam a Web (Questão 2): o coeficiente para a resposta à segunda questão $(0,3758)$ é um indício de que conhecer as necessidades de pessoas com necessidades especiais é um fator importante para que a acessibilidade seja efetivamente considerada nos projetos.

- Baixa influência do conhecimento sobre tecnologias assistivas (Questão 3): a baixa influência sobre o conhecimento das tecnologias assistivas também foi um resultado curioso. A maioria das variáveis correspondentes a tecnologias não foram incluídas no modelo durante a otimização, e as variáveis correspondentes a duas tecnologias incluídas tiveram coeficientes negativos (ampliador de tela com -0,5227 e navegador com voz com -0,3479). Estes resultados indicam que o simples conhecimento sobre a existência de tecnologias assistivas não tem grande influência sobre a consideração da acessibilidade nos projetos.

\section{- Influência não significativa do conhecimento sobre a legislação de acessibilidade (Ques-} tão 4): a resposta à questão 4, referente ao conhecimento sobre o Decreto Lei No. 5.296/2004 não foi considerada relevante para o modelo durante a otimização. Isso pode indicar que, além do fato da legislação ser pouco conhecida por pessoas que participam de projetos Web, como verificado na Seção 6.5.1, ela ainda é pouco eficaz como instrumento para a introdução efetiva da acessibilidade na agenda de projetos de sistemas Web.

- Importância do conhecimento sobre diretrizes de acessibilidade (Questão 5): o coeficiente para as respostas à questão $5(0,2727)$ revela que o conhecimento sobre diretrizes de acessibilidade é um fator positivo para contribuir com a consideração da acessibilidade em projetos Web.

- Importância relativa de diferentes tipos de treinamento (Questão 6): variáveis sobre diferentes tipos de treinamento tiveram diferentes comportamentos na geração do modelo. Somente as variávies referentes a disciplinas de curso técnico e cursos de Web design foram incluídas, com coeficientes 2,0161 e 0,7274, respectivamente. A variável correspondente aos participantes que responderam não ter tido nenhum tipo de treinamento também foi incluída no modelo, com um coeficiente de -1,1064 e p-valor =1,62e-05.

A análise do coeficiente da variável referente a participantes que não tiveram nenhum treinamento revela indícios de que realmente a falta de treinamento é um fator muito prejudicial para a efetiva consideração da acessibilidade em projetos Web.

A inclusão das variáveis de disciplinas de cursos técnicos e de cursos de Web design com valores positivos mostram indícios de que a abordagem da acessibilidade nesses tipos de curso têm tido uma contribuição efetiva entre os participantes da pesquisa. Já a não inclusão de outras variáveis, como a abordagem da acessibilidade em disciplinas de cursos superiores (graduação e pós-graduação), nas empresas e em palestras pode mostrar indícios de que o treinamento em acessibilidade nesses contextos não têm sido eficazes. 
- Importância dos diferentes tipos de avaliações de acessibilidade (Questão 7): somente duas variáveis referentes a avaliações de acessibilidade foram incluídas no modelo a partir da otimização realizada, mas ambas com coeficientes positivos: avaliação com usuários idosos $(0,8180)$ e avaliação com ferramentas automáticas $(0,5688)$. Contudo, fazendo outros testes com um outro modelo não otimizado incluindo outros testes, verificou-se que as outras formas de avaliações também tinham coeficiente positivo. Isto indica que há fortes indícios de que o uso de métodos de avaliação têm uma contribuição muito positiva para a consideração da acessibilidade em projetos Web.

\section{Modelo contínuo - Análise com as métricas das páginas avaliadas}

No segundo modelo, utilizou-se a como variável resposta o índice de barreiras WAB dos sítios informados pelos participantes. Desta vez, todo o conjunto de variáveis foi utilizado para compor o modelo estatístico. O objetivo foi de verificar que variáveis contribuem para ter um índice de barreiras maior ou menor.

A variável analisada correspondia ao menor índice de barreiras obtido entre as médias de barreiras dos sítios apontados pelos participantes. No total, 181 participantes informaram o endereço de pelo menos uma URL a ser avaliada.

A métrica WAB foi escolhida devido à facilidade de entendimento, por ser relacionada de forma mais direta com as diretrizes do WCAG e por ter tido bom desempenho nos estudos de caso realizados, reportados na Seção 5.4. O modelo estatístico utilizado foi um modelo linear para dados contínuos (Paula, 2008).

Neste modelo, também foi utilizado o método AIC com backward para seleção de variáveis relevantes. As variáveis selecionadas foram as das questões 1, 3, 4, 5, 6, 7, 9 e 10.

No segundo modelo, deve-se considerar que a variável analisada corresponde a um índice de barreiras obtido por meio de uma avaliação com uma ferramenta automática. Desta forma, somente um sub-conjunto de diretrizes do WCAG foi efetivamente avaliado. Assim, não se pode afirmar que páginas com um índice WAB baixo realmente sejam páginas acessíveis. Nesta análise, portanto, pode-se verificar quais fatores mais influenciam para que haja um índice de barreiras maior ou menor de acordo com os fatores analisados.

Também é importante ressaltar que quanto maior o índice de barreiras, mais problemas de acessibilidade os sítios avaliados têm. Desta forma, nesta análise, os fatores que são considerados como favoráveis à acessibilidade são os fatores com valores negativos no modelo.

Nesta análise, as variáveis que possuem valores negativos são aquelas que tendem a diminuir o valor esperado do índice de barreiras resultante da análise das páginas. Em outras palavras, índices negativos apresentam indícios que de acordo com a amostra, uma dada variável tende a diminuir o índice de barreiras esperado.

A seguir, são apresentadas as discussões referentes à influência dos fatores analisados em relação a métricas de acessibilidade: 
- Conhecimento sobre linguagens (Questão 1): ao contrário da análise em relação à consideração sobre acessibilidade nos projetos na opinião dos participantes, no modelo sobre o índice de barreiras o conhecimento sobre linguagens teve um índice favorável (-0,13038), o que indica que esse conhecimento contribui para produzir páginas com menores índices de barreiras. Isso indica que o conhecimento sobre linguagens não necessariamente proporciona um aumento na conscientização, mas que tem uma contribuição efetiva para a obtenção de páginas com menores índices de barreiras.

- Conhecimento de tecnologias assistivas (Questão 3): três tecnologias assistivas foram incluídas no modelo, e duas delas tiveram coeficientes favoráveis, a saber: leitor de tela (0,30313) e mouses alternativos (-0,25198). O ampliador de tela teve coeficiente 0,1839 . Verifica-se que há indícios de que o conhecimento sobre tecnologias assistivas que têm grande impacto sobre a interação apresenta um impacto favorável para a obtenção de páginas com menores índices de barreiras.

- Conhecimento sobre legislação e diretrizes (Questões 4 e 5): o conhecimento sobre a legislação brasileira de acessibilidade apresentou um valor não favorável $(0,11376)$, o que mostra indícios de que ela não tem uma contribuição favorável para a obtenção de páginas com menores índices de barreiras. O conhecimento sobre as diretrizes do WCAG teve um coeficiente negativo pequeno (-0,04752), mostrando índicios de que tem uma contribuição favorável, mas tímida para a obtenção de páginas com menores índices de barreiras.

- Influência do treinamento (Questão 6): o treinamento recebido em empresa teve um coeficiente favorável $(-0,44268)$, enquanto que não ter tido nenhum tipo de treinamento teve coeficiente 0,45296 e treinamento por palestra teve 0,54082. Esses dados dão indícios de que a falta de treinamento ou o fornecimento de treinamentos superficiais têm uma influência negativa na obtenção de páginas com baixos índices de barreiras.

- Técnicas de avaliação (Questão 7): as técnicas de avaliação de validação de CSS e de avaliação com ferramentas tiveram coeficientes favoráveis $(-0,30340$ e - $-0,72759$, respectivamente), o que dá indícios de que o uso de técnicas de avaliação realmente contribui com a obtenção de páginas com menores índices de barreiras.

- Motivos para considerar acessibilidade nos projetos (Questão 9): dos motivos apontados pelos participantes que afirmam considerar acessibilidade nos projetos em que participam, a observância a fatores legais, exigência dos clientes e aderência a Web standards não tiveram fatores favoráveis $(0,45126,0,48715$ e 0,58297 , respectivamente). A reputação da empresa e a compatibilidade com dispositivos móveis tiveram fatores favoráveis (-0,49653 e -0,37637), o que mostra indícios de que organizações que prezam por manter uma imagem de que consideram acessibilidade e organizações que se preocupam com a compatibilidade com novas tecnologias tendem a produzir páginas com menores índices de barreiras. 
- Motivos para não considerar acessibilidade nos projetos (Questão 10): como esperado, todos as variáveis incluídas no modelo apontadas como motivos para não considerar acessibilidade tiveram coeficientes não favoráveis. Os motivos de que a legislação vigente não se aplica às organizações e a afirmação de que a acessibilidade prejudica o layout tiveram respectivamente fatores 0,3736 e 0,79325 , que não foram favoráveis.

Na Tabela 6.1 é apresentado um sumário com a comparação entre os resultados das inferências com os dois modelos estatísticos. A partir da análise desta tabela, pode-se contrastar os diferentes impactos das questões investigadas sobre a percepção sobre a consideração da acessibilidade nos projetos ou não (modelo logístico) e os indícios de páginas com menos barreiras a partir da análise com métricas (modelo contínuo). Foram incluídas neste sumário as questões demográficas e as questões de 1 a 7, que fizeram parte dos dois modelos. Observa-se que nos dois casos os dados demográficos não tiveram impacto significativo e não foram incluídos nos modelos.

Tabela 6.1: Sumário com as inferências obtidas por meio dos modelos estatísticos

\begin{tabular}{|c|c|c|c|c|}
\hline Questão & $\begin{array}{l}\text { Coeficiente no } \\
\text { modelo logís- } \\
\text { tico }\end{array}$ & $\begin{array}{l}\text { Impacto sobre a per- } \\
\text { cepção }\end{array}$ & $\begin{array}{l}\text { Coeficiente no } \\
\text { modelo contí- } \\
\text { nuo }\end{array}$ & $\begin{array}{l}\text { Impacto sobre o índice } \\
\text { de barreiras }\end{array}$ \\
\hline Dados demográficos & Não incluído & $\begin{array}{l}\text { Impacto não significa- } \\
\text { tivo }\end{array}$ & Não incluído & $\begin{array}{l}\text { Impacto não significa- } \\
\text { tivo }\end{array}$ \\
\hline $\begin{array}{l}\text { Conhecimento sobre } \\
\text { HTML e CSS (Questão } \\
\text { 1) }\end{array}$ & $-0,2513$ & $\begin{array}{l}\text { Impacto levemente des- } \\
\text { favorável, não contribui } \\
\text { com o aumento da per- } \\
\text { cepção }\end{array}$ & $-0,13038$ & $\begin{array}{l}\text { Tem pequena contribui- } \\
\text { ção com a diminuição do } \\
\text { índice de barreiras }\end{array}$ \\
\hline $\begin{array}{l}\text { Percepção sobre o } \\
\text { uso da Web por cegos } \\
\text { (Questão 2) }\end{array}$ & 0,3758 & $\begin{array}{l}\text { Impacto favorável, com } \\
\text { pequena contribuição } \\
\text { para o aumento da } \\
\text { percepção }\end{array}$ & Não incluído & $\begin{array}{l}\text { Sem indícios de impacto } \\
\text { significativo sobre a re- } \\
\text { dução do índice de bar- } \\
\text { reiras }\end{array}$ \\
\hline $\begin{array}{l}\text { Tecnologias Assistivas } \\
\text { (Questão 3) }\end{array}$ & $\begin{array}{l}\text { Ampliador de } \\
\text { tela: }-0,5227 \text {, } \\
\text { Navegador } \\
\text { com voz: } \\
-0,3479\end{array}$ & $\begin{array}{l}\text { Poucas tecnologias } \\
\text { incluídas, conhecimento } \\
\text { sobre tecnologias mais } \\
\text { populares não contri- } \\
\text { bui para o aumento da } \\
\text { percepção }\end{array}$ & $\begin{array}{l}\text { Leitor de tela: } \\
-0,30313 \text {, } \\
\text { Mouses al- } \\
\text { ternativos: } \\
-0,25198\end{array}$ & $\begin{array}{l}\text { Conhecimento sobre tec- } \\
\text { nologias mais relaciona- } \\
\text { das a deficiências contri- } \\
\text { buem mais para a dimi- } \\
\text { nuição do índice de bar- } \\
\text { reiras }\end{array}$ \\
\hline $\begin{array}{l}\text { Conhecimento da legis- } \\
\text { lação (Questão 4) }\end{array}$ & Não incluído & $\begin{array}{l}\text { Impacto não significa- } \\
\text { tivo }\end{array}$ & 0,1839 & $\begin{array}{l}\text { Impacto levemente des- } \\
\text { favorável, com indícios } \\
\text { de contribuição para o } \\
\text { aumento do índice de } \\
\text { barreiras }\end{array}$ \\
\hline $\begin{array}{l}\text { Conhecimento } r \text { sobre } \\
\text { diretrizes do WCAG } \\
\text { (Questão 5) }\end{array}$ & 0,2727 & $\begin{array}{l}\text { Impacto positivo, com } \\
\text { pequena } \\
\text { ção para aumentribui- } \\
\text { percepção }\end{array}$ & $-0,04752$ & $\begin{array}{l}\text { Impacto levemente favo- } \\
\text { rável, mas tímido }\end{array}$ \\
\hline
\end{tabular}




\begin{tabular}{|c|c|c|c|c|}
\hline Questão & $\begin{array}{l}\text { Coeficiente no } \\
\text { modelo logís- } \\
\text { tico }\end{array}$ & $\begin{array}{l}\text { Impacto sobre a per- } \\
\text { cepção }\end{array}$ & $\begin{array}{l}\text { Coeficiente no } \\
\text { modelo contí- } \\
\text { nuo }\end{array}$ & $\begin{array}{l}\text { Impacto sobre o índice } \\
\text { de barreiras }\end{array}$ \\
\hline $\begin{array}{l}\text { Treinamentos recebi- } \\
\text { dos (Questão 6) }\end{array}$ & $\begin{array}{l}\text { Curso téc- } \\
\text { nico: } 2,0161, \\
\text { Curso de Web } \\
\text { design: } 0,7274\end{array}$ & $\begin{array}{l}\text { Cursos mais "aplicados" } \\
\text { apresentam índices favo- } \\
\text { ráveis para aumentar a } \\
\text { percepção }\end{array}$ & $\begin{array}{l}\text { Treinamento } \\
\text { em empresa: } \\
\text {-0,44268, Sem } \\
\text { treinamento: } \\
0,45296, \quad \mathrm{~Pa}- \\
\text { lestra: } 0,54082\end{array}$ & $\begin{array}{l}\text { Confirma que treinamen- } \\
\text { tos aplicados (no caso da } \\
\text { empresa) contribui favo- } \\
\text { ravelmente também para } \\
\text { a diminuição do índice } \\
\text { de barreiras. Falta de } \\
\text { treinamento ou treina- } \\
\text { mentos superficiais têm } \\
\text { contribuição desfavorá- } \\
\text { vel }\end{array}$ \\
\hline $\begin{array}{l}\text { Técnicas de teste } \\
\text { (Questão 7) }\end{array}$ & $\begin{array}{l}\text { Teste com } \\
\text { usuários ido- } \\
\text { sos: } 0,8180 \text { e } \\
\text { Avaliação com } \\
\text { ferramentas: } \\
0,5688\end{array}$ & $\begin{array}{l}\text { Avaliação no geral apre- } \\
\text { senta contribuição favo- } \\
\text { rável para aumentar a } \\
\text { percepção }\end{array}$ & $\begin{array}{l}\text { Validação } \\
\text { de CSS: - } \\
0,30340 \quad \text { e } \\
\text { Avaliação com } \\
\text { ferramentas: } \\
\text {-0,72759) }\end{array}$ & $\begin{array}{l}\text { Uso de avaliação para se- } \\
\text { guir padrões e avaliações } \\
\text { específicas de acessibili- } \\
\text { dade contribuem favora- } \\
\text { velmente para diminuir o } \\
\text { índice de barreiras }\end{array}$ \\
\hline
\end{tabular}

\subsubsection{Análise da validade}

A validade interna se refere à isenção de erros no processo de amostragem. Nesta pesquisa, procurou-se utilizar mecanismos para evitar que houvessem erros na amostragem dos dados. Como o preenchimento do questionário foi efetuado por meio da Web, era possível que respostas inválidas fossem informadas.

Como este procedimento de coleta de dados era uma ameaça à validade interna, as entradas de dados de todos os participantes foram conferidas para verificar se não haviam dados inválidos, e se os participantes realmente se encontravam no perfil esperado para a pesquisa. Como resultado, 17 respostas foram excluídas da análise.

A validade externa se refere às condições para generalização dos resultados. Dada a característica deste estudo de analisar o perfil de pessoas envolvidas com projetos de sistemas Web, não era possível utilizar de instrumentos de amostragem probabilística.

Um dos problemas para a utilização da amostragem probabilística é a dificuldade para determinar na totalidade a população estudada. Não há nenhum catálogo completo de pessoas que trabalhem com esse tipo de projeto.

Desta forma, a utilização de uma amostragem não probabilística reduz a validade externa do estudo. Entretanto, como o estudo contou com uma participação bastante ampla, com participantes de todo o país e distribuídos nas diferentes áreas de atuação, acredita-se que o estudo é bastante 
representativo, e que alguns resultados podem ser utilizados para generalizações de algumas conclusões sobre a população estudada de maneira limitada.

\subsection{Considerações finais}

Neste capítulo foi apresentado o processo para condução do levantamento sobre acessibilidade com pessoas envolvidas com projetos de desenvolvimento de sistemas Web.

Foram apresentados alguns conceitos envolvidos com a realização de pesquisas do tipo levantamento, importantes para a realização deste trabalho, e também quatro trabalhos relacionados referentes a outros levantamentos similares. Dois desses levantamentos haviam sido realizados no exterior, e outros dois no Brasil.

O levantamento realizado foi apresentado desde o seu planejamento, condução até a análise dos resultados. Um total de 613 respostas válidas foi utilizada no levantamento.

A análise das estatísticas descritivas e das inferências efetuadas mostram que há um longo caminho a ser trilhado para a efetiva incorporação da acessibilidade em projetos de sistemas Web no Brasil.

O número de pessoas que afirmam estar cientes sobre os conceitos, legislação e técnicas para acessibilidade ainda é bastante pequeno. A necessidade de maior divulgação da legislação e de diretrizes de acessibilidade, bem como a necessidade de mais treinamento sobre o tema são fatores muito importantes para a maior disseminação da acessibilidade.

No próximo capítulo, são apresentadas as conclusões gerais deste trabalho e apontamentos para trabalhos futuros. 


\section{Conclusões e trabalhos futuros}

\subsection{Contribuições}

Neste trabalho, o principal objetivo proposto foi a investigação da percepção da questão da acessibilidade no contexto de desenvolvimento de projetos de sistemas Web no Brasil. Assim, a principal contribuição do trabalho corresponde ao levantamento realizado com pessoas envolvidas em projetos de sistemas Web de todo o Brasil. Entretanto, diversas outras contribuições obtidas durante o progresso do trabalho colaboram para a agregação de valor a esta contribuição principal.

O estudo realizado sobre o tema "acessibilidade", fundamental para a realização de todas as atividades envolvidas, foi importante para verificar que a introdução deste tema é fundamental para a promoção da inclusão de todas as pessoas na "Sociedade da informação". Acessibilidade é hoje uma das grandes questões a serem tratadas para enfrentar o desafio de garantir "acesso universal e participativo ao conhecimento".

A partir da realização do levantamento por meio do uso de técnicas de revisão sistemática, pôde-se concluir que a acessibilidade tem sido objeto de estudo de muitas pesquisas, e que essas pesquisas têm crescido em número e abrangência nos últimos anos. Contudo, este levantamento também mostrou que, do ponto de vista de processos de desenvolvimento, ainda há muito o que ser explorado para desenvolver técnicas para apoiar a introdução da acessibilidade no desenvolvimento Web.

Em particular, o estudo sobre métricas de acessibilidade propostas na literatura mostrou que a necessidade de verificar quantitativamente e monitorar acessibilidade é crescente. A análise sobre as métricas efetuada neste trabalho é uma das mais abrangentes encontradas na literatura, 
abrangendo desde as primeiras métricas propostas até métricas propostas muito recentemente, com discussões e análises sobre a aplicabilidade das métricas.

Além do estudo aprofundado sobre as métricas, uma outra contribuição importante do trabalho foi a proposta e implementação de um módulo para apoiar os procedimentos de medição de acessibilidade a partir de avaliação automática com diretrizes. A realização dos dois estudos de caso com sítios governamentais nas esferas estadual e municipal no Brasil também foram importantes para as análises quantitativas que demonstram a grande necessidade de melhoria da acessibilidade das páginas governamentais.

Finalmente, a partir dos resultados alcançados por meio dos estudos e implementações realizados, foi possível obter conclusões interessantes e abrangentes sobre a acessibilidade no desenvolvimento de sistemas Web no Brasil. A realização do questionário com a participação de mais de 600 pessoas de todo o Brasil revelou questões interessantes e apontou diretrizes estratégicas para a melhoria da acessibilidade no Brasil, a partir da inquietante constatação de que somente 19,9\% dos participantes afirmam considerar acessibilidade em seus projetos, no período da veiculação do questionário.

Os resultados das análises descritivas e inferências estatísticas confirmam diversas premissas, principalmente de que somente o conhecimento de aspectos técnicos não é suficiente para uma conscientização efetiva sobre as necessidades de diferentes tipos de usuários. Também verificouse que a inserção da acessibilidade de forma efetiva na formação das pessoas envolvidas com desenvolvimento é uma necessidade crucial. Além disso, as respostas mostram que a legislação de acessibilidade brasileira ainda é menos efetiva do que deveria ser e, portanto, novos mecanismos de divulgação e de regulamentação devem ser instituídos.

A realização deste trabalho de mestrado também foi muito importante para contribuir com a formação do autor como pesquisador. A utilização de métodos científicos e o aprendizado com a busca por soluções para os problemas encontrados colaboraram muito para o desenvolvimento de habilidades para o desenvolvimento de pesquisas futuras em nível de doutorado. Além disso, o projeto proporcionou muitas oportunidades para aprofundar o conhecimento sobre conceitos de Estatística, de Interação Humano-Computador e de Engenharia de Software.

\subsection{Limitações}

Durante todo o desenvolvimento do trabalho, buscou-se realizar todas as atividades com o devido rigor científico. Entretanto, as contribuições apresentadas apresentam limitações devido tanto ao escopo da proposta para este projeto, pelo tempo para realização, por restrições inerentes à metodologia utilizada e por outras variáveis.

Do levantamento da literatura realizado sobre técnicas, não foi possível utilizar completamente o método de revisão sistemática, devido à grande abrangência do tema e à dificuldade em definir uma questão de pesquisa tão específica quanto é necessária para este método. 
$\mathrm{Na}$ análise das páginas realizadas por meio do uso de métricas, uma grande limitação imposta pelas métricas encontradas é a falta de coeficientes para barreiras definidos por meio de resultados experimentais. Assim, a maioria dos valores utilizados fornecem dados a partir dos pesos das barreiras em relação a diretrizes, e não necessariamente sobre a percepção real de usuários.

Além das limitações das métricas, uma outra limitação do trabalho é a utilização de mecanismos de avaliação baseados unicamente em métodos automáticos. Muitos pontos de verificação necessitam de métodos de inspeção manuais e testes com usuários. Entretanto, como foi proposta a realização de avaliação de um grande volume de páginas, seria inviável utilizar tais métodos. Desta forma, as conclusões sobre a avaliação se restringem à aderência ou não aos critérios passíveis de avaliação automática.

Finalmente, o questionário realizado também apresenta limitações referentes ao processo de amostragem e à forma de preenchimento. Infelizmente não foi possível utilizar amostragem probabilística, dada a dificuldade em delimitar a população. Apesar da tentativa de distribuir os respondentes entre os grupos de pessoas do ambiente acadêmico, indústria e governo, a participação de pessoas da indústria e do governo foi aquém do esperado. Além disso, o fato de o questionário ter sido respondido por meio de formulários Web impede que se certifique a veracidade das afirmações fornecidas pelos participantes.

\subsection{Trabalhos futuros}

A realização deste trabalho criou diversas perspectivas para a realização de trabalhos futuros como continuação desta pesquisa.

Novas estratégias para treinamento de pessoas envolvidas com desenvolvimento de projetos Web deverão ser investigadas, de forma a proporcionar um maior contato com os problemas reais enfrentados pelos usuários e familiarização com o uso de tecnologias assistivas em inspeções e testes com usuários.

Deverão ser realizados estudos por meio do método de revisão sistemática com o objetivo de investigar de maneira mais aprofundada o panorama sobre a acessibilidade a partir da análise sistemática de estudos exploratórios reportados na literatura. A condução de revisões sistemáticas com vistas à verificação da efetividade da utilização de métodos populares de inspeção também se apresenta como uma perspectiva de pesquisa promissora.

Serão realizados também estudos com análises com diferentes leituras dos dados coletados, com separação por segmentos e análise comparativa entre diferentes grupos. Também deverão ser analisadas questões ligadas ao relacionamento entre os pontos de vista sobre a percepção de acessibilidade por participantes que são membros de uma mesma organização.

Mais estudos sobre a utilização de métricas de acessibilidade no processo de desenvolvimento de sistemas Web deverão ser realizadas. Aspectos sobre o impacto da percepção dos usuários sobre as barreiras e a efetividade do uso de métricas derivadas da percepção do usuário deverão ser alvo 
de investigação de pesquisas do candidato em seu trabalho de doutorado. Também deverão ser examinadas as questões ligadas à utilização de métricas de acessibilidade a partir de outras formas de avaliação de acessibilidade diferentes da avaliação por revisão de diretrizes.

O aprimoramento do módulo para cálculo de métricas com vistas à utilização em avaliações com o e-MAG e melhoria do desempenho serão realizados no contexto do projeto "Suporte para avaliação de acessibilidade de Web sites baseada em métricas de acordo com o e-MAG”, financiado pelo $\mathrm{CNPq}^{1}$. O projeto, de co-autoria do autor desta dissertação será coordenado pela Profa. Dra. Débora Maria Barroso Paiva, do DCT-UFMS, e será desenvolvido com a participação do ICMCUSP, com início previsto para janeiro de 2008.

No projeto "PorSimples", financiado pela Fapesp com o apoio da Microsoft, serão investigadas questões de acessibilidade relacionadas à simplificação de textos em língua portuguesa pra analfabetos funcionais e pessoas com outras limitações relacionadas à linguagem, como por exemplo, pessoas com surdez, dislexia, entre outros. O projeto entrou em vigor em dezembro de 2007.

\subsection{Produção científica}

\section{Artigos completos em periódicos}

1. Freire, A. P., Paiva, D. M. B., Turine, M. A. S., Fortes, R. P. M. 2007. "Using screen readers to reinforce web accessibility education”. ACM SIGCSE Bull. 39, 3 (Jun. 2007), 82-86, ACM Press.

\section{Artigos completos em anais de eventos}

1. Freire, A. P., Bittar, T. J., Fortes, R. P. M. “An approach based on metrics for monitoring Web accessibility in Brazilian municipalities Web sites" . In: Proceedings of the 23rd Annual ACM Symposium on Applied Computing (ACM SAC'08'). (Fortaleza, CE, Brazil, March 16 - 20, 2008). ACM SAC'08. ACM Press, New York, NY, p. 2420 - 2424.

2. Freire, A. P., Goularte, R., Fortes, R. P. M. 2007. “Techniques for developing more accessible web applications: a survey towards a process classification". In Proceedings of the 25th Annual ACM international Conference on Design of Communication (El Paso, Texas, USA, October 22 - 24, 2007). SIGDOC ’07. ACM, New York, NY, 162-169.

3. Freire, A. P., Tanaka, E. H., Lara, S. M. A., Rocha, H. V., Fortes, R. P. M. "Comparing Accessibility in e-learning Web environments: a metric based approach". In: Proceedings of the XIII Brazilian Symposium on Multimedia and the Web (WebMedia'07), 2007, Gramado, RS. Porto Alegre, RS: ACM Press, 2007. v.1. p.49-56.

\footnotetext{
${ }^{1}$ Processo CNPq551017/2007-4 - Edital MCT/CNPq/CT-INFO nº 07/2007 - Grandes desafios da computação
} 


\section{Artigos resumidos em anais de eventos}

1. Oliveira Jr, E. A., Motti, V. G., Freire, A. P., Fortes, R. P. M. "Supporting Web Page Accessibility by using Earl Reports". In: Proceedings of The XIII Brazilian Symposium on Multimedia and the Web, 2007, Gramado, RS. Porto Alegre, RS :SBC, 2007. p. 32-36.

\section{Relatórios técnicos}

1. Freire, A. P., Goularte, R., Fortes, R. P. M. "Técnicas para desenvolvimento de aplicações Web mais acessíveis”. Relatórios técnicos do ICMC-USP, número 303, 2007.

\section{Outras publicações geradas durante o mestrado}

1. Paiva, D. M. B. ; Freire, A. P. ; Lucredio, D. ; Braga, R. T. V. ; Fortes, R. P. M. "Reinforcing Design Rationale in Software Projects Developed in Academic Environment". International Transactions on Systems Science and Applications. v. 3, n. 3 (Oct. 2007), 238-248, Xiaglow Research.

2. Carvalho, D. F., Estrella, J. C., Freire, A. P., Goularte, R., Santana, R. H., and Fortes, R. P. M. 2007. "Functional and device interoperability in an architectural model of geographic information system". In Proceedings of the 25th Annual ACM international Conference on Design of Communication (El Paso, Texas, USA, October 22 - 24, 2007). SIGDOC '07. ACM, New York, NY, 127-133.

3. Freire, A. P. ; Lara, S. M. A. ; Fortes, R. P. M. "Engenharia de Usabilidade na Web: um estudo de caso". In: Anais do XII Simpósio Brasileiro de Sistemas Multimídia e WEB (WebMedia'06) - SBC, 2006, Natal, RN. Porto Alegre,RS : SBC, 2006. v. 1. p. 32-35.

4. Paiva, D. M. B. ; Freire, A. P. ; Fortes, R. P. M. "Design Rationale in Academic Software Development: Requirements for a Representation Model". In: Proceedings of the International Conference on Software Engineering \& Knowledge Engineering (SEKE), 2006, San Francisco. p. 469-472. 



\section{Referências Bibliográficas}

Abascal, J.; Arrue, M.; Fajardo, I.; Garay, N.; Tomas, J. The use of guidelines to automatically verify web accessibility. Universal Access in the Information Society, v. 3, n. 1, p. 71-79, 2004.

Disponível em: http://dx.doi.org/10.1007/s10209-003-0069-3 (Acessado em Janeiro/2007)

ACESSIBILIDADE BRASIL daSilva. 2007.

Disponível em: http: / / www. dasilva.org.br (Acessado em Janeiro/2007)

Ahmad, R.; Zhang, L.; AzAm, F. Measuring navigational burden. In: Fourth International Conference on Proceedings of Software Engineering Research, Management and Applications, , IEEE, 2006, p. 307-314.

Atkinson, M. T.; Dhiensa, J.; Machin, C. H. C. Opening up access to online documents using essentiality tracks. In: W4A: Proceedings of the 2006 international cross-disciplinary workshop on Web accessibility (W4A), New York, NY, USA: ACM Press, 2006, p. 6-13.

Ault, H.; Deloge, J.; Lapp, R.; Morgan, M.; Barnett, J. Evaluation of long descriptions of statistical graphics for blind and low vision web users. In: Proceedings of 8th International Conference on Computers Helping People with Special Needs, Linz, Austria: Springer Berlin / Heidelberg, 2002, p. 517.

BAIley, J.; Burd, E. Tree-map visualisation for web accessibility. In: Proceedings of 29th Annual International Computer Software and Applications Conference, 2005. COMPSAC 2005, 2005, p. 275-280.

Beirekdar, A.; Keita, M.; Noirhomme, M.; Randolet, F.; Vanderdonckt, J.; Mariage, C. Flexible reporting for automated usability and accessibility evaluation of web sites. In: Proceedings of 2005 Internacional Conference on Human-Computer Interaction, Springer Berlin / Heidelberg, 2005, p. 281-294.

Benavídez, C.; Fuertes, J.; Gutiérrez, E.; Martínez, L. Semi-Automatic Evaluation of Web Accessibility with HERA 2.0. In: Proceedings of the 10th International Conference on Computers Helping People with Special Needs (ICCHP 2006), Springer, 2006, p. 199-106.

Benavídez, C.; Fuertes, J. L.; Gutiérrez, E.; Martínez, L. Teaching web accessibility with contramano and hera. In: Proceedings of 10h Internacional Conference on Computers Helping People With Special Needs, Springer Berlin / Heidelberg, 2006, p. 341-348.

BERLISS-VINCENT, J. International websites relating to assistive technology \& universal design. Disability World, , n. 2, 2000.

Disponível em: http: / /www.disabilityworld.org/ (Acessado em Janeiro/2007) 
Biolchini, J.; Mian, P.; Natali, A.; Travassos, G. Systematic review in software engineering: Relevance and utility. Relatório Técnico RT - ES 679/05, PESC - COPPE/UFRJ, 2005.

Disponível em: http: / / cronos.cos.ufrj.br/publicacoes/reltec/es67905.pdf (Acessado em Fevereiro/2007)

BITTAR, T. J. Abordagem para diagnóstico de problemas em aplicações de e-gov - um retrato dos municípios brasileiros. Dissertação de Mestrado, Departamento de Computação (DC), Universidade Federal de São Carlos (UFSCar), 2006.

Bittar, T. J.; Silva, J. C. A.; Penteado, R. A. D.; Filgueiras, L. Short presentation of 'e-govmeter municipios', a brazilian monitoring system of electronic government (e-gov) municipal web services. In: Proceedings of X Brazilian Symposium on Multimedia and the Web (WebMedia), ACM Press, 2005.

BoldyrefF, C.; Burd, E.; Donkin, J.; Marshall, S. The case for the use of plain english to increase web accessibility. In: Proceedings of 3rd International Workshop on Web Site Evolution, IEEE, 2001, p. 42-48.

Brajnik, G. Comparing accessibility evaluation tools: a method for tool effectiveness. Univers. Access Inf. Soc., v. 3, n. 3, p. 252-263, 2004a.

BRAJNIK, G. Using automatic tools in accessibility and usability assurance processes. In: Proceedings of 8th ERCIM Workshop on User Interfaces for All, Viena, Austria: Springer Berlin / Heidelberg, 2004b, p. $219-234$.

BrajNIK, G. Web accessibility testing: When the method is the culprit. In: Proceedings of 10th International Conference on Computers Helping People with Special Needs, Linz, Austria: Springer Berlin / Heidelberg, 2006, p. 156-163.

Bühler, C.; Heck, H.; Perlick, O.; Nietzio, A.; Ulltveit-Moe, N. Interpreting results from large scale automatic evaluation of web accessibility. In: Computers Helping People with Special Needs, Springer Berlin / Heidelberg, 2006, p. 184-191.

Centeno, V. L.; Kloos, C. D.; Gaedke, M.; Nussbaumer, M. Web composition with wcag in mind. In: W4A '05: Proceedings of the 2005 International Cross-Disciplinary Workshop on Web Accessibility (W4A), New York, NY, USA: ACM Press, 2005, p. 38-45.

Ceri, S.; Fraternali, P.; Bongio, A. Web Modeling Language (WebML): a modeling language for designing Web sites. In: Proceedings of the 9th international World Wide Web conference on Computer networks : the international journal of computer and telecommunications netowrking, Amsterdam, The Netherlands, The Netherlands: North-Holland Publishing Co., 2000, p. 137-157.

Chen, Y.-L.; Chen, Y.-Y.; Shao, M. 2005 accessibility diagnosis on the government web sites in taiwan, r.o.c. In: W4A: Proceedings of the 2006 international cross-disciplinary workshop on Web accessibility (W4A), New York, NY, USA: ACM Press, 2006, p. 132-142.

ChÊne, D.; HoËL, M. Web site accessibility auditing tool for visually deficient persons ocawa. In: Proceedings of 8th International Conference on Computers Helping People with Special Needs, Linz, Austria, 2002, p. 27.

Cluster, W. W. A. B. Unified Web Evaluation Methodology (UWEM 0.5). 2006 a.

Disponível em: http: / / www. wabcluster.org/uwem05/ (Acessado em Janeiro/2007)

Cluster, W. W. A. B. Unified Web Evaluation Methodology (UWEM 1.0). $2006 \mathrm{~b}$.

Disponível em: http: / / www . wabcluster. org/uwem/ (Acessado em Janeiro/2007) 
Conallen, J. Building Web Applications with UML. second ed. Addison-Wesley, 468p p., 2002.

Conte, T. U.; Mendes, M. E.; Travassos, G. H. Processos de Desenvolvimento para Aplicações Web: Uma Revisão Sistemática. In: Proccedings of XI Brazilian Symposium on Multimedia and Web, Pocos de Caldas: Brazilian Computer Society, 2005, p. 63-75.

Cook, A. M.; Hussey, S. M. Assistive technologies: Principles and practice. 2a ed. Mosby - Year Book, Inc., 523 p., 2001.

CORReAni, F.; LePOrini, B.; PATERnÒ, F. Automatic inspection-based support for obtaining usable web sites for vision-impaired users. Universal Access in the Information Society, v. 5, n. 1, p. 82-95, 2005.

Costagliota, G.; Ferrucci, F.; Francese, R. Handbook of software engineering and knowledge engineering, emerging technologies, cáp. Web Engineering: Models and Methodologies for Design of Hypermedia Applications World Scientific Publishing, p. 181-199, 2002.

Deshrande, Y.; Murugesan, S.; Ginige, A.; Hansen, S.; Schwabe, D.; Gaedke, M.; ; White, B. Web Engineering. Journal of Web Engineering, v. 1, n. 1, p. 3-17, 2002.

Disponível em: http://www.rintonpress.com/xjwe1/jwe-1-1/003-017.pdf (Acessado em Janeiro/2007)

DiX, A.; Finlay, J. E.; Abowd, G. D.; Beale, R. Human-computer interaction. 3a ed. Prentice Hall, 832 p., 2003.

ENABLED Enabled web developer survey. 2005.

Disponível em: http://www. enabledweb.org/public_results/survey_results/analysis. html (Acessado em Acesso em fevereiro/2007)

FAPESP TIDIA-Ae - Tecnologia da Informação no Desenvolvimento da Internet Avançada - Aprendizado Eletrônico. 2008.

Disponível em: http: //tidia-ae. incubadora. fapesp.br/portal (Acessado em Janeiro de 2008)

Fenton, N. E.; Pfleeger, S. L. Software metrics: A rigorous and practical approach. Boston, MA, USA: PWS Publishing Co., 1998.

Ferreira, S. B. L.; Santos, R. C.; Silveira, D. S. Panorama da Acessibilidade na Web Brasileira. In: Anais do XXXI Encontro da ANPAD - EnANPAD, 2007, p. 17p.

Filepp, R.; Challenger, J.; Rosu, D. Improving the accessibility of aurally rendered html tables. In: Assets '02: Proceedings of the fifth international ACM conference on Assistive technologies, New York, NY, USA: ACM Press, 2002, p. 9-16.

Fons, J.; Pelechano, V.; Albert, M.; Pastor, O. Development of web applications from web enhanced conceptual schemas. In: Conceptual Modeling - ER 2003, Springer Berlin / Heidelberg, 2003, p. $232-245$.

Fortes, R. P. M.; Lara, S. M. A.; Freire, A. P.; Pansanato, L. T. E. Minicursos do Webmedia 2005, v. 1, cáp. 7- Acessibilidade no Projeto de Aplicações Web. 1 ed Belo Horizonte-MG: FuMARC Editora, p. 197-226, $2005 a$.

Fortes, R. P. M.; Pansanato, L. T. E.; LARA, S. M. A.; Freire, A. P. Minicursos do XVI Simpósio Brasileiro de Informática na Educação, v. 1, cáp. 2- Universalização do Acesso a Conteúdo Educacional em Aplicações Web. 1 ed Juiz de Fora-MG: Editar Editora Associada, p. 21-42, 2005 b. 
Fraternali, P.; Paolini, P. A conceptual model and a tool environment for developing more scalable, dynamic, and customizable web applications. In: Advances in Database Technology - EDBT'98, Springer Berlin / Heidelberg, 1998, p. 419-435.

FREEDOM SCIENTIFIC JAWS. 2006.

Disponível em: http: //www. freedomscientific.com/ (Acessado em Dezembro/2006)

Freire, A. P.; Bittar, T. J.; Fortes, R. P. M. An approach based on metrics for monitoring web accessibility in brazilian municipalities web sites. In: Proceedings of the 23rd Annual ACM Symposium on Applied Computing, ACM Press, 2008, p. 2420-2424.

Freire, A. P.; Fortes, R. P. M. Automatic accessibility evaluation of dynamic web pages generated through xslt. In: W4A '05: Proceedings of the 2005 International Cross-Disciplinary Workshop on Web Accessibility (W4A), New York, NY, USA: ACM Press, 2005, p. 81-84.

Freire, A. P.; Goularte, R.; Fortes, R. P. M. Técnicas para desenvolvimento de aplicações web acessíveis. Relatório Técnico 303, ICMC - University of Sao Paulo, Sao Carlos, SP, 2007a.

Freire, A. P.; Goularte, R.; Mattos Fortes, R. P. Techniques for developing more accessible web applications: a survey towards a process classification. In: SIGDOC '07: Proceedings of the 25th annual ACM international conference on Design of communication, New York, NY, USA: ACM, 2007b, p. 162-169.

Freire, A. P.; Mattos Fortes, R. P.; Paiva, D. M. B.; Turine, M. A. S. Using screen readers to reinforce web accessibility education. SIGCSE Bull., v. 39, n. 3, p. 82-86, 2007c.

Freire, A. P.; TAnaka, E. H.; Lara, S. M. A.; Rocha, H. V.; Fortes, R. P. M. Comparing accessibility in web based e-learning environments: a metric based approach. In: Proceedings of the XIII Brazilian Symposium on Multimedia and the Web (Webmedia), ACM Press, 2007d, p. 49-56.

Freitas, H.; Oliveira, M.; Saccol, A. Z.; Moscarola, J. O método de pesquisa survey. Revista de Administração da USP, RAUSP, v. 35, n. 3, p. 105-112, 2000.

Fukuda, K.; Saito, S.; Takagi, H.; Asakawa, C. Proposing new metrics to evaluate web usability for the blind. In: CHI '05: CHI '05 extended abstracts on Human factors in computing systems, New York, NY, USA: ACM Press, 2005, p. 1387-1390.

FUNDAÇÃo SAKAI Projeto sakai. 2008.

Disponível em: http: / / www. sakaiproject.org (Acessado em Janeiro de 2008)

Gellenbeck, E. Integrating accessibility into the computer science curriculum. J. Comput. Small Coll., v. 21, n. 1, p. 267-273, 2005.

GIL, A. Como elaborar projetos de pesquisa. Atlas, 1991.

Gjøsæter, T.; Nytun, J. P.; Prinz, A.; Snaprud, M.; Tveit, M. S. Modelling accessibility constraints. In: Proceedings of 10th International Conference on Computers Helping People with Special Needs, Springer Berlin / Heidelberg, 2006, p. 40-47.

Goette, T.; Collier, C.; White, J. D. An exploratory study of the accessibility of state government Web sites. Universal Access in the Information Society, v. 5, n. 1, p. 41-50, 2006. 
GonzÁlez, J.; Macías, M.; RodríGuez, R.; SÁnchez, F. Accessibility metrics of web pages for blind endusers. In: Proceedings of 2003 International Conference on Web Engineering, Oviedo, Spain: Springer Berlin / Heidelberg, 2003, p. 374-383.

Governo Brasileiro Modelo de Acessibilidade de Governo Eletrônico - versão 2.0. 2008.

Disponível em: http: //www.governoeletronico.gov.br/emag/(Acessado em Janeiro/2008)

Hackett, S.; Parmanto, B.; Zeng, X. Accessibility of internet websites through time. In: Assets '04: Proceedings of the 6th international ACM SIGACCESS conference on Computers and accessibility, New York, NY, USA: ACM Press, 2004, p. 32-39.

Herramhof, S.; Petrie, H.; Strobbe, C.; Vlachogiannis, E.; Weimann, K.; Weber, G.; Velasco, C. A. Test case management tools for accessibility testing. In: Proceedings of 10th International Conference on Computers Helping People With Disabilities, Linz, Austria: Springer Berlin / Heidelberg, 2006, p. $215-222$.

Hoffman, D.; E. GRIVEL, L. B. Designing software architectures to facilitate accessible web applications. IBM Systems Journal, v. 44, n. 3, p. 467, 2005.

Horton, S. Designing beneath the surface of the web. In: W4A: Proceedings of the 2006 international crossdisciplinary workshop on Web accessibility (W4A), New York, NY, USA: ACM Press, 2006, p. 1-5.

HTTRACK HTTrack - Web site copier. 2008.

Disponível em: Disponívelemhttp: / / www . httrack . com (Acessado em Janeiro de 2008)

Hull, L. Accessibility: it's not just for disabilities any more. Interactions, v. 11, n. 2, p. 36-41, 2004.

IBGE Censo demográfico 2000. 2000.

Disponível em: http: / /www.ibge.gov.br/censo/ (Acessado em Janeiro/2007)

IBGE Síntese de indicadores sociais 2004. estudos e pesquisas: Informação demográfica e socioeconômica. 2005.

Disponível em: http://www.ibge.gov.br/home/estatistica/populacao/condicaodevida/ indicadoresminimos/sinteseindicsociais2004/default.shtm (Acessado em Fevereiro/2007)

INTERnET ARQUIVE Way Back Machine. 2008.

Disponível em: Disponívelemhttp: / / www. archive.org (Acessado em Janeiro de 2008)

ISO - INTERNATIONAL STANDARD ORGANIZATION (ISO/IEC 12207) Standard for Information TechnologySoftware Lifecycle Processes. New York, NY, 85 S., 1998.

IVORY, M.; MANKOFF, J.; LE, A. Using automated tools to improve web site usage by users with diverse abilities. IT and Society, v. 1, n. 3, p. 195-236, 2003.

IVORY, M. Y. Automated web site evaluation : Researchers' and practitioners' perspectives. Kluwer Academic Publishers, 225 p., 2003.

King, M.; Thatcher, J. W.; Bronstad, P. M.; EAston, R. Managing usability for people with disabilities in a large web presence. IBM Systems Journal, v. 44, n. 3, p. 519, 2005.

KIRCHNER, M. Benchmark for testing the evaluation tools for web pages accessibility. In: Proceedings of Fifth IEEE International Workshop on Web Site Evolution - Theme: Architecture, 2003, p. 66-73. 
Kitchenham, B. Procedures for performing systematic reviews. Joint Technical Report Software Engineering Group, Department of Computer Science Keele University, United King and Empirical Software Engineering, National ICT Australia Ltd, Australia., 2004.

Disponível em: http://www.elsevier.com/inca/publications/misc/inf-systrev.pdf (Acessado em Janeiro/2007)

Kitchenham, B.; Mendes, M. E.; Travassos, G. H. A Systematic Review of Cross-vs. Within-Company Cost Estimation Studies. In: 10th International Conference on Evaluation and Assessment in Software Engineering, Staffordshire, 2006, p. 47-55.

Koch, N.; Kraus, A. The expressive Power of UML-based Web Engineering. In: Proc. of Second International Workshop on Web-oriented Software Technology (IWWOST02), 2002, p. 105-119.

Kouroupetroglou, C.; Salampasis, M.; Manitsaris, A. A semantic-web based framework for developing applications to improve accessibility in the www. In: W4A: Proceedings of the 2006 international crossdisciplinary workshop on Web accessibility (W4A), New York, NY, USA: ACM Press, 2006, p. 98-108.

Kurniawan, S.; Zaphiris, P. Research-derived web design guidelines for older people. In: Assets '05: Proceedings of the 7th international ACM SIGACCESS conference on Computers and accessibility, New York, NY, USA: ACM Press, 2005, p. 129-135.

LAW, C.; JACKO, J.; EdWARds, P. Programmer-focused website accessibility evaluations. In: Assets '05: Proceedings of the 7th international ACM SIGACCESS conference on Computers and accessibility, New York, NY, USA: ACM Press, 2005, p. 20-27.

Lazar, J.; Dudley-Sponaugle, A.; Greenidge, K. Improving Web Accessibility: A Study of Webmaster Perceptions. Computers and Human Behavior, v. 20, n. 2, p. 269-288, 2004.

LEPORINI, B.; PATERNÒ, F. Increasing usability when interacting through screen readers. Universal Access in the Information Society, v. 3, n. 1, p. 57-70, 2004.

LePorini, B.; PATERnò, F.; SCORCIA, A. An environment for defining and handling guidelines for the web. In: Proceedings of 10th International Conference on Computers Helping People with Special Needs, Linz, Austria: Springer Berlin / Heidelberg, 2006, p. 176-183.

Lucca, G. A. D.; Fasolino, A. R.; Tramontana, P. Web site accessibility: identifying and fixing accessibility problems in client page code. In: Proceedings of Seventh IEEE International Symposium Web Site Evolution, 2005. (WSE 2005), 2005, p. 71-78.

MacíAs, M.; GonZÁlez, J.; SÁncheZ, F. On adaptability of web sites for visually handicapped people. In: Second International Conference on Adaptive Hypermedia and Adaptive Web-Based Systems: Second International Conference, Springer Berlin / Heidelberg, 2002, p. 264.

Mafra, S. N.; Travassos, G. H. Tecnicas de Leitura de Software: Uma Revisão Sistemática. In: Proceedings of XIX Brazilian Symposium on Software Engineering, Uberlandia-Brazil: Brazilian Computer Society, 2005, p. 72-87.

MasuWA-Morgan, K. R.; BurRell, P. Justification of the need for an ontology for accessibility requirements (Theoretic framework). Interacting with Computers, v. 16, p. 523-555, 2004.

Mattar, F. Pesquisa de marketing. Atlas, 1996. 
Melo, A. M.; Baranauskas, M. C. C. Design e avaliação de tecnologia web-acessível. In: Jornadas de Atualização em Informática - Congresso da SBC, 2005, SBC, 2005, p. 1500-1545.

Melo, A. M.; Baranauskas, M. C. C. An inclusive approach to cooperative evaluation of web user interfaces. In: Proceedings of Eigth International Conference on Enterprise Information Systems, Paphos, Cyprus, $2006 \mathrm{a}, \mathrm{p}$. 65-70.

Melo, A. M.; Baranauskas, M. C. C. Simpósio sobre Fatores Humanos em Sistemas Computacionais, Simpósio Brasileiro de Sistemas Multimídia e Web e Simpósio Brasileiro de Sistemas Colaborativos, v. 1, cáp. Design inclusivo de sistemas de informação na Web. 1 ed Natal, RN: SBC, p. 167-212, 2006b.

Melo, A. M.; Baranauskas, M. C. C. Uma opção inclusiva à avaliação cooperativa de interfaces de usuário. In: Anais do XXVI Congresso da Sociedade Brasileira de Computação, XXXIII SEMISH, SBC, 2006c, p. $447-461$.

Mirabella, V.; Kimani, S.; CATARCi, T. A no-frills approach for accessible web-based learning material. In: W4A '04: Proceedings of the 2004 international cross-disciplinary workshop on Web accessibility (W4A), New York, NY, USA: ACM Press, 2004, p. 19-27.

Moehling, J. L.; Smith, R. L.; Stewart, M. D.; Swenson, J. A. Considering accessibility for visually impaired users [web site design]. In: Proceedings of IEEE International Professional Communication Conference, 1999. IPCC 99. Communication Jazz: Improvising the New International Communication Culture, 1999, p. 335343.

Moodle Moodle - A Free, Open-Source Course Management System for Online Learning. 2008. Disponível em: http: / / www. moodle.org (Acessado em Janeiro de 2008)

NCE-UFRJ Projeto DOSVOX. 2007.

Disponível em: http: // intervox.nce.ufrj.br/dosvox/ (Acessado em Janeiro/2007)

Neter, J.; Kutner, M. H.; Nachtsheim, C. J.; Wasserman, W. Applied linear regression models. 3 ed. Irwin, Illinois, 720 p., 1996.

NiAZI, M.; StaPles, M. Systematic Review of Organizational Motivations for Adopting CMM-based SPI. Relatório Técnico PA005957, National ICT Australia Technical Report, 2006.

Nielsen, J. Designing Web Usability. Peachpit Press, 432 p., 2000.

Olsina, L.; Lafuente, G.; Rossi, G. Specifying quality characteristics and attributes for websites. In: Web Engineering : Software Engineering and Web Application Development, Springer Berlin / Heidelberg, 2001, p. 266-279.

OlsinA, L.; Rossi, G. Measuring Web Application Quality with WebQEM. IEEE MultiMedia, v. 9, n. 4, p. 20-29, 2002.

Disponível em: http: //dx.doi.org/10.1109/MMUL.2002.1041945 (Acessado em Janeiro/2007)

PAdDisOn, C.; ENGLEFIELD, P. Applying heuristics to perform a rigorous accessibility inspection in a commercial context. In: CUU '03: Proceedings of the 2003 conference on Universal usability, New York, NY, USA: ACM Press, 2003, p. 126-133.

Paddison, C.; Englefield, P. Applying heuristics to accessibility inspections. Interacting with Computers, v. 16, p. 507-521, 2004. 
PARmanto, B.; ZENG, X. Metric for Web accessibility evaluation. Journal of the American Society for Information Science and Technology, v. 56, n. 33, p. 1394-1404, 2005.

PATERnò, F. Models for universal usability. In: IHM 2003: Proceedings of the 15th French-speaking conference on human-computer interaction on 15eme Conference Francophone sur l'Interaction Homme-Machine, New York, NY, USA: ACM Press, 2003, p. 9-16.

PAUlA, G. A. Modelos de regressão com apoio computacional. IME-USP, 253 p., 2004.

Disponível em: http: / / www. ime.usp.br/ giapaula/livro.html (Acessado em Janeiro de 2008)

Paula, G. A. Modelos lineares generalizados. 2008.

Disponível em: http://www.ime.usp.br/ giapaula/slides3_mlgs_07.pdf (Acessado em Janeiro de 2008)

Perlman, G. Achieving universal usability by designing for change. IEEE Internet Computing, v. 6, n. 2, p. 46-55, 2002.

Petrie, H.; Hamilton, F.; King, N. Tension? what tension?: website accessibility and visual design. SIGCAPH Comput. Phys. Handicap., , n. 76, p. 6-7, 2003.

Petrie, H.; Hamilton, F.; King, N.; Pavan, P. Remote usability evaluations with disabled people. In: $C H I$ '06: Proceedings of the SIGCHI conference on Human Factors in computing systems, New York, NY, USA: ACM Press, 2006, p. 1133-1141.

Pinsonneault, A.; Kraemer, K. Survey research methodology in management information systems: an assessment. Journal of Management Information Systems, v. 10, n. 2, p. 75-105, 1993.

Plessers, P.; Casteleyn, S.; Yesilada, Y.; Troyer, O. D.; Stevens, R.; Harper, S.; Goble, C. Accessibility: a web engineering approach. In: WWW'05: Proceedings of the 14th international conference on World Wide Web, New York, NY, USA: ACM Press, 2005, p. 353-362.

Plone Plone: A user-friendly and powerful open source Content Management System. 2007. Disponível em: http: / / www.plone.org (Acessado em Janeiro/2007)

Pressman, R. Engenharia de Software. 6a ed. McGraw-Hill, 880 p., 2006.

R Development Core Team R: A language and environment for statistical computing. R Foundation for Statistical Computing, Vienna, Austria, ISBN 3-900051-07-0, 2007.

Disponível em: http://www.R-project.org

REgan, B. Accessibility and design: a failure of the imagination. In: W4A '04: Proceedings of the 2004 international cross-disciplinary workshop on Web accessibility (W4A), New York, NY, USA: ACM Press, 2004, p. 29-37.

Rocha, H. V.; Baranauskas, M. C. C. Design e Avaliação de Interfaces Humano-Computador. EdUnicamp, 2003.

Rosmaita, B. J. Accessibility first!: a new approach to web design. In: SIGCSE '06: Proceedings of the 37th SIGCSE technical symposium on Computer science education, New York, NY, USA: ACM Press, 2006, p. 270274. 
Rowan, M.; Gregor, P.; SloAn, D.; BоOth, P. Evaluating web resources for disability access. In: Assets '00: Proceedings of the fourth international ACM conference on Assistive technologies, New York, NY, USA: ACM Press, 2000, p. 80-84.

Schwabe, D.; Rossi, G.; Barbosa, S. D. J. Systematic hypermedia application design with OOHDM. In: HYPERTEXT '96: Proceedings of the the seventh ACM conference on Hypertext, New York, NY, USA: ACM Press, 1996, p. 116-128.

SERPRO Acessibilidade na Web. 2004.

Disponível em: http://www.serpro.gov.br/acessibilidade (Acessado em Janeiro/2007)

Shull, F.; Mendonca, M. G.; Basili, V.; Carver, J.; Maldonado, J. C.; Fabbri, S.; Travassos, G. H.; FERreIRA, M. C. Knowledge-Sharing Issues in Experimental Software Engineering. Empirical Softw. Engg., v. 9, n. 1-2, p. 111-137, 2004.

Sloan, D.; Gregor, P.; Rowan, M.; Booth, P. Accessible accessibility. In: CUU '00: Proceedings on the 2000 conference on Universal Usability, New York, NY, USA: ACM Press, 2000, p. 96-101.

Sloan, D.; Heath, A.; Hamilton, F.; Kelly, B.; Petrie, H.; Phipps, L. Contextual web accessibility - maximizing the benefit of accessibility guidelines. In: W4A: Proceedings of the 2006 international crossdisciplinary workshop on Web accessibility (W4A), New York, NY, USA: ACM Press, 2006, p. 121-131.

Snaprud, M. H.; Ulltveit-Moe, N.; Pillai, A. B.; Olsen, M. G. A proposed architecture for large scale web accessibility assessment. In: Proceedings of 9th International Conference on Computers Helping People with Special Needs, Springer Berlin / Heidelberg, 2006, p. 234-241.

Sullivan, T.; Matson, R. Barriers to use: usability and content accessibility on the Web's most popular sites. In: CUU '00: Proceedings on the 2000 conference on Universal Usability, New York, NY, USA: ACM Press, 2000, p. 139-144.

Disponível em: http://doi.acm.org/10.1145/355460.355549 (Acessado em Fevereiro/2007)

Takagi, H.; Asakawa, C.; Fukuda, K.; Maeda, J. Accessibility designer: visualizing usability for the blind. In: Assets '04: Proceedings of the 6th international ACM SIGACCESS conference on Computers and accessibility, New York, NY, USA: ACM Press, 2004, p. 177-184.

TANGARIfE, T. M. A acessibilidade nos websites governamentais: um estudo de caso no site da eletrobrás. Dissertação de Mestrado, Departamento de Artes e Design, Pontifícia Universidade Católica do Rio de Janeiro (PUC-Rio), 2007.

TAngarife, T. M.; Mont'Alvão, C. O que os desenvolvedores brasileiros sabem sobre acessibilidade web e inclusão digital? In: Anais do $6^{\circ}$ USIHC - $6^{\circ}$ Congresso Internacional de Ergonomia e Usabilidade, Design de Interfaces e Interação Humano- Computador, 2006, p. 6p.

Thatcher, J.; Bohman, P.; Burks, M.; Henry, S. L.; Regan, B.; Swierenga, S.; Urban, M. Constructing accessible web sites. 1a ed. Glasshaus, 415 p., 2002.

Trewin, S.; Zimmermann, G.; VAnderheiden, G. Abstract representations as a basis for usable user interfaces. Interacting with Computers, v. 16, p. 477-506, 2004.

U.S. Government Section 508. 2007.

Disponível em: http: / / www . section508 . gov (Acessado em Janeiro/2007) 
VAnderdonckt, J.; Beirekdar, A.; Noirhomme-Fraiture, M. Automated evaluation of web usability and accessibility by guideline review. In: Proceedings of 4th International Conference, Munich, Germany: Springer Berlin / Heidelberg, 2004, p. 17-30.

VANDERHEIDEn, G. Fundamental principles and priority setting for universal usability. In: CUU '00: Proceedings on the 2000 conference on Universal Usability, New York, NY, USA: ACM Press, 2000, p. 32-37.

Vigo, M.; Arrue, M.; Brajnik, G.; Lomuscio, R.; AbAscal, J. Quantitative metrics for measuring web accessibility. In: W4A '07: Proceedings of the 2007 international cross-disciplinary conference on Web accessibility (W4A), New York, NY, USA: ACM Press, 2007, p. 99-107.

W3C HTML 4.01 Specification. 1999.

Disponível em: http: //www.w3 .org/TR/html4/ (Acessado em Janeiro/2007)

W3C Web Content Acessibility Guidelines 1.0. 1999a.

Disponível em: http://www.w3 .org/TR/WCAG10/ (Acessado em Fevereiro/2007)

W3C XSL Transformations (XSLT). Disponível online em http://www.w3c.org/TR/xslt. Acesso em janeiro/2004, 1999b.

W3C Authoring Tool Accessibility Guidelines 1.0. 2000.

Disponível em: http: / / www.w3.org/TR/ATAG10/ (Acessado em Fevereiro/2007)

W3C User Agent Accessibility Guidelines 1.0. 2002a.

Disponível em: http: / / www.w3 .org/TR/UAAG10/ (Acessado em Fevereiro/2007)

W3C XHTML - 1.0 The Extensible HyperText Markup Language (Second Edition). 2002b.

Disponível em: Disponívelemhttp: / / www.w3.org/TR/xhtml1/ (Acessado em Janeiro de 2008)

W3C Evaluating web sites for accessibility. Disponível online em http://www.w3c.org/WAI/eval. Acesso em novembro/2003, 2003.

W3C Earl Schema - Content Evaluation and Report Language (EARL) 1.0 Schema - Editors' Draft 23 March 2007. 2007a.

Disponível em: Disponívelemhttp://WwW.w3.org/TR/2007/WD-EARL10-Schema-20070323 (Acessado em Janeiro de 2008)

W3C Web Content Acessibility Guidelines 2.0 - Working Draft. 2007b.

Disponível em: http: / / www .w3.org/TR/WCAG20 / (Acessado em Dezembro/2007)

Y. TAKata, Y.; NaKamura, T.; SeKi, H. Accessibility verification of www documents by an automatic guideline verification tool. In: Proceedings of the 37th Annual Hawaii International Conference on System Sciences, IEEE CS, 2004, p. 10 pp.

ZAJICEK, M. Patterns for encapsulating speech interface design solutions for older adults. In: CUU '03: Proceedings of the 2003 conference on Universal usability, New York, NY, USA: ACM Press, 2003, p. 54-60.

ZAJICEK, M. Successful and available: interface design exemplars for older users. Interacting with Computers, v. 16, p. 411-430, 2004.

Zaphiris, P.; Ghiawadwala, M.; Mughal, S. Age-centered research-based web design guidelines. In: $\mathrm{CHI}$ '05: CHI '05 extended abstracts on Human factors in computing systems, New York, NY, USA: ACM Press, 2005, p. 1897-1900. 


\begin{tabular}{|l|l|}
\hline Termo & Definição \\
\hline API & $\begin{array}{l}\text { Application Program Interface: conjunto de rotinas disponibilizadas como } \\
\text { interface para utilização das funcionalidades de um software }\end{array}$ \\
\hline ABNT & Associação Brasileira de Normas Técnicas \\
\hline ATAG & $\begin{array}{l}\text { Authoring Tools Accessibility Guidelines (W3C, 2000): conjunto de diretri- } \\
\text { zes de acessibilidade para ferramentas de autoria }\end{array}$ \\
\hline Checkpoint & Vide Ponto de verificação \\
\hline Coeficiente de correlação & Coeficiente que indica o qual correlacionadas são duas variáveis aleatórias \\
\hline Crawler & Aplicação que navega automaticamente por páginas Web \\
\hline Diretriz & $\begin{array}{l}\text { Elemento referente a uma recomendação sobre como fazer determinada ta- } \\
\text { refa (usado como tradução para guideline) }\end{array}$ \\
\hline e-MAG & Modelo de Acessibilidade de Governo Eletrônico brasileiro \\
\hline Engenharia Reversa & $\begin{array}{l}\text { Processo de obter artefatos de software de fases anteriores do processo de } \\
\text { software a partir de outros documentos. Por exemplo, obter documentos de } \\
\text { projeto a partir de código fonte. }\end{array}$ \\
\hline Guideline & Vide Diretriz \\
\hline IBGE & Instituto Brasileiro de Geografia e Estatística \\
\hline ONG & Organização Não Governamental \\
\hline Ponto de verificação & $\begin{array}{l}\text { Elemento pontual de uma diretriz. Uma diretriz geralmente contém diversos } \\
\text { pontos de verificação }\end{array}$ \\
\hline URL & Uniform Resource Locator: endereço de um objeto na Web \\
\hline UUAG & $\begin{array}{l}\text { User Agent Accessibility Guidelines: diretrizes para acessibilidade de siste- } \\
\text { mas para usuários, como navegadores }\end{array}$ \\
\hline WCAG & $\begin{array}{l}\text { Web Content Accessibility Guidelines: diretrizes para criação de conteúdo } \\
\text { Web acessível }\end{array}$ \\
\hline &
\end{tabular}




\begin{tabular}{|l|l|}
\hline Termo & Definição \\
\hline W3C & $\begin{array}{l}\text { World Wide Web Consortium: organismo internacional responsável pela de- } \\
\text { finições de padrões para a Web }\end{array}$ \\
\hline XML & $\begin{array}{l}\text { eXtensible Markup Language: linguagem de marcação poderosa e extensí- } \\
\text { vel, que pode representar inúmeros tipos de dados na forma de documentos } \\
\text { estruturados }\end{array}$ \\
\hline XSLT & $\begin{array}{l}\text { XML Transformations: padrão para transformação de documentos XML em } \\
\text { outros tipos de documentos }\end{array}$ \\
\hline
\end{tabular}


Neste apêndice, são apresentadas as diretrizes e pontos de verificação do WCAG 1.0 (Web Content Accessibility Guidelines) do W3C (W3C, 1999a).

\section{Diretriz 1 - Fornecer alternativas ao conteúdo sonoro e visual}

1.1 Fornecer um equivalente textual a cada elemento não textual (Prioridade 1)

1.2 Fornecer links de texto redundantes relativos a cada região ativa de um mapa de imagem armazenado no servidor. (Prioridade 1)

1.3 Fornecer uma descrição sonora das informações importantes veiculadas em trechos visuais das apresentações multimídia, até que os agentes do usuário consigam ler, automaticamente e em voz alta, o equivalente textual dos trechos visuais. (Prioridade 1)

1.4 Em apresentações multimídia baseadas em tempo (filme ou animação), sincronizar as alternativas equivalentes (legendas ou descrições sonoras dos trechos visuais) e a apresentação. (Prioridade 1)

1.5 Fornecer links textuais redundantes para cada região ativa dos mapas de imagem no cliente, até que os agentes do usuário proporcionem equivalentes textuais dos links a mapas de imagem armazenados no cliente. (Prioridade 3) 


\section{Diretriz 2 - Não recorrer apenas à cor}

2.1 Assegurar que todas as informações veiculadas com cor estejam também disponíveis sem cor, por exemplo a partir do contexto ou de marcações. (Prioridade 1)

2.2 Assegurar que a combinação de cores entre o fundo e o primeiro plano seja suficientemente contrastante para poder ser vista por pessoas com cromodeficiências, bem como pelas que utilizam monitores de vídeo monocromáticos. (Prioridade 2 para imagens; prioridade 3 para texto)

\section{Diretriz 3 - Utilizar corretamente marcações e folhas de estilo}

3.1 Sempre que existir uma linguagem de marcação apropriada, utilizar marcações em vez de imagens para transmitir informações. (Prioridade 2)

3.2 Criar documentos passíveis de validação por gramáticas formais, publicadas. (Prioridade 2)

3.3 Utilizar folhas de estilo para controlar a paginação (disposição em página) e a apresentação. (Prioridade 2)

3.4 Utilizar unidades relativas, e não absolutas, nos valores dos atributos da linguagem de marcação e nos valores das propriedades das folhas de estilo. (Prioridade 2)

3.5 Utilizar elementos de cabeçalho indicativos da estrutura do documento, de acordo com as especificações. (Prioridade 2)

3.6 Marcar corretamente listas e pontos de enumeração em listas. (Prioridade 2)

3.7 Marcar as citações. Não utilizar marcações de citação para efeitos de formatação, como, por exemplo, o avanço de texto. (Prioridade 2)

\section{Diretriz 4 - Indicar claramente qual o idioma utilizado}

4.1 Identificar claramente quaisquer mudanças de idioma no texto de um documento, bem como nos equivalentes textuais (por ex., legendas). (Prioridade 1)

4.2 Especificar por extenso cada abreviatura ou sigla quando da sua primeira ocorrência em um documento. (Prioridade 3)

4.3 Identificar o principal idioma utilizado nos documentos. (Prioridade 3)

\section{Diretriz 5 - Criar tabelas passíveis de transformação harmoniosa}

5.1 Em tabelas de dados, identificar os cabeçalhos de linha e de coluna. (Prioridade 1)

5.2 Em tabelas de dados com dois ou mais níveis lógicos de cabeçalhos de linha ou de coluna, utilizar marcações para associar as células de dados às células de cabeçalho. (Prioridade 1)

5.3 Não utilizar tabelas para efeitos de disposição em página, a não ser que a tabela continue a fazer sentido depois de ser linearizada. Se não for o caso, fornecer um equivalente alternativo (que pode ser uma versão linearizada). (Prioridade 2) 
5.4 Se for utilizada uma tabela para efeitos de disposição em página, não utilizar qualquer marcação estrutural para efeitos de formatação visual. (Prioridade 2)

5.5 Fornecer resumos das tabelas. (Prioridade 3)

5.6 Fornecer abreviaturas para os rótulos de cabeçalho. (Prioridade 3)

\section{Diretriz 6 - Assegurar que as páginas dotadas de novas tecnologias sejam trans- formadas harmoniosamente}

6.1 Organizar os documentos de tal forma que possam ser lidos sem recurso a folhas de estilo. Por exemplo, se um documento em HTML for reproduzido sem as folhas de estilo que lhe estão associadas, deve continuar a ser possível lê-lo. (Prioridade 1)

6.2 Assegurar que os equivalentes de conteúdo dinâmico sejam atualizados sempre que esse conteúdo mudar. (Prioridade 1)

6.3 Assegurar que todas as páginas possam ser utilizadas mesmo que os programas interpretáveis, os applets ou outros objetos programados tenham sido desativados ou não sejam suportados. Se isso não for possível, fornecer informações equivalentes em uma página alternativa, acessível. (Prioridade 1)

6.4 Em programas interpretáveis e applets, assegurar que a resposta a eventos seja independente do dispositivo de entrada. (Prioridade 2)

6.5 Assegurar a acessibilidade do conteúdo dinâmico ou fornecer apresentação ou página alternativas. (Prioridade 2)

\section{Diretriz 7 - Assegurar o controle do usuário sobre as alterações temporais do con- teúdo}

7.1 Evitar concepções que possam provocar intermitência da tela, até que os agentes do usuário possibilitem o seu controle. (Prioridade 1)

7.2 Evitar situações que possam provocar o piscar do conteúdo das páginas (isto é, alterar a apresentação a intervalos regulares, como ligar e desligar), até que os agentes do usuário possibilitem o controle desse efeito. (Prioridade 2)

7.3 Evitar páginas contendo movimento, até que os agentes do usuário possibilitem a imobilização do conteúdo. (Prioridade 2)

7.4 Não criar páginas de atualização automática periódica, até que os agentes do usuário possibilitem parar essa atualização. (Prioridade 2)

7.5 Não utilizar marcações para redirecionar as páginas automaticamente, até que os agentes do usuário possibilitem parar o redirecionamento automático. Ao invés de utilizar marcações, configurar o servidor para que execute os redirecionamentos. (Prioridade 2) 


\section{Diretriz 8 - Assegurar a acessibilidade direta de interfaces do usuário integradas}

8.1 Criar elementos de programação, tais como programas interpretáveis e applets, diretamente acessíveis pelas tecnologias de apoio ou com elas compatíveis (prioridade 1 se a funcionalidade for importante e não estiver presente em outro local; prioridade 2, se não for o caso)

\section{Diretriz 9 - Projetar páginas considerando a independência de dispositivos}

9.1 Fornecer mapas de imagem armazenados no cliente ao invés de no servidor, exceto quando as regiões não puderem ser definidas por forma geométrica disponível. (Prioridade 1)

9.2 Assegurar que qualquer elemento dotado de interface própria possa funcionar de modo independente de dispositivos. (Prioridade 2)

9.3 Em programas interpretáveis, especificar respostas a eventos, preferindo-as a rotinas dependentes de dispositivos. (Prioridade 2)

9.4 Criar uma seqüência lógica de tabulação para percorrer links, controles de formulários e objetos. (Prioridade 3)

9.5 Fornecer atalhos por teclado que apontem para links importantes (incluindo os contidos em mapas de imagem armazenados no cliente), controles de formulários e grupo de controles de formulários. (Prioridade 3)

\section{Diretriz 10 - Utilizar soluções de transição}

10.1 Não provocar o aparecimento de janelas de sobreposição ou outras quaisquer, e não fazer com que o conteúdo da janela atual seja modificado sem que o usuário seja informado disso, até que os agentes do usuário tornem possível a desativação de janelas secundárias. (Prioridade 2)

10.2 Assegurar o correto posicionamento de todos os controles de formulários que tenham rótulos implicitamente associados, até que os agentes do usuário venham a suportar associações explícitas entre rótulos e controles de formulários. (Prioridade 2)

10.3 Proporcionar uma alternativa de texto linear (na mesma ou em outra página), em relação a todas as tabelas que apresentem o texto em colunas paralelas e com translineação, até que os agentes do usuário (incluindo as tecnologias de apoio) reproduzam corretamente texto colocado lado a lado. (Prioridade 3 )

10.4 Incluir caracteres predefinidos de preenchimento nas caixas de edição e nas áreas de texto, até que os agentes do usuário tratem corretamente os controles vazios. (Prioridade 3)

10.5 Inserir, entre links adjacentes, caracteres que não funcionem como link e sejam passíveis de impressão (com um espaço de início e outro de fim), até que os agentes do usuário (incluindo as tecnologias de apoio) reproduzam clara e distintamente os links adjacentes. (Prioridade 3) 


\section{Diretriz 11 - Utilizar tecnologias e recomendações do W3C}

11.1 Utilizar tecnologias do W3C sempre disponíveis e adequadas a uma determinada tarefa; utilizar as versões mais recentes, desde que suportadas. (Prioridade 2)

11.2 Evitar funcionalidades desatualizadas de tecnologias do W3C. (Prioridade 2)

11.3 Fornecer informações que possibilitem aos usuários receber os documentos de acordo com as suas preferências (por ex., por idioma ou por tipo de conteúdo) (Prioridade 3)

11.4 Se, apesar de todos os esforços, não for possível criar uma página acessível, fornecer um link a uma página alternativa que utilize tecnologias do W3C, seja acessível, contenha informações (ou funcionalidade) equivalentes e seja atualizada tão frequientemente quanto a página original, considerada inacessível. (Prioridade 1)

\section{Diretriz 12 - Fornecer informações de contexto e orientações}

12.1 Dar, a cada frame, um título que facilite a identificação dos frames e sua navegação. (Prioridade 1)

12.2 Descrever a finalidade dos frames e o modo como se relacionam entre si, se isso não for óbvio a partir unicamente dos títulos. (Prioridade 2)

12.3 Dividir grandes blocos de informação em grupos mais fáceis de gerenciar, sempre que for o caso. (Prioridade 2)

12.4 Associar explicitamente os rótulos aos respectivos controles. (Prioridade 2)

\section{Diretriz 13 - Fornecer mecanismos de navegação claros}

13.1 Identificar claramente o destino de cada link. (Prioridade 2)

13.2 Fornecer metadados para acrescentar informações semânticas a páginas ou sites. (Prioridade 2)

13.3 Dar informações sobre a organização geral de um site (por ex., por meio de um mapa do site ou de um sumário). (Prioridade 2)

13.4 Utilizar os mecanismos de navegação de maneira coerente e sistemática. (Prioridade 2)

13.5 Fornecer barras de navegação para destacar e dar acesso ao mecanismo de navegação. (Prioridade 3)

13.6 Agrupar links relacionados entre si, identificar o grupo (em benefício dos agentes do usuário) e, até que os agentes do usuário se encarreguem de tal função, fornecer um modo de contornar determinado grupo. (Prioridade 3)

13.7 Se forem oferecidas funções de pesquisa, ativar diferentes tipos de pesquisa de modo a corresponderem a diferentes níveis de competência e às preferências dos usuários. (Prioridade 3)

13.8 Colocar informações identificativas no início de cabeçalhos, parágrafos, listas. (Prioridade 3) 
13.9 Fornecer informações sobre coleções de documentos (isto é, documentos compostos por várias páginas). (Prioridade 3)

13.10 Fornecer meios para ignorar inserções de arte ASCII com várias linhas. (Prioridade 3)

\section{Diretriz 14 - Assegurar a clareza e a simplicidade dos documentos}

14.1 Utilizar linguagem a mais clara e simples possível, adequada ao conteúdo do site. (Prioridade 1)

14.2 Complementar o texto com apresentações gráficas ou sonoras, sempre que facilitarem a compreensão da página. (Prioridade 3)

14.3 Criar um estilo de apresentação coerente e sistemático, ao longo das diferentes páginas. (Prioridade 3) 


\section{Levantamento sobre técnicas para desenvolvimento Web acessível}

Neste apêndice, são listados os trabalhos incluídos no levantamento sobre trabalhos referentes a técnicas para apoio a desenvolvimento de aplicações Web acessíveis. Na Tabela C.1 é apresentada a lista de artigos encontrados, constando o nome da técnica, o nome da ferramenta associada (se existir) e se foi reportada ou não algum tipo de validação experimental. A lista detalhada com a descrição de cada um dos estudos foi reportada em um relatório técnico (Freire et al., 2007a).

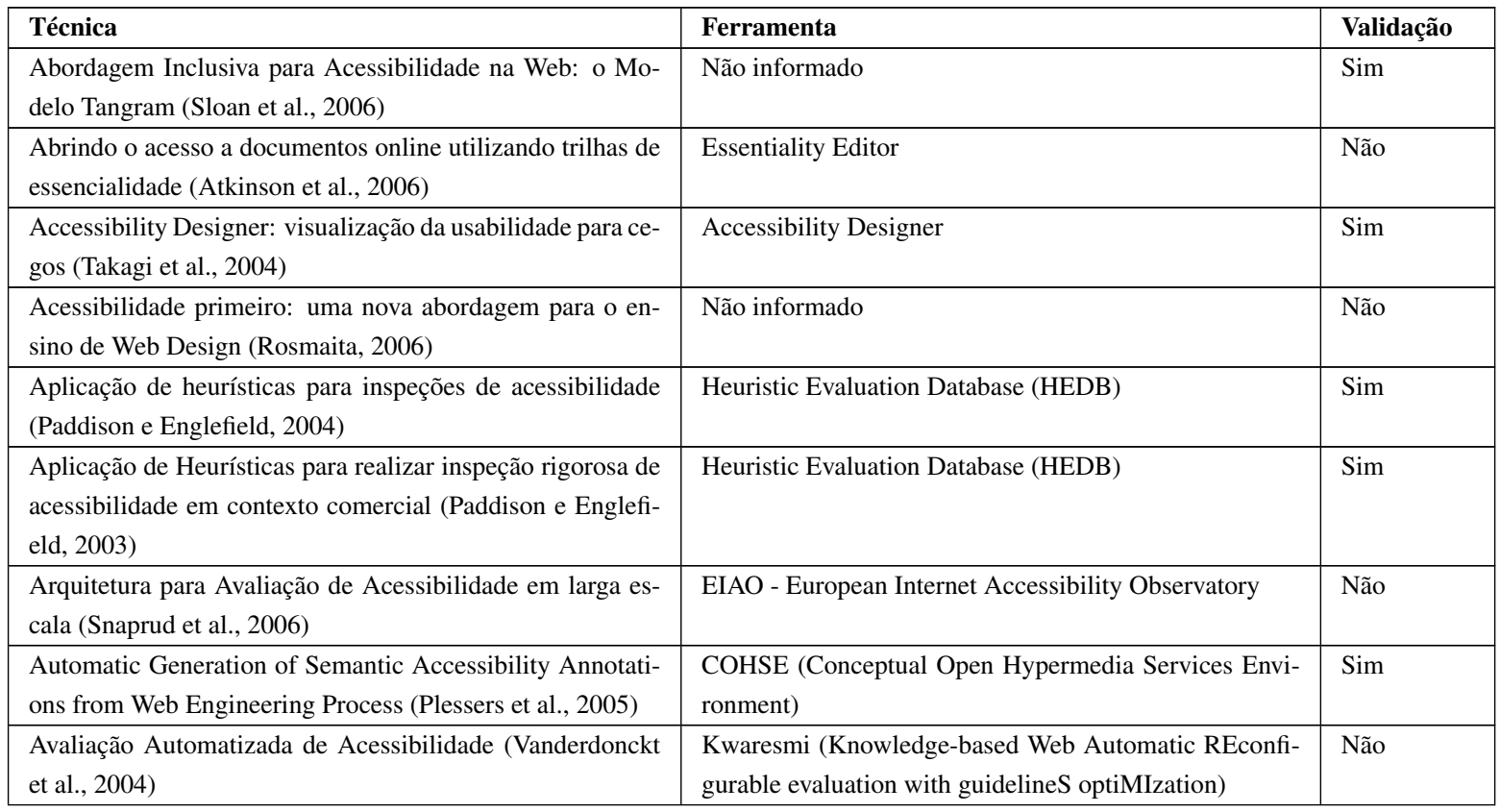




\begin{tabular}{|c|c|c|}
\hline $\begin{array}{l}\text { Avaliação de Acessibilidade com Guidelines (Abascal et al., } \\
\text { 2004) }\end{array}$ & EvalIris & Não \\
\hline $\begin{array}{l}\text { Avaliação de Acessibilidade de Websites focada no progra- } \\
\text { mador (Law et al., 2005) }\end{array}$ & Não informado & Não \\
\hline $\begin{array}{l}\text { Avaliação de Usabilidade Remota com Pessoas com defici- } \\
\text { ência (Petrie et al., 2006) }\end{array}$ & Não informado & Sim \\
\hline $\begin{array}{l}\text { Benckmark para teste de ferramentas de avaliação de aces- } \\
\text { sibilidade de páginas web (Kirchner, 2003) }\end{array}$ & Não informado. & Sim \\
\hline $\begin{array}{l}\text { Comparing accessibility evaluation tools: a method for tool } \\
\text { effectiveness (Brajnik, 2004a) }\end{array}$ & Não informado. & Sim \\
\hline $\begin{array}{l}\text { Composição de elementos Web com WCAG em mente } \\
\text { (Centeno et al., 2005) }\end{array}$ & WSLS (WebComposition Service Linking) & Não \\
\hline $\begin{array}{l}\text { Correção de Páginas por meio de Engenharia Reversa (Chen } \\
\text { et al., 2006) }\end{array}$ & PURE (Page clean-Up through Reverse Engineering) & Sim \\
\hline $\begin{array}{l}\text { Critérios para melhorar a usabilidade de sites acessíveis } \\
\text { para pessoas que utilizam a Web com screen readers (Le- } \\
\text { porini e Paternò, 2004) }\end{array}$ & Não informado & Não \\
\hline $\begin{array}{l}\text { Definição e Gerenciamento de Guidelines para Web (Lepo- } \\
\text { rini et al., 2006) }\end{array}$ & $\begin{array}{l}\text { MAGENTA (Multi-Analysis of Guidelines by an } \\
\text { ENhanced Tool for Accessibility) - GE (Guideline Edi- } \\
\text { tor) }\end{array}$ & Não \\
\hline $\begin{array}{l}\text { Design Acessível para Usuários com Deficiência Visual } \\
\text { (Moehling et al., 1999) }\end{array}$ & Não informado & Não \\
\hline $\begin{array}{l}\text { Design com Blind Markup Language (BML) (Macías et al., } \\
\text { 2002) }\end{array}$ & KAI (Accessibility Kit for the Internet) & Não \\
\hline $\begin{array}{l}\text { Design de arquiteturas de software para facilitar o desenvol- } \\
\text { vimento de aplicações Web acessíveis (Hoffman e E. Grivel, } \\
\text { 2005) }\end{array}$ & Não informado & Não \\
\hline $\begin{array}{l}\text { Design para mudanças utilizando templates (Perlman, } \\
\text { 2002) }\end{array}$ & Não informado & Não \\
\hline $\begin{array}{l}\text { Ensino de Acessibilidade com Contramano e HERA (Bena- } \\
\text { vídez et al., 2006) }\end{array}$ & $\begin{array}{l}\text { Contramano (página exemplo) e HERA (ferramenta de } \\
\text { avaliação) }\end{array}$ & $\operatorname{Sim}$ \\
\hline $\begin{array}{l}\text { Ferramenta de Auditoria de Acessibilidade de sites Web } \\
\text { para pessoas com deficiência visual: OCAWA (Chêne e } \\
\text { Hoël, 2002) }\end{array}$ & OCAWA & Não \\
\hline $\begin{array}{l}\text { Ferramentas para Gerenciamento de casos de teste para } \\
\text { acessibilidade (Herramhof et al., 2006) }\end{array}$ & BenToWeb Parsifal & Não \\
\hline $\begin{array}{l}\text { Geração Flexível de relatórios para avaliação automatizada } \\
\text { de usabilidade e acessibilidade de Web Sites (Beirekdar et } \\
\text { al., 2005) }\end{array}$ & $\begin{array}{l}\text { DESTINE (Design and Evaluation STudio for INtent- } \\
\text { based Ergonomic web sites) e GDL Editor }\end{array}$ & Não \\
\hline $\begin{array}{l}\text { Gerenciamento de usabilidade para pessoas com deficiência } \\
\text { em aplicações Web de grande porte (King et al., 2005) }\end{array}$ & $\begin{array}{l}\text { Web Accessibility Standards Reporting Process } \\
\text { (WASRP) IWSC (IBM Web Standard Checker) }\end{array}$ & Sim \\
\hline $\begin{array}{l}\text { Guidelines para Descrição de Gráficos estatísticos para } \\
\text { usuários de páginas Web cegos ou com baixa visão (Ault } \\
\text { et al., 2002) }\end{array}$ & Não informado. & Sim \\
\hline Guidelines para Usabilidade Universal (Horton, 2006) & Não informado & Não \\
\hline $\begin{array}{l}\text { Guidelines para Web Design direcionadas para pessoas iso- } \\
\text { das derivadas de pesquisas (Kurniawan e Zaphiris, 2005) } \\
\text { (Zaphiris et al., 2005) }\end{array}$ & Não informado & Sim \\
\hline $\begin{array}{l}\text { Identificação e Correção de Problemas de Acessibilidade } \\
\text { em Páginas Web (Lucca et al., 2005) }\end{array}$ & Ferramenta de Identificação e Correção & Sim \\
\hline $\begin{array}{l}\text { Integração de Acessibilidade no currículo do curso de Ciên- } \\
\text { cia da Computação (Gellenbeck, 2005) }\end{array}$ & Não informado & Sim \\
\hline $\begin{array}{l}\text { Interpretação de Resultados de Avaliações Automáticas de } \\
\text { Acessibilidade em larga escala (Bühler et al., 2006) }\end{array}$ & EIAO (European Internet Accessibility Observatory) & Sim \\
\hline Medição de Sobrecarga de Navegação (Ahmad et al., 2006) & Não informado. & Não \\
\hline $\begin{array}{l}\text { Melhoria da acessibilidade de tabelas HTML renderizadas } \\
\text { por voz (Filepp et al., 2002) }\end{array}$ & Foi reportado o desenvolvimento de um protótipo & Não \\
\hline
\end{tabular}




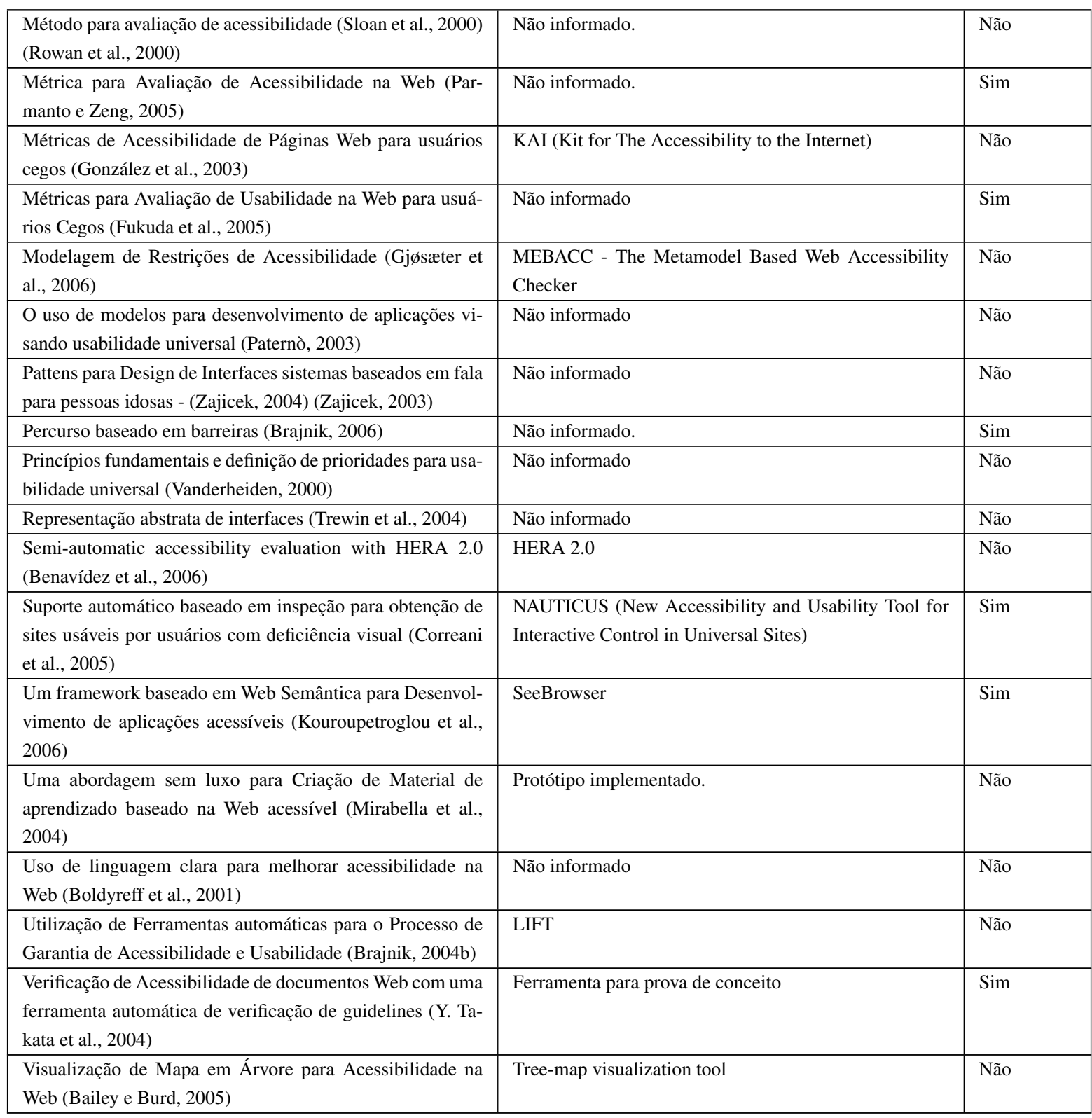

Tabela C.1: Lista de trabalhos incluídos na revisão da literatura 

APÊNDICE

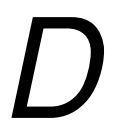

\section{Avaliação dos sítios dos governos estaduais brasileiros entre 1996 e 2007}

Na Figura D.1 é apresentado um gráfico onde é ilustrado o número de estados com sítio Web por ano entre 1996 e 2007. Pode-se observar que a partir de 2003, todos os estados tinham um sítio web disponibilizado.

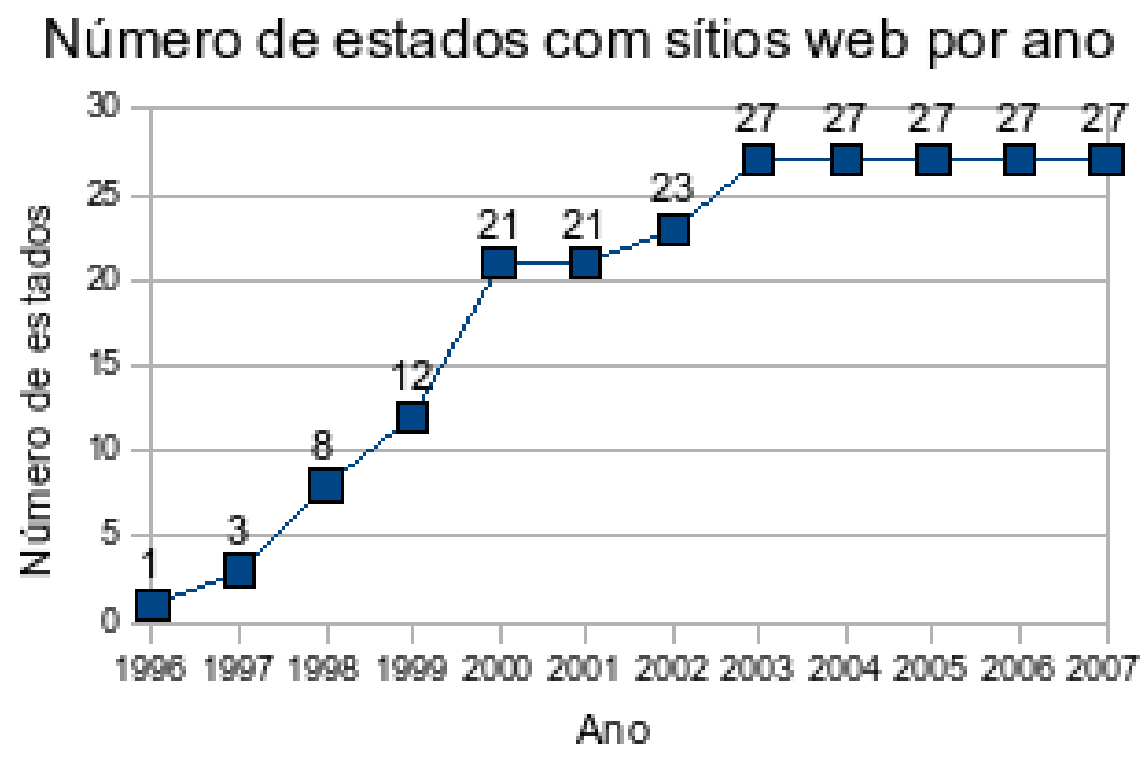

Figura D.1: Número de estados com sítios web por ano entre 1996 e 2007

Nas figuras a seguir são apresentadas as séries histórias das análises dos sítios web dos governos estaduais entre 1996 e 2007. Na Figura D.2 é apresentado o histórico de acordo com a métrica 
A3; na Figura D.3 é apresentado o histórico de acordo com a métrica UWEM; na Figura D.4 é apresentado o histórico de acordo com a métrica WAB e, finalmente na Figura D.5 é apresentado o histórico de acordo com a métrica WAQM.

É importante ressaltar que as métricas A3, UWEM e WAB apresentam o índice de barreiras, ou seja, quanto maior o índice, mais barreiras de acessibilidade têm os sítios. Já a métrica WAQM representa uma nota de 0 a 100, onde sítios com notas mais altas possuem um índice mais baixo de barreiras de acessibilidade.
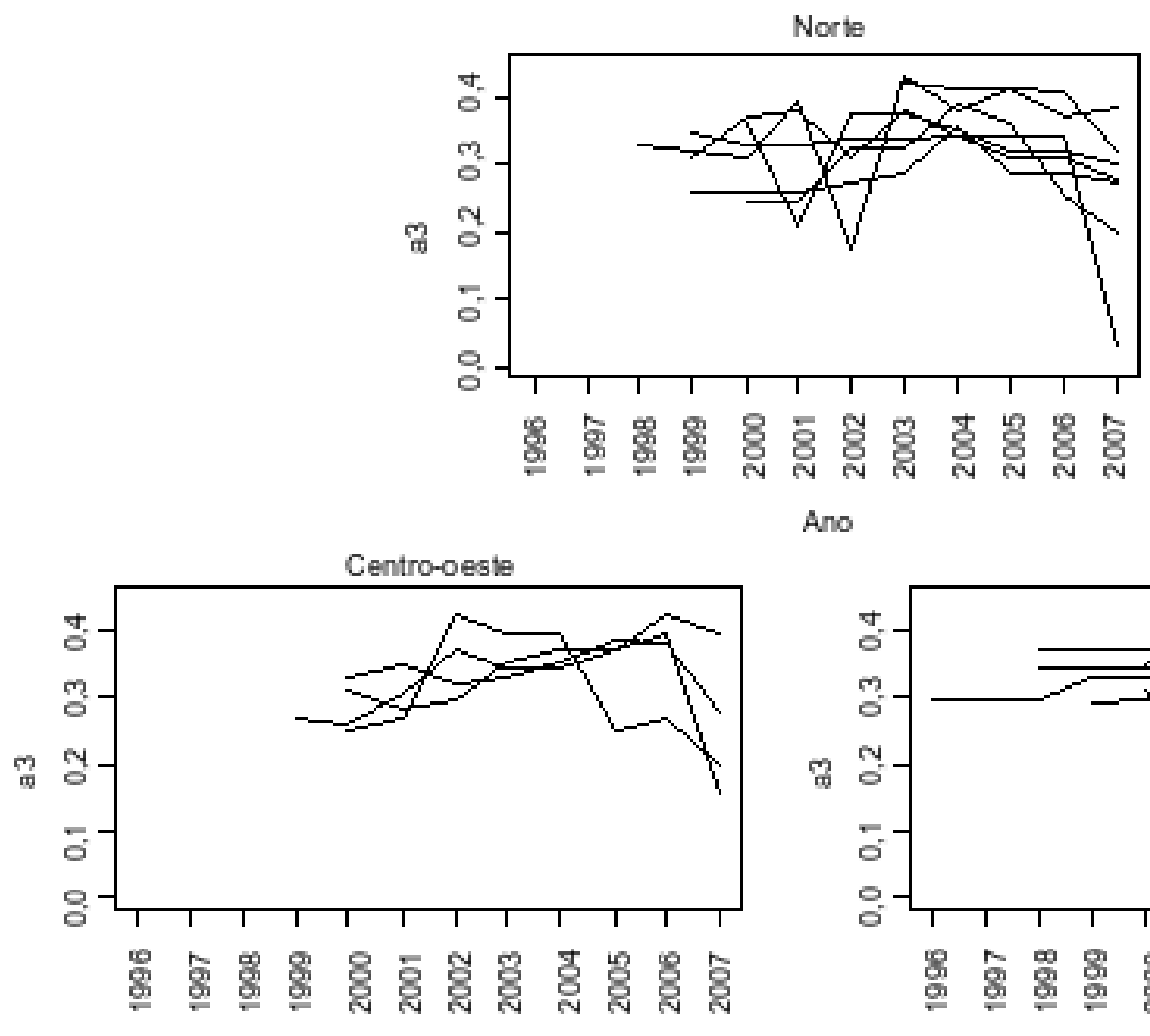

Ano

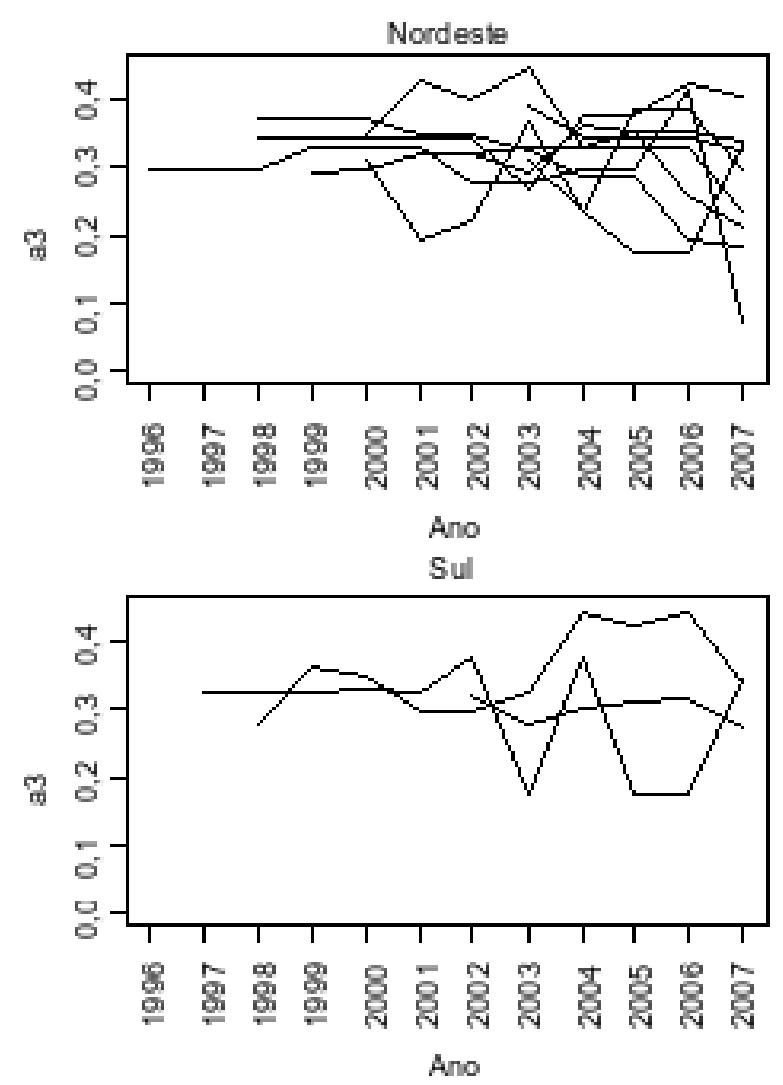

Figura D.2: Série histórica da análise das páginas com a métrica A3 dos sítios dos estados 

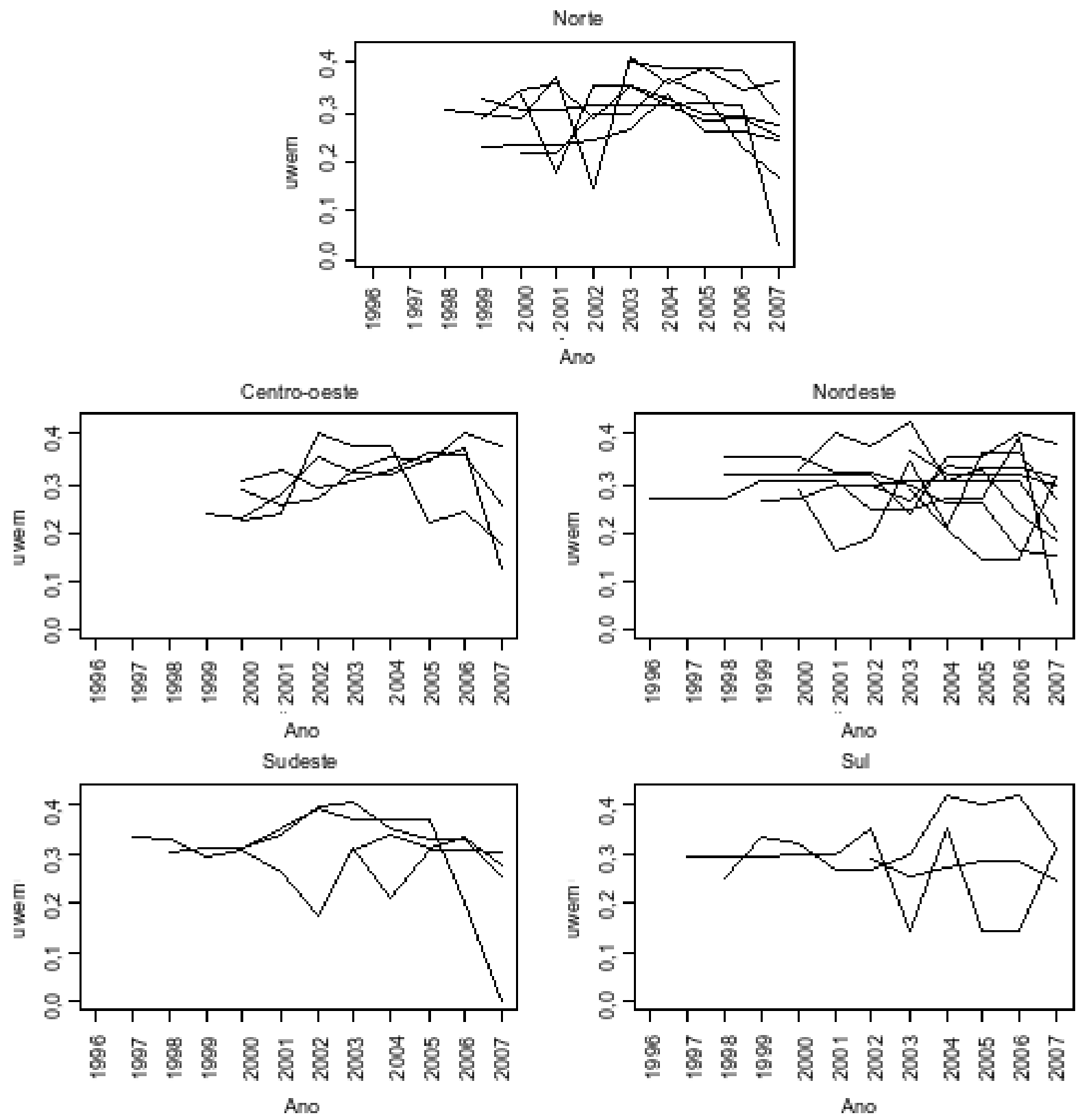

Figura D.3: Série histórica da análise das páginas com a métrica UWEM dos sítios dos estados 

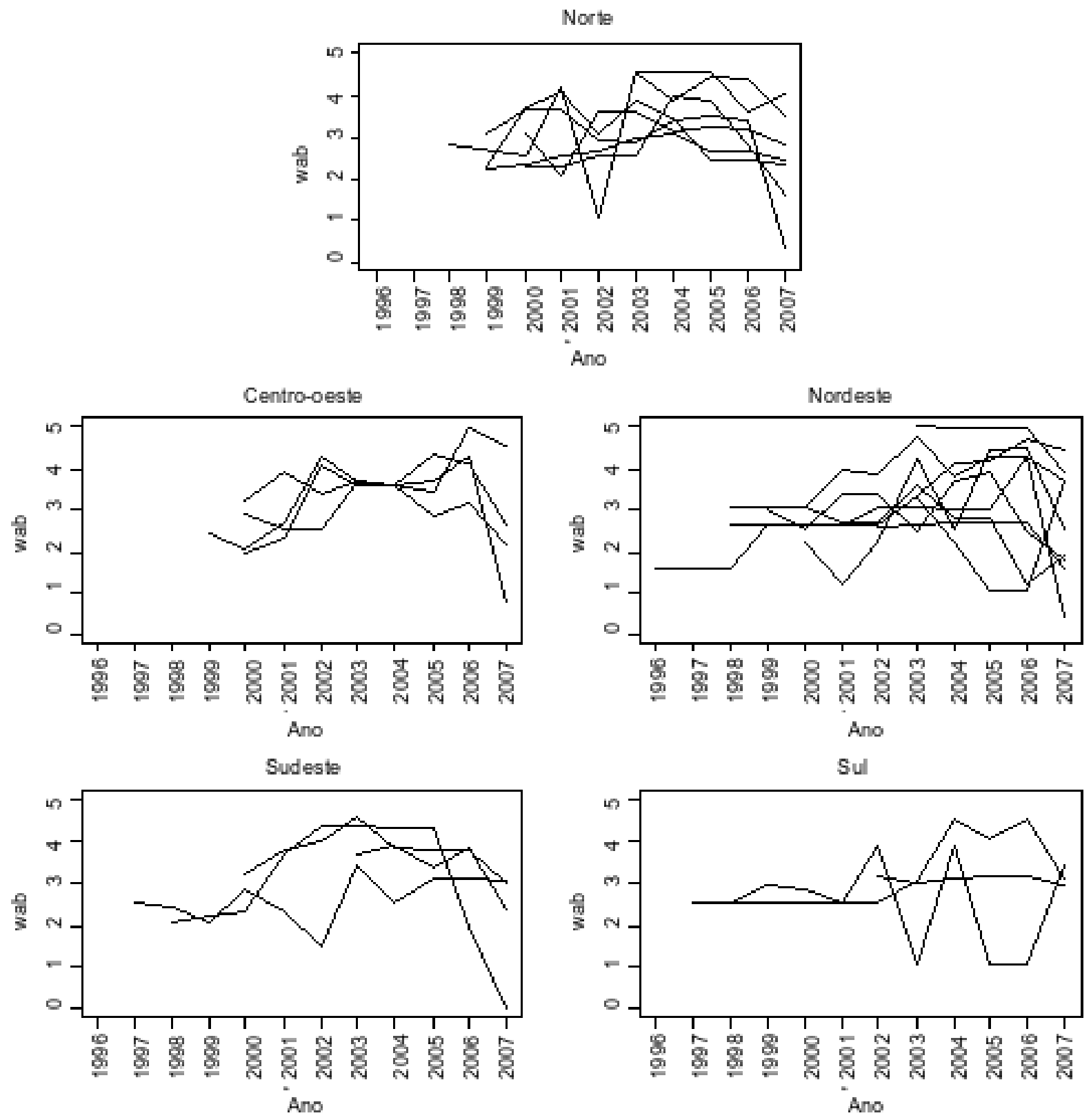

Figura D.4: Série histórica da análise das páginas com a métrica WAB dos sítios dos estados 

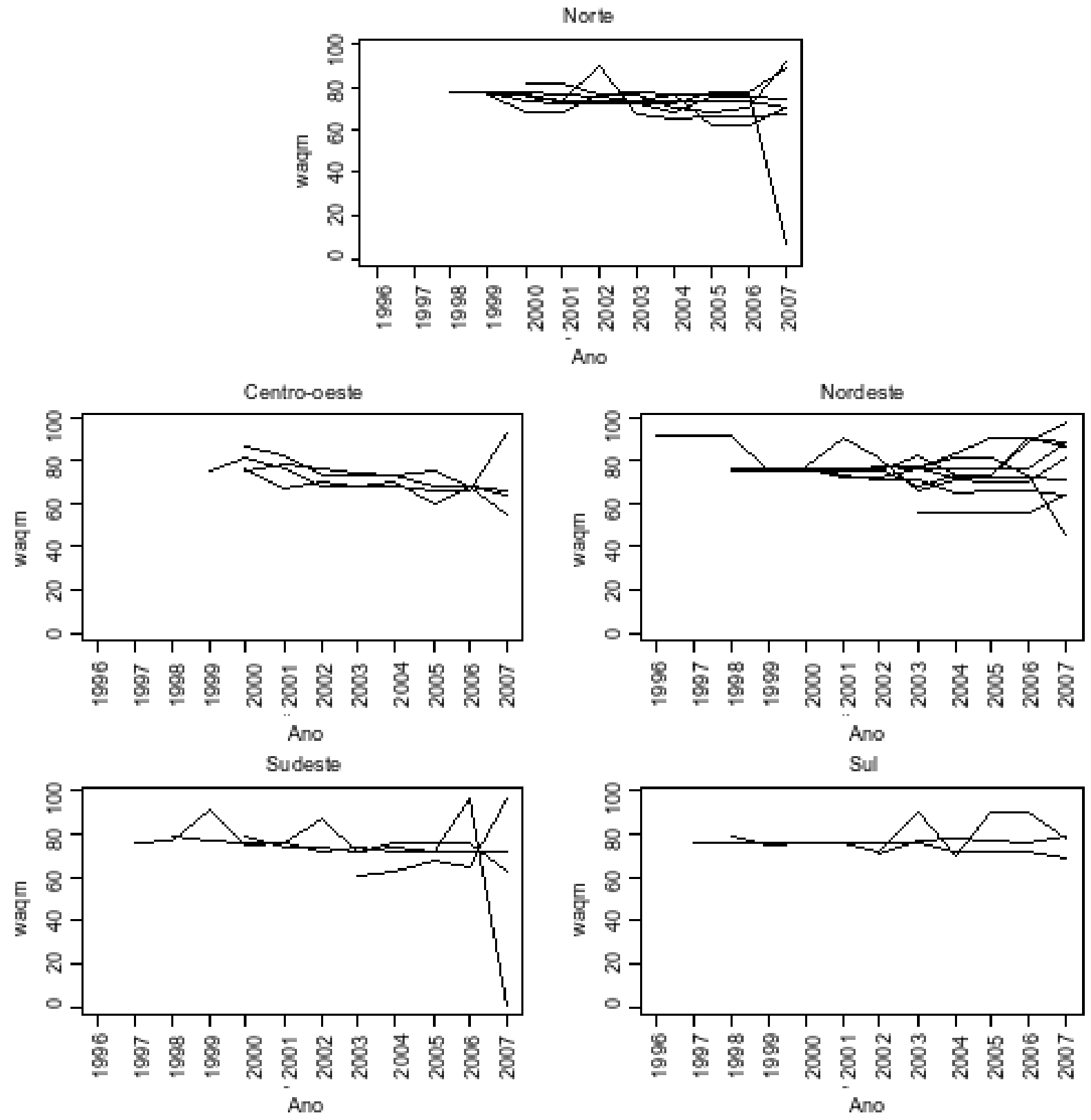

Figura D.5: Série histórica da análise das páginas com a métrica WAQM dos sítios dos estados 



\section{Avaliação dos sítios das prefeituras municipais brasileiras}

Neste apêndice, são apresentadas as tabelas com as médias dos índices de acessibilidade com as métricas A3, UWEM e WAQM e a listagem com a avaliação por meio da métrica WAB (Parmanto e Zeng, 2005) dos municípios brasileiros com sítios Web. As avaliações foram efetuadas de acordo com o método descrito na Subseção 5.4.2.

$\mathrm{Na}$ Tabela E.1 são exibidos os resultados para a métrica A3, variando entre 0 e 1 . Na Tabela E.2 são apresentados os resultados para a métrica UWEM, também variando entre 0 e 1 . Na Tabela E são apresentados os resultados para a métrica WAQM, variando entre 0 e 100 e considerando que valores altos correspondem a páginas mais acessíveis, diferentemente das outras métricas.

Tabela E.1: Resultados da avaliação dos sítios dos governos municipais com a métrica A3

\begin{tabular}{|l|c|c|}
\hline Região & Média & Desvio padrão \\
\hline Sul & 0.28 & 0.08 \\
\hline Sudeste & 0.29 & 0.07 \\
\hline Centro-oeste & 0.31 & 0.06 \\
\hline Nordeste & 0.29 & 0.08 \\
\hline Norte & 0.28 & 0.06 \\
\hline
\end{tabular}

$\mathrm{Na}$ listagem a seguir, são enumerados os 15 municípios com os menores índices de barreira (melhor acessibilidade) e os 15 municípios com os maiores índices de barreira (pior acessibilidade). Foram eliminados da listagem dos menores índices municípios com sítios em construção, sítios que tinham somente imagens, sítios com frames e tabelas para layout. 
Tabela E.2: Resultados da avaliação dos sítios dos governos municipais com a métrica UWEM

\begin{tabular}{|l|c|c|}
\hline Região & Média & Desvio padrão \\
\hline Sul & 0.25 & 0.08 \\
\hline Sudeste & 0.26 & 0.07 \\
\hline Centro-oeste & 0.28 & 0.07 \\
\hline Nordeste & 0.26 & 0.08 \\
\hline Norte & 0.25 & 0.07 \\
\hline
\end{tabular}

Tabela E.3: Resultados da avaliação dos sítios dos governos municipais com a métrica WAQM

\begin{tabular}{|l|c|c|}
\hline Região & Média & Desvio padrão \\
\hline Sul & 77.34 & 14.09 \\
\hline Sudeste & 77.12 & 10.97 \\
\hline Centro-oeste & 74.84 & 11.01 \\
\hline Nordeste & 76.17 & 13.37 \\
\hline Norte & 77.01 & 12.44 \\
\hline
\end{tabular}

Esta avaliação foi efetuada a partir de uma lista com 5551 municípios, obtida a partir da ferramenta E-GOVMeter (Bittar et al., 2005), dos quais 1980 tinham sítios na Web. Desta forma, como a quantidade de sítios avaliados era muito grande, deve-se ressaltar que esta avaliação foi efetuada utilizando exclusivamente métodos automáticos. Assim, não se pode afirmar que os municípios com baixos índices de barreiras realmente têm sítios realmente acessíveis.

Desta avaliação, só se pode inferir o quanto estes sítios ferem ou não barreiras de acessibilidade que podem ser verificadas automaticamente. Na Tabela E. 4 são listadas os 15 municípios cujos sítios obtiveram os menores índices de WAB. 
Tabela E.4: Lista dos quinze municípios com menores índices WAB

\begin{tabular}{|l|l|l|l|l|}
\hline Número & Cidade & Estado & URL & $\begin{array}{l}\text { Índice } \\
\text { WAB }\end{array}$ \\
\hline 1 & Tubarão & SC & http://www.tubarao.sc.gov.br & 0,25 \\
\hline 2 & Indaiatuba & SP & http://www.indaiatuba.sp.gov.br/ & 0,285088 \\
\hline 3 & Abatiá & PR & http://www.abatia.pr.gov.br/ & 0,461538 \\
\hline 4 & Doutor Pedrinho & SC & http://www.doutorpedrinho.sc.gov.br/ & 0,583333 \\
\hline 5 & Laguna & SC & http://www.laguna.sc.gov.br/ & 0,762319 \\
\hline 6 & Viçosa & AL & http://www.vicosa.al.gov.br/ & 0,833333 \\
\hline 7 & Pirajuba & MG & http://www.pirajuba.mg.gov.br/ & 0,833333 \\
\hline 8 & Passira & PE & http://www.passira.pe.gov.br/ & 0,833333 \\
\hline 9 & Limeira & SP & http://www.limeira.sp.gov.br/ & 0,833333 \\
\hline 10 & Gramado & RS & http://www.gramado.rs.gov.br/ & 0,833333 \\
\hline 11 & Alto Paraná & PR & http://www.altoparana.pr.gov.br/ & 0,833333 \\
\hline 12 & Camanducaia & MG & http://www.camanducaia.mg.gov.br/ & 0,845833 \\
\hline 13 & Natal & RN & http://www.natal.rn.gov.br/ & 0,897023 \\
\hline 14 & Rio Pardo & RS & http://www.riopardo.rs.gov.br/ & 0,957071 \\
\hline 15 & Irati & SC & http://www.irati.sc.gov.br/ & 1,02778 \\
\hline
\end{tabular}

Na Tabela E.5 é apresentada a lista com os 15 municípios com os maiores índices WAB.

Tabela E.5: Lista dos quinze municípios com maiores índices WAB

\begin{tabular}{|c|c|c|c|c|}
\hline Número & Cidade & Estado & URL & $\begin{array}{l}\text { Índice } \\
\text { WAB }\end{array}$ \\
\hline 1 & Ipueiras & $\mathrm{CE}$ & http://www.ipueiras.ce.gov.br/ & 6,1119 \\
\hline 2 & Varzea & PB & http://www.varzea.pb.gov.br/ & 5,80225 \\
\hline 3 & Ipojuca & $\mathrm{PE}$ & http://www.ipojuca.pe.gov.br/ & 5,6119 \\
\hline 4 & Belmiro Braga & MG & http://www.belmirobraga.mg.gov.br/ & 5,50696 \\
\hline 5 & Joaima & MG & http://www.joaima.mg.gov.br/ & 5,49638 \\
\hline 6 & Machados & $\mathrm{PE}$ & http://www.machados.pe.gov.br/ & 5,45922 \\
\hline 7 & Ariranha do Ivaí & PR & http://www.ariranhadoivai.pr.gov.br/ & 5,43666 \\
\hline 8 & Vargem Grande & MA & http://www.vargemgrande.ma.gov.br/ & 5,43623 \\
\hline 9 & Russas & $\mathrm{CE}$ & http://www.russas.ce.gov.br/ & 5,41434 \\
\hline 10 & Sabaudia & PR & http://www.sabaudia.pr.gov.br/ & 5,39729 \\
\hline 11 & Parnaíba & PI & http://www.parnaiba.pi.gov.br/ & 5,36581 \\
\hline 12 & Ipiaçu & MG & http://www.ipiacu.mg.gov.br/ & 5,35349 \\
\hline 13 & São João da Paraúna & GO & \multicolumn{2}{|c|}{ http://www.saojoaodaparauna.go.gov.br/5,29672 } \\
\hline 14 & Martins & $\mathrm{RN}$ & http://www.martins.rn.gov.br/ & 5,28775 \\
\hline 15 & Pedranópolis & SP & http://www.pedranopolis.sp.gov.br/ & 5,27288 \\
\hline
\end{tabular}





\section{Instrumentos utilizados na pesquisa levantamento}

Neste apêndice são apresentados os instrumentos utilizados durante a condução do levantamento com pessoas envolvidas no projeto de sistemas Web. Na Seção F.1 é apresentado o questionário utilizado, e na Seção F.2 é apresentado o e-mail enviado com o convite para participação na pesquisa.

\section{F.1 Questionário}

\section{Pesquisa: O cenário brasileiro sobre acessibilidade no desenvolvimento Web}

Responsável: André Pimenta Freire - apfreire@icmc.usp.br

O objetivo deste questionário é identificar a percepção dos desenvolvedores Web de diferentes organizações no Brasil sobre acessibilidade. Não há respostas certas ou erradas em relação a qualquer dos itens, pretendendo-se apenas obter sua opinião pessoal e sincera. Este questionário é de natureza confidencial. O tratamento dos dados será feito de forma global, de forma que não será efetuada nenhuma análise individualizada, com o objetivo de manter o anonimato e sigilo dos participantes.

O questionário leva em média 10 minutos para ser respondido. Sua participação será muito importante para o sucesso deste estudo!

Algumas questões admitem uma única resposta e outras admitem múltiplas respostas. Em cada questão, haverá uma identificação clara sobre o número de respostas possíveis. Confira o preenchimento dos dados antes de continuar.

\section{Questionário}

Os dados de identificação são confidenciais. O preenchimento do formulário será somente para os fins desta pesquisa, e os pesquisadores responsáveis asseguram que os dados não serão utilizados para nenhum outro fim. 
Identificação:

Nome:

Instituição/Empresa:

E-mail:

Gênero: ( ) Masculino ( ) Feminino

1) Sua idade se inclui em qual das seguintes faixas etárias? (resposta única)

( ) 18-24 ( ) 25-35 ( ) 36-45 ( ) 46-60 ( ) 60-70 ( ) Mais de 70

2) Qual é a sua principal área de atuação profissional, ou área de atuação da organização em que você atua? (resposta única)
( ) Órgão/Entidade Governamental ( ) Instituição de ensino/pesquisa
( ) Empresa/profissional da área de TI ( ) Empresa/profissional da área de Design
( ) Empresa/profissional de outra área ( ) Outro:

3) Em que local você reside atualmente?

Cidade:

Estado:

4) Qual é o seu maior nível de formação? (resposta única)

( ) Ensino Fundamental incompleto ( ) Ensino Fundamental completo

( ) Ensino Médio incompleto ( ) Ensino Médio completo

( ) Curso superior incompleto ( ) Curso superior completo

( ) Especialização ( ) Mestrado

( ) Doutorado

5) Qual a principal função que você exerce profissionalmente, seja como trabalhador autônomo ou dentro da sua organização? (resposta única)

( ) Gerente ( ) Coordenador ( ) Analista ( ) Programador ( ) Pesquisador/Docente

( ) Técnico ( ) Designer ( ) Outro (especifique):

\section{Questões}

1. Como você classifica seu conhecimento sobre linguagens de marcação e de estilo para Web (HTML e CSS Cascading style sheets)? (resposta única)

( ) Nenhum ( ) Básico ( ) Intermediário ( ) Avançado ( ) Especialista

2. Você tem consciência sobre os problemas envolvidos com a criação de páginas Web que possam ser utilizadas por pessoas cegas? (resposta única)

( ) Não sabia que era possível que cegos utilizassem a Web

( ) Já ouvi falar sobre a possibilidade de cegos utilizarem a Web, mas não sei como isso é possível

( ) Conheço tecnologias que permitem que cegos utilizem a Web, mas não sei como criar páginas adequadas para eles

( ) Conheço tecnologias que permitem que cegos utilizem a Web, e já produzi páginas que podem ser utilizadas por cegos

( ) Conheço tecnologias que permitem que cegos utilizem a Web, e considero as questões de acessibilidade envolvidas em todos os projetos em que atuo

3. Selecione quais das tecnologias assistivas (tecnologias utilizadas por pessoas com deficiência) a seguir você conhece ou já utilizou: (múltiplas respostas) 
( ) Leitor de tela ( ) Navegador textual ( ) Navegador com voz

( ) Ampliador de tela ( ) Teclados alternativos ( ) Mouses alternativos

( ) Impressora braille ( ) Outros (especifique):

4. Você conhece a legislação brasileira de acessibilidade, e em particular o Decreto Lei No. 5.296/2004, bem como suas implicações para acessibilidade na Web ? (resposta única)

( ) Nunca ouvi falar

( ) Já ouvi falar, mas não conheço ou conheço vagamente

( ) Conheço o decreto, mas não suas implicações para Web

( ) Conheço o decreto, sei de suas implicações, mas minha instituição ainda não atende as recomendações

( ) Conheço o decreto, sei de suas implicações e minha instituição atende às suas recomendações

5. Como você classifica seu conhecimento sobre diretrizes de acessibilidade, como por exemplo o "Recomendações para Acessibilidade de Conteúdo Web” (WCAG) do W3C? (resposta única)

( ) Nenhum ( ) Básico ( ) Intermediário ( ) Avançado ( ) Especialista

6. Você recebeu algum tipo de treinamento sobre acessibilidade? Se sim, em que contexto? Se você não recebeu nenhum treinamento, marque somente 'nenhum'. (múltiplas respostas).

( ) nenhum ( ) Palestra ( ) Treinamento em empresa

( ) Curso de extensão ( ) Disciplina de graduação ( ) Disciplina de pós-graduação

( ) Disciplina de curso técnico de nível médio ( ) Curso de Web Design ( ) Outros (especifique):

7. Você efetua algum tipo de teste para verificar a validade do código das páginas produzidas e a acessibilidade das suas páginas? Se você não realize nenhum teste, marque somente 'nenhum'. (múltiplas respostas).

( ) nenhum ( ) Validação de código HTML ( ) Teste com usuários com deficiência

( ) Validação de folhas de estilo CSS ( ) Revisão de guidelines de acessibilidade manual ( ) Teste com usuários idosos

( ) Avaliação de acessibilidade com ferramentas automáticas (como daSilva, Bobby, WebXACT, Hera, etc)

( ) Inspeção de acessibilidade com tecnologias assistivas

( ) Outros (especifique):

8. Na sua opinião, a acessibilidade é considerada nos projetos de páginas ou aplicações Web que você participa? (resposta única - preenchimento obrigatório)

( ) Sim ( ) Não ( ) Parcialmente

9. Se você respondeu "Sim" na questão número 8, indique os principais motivos que levam você ou sua organização a desenvolver páginas mais acessíveis. (múltiplas respostas)

( ) Fatores legais ( ) Motivação pessoal ( ) Exigência da empresa

( ) Exigência de clientes ( ) Pessoas com necessidades especiais fazem parte de nosso público alvo

( ) Possibilidade de atingir um número maior de clientes

( ) Prezar pela reputação da organização

( ) Aumentar compatibilidade das páginas com dispositivos móveis

( ) Melhor adequação das páginas aos Web standards

( ) Outros (especifique):

10. Se você respondeu "Não" ou "Parcialmente" na questão número 7, indique os principais motivos por que você ou sua organização não consideram acessibilidade no desenvolvimento de páginas e aplicações (múltiplas respostas). 
( ) Legislação não se aplica à minha organização ( ) Não há exigência da empresa

( ) Clientes não exigem este requisito ( ) Falta de treinamento adequado

( ) Alto custo de ferramentas específicas ( ) Aumento no tempo para produção

( ) Falta de material disponível em português ( ) Aumento no custo para desenvolvimento

( ) Considerar acessibilidade prejudica o layout ( ) Falta de conhecimento sobre linguagens de marcação

( ) Pessoas com necessidades especiais não são o público alvo de nossos produtos

( ) Outros (especifique):

11. Dê a sua opinião sobre a importância que a acessibilidade e a inclusão ocupam no planejamento de seus projetos e nos projetos de sua organização. (resposta aberta)

12. Que tipo de ações poderiam ser tomadas para melhorar a acessibilidade das páginas criadas por desenvolvedores brasileiros? (resposta aberta)

13. Como parte desta pesquisa, faremos algumas análises de páginas produzidas pelos participantes, que resultarão em métricas sobre a acessibilidade das páginas. Caso seja do seu interesse participar deste estudo, forneça a URL de uma ou mais páginas produzidas por você ou por sua organização (caso atue em desenvolvimento de páginas Web).

Os resultados desta análise serão utilizados somente para os fins deste estudo. As análises serão feitas somente de forma global, de modo que não serão divulgados nomes de pessoas ou organizações.

Se houver interesse em receber os resultados individuais da análise, eles serão enviados unicamente ao participante no endereço de e-mail fornecido.

( ) Concordo em disponibilizar as páginas nas seguintes URLs para análise:

( ) Gostaria de receber o resultado das análises em meu e-mail

Agradecemos suas respostas, pois serão MUITO importantes para a pesquisa relativa ao cenário brasileiro sobre acessibilidade no desenvolvimento Web!!

\section{F.2 E-mail convite}

Prezado(a) (participante)

Gostaríamos de lhe convidar para participar de uma pesquisa sobre acessibilidade na Web que está sendo realizada pelo Laboratório Intermídia da USP (Universidade de São Paulo).

O objetivo da pesquisa é de levantar dados sobre acessibilidade no desenvolvimento de páginas e aplicações Web no contexto brasileiro.

O questionário contém 12 questões simples, e leva em média de 5 a 10 minutos para ser respondido. Todas as respostas são confidenciais, e serão utilizadas somente para os fins da pesquisa.

O preenchimento pode ser feito via Web, por meio do link:

http://agua.intermidia.icmc.usp.br/acessibilidade/index.php

Caso você considere que não é a pessoa mais indicada em sua organização para responder o questionário, pedimos por favor que encaminhe este convite para as pessoas mais indicadas.

A participação também é aberta a outras pessoas envolvidas com desenvolvimento Web e projetos de interface. Tenha a liberdade de encaminhar este convite para outras pessoas que possam se interessar.

Sua participação será muito importante para o sucesso desta pesquisa. O questionário estará disponível até o dia 20 de agosto de 2007.

Desde já agradecemos muito pela sua colaboração. 
APÊNDICE

\section{G}

\section{Modelos estatísticos do levantamento}

Neste apêndice, são apresentados os dois modelos estatísticos gerados por meio de técnicas de regressão linear, apresentados na Seção 6.5.2. Os coeficientes Estimate correspondem ao valor atribuído na regressão, referente à contribuição de cada variável para a função de aproximação. $\mathrm{O}$ valor Std. Error é o desvio padrão do coeficiente. O $z$ value corresponde ao valor da região em que o valor obtido no teste estatístico ficou localizado e, finalmente, o valor $\operatorname{Pr}(>|z|)$ corresponde à probabilidade de que a hipótese nula (a variável em questão não é relevante) seja rejeitada.

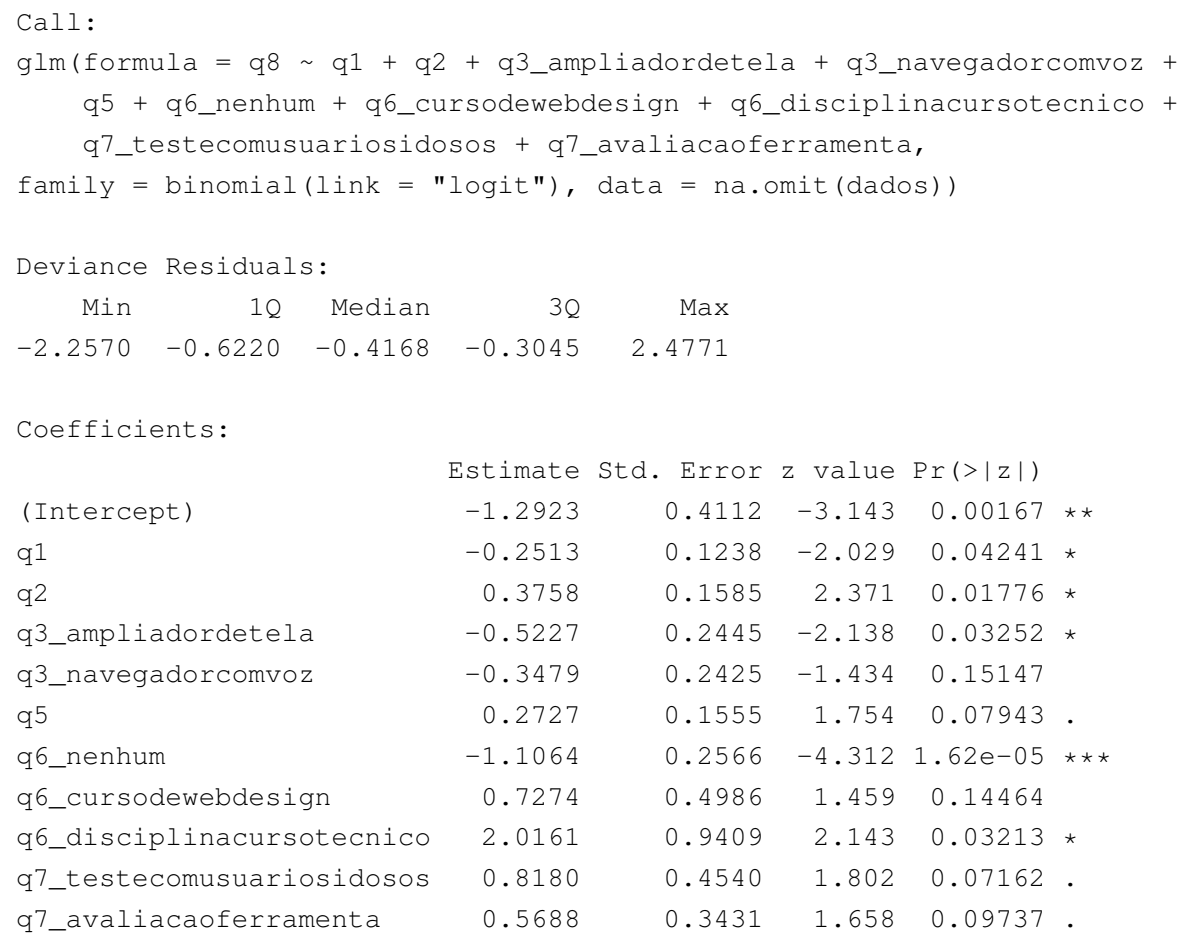


Signif. codes: 0 ?***? 0.001 ?**? 0.01 ?*? 0.05 ?.? 0.1 ? ? 1

(Dispersion parameter for binomial family taken to be 1)

Null deviance: 586.42 on 580 degrees of freedom

Residual deviance: 480.50 on 570 degrees of freedom

AIC : 502.5

Number of Fisher Scoring iterations: 5

Call :

$\operatorname{lm}$ (formula $=$ wab $\sim$ q1 + q3_leitordetela + q3_ampliadordetela +

q3_mousesalternativos + q3_outros + q4 + q5 + q6_nenhum +

q6_palestra + q6_treinamentoempresa + q7_nenhum + q7_validacaocss +

q7_avaliacaoferramenta + q7_outros + q9_fatoreslegais + q9_exigenciaclientes +

q9_reputacao + q9_compatibilidademoveis + q9_webstandards +

q10_legislacaonaoaplica + q10_prejudicalayout, data = na.omit(dados))

Residuals:

Min $1 Q$ Median $3 Q \quad$ Max

$-1.4686-0.4747-0.0379 \quad 0.4492 \quad 1.4063$

Coefficients:

(Intercept)

q1

q3_leitordetela

q3_ampliadordetela

q3_mousesalternativos

Estimate Std. Error t value $\operatorname{Pr}(>|t|)$

q4

q5

2.62403

$0.2109712 .438<2 e-16 \star \star *$

$\begin{array}{llll}-0.13038 & 0.05717 & -2.281 & 0.023837 *\end{array}$

$\begin{array}{llll}-0.30313 & 0.11384 & -2.663 & 0.008514 * *\end{array}$

$\begin{array}{llll}0.18390 & 0.10827 & 1.699 & 0.091281 .\end{array}$

$\begin{array}{llll}-0.25198 & 0.16493 & -1.528 & 0.128472\end{array}$

q6_nenhum $\quad 0.45296 \quad 0.14108 \quad 3.2110 .001590 * *$

q6_palestra $\quad 0.54082 \quad 0.15495 \quad 3.490 \quad 0.000618 * * *$

q6_treinamentoempresa $\quad-0.44268 \quad 0.22561 \quad-1.9620 .051416$.

q7_nenhum $\quad-0.22484 \quad 0.14544 \quad-1.546 \quad 0.124022$

q7_validacaocss $\quad-0.30340 \quad 0.14835 \quad-2.0450 .042422$ *

q7_avaliacaoferramenta $\quad-0.72579 \quad 0.17005 \quad-4.268 \quad 3.30$ e-05 $* * *$

q9_fatoreslegais $\quad 0.45126 \quad 0.19521 \quad 2.312 \quad 0.022027$ *

q9_exigenciaclientes $\quad 0.48715 \quad 0.26472 \quad 1.840 \quad 0.067523$.

q9_reputacao $\quad-0.49653 \quad 0.22977 \quad-2.161 \quad 0.032133$ *

q9_compatibilidademoveis $\begin{array}{rlllll}-0.37637 & 0.24057 & -1.564 & 0.119607\end{array}$

q9_webstandards $\quad 0.58297 \quad 0.24565 \quad 2.373 \quad 0.018778$ *

q10_legislacaonaoaplica $\quad \begin{array}{lllll}0.37036 & 0.24508 & 1.511 & 0.132635\end{array}$

q10_prejudicalayout $\quad 0.79325 \quad 0.30844 \quad 2.5720 .010994$ *

$---$

Signif. codes: 0 ?***? 0.001 ?**? 0.01 ?*? 0.05 ?.? 0.1 ? ? 1

Residual standard error: 0.66 on 166 degrees of freedom

Multiple R-Squared: 0.4174, Adjusted R-squared: 0.3437

F-statistic: 5.664 on 21 and 166 DF, p-value: 2.638e-11 